University of Louisville

ThinkIR: The University of Louisville's Institutional Repository

Electronic Theses and Dissertations

$12-2013$

\title{
Predictors of HIV risk behaviors among older adults : a multilevel analysis.
}

Laneshia Rae' McCord

University of Louisville

Follow this and additional works at: https://ir.library.louisville.edu/etd

\section{Recommended Citation}

McCord, Laneshia Rae', "Predictors of HIV risk behaviors among older adults : a multilevel analysis." (2013). Electronic Theses and Dissertations. Paper 939.

https://doi.org/10.18297/etd/939

This Doctoral Dissertation is brought to you for free and open access by ThinkIR: The University of Louisville's Institutional Repository. It has been accepted for inclusion in Electronic Theses and Dissertations by an authorized administrator of ThinkIR: The University of Louisville's Institutional Repository. This title appears here courtesy of the author, who has retained all other copyrights. For more information, please contact thinkir@louisville.edu. 
PREDICTORS OF HIV RISK BEHAVIORS AMONG OLDER ADULTS:

A MULTILEVEL ANALYSIS

By

Laneshia Rae' McCord

B.S.W., University of Kentucky, 2002

M.S.W., University of Georgia, 2008

A Dissertation

Submitted to the Faculty of the

Raymond A. Kent School of Social Work of the University of Louisville

In Partial Fulfillment of the Requirements

For the Degree of

Doctor of Philosophy

Kent School of Social Work

University of Louisville

Louisville, KY

December 2013 
Copyright 2013 by Laneshia Rae’ McCord All rights reserved 

PREDICTORS OF HIV RISK BEHAVIORS AMONG OLDER ADULTS: A MULTILEVEL ANALYSIS

\author{
By \\ Laneshia Rae' McCord \\ B.S.W., University of Kentucky, 2002 \\ M.S.W., University of Georgia, 2007 \\ A Dissertation Approved on
}

November 11, 2013

by the following Dissertation Committee:

Anna C. Faul, Ph.D., Chair

Muriel Harris, Ph.D.

Anita Barbee, Ph.D.

Karla Washington, Ph.D.

Ike Adams, Ph.D. 


\section{DEDICATION}

This dissertation is dedicated to my loved ones, those present and those who have passed on. 


\section{ACKNOWLEDGEMENTS}

"When we become more fully aware that our success is due in large measure to the loyalty, helpfulness, and encouragement we have received from others, our desire grows to pass on similar gifts. Gratitude spurs us on to prove ourselves worthy of what others have done for us. The spirit of gratitude is a powerful energizer."

Wilferd A. Peterson (1900-1995); Author, Businessman

I would like to extend my gratitude to all the energizers that have gotten me to this point in my life and career. Unwavering love and support have been the core foundation on which I stand.

Praise and honor go to the Most High God, for residing in my spirit and touching those placed in my life to help me accomplish this professional goal. It is because of the deep-rooted connection with you and presence of you that has allowed me to spend these past four years at the University of Louisville learning, growing, and sharing.

To my Kennedy and my Jordan, you have allowed me to divide my attention and energy from our family unit in order to pursue a dream opportunity. I hope that you see this as a marker that as women, we can be goal-oriented and 
loving, in our own special ways. We write the script of our lives, and with the direction of God and the production company of those who love us, we can star in the most awesome and rewarding movie called life.

To my family near and far, I appreciate and felt all the encouragement during this journey. A special thanks to my mother, Anita, "Granny” (Nancy), my brothers and sisters, and my Uncles Eric, Ronnie (miss you), and Kenny, several sister-friends and brother-friends, and all other close friends and family. My first mentor, Dr. Rufus Larkin, for ushering me in as a Jedi-Princess in learning, and developing and supporting my interest in pursuing doctoral studies. For all the laughs and moments of relief that I could never quantify, there is a special place for each of you in my heart.

When looking for an adjective that describes my beloved mentor Dr. Annatjie Faul, I was not surprised to see that extraordinary, from the Latin derivative of extra ordinem meant 'out of order', especially the usual order! And when I reflect on the dynamics of our relationship, laughter we have shared, experiences we have had, I feel good about saying that we have an extraordinary connection, a special relationship that has challenged my way of thinking in the best kind of way. Your firm guidance has proven to be instrumental to the scholar that I have become, the educator I have become, and the academic I will be. I am indebted to you. To Dr. Muriel Harris, I truly appreciate all the interactions and insight that you have provided most generously during my doctoral journey. Dr. Anita Barbee, your endearing smile and hearty laughter have always put me at ease, and your insight and encouragement makes you very memorable in my 
heart. Dr. Karla Washington, you have been a huge support system as I developed my scholarship, encouraging my focus on aging issues and making the time to be involved with my qualitative inquiries. Dr. Ike Adams, you have provided me with a broad lens, challenging me to view my research interests as they relate to implications for future social work education and practice, as well as social welfare policy.

To my Kent family, I love and appreciate each of you that I have interacted with. To all my instructors, including Drs. Lawson, Stone, Jewell, Golder, van Zyl, Barber, and Sar, a personal thank you for your preparation for academe that you provided to me. Dr. Ruth Huber, a special thank you to who you are as an academic and the "mom" you were for us students upon entry into the program. All it takes is one person, and you have been that one. To the most supportive Support Staff, Norma Kyriss and Debra Evans, you have been invaluable assets to my experience at the University of Louisville, smoothing out the rough patches and riding the bumpy ones with me. To an endearing colleague, Dr. Pam Yankeelov, who provided a very special way of supporting me and guiding me. To a passionate, candid, and personable dean, Dr. Terry Singer, your backing and reinforcement have made my doctoral experience positive and unique.

My newfound family- brothers Reggie, Charlos, and Joe; sisters April and Shawnise. Each of you shared your lives and insight, and that is only something that family knows how to do. Reggie, you know there is a special place in my heart for you and your loving family. Charlos, there is a separate special nook 
just for you and your family. You have always been inspiring and both you and Reggie were very crucial in my strength of having Jordan in class with us during the second year! You will never know what that type of support and encouragement meant to the girls and me.

Special thanks to the Southern Regional Education Board (SREB), the University of Louisville, and the School of Interdisciplinary and Graduate Studies for the continued support and pathway for my experience. Special people like Dr. Ansley Abraham, Toccara Porter (U of L), and Adam Robinson (U of L) have created many helpful avenues for me. Now, the work begins... 


\section{ABSTRACT \\ PREDICTORS OF HIV RISK BEHAVIORS AMONG OLDER ADULTS: A MULTILEVEL ANALYSIS}

November 11, 2013

Laneshia R. McCord

Over the past thirty years, HIV has become a worldwide epidemic. Given the surge in the rate of sexually transmitted diseases including HIV, this sheds light as a new worry for sexually active older adults, raising questions about risk behaviors among this group. The issues facing older adults are three-fold in that they are 1) not identifying themselves as being at risk; 2) not identifying risk behaviors; and 3) are not largely being identified in the public realm as participating in risk behaviors. For these reasons, understanding both environmental and individual factors and their unique influences on HIV risk behaviors among older adults is very important. A study was undertaken to develop an understanding of the environmental and individual population factors that predict HIV risk behaviors among older adults using population- based data from the Behavioral Risk Factor Surveillance System and eight state level data sources, guided by Andersen's Behavioral Model of Health Utilization (2007). The model investigated the predictive ability of social and environmental factors in addition to individual factors on HIV risk behaviors. Methods: The research design for the study was a multilevel repeated cross-sectional design with a three level nested structure. The software package 
MLwiN was used to conduct the multilevel analysis using the Deviance Information Criterion (DIC) analytical method to assess the fit of models with Markov chain Monte Carlo (MCMC) estimation. Using a nationally representative sample of 23,950 individuals from 2008 to 2011, nested in 51 states, the trend study allowed for an understanding of the state and individual-level factors that predict participating in HIV risk behaviors.

Results: In each step, the model fit improved the DIC statistic. Overall, the results indicated that there were differences between states and their levels of HIV risk behaviors. While HIV risk behaviors decreased from 2008 to 2011, there was significant variation between and within states in the probability of individual HIV risk behaviors. States that had a higher percentage white females, a higher percentage of persons uninsured, a higher percentage of whites with AIDS, a lower percentage of Asians with AIDS, and a lower percentage of Other races with AIDS had a higher probability of individuals participating in HIV risk behaviors. All of the individual predictors of HIV risk behaviors were statistically significant.

Conclusion: With the increase in older adults living with HIV or becoming diagnosed or infected later in life, it is paramount that HIV risk behaviors are examined in this population. Results indicated that states that had more white females, more people who are uninsured, and whites, Asians, and other races living with AIDS were environments that had higher levels of HIV risk behaviors. Recommendations for future research are made, with education, policy, and practice implications discussed. 


\section{TABLE OF CONTENTS}

Page

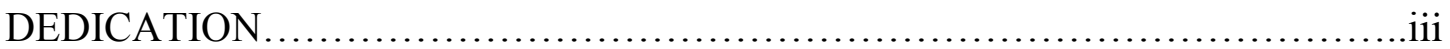

ACKNOWLEDGEMENTS ........................................................

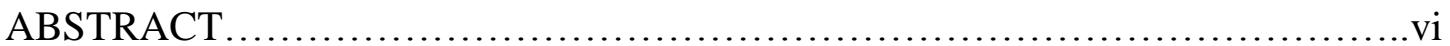

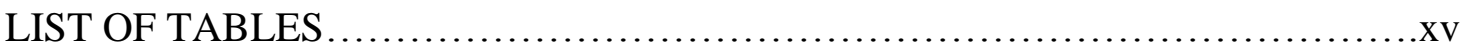

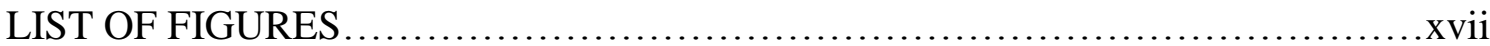

\begin{tabular}{|c|c|}
\hline $\begin{array}{l}\text { CHAPTER I: } \\
\text { INTRODUCTION }\end{array}$ & (1, \\
\hline HIV and AIDS: The Disease & \\
\hline Modes of Transmission & \\
\hline Risk Behaviors & ...6 \\
\hline $\begin{array}{l}\text { Groups with Increased HIV } \\
\text { Risk Behaviors }\end{array}$ & (1) \\
\hline
\end{tabular}

Geographic Location $\quad$.................................10

Race

Gender $\quad$.................................13

Age

Influences on Older Adults' HIV Risk $\quad$..................................15

Behaviors

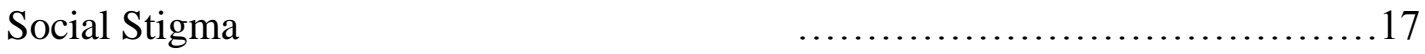

Media Influence

Summary and Conclusion $\quad$................................19

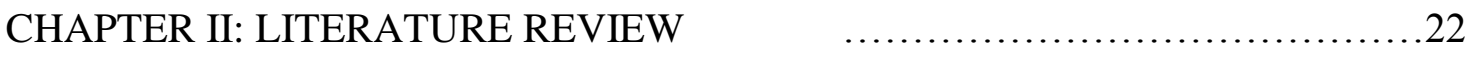

Theory of Gender and Power $\quad$................................23

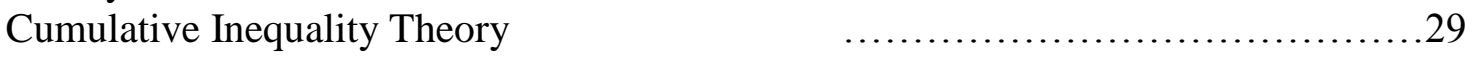


The Five Domains of Cumulative Inequality

............................... 30

Theory

Andersen's Behavioral Model of Health

n............................... 36

Utilization

Proposed Conceptual Model

State Characteristics as Environmental-level

Predictors

Individual Characteristics as Individual-level

Predictors

HIV Risk Behavior as the Outcome Variable

Environmental Predisposing Demographic

Characteristics

Environmental Predisposing Social Structure

Characteristics

Environmental Enabling Resources

Environmental Need Factors

Individual Predisposing Demographic

Characteristics

Individual Predisposing Social Structure

Characteristics

Individual Enabling Resources

Individual Need Factors

Individual Health Behavior

Summary and Conclusions

CHAPTER III: METHODOLOGY

Research Goal and Hypotheses

Research Design

Multilevel Modeling

Data Sources 


Sample
Power
Operationalization of Variables
Environmental Predictor Variables
Individual Predictor Variables


Conditional Growth Model with Individual

Predictors

Conditional Growth Model with State Effects

Individual Main Effects

State Main Effects

Summary and Conclusion

CHAPTER V: DISCUSSION

Discussion of Hypothesis 1

Individual Predisposing Characteristics

Individual Enabling Characteristics

Individual Need Characteristics

State Predisposing Characteristics

State Enabling Characteristics

State Need Characteristics

Discussion of Hypothesis 2

Discussion of Hypothesis 3

Implications of the Study

Limitations

Summary and Conclusion

REFERENCES

APPENDICES

CURRICULUM VITAE

.238




\section{LIST OF TABLES}

\begin{tabular}{l}
\hline Table \\
1. Study Participants per Year \\
2. Environmental Characteristics (Level 2) \\
3. Individual Characteristics (Level 1) \\
4. Health Behavior (Level 1) \\
5. Correlation Matrix for State Predisposing Demographic and Social Structure \\
Variables
\end{tabular}

6. Correlation Matrix with Enabling Variables Added 07

7. Correlation Matrix with Need Variables Added

8. Skewness Transformations

9. Level 3 State Predictors

10. Level 2 State Cohort Predictors

11. Level 1 Predisposing Demographic Characteristics ( $N=23,950)$

12. Level 1 Predisposing Social Structure Characteristics $(\mathrm{N}=23,950)$

13. Level 1 Enabling Resource Characteristics of Study Population $(\mathrm{N}=23,950)$

14. Level 1 Need Characteristics of Study Population $(\mathrm{N}=23,950)$

15. Study Participants per Year on the Outcome Variable

16. Unconditional model (null model)

17. Comparison of Null Model to Growth Model 
18. Comparison of Null Model, Growth Model and Growth Model with Main

$\ldots \ldots . .142$ Individual Effects

19. Comparison of All Models

$\ldots \ldots \ldots 148$ 


\section{LIST OF FIGURES}

\begin{tabular}{|c|c|}
\hline Figure & Page \\
\hline $\begin{array}{l}\text { 1. Estimated percentage of persons living with HIV/AIDS who are 50+ } \\
\text { by year, 2001-2007 }\end{array}$ & ......1 \\
\hline 2. Estimated new HIV infections by transmission category & .6 \\
\hline $\begin{array}{l}\text { 3. Estimates of new HIV infections, by race/ethnicity, risk group, and } \\
\text { gender for the most affected U.S. populations }\end{array}$ &. .9 \\
\hline 4. Rates of persons diagnosed with HIV, year-end 2008 & .11 \\
\hline 5. AIDS in the United States by Geographic location & .12 \\
\hline 6. Estimated new HIV infections by race $(n=47,500)$ & .13 \\
\hline $\begin{array}{l}\text { 7. Estimated rate of new HIV infections per } 100,000 \text { individuals, } \\
2010 \text { - United States }\end{array}$ &. .14 \\
\hline 8. Behavioral Model of Health Utilization & $\ldots .37$ \\
\hline 9. Conceptual framework for determining HIV risk behavior & .43 \\
\hline 10. Multilevel structures and classifications & .81 \\
\hline $\begin{array}{l}\text { 11. State-level predisposing demographic and social structure variables, } \\
\text { highest and lowest states }\end{array}$ & $\ldots 116$ \\
\hline 12. State-level enabling variables, highest and lowest states & .......117 \\
\hline 13. State-level need variables, highest and lowest states &. .118 \\
\hline 14. Empirical growth plots for state HIV risk behaviors over time &. .134 \\
\hline 15. Null model & .135 \\
\hline $\begin{array}{l}\text { 16. Caterpillar plot showing state residuals with } 95 \% \text { confidence intervals } \\
\text { for log odds of participating in HIV risk behaviors }\end{array}$ & $\ldots 138$ \\
\hline 17. Unconditional growth model & $\ldots 139$ \\
\hline 18. HIV risk behavior of the & $\ldots 140$ \\
\hline 19. Growth model with individual variables added & $\ldots 141$ \\
\hline $\begin{array}{l}\text { 20. HIV risk behavior of the whole sample over time with individual } \\
\text { predictors }\end{array}$ & $\ldots \ldots \ldots \ldots \ldots 144$ \\
\hline 21. Growth model with main effects and interaction effects & $\ldots \ldots \ldots \ldots \ldots 145$ \\
\hline $\begin{array}{l}\text { 22. Caterpillar plot showing state residuals with } 95 \% \text { confidence intervals } \\
\text { for log odds of participating in HIV risk behaviors after adding predictors }\end{array}$ &. .146 \\
\hline $\begin{array}{l}\text { 23. HIV risk behaviors of the whole sample over time with individual } \\
\text { and state predictors. }\end{array}$ & $\ldots 150$ \\
\hline 24. Predicted probabilities for age on participating in HIV risk behaviors & $\ldots 151$ \\
\hline $\begin{array}{l}\text { 25. Predicted probabilities for gender on participating in HIV risk } \\
\text { behaviors. }\end{array}$ & $\ldots \ldots \ldots \ldots \ldots 152$ \\
\hline
\end{tabular}


26. Predicted probabilities for marital status in participating in HIV risk behaviors.

27. Predicted probabilities for race on participating in HIV risk behaviors.

28. Predicted probabilities for education on participating in HIV risk behaviors.

29. Predicted probabilities for employment status on participating in HIV 156 risk behaviors.

30. Predicted probabilities for residence status on participating in HIV risk behaviors.

31. Predicted probabilities for cost as a barrier to care on participating in 158 HIV risk behaviors.

32. Predicted probabilities for mental health status on participating in HIV risk behaviors.

33. Predicted probabilities on general health status on participating in HIV 160 risk behaviors.

34. Predicted probabilities for physical health status on participating in HIV risk behaviors.

35. Predicted probabilities for drinking alcohol on participating in HIV risk behaviors.

36. Predicted probabilities for percentage of white females in each state 163 on participating in HIV risk behaviors.

37. Predicted probabilities for percentage of persons uninsured in each state on participating in HIV risk behaviors.

38. Predicted probabilities for percentage of AIDS diagnoses of persons who were white in each state on participating in HIV risk behaviors.

39. Predicted probabilities for percentage of AIDS diagnoses of persons 166 who were Asian in each state on participating in HIV risk behaviors.

40. Predicted probabilities for percentage of AIDS diagnoses of persons 167 who were of Other race groups in each state on participating in HIV risk behaviors. 
Figure 41. Type of illicit drugs used in the past year among adults age 50 179 or older who used illicit drugs in the past year: 2006 to 2008 


\title{
CHAPTER I: INTRODUCTION
}

\begin{abstract}
"There will be a vaccine in a few years and a cure for AIDS before 1990." $\sim$ Margaret Heckler (Former Secretary of Health and Human Services, Reagan administration, 1984)
\end{abstract}

Over time, it has been made evident that as people age, they continue to engage in sexual activity (Fullilove, Fullilove, Haynes, \& Gross, 1990; Inelman, Gasparini, \& Enzi, 2005; Levy-Dweck, 2005; Levy, Holmes, \& Smith, 2003; Waysdorf, 2002). The frequency and intensity may be less, yet older women and men continue to engage and explore their intimate selves well into their 80s and beyond (Emlet \& Poindexter, 2004; Estabrooks \& Carron, 1999; Levy et al., 2003; Szirony, 1999; Waysdorf, 2002). While the activity may be the same, the context has certainly changed. Over the past thirty years, Human Immunodeficiency Virus, referred to here on out as HIV, has become a worldwide epidemic, and there has been a surge in the rate of both sexually transmitted infections or diseases (STIs/STDs), including HIV. Both have become new worries for sexually active older adults, raising questions about risk behaviors among this group.

Persons over the age of 50 do participate in risk behaviors, thus leading to their becoming infected with HIV (Poindexter, 2009). The prevalence of HIV and Acquired Immunodeficiency Syndrome (AIDS) in this population increased from 2007 to 2009; the largest group among older adults living with HIV are those aged 50-54, Baby Boomeraged persons 
(U.S. Department of Health and Human Services, Centers for Disease Control and Prevention [CDC], 2013). One explanation for this is that older adults diagnosed with HIV are living longer. The growth of older adults with HIV can be seen in Figure 1.

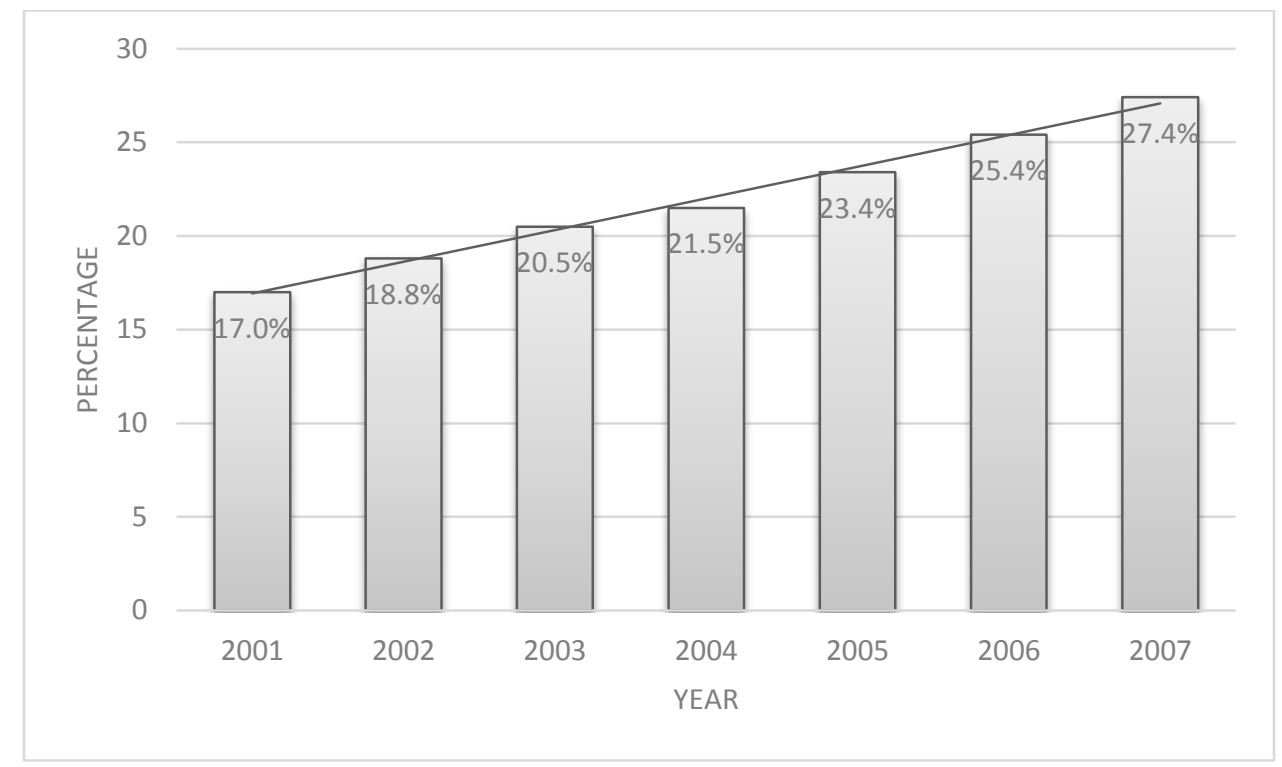

Figure 1. Estimated percentage of persons 50+ living with HIV/AIDS by year (Cahill et al., 2010).

Many in the generations that constitute older adults (namely Traditionals and Baby Boomers) were socialized as younger adults to believe that condoms were for risk prevention, associating "risk" as the increased likelihood of an unplanned pregnancy or transmitting an STD. As a result of this frame of thought, heterosexual older adults largely ignore condom use as pregnancy is no longer an issue for them (Williams \& Donnelly, 2002). Age-related physiological changes and a natural decline in the immune system of most aging women and men place them at greater risk for acquiring STIs or HIV, and as aforementioned, the low use of protective barriers opens the door to their risk exposure. 
It is also important to point out that due to low perception of risk and unknown status among this group, the prevalence of the disease may be higher than reported (The Henry Kaiser Family Foundation [HKFF], 2011). Unlike younger adults, one-half of older adults diagnosed with HIV were also diagnosed with AIDS within a year of the HIV diagnoses (U.S. Department of Health and Human Services, Health Resources and Services Administration [HRSA], 2010a). Older individuals who have HIV have a decrease in life expectancy compared to older adults without HIV. This is due to the compounding effects of age-related conditions and the non-physiological factors that impact overall health and well-being along with HIV-related complications (HRSA, 2010a) .

Older adults can enhance their intimate lives by engaging in sexual relationships with not only their peers but also those younger than them. Due to such "late-life romances" (Waysdorf, 2002, p. 73), older adults are more likely to re-enter the dating scene and /or remarry, however, "cultural barriers and longstanding habits among seniors restrict [them from asking about] possible risk factors" (p.73). This surge in sexual activity opens older adults up to a 'market' of intimate partners that can lead to increased participation in HIV risk behaviors such as unprotected sex, having multiple partners, sex exchange culture, and injecting drug practices where HIV status is unknown or positive. These activities increase exposure to STDs as well as HIV. Based on these risk behaviors, older adults should be viewed in the public's eye as equally susceptible to HIV (Hesselgrave, 1998) as those in younger age groups.

Similarly, external factors that influence the participation of older adults in highrisk behaviors must be taken into consideration. These factors are also referred to as 
social determinants of health, and preclude that health behaviors and outcomes are more than reactions to biological relationships, that they are also affected by external factors that form the environment in which they exist. Increasingly, more health models are sought and used to develop a better understanding of this interaction and impact on health outcomes, and how certain groups are considered "more vulnerable" than others based on their exposure to risk (Andersen, 1995; Andersen \& Davidson, 2007).

The main aim of this study is to develop a multilevel model of the environmental and individual population factors that predict HIV risk behaviors among older adults using population- based data and guided by Andersen's Behavioral Model of Health Utilization (2007). This dissertation will address the gap in knowledge of HIV risk behaviors among older adults by providing an understanding of how both individual and contextual characteristics can influence and shape older adults' behavior. Older adults share many of the same risk factors that affect younger adults, such as participating in sexual high-risk behaviors, drug use, and belonging to an ethnic minority group. In addition to those, they also are at increased risk of having less knowledge about HIV and AIDS and being under recognized and misdiagnosed by health professionals (CDC,2008a). There is substantial evidence that supports examining the context of risk behaviors because it highlights the dynamics that are outside of personal control and how they form the environment where an individual exists. To examine such an issue solely at the individual level and place all responsibility at that level is short sighted (Quinn, 1993).

The following section will explain the HIV and AIDS disease, modes of transmission, and risk behaviors. Following that, the distribution of new HIV infections 
and current HIV diagnoses will be discussed by geographic location, race, gender, and age. After that, there will be a discussion of HIV risk behaviors as they relate to groups that are disproportionately affected by HIV. Lastly, influences of older adults' risk behaviors are described, with respect to the effect of social stigma and media influences.

\section{HIV and AIDS: The Disease}

HIV is a virus that impedes the body's natural ability to ward off disease, viruses, and infections and can lead to the chronic condition known as AIDS (CDC,2006b;2008a). HIV has three domains that should be understood in order to fully capture the magnitude and impact of the disease. Biologically, HIV attacks the body's immune system by invading the T-helper cells, known as CD4 cells, replicating them to make more invading cells, and ultimately destroying them (CDC,2008a). An infected individual transmits the virus into the bloodstream and there must be a sufficient quantity of the virus present. Socially, HIV/AIDS severely affects persons who engage in non-heterosexual behavior, specifically men who have ever had sexual contact with other men and/or bisexual contact, referred to here on out as men who have sex with men (MSMs). Persons belonging to these groups make up over $50 \%$ of new HIV infections and represent almost half of all people living with HIV in the nation (CDC,2010). Also important to note is that individuals who engage in heterosexual sexual behavior account for $31 \%$ of new cases of HIV and $28 \%$ of people living with HIV (CDC, 2010). Physically, HIV/AIDS has undergone a transformation from being an acute condition resulting in a death sentence to a manageable chronic disease. This change is the result of advances in rapid response testing and treatment regimens. A diagnosis of AIDS occurs when a person is 
HIV-positive and has an opportunistic disease or a CD4 count below 200 (Card et al., 2007). In the absence of these criteria, one can be diagnosed as HIV-positive for life.

Worldwide, there are approximately 34 million people infected with HIV (HKFF,2011). In North America, it is estimated that more than 1.1 million people are living with HIV, with 47,129 HIV diagnoses in 2010. Domestically, it is estimated that nearly one in five (18.1\%) people infected with HIV are not aware of their status (CDC,2013a), thus the numbers are probably closer to 1.3 million. In the state of Kentucky, it is estimated that there are 389 cases of persons diagnosed with HIV in 2010 (HKFF, 2012) and 5,723 cumulative cases of persons living with an AIDS diagnosis, being HIV-positive, and having an opportunistic disease or a CD4 count below 200 (HKFF, 2012).

\section{Modes of Transmission}

In the U.S., HIV is most widely spread by transmission of bodily fluids from an infected person to another person, through male-to-male sexual contact, heterosexual sex, and/or injection drug use with a partner who is high risk or known to have HIV infection. In order for the virus to be transmitted, certain conditions have to be met. The virus can only be transmitted through the exchange of mucous membranes (i.e., blood, semen, genital secretions, and breast milk). There also needs to be a certain concentration of the virus present. Viral loads vary in concentration depending on where one is on the infection continuum, with a higher viral load after immediate exposure to HIV, typically those first 6-12 weeks, and near the end as HIV progresses to AIDS (Card et al., 2007). Concentrations also vary depending on the mode of transmission (i.e., there is a lower 
concentration of HIV in saliva; the highest concentration is in blood and semen). Figure 2 illustrates new HIV infections in 2010.

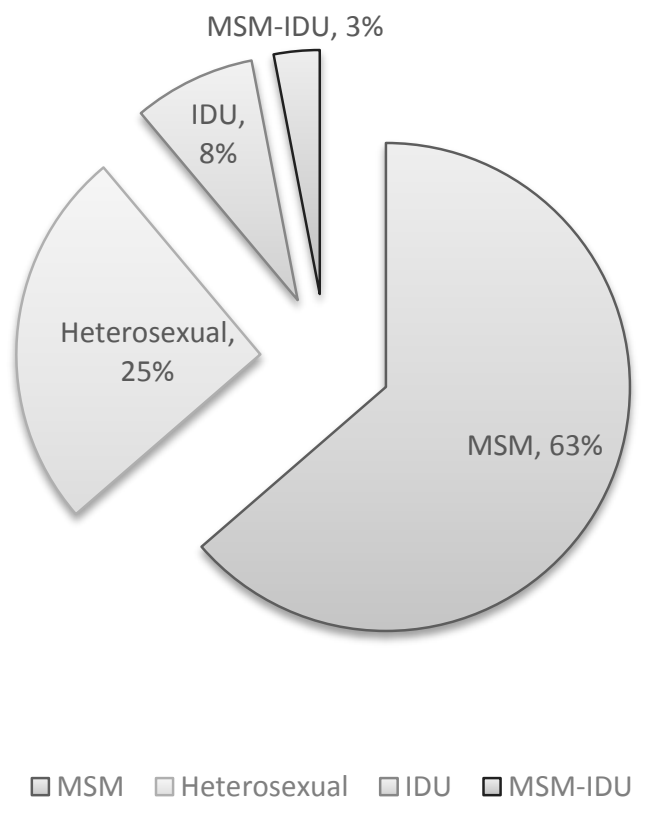

Figure 2. Estimated new HIV infections by transmission category, CDC (2012).

\section{Risk Behaviors}

In the United States, having unprotected sex with an infected person is the most common HIV risk behavior and primary mode of transmission for HIV. Anal sex places persons at the most risk, followed by vaginal sex. Also, having multiple partners or sharing needles or other equipment used to prepare injection drugs with a person who is HIV infected is a high risk behavior.

There is a profound link between STDs and HIV transmission. For those who are HIV infected and have an STD, there is an increased likelihood of transmitting HIV than 
persons with HIV who are STD free (e.g., Wasserheit, 1992). In some cases, persons who are infected with an STD, particularly those that are viral such as genital herpes or syphilis, are two to five times more likely to contract sexually transmitted HIV (CDC,2010). Skin-related issues (e.g., genital ulcers) and the amount of concentration of cells in genital secretions increase the likelihood of skin breakdown from ulcers, allowing for both easy transmittal of STDS as well as presence of cells that increase the susceptibility to HIV because it increases the viral load (CDC,2010). Similar to HIV, there is a higher concentration of cells in semen and genital fluids, which is why there is an increase risk in the sexual transmission of STDs. Nationally, there has been an observed increase in chlamydia and gonorrhea, while syphilis has remained stable (CDC, 2010). According to the CDC, the highest numbers of chlamydia and gonorrhea cases are those among aged 15-24. Despite syphilis rates being stable, there has been a steady rise over the past few years in syphilis among men who have sex with men (MSMs) and bisexual men (CDC, 2010). In lieu of exposure and transmission rates of STDs, intervention studies have found that detection and treatment of STDs can reduce and prevent the transmission of HIV (CDC,2010).

In drug use culture, specifically injecting drug use, it has been found that along with unsafe needle sharing practices is also the presence of unsafe sex behaviors. There is an increase of violence, more sexual partners, higher frequency of unprotected sex, and use of alcohol and drugs during sex among those who are injecting drug users (Logan, Cole, \& Leukefeld, 2002). Also familiar to this culture is the practice of sex exchange, to be able to obtain drugs or money to purchase drugs (Logan et al., 2002). 


\section{Groups with Increased HIV Risk Behaviors}

Groups that are at increased risk of HIV exposure are men who have sex with men (MSM), persons engaging in heterosexual sex, and persons who engage in injecting drug use (IDU). Receptive anal sex is riskier than insertive anal sex and is the primary high risk sex behavior. While roughly four percent of the population, MSMs account for $78 \%$ of new HIV infections and 52\% of persons living with HIV. Similarly, for older adults, the transmission category of MSM contributed to the highest percent (60\%) of HIV infection (CDC, 2013). Vaginal sex is the second high-risk behavior. Heterosexuals account for one-third of new HIV infections and $28 \%$ of those living with HIV. Among older adults, $23 \%$ are infected through heterosexual contact. Having multiple sex partners or having STDs can also increase the risk of infections for both groups. Injection drug users account for $8 \%$ of new HIV infections and $16 \%$ of those living with HIV. Among older adults, $14 \%$ of new infections are from injection drug use and $3 \%$ are from MSM who are also IDUs (MSM/IDU) (CDC, 2013). For older MSM, their infection rates increased during 2007 to 2010, with heterosexual rates remaining stable, and IDU and MSM/IDU decreasing. For older women, $82 \%$ of infections were from heterosexual contact, which had increased, and $18 \%$ by injection drug use, which had decreased (CDC, 2013).

As illustrated in Figure 3, white MSM had the largest number of new HIV infections among all risk groups, followed by black MSM, in 2010. Over two-thirds (63\%) of new cases are young MSM (those aged 13-24), and over half (55\%) of those are among African Americans. This change shows a 12\% increase from 2008 to 2010. 


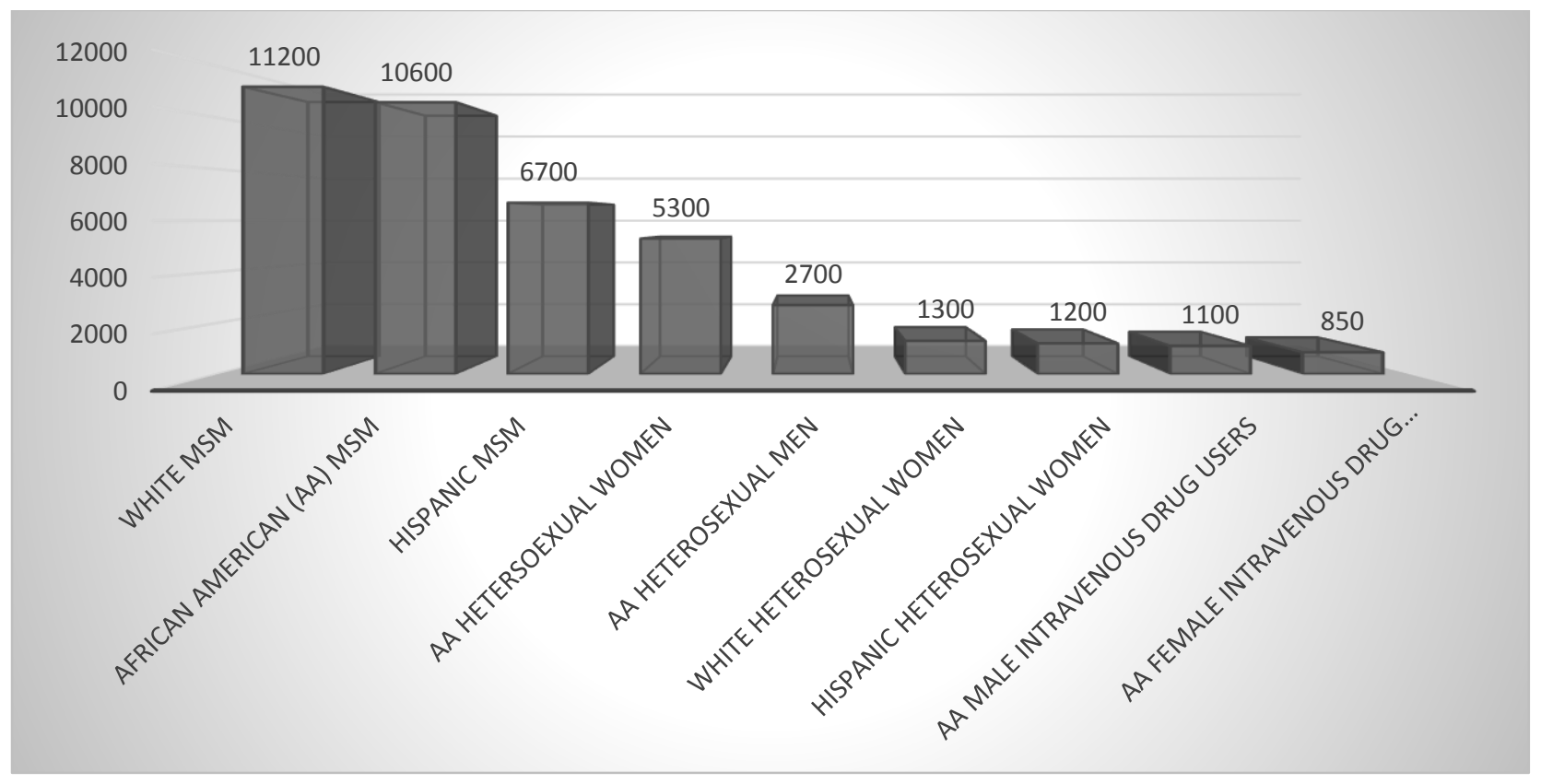

Figure 3. Estimates of new HIV infections, by race/ethnicity, risk group, and gender for the most affected U.S. populations, 2010 (CDC, 2012a).

Among heterosexual transmission, receptive partners (women) are at an increased risk than the insertive partners (males), because the vagina and mucous membranes better facilitate HIV transmission than the urethra or tears/cuts on a penis (CDC, 2010d) . Another disproportionate effect of HIV is seen across this transmission route, as illustrated in Figure 6. White women make up over half of the female population (67\%), with Hispanic women coming second (17\%), following with African American women at 12\% (HKFF, 2012e). In contrast, African American women account for over half of new HIV diagnoses among women (64\%), White women at 18\%, and Hispanic women at $15 \%$. Because there are not any confirmed reports of female-tofemale transmission of HIV (CDC, 2006b), it is okay to accept that heterosexual transmission is the primary cause of HIV infection among women. While extremely low there exists the possibility that female-to-female transmission is a risk factor due to the 
exposure to vaginal secretions yet it is unfounded (CDC, 2006b). There are no confirmed reports of female-to-female transmission, because women who reported only having sex with women had other risk factors that were later identified, declined to be interviewed, or the information was not asked or volunteered.

Injection drug use (IDU) heavily affects HIV transmission among racial and ethnic minorities and among more women than men (CDC, 2007), as more women have reported being IDUs or having sex with partners who are IDUs. Among older men, an estimated $14 \%$ of diagnosed infections were due to being IDUs and $21 \%$ of those living with HIV, and among older women, an estimated $18 \%$ of infections were due to being IDUs and 33\% of those living with HIV (CDC, 2007).

\section{New HIV/AIDS Infections and Current HIV/AIDS Diagnoses}

\section{Geographic Location}

Urbanization affects the spread of diseases such as HIV/AIDS, where increased population densities and participation in risk behaviors in urban areas can ease the transmission of disease and increase that area's vulnerability to disease ("Population Action International", 2012). There are higher concentrations of HIV/AIDS in urban areas, so states that report higher numbers of HIV/AIDS have major metropolitan areas (CDC,2012d). As seen in Figure 4, states in the Northeast and South reported the highest rates of persons living with HIV, with the exception of California, Nevada, and Illinois (CDC, 2012d). To understand what type of environment this creates for older adults, it should be considered that one third (36\%) of the nation's older adult population reside in 
the South, one of the areas with the highest rate of HIV, followed by the Midwest (24\%), Northeast (21\%), and West regions (20\%) (Colello, 2007).

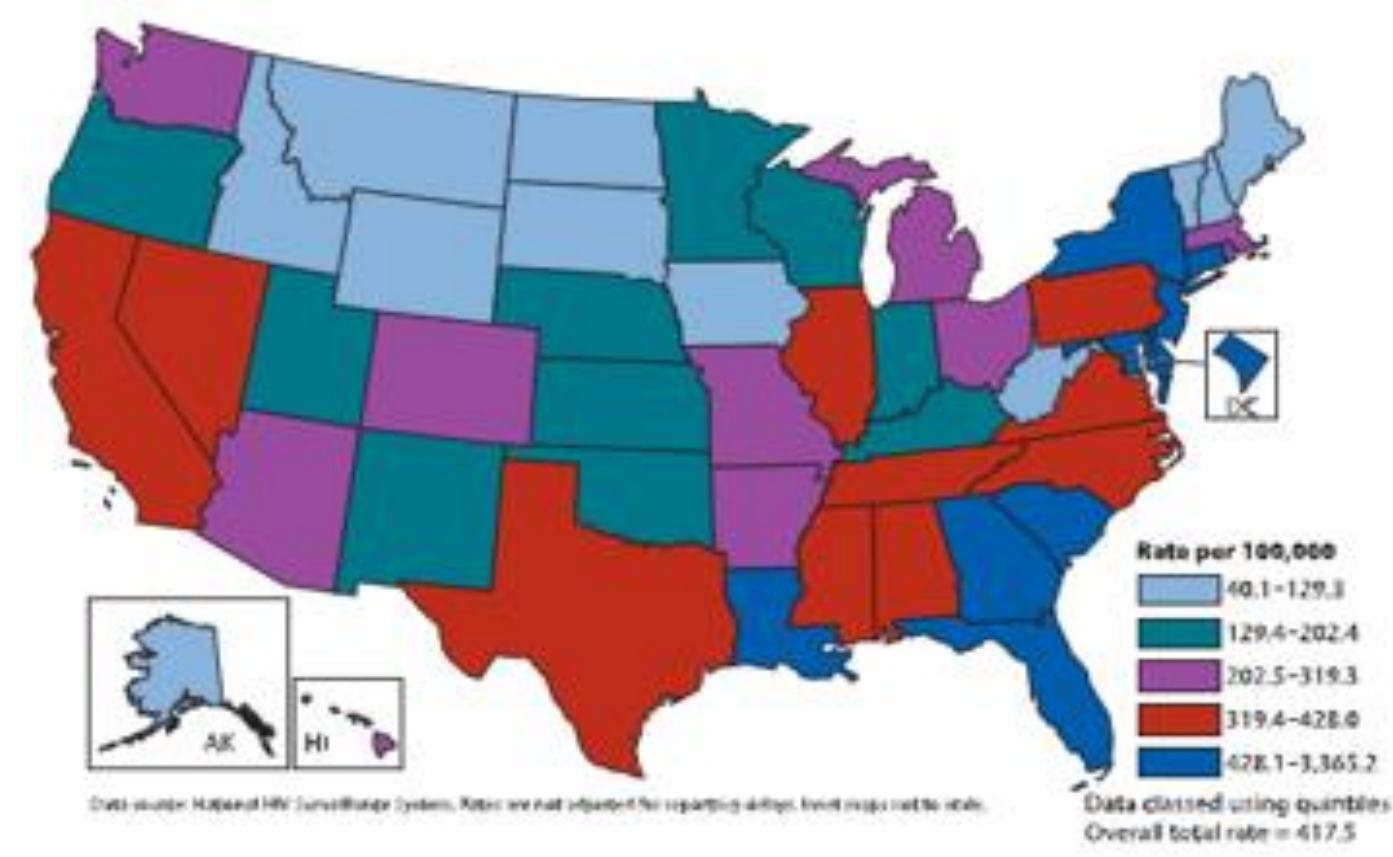

Figure 4. Rates of persons diagnosed with HIV, year-end 2008 (CDC,2012d)

In terms of incidence, Figure 5 illustrates that the Southern region accounted for almost half of all estimated new AIDS diagnoses (47\%), with the Northeast in second at $25 \%$, the West at $17 \%$, and the Midwest at $11 \%{ }^{1}$. The South also accounted for $40 \%$ of persons living with AIDS (PLWAs), with the Northeast at 29\%, the West at 20\%, and the Midwest at $11 \%$. This also holds true for older adults, as the highest rates of HIV infection for older adults are in the South and Northeast regions (CDC,2013).

\footnotetext{
1 Northeast: CT, ME, MA, NH, NJ, NY, PA, RI, VT

Midwest: IL, IN, IA, KS, MI, MN, MO, NE, ND, OH, SD, WI

South: AL, AR, DE, DC, FL, GA, KY, LA, MD, MS, NC, OK, SC, TN, TX, VA, WV

West: AK, AZ, CA, CO, HI, ID, MT, NV, NM, OR, UT, WA, WY
} 


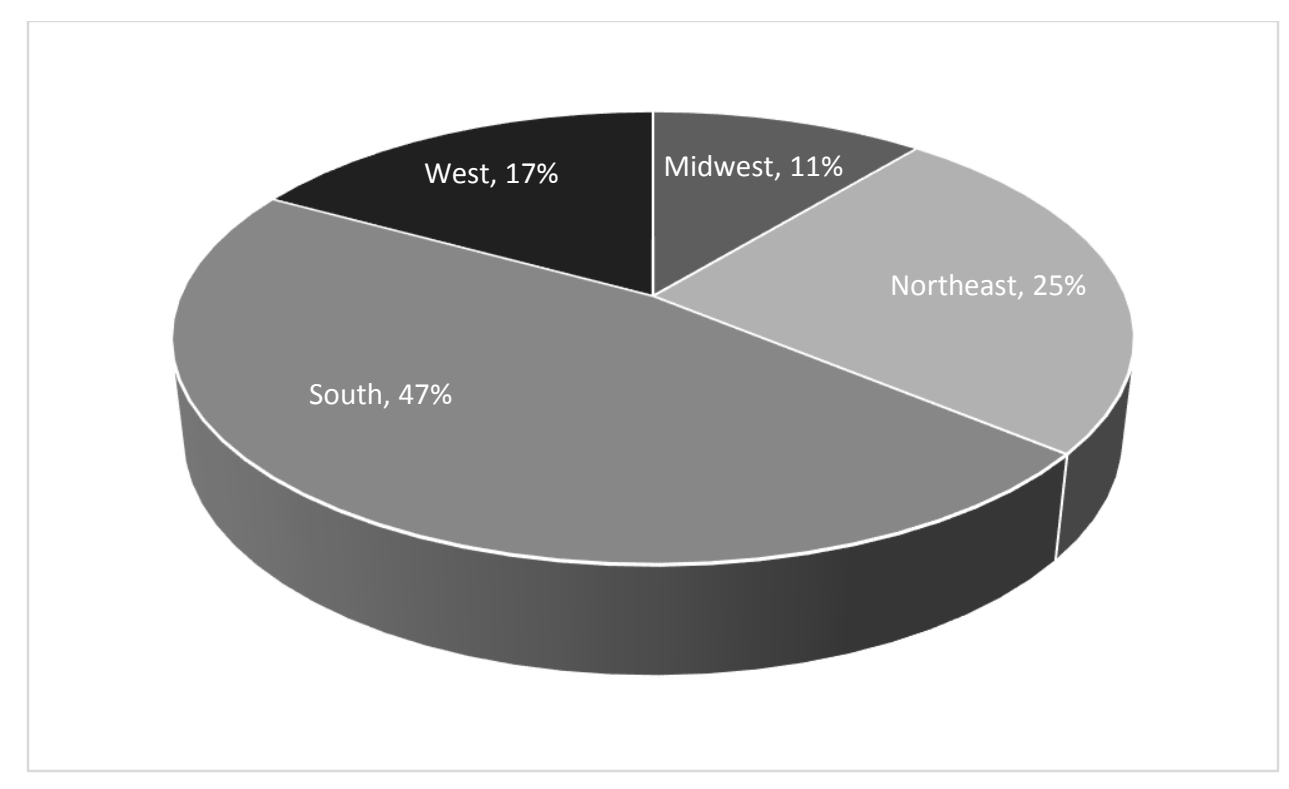

Figure 5. AIDS in the United States by geographic location (CDC,2012d).

\section{Race}

Examination by racial/ethnic group shows that while African Americans represent $14 \%$ of the population, this group makeup almost half of all estimated new HIV cases as illustrated in Figure 6, increasing 12\% from 2005 to 2008 (CDC, 2010b). Whites account for about $31 \%$ of estimated new cases, and Hispanics account for $21 \%$ of estimated new cases (CDC,2012a;2012c). Among adults 50-64, new cases of HIV infections rates remained stable among African Americans and whites (CDC, 2013). The same source reported that HIV incidence among older Hispanics, Asians, and older adults belonging to multiple race groups decreased. 


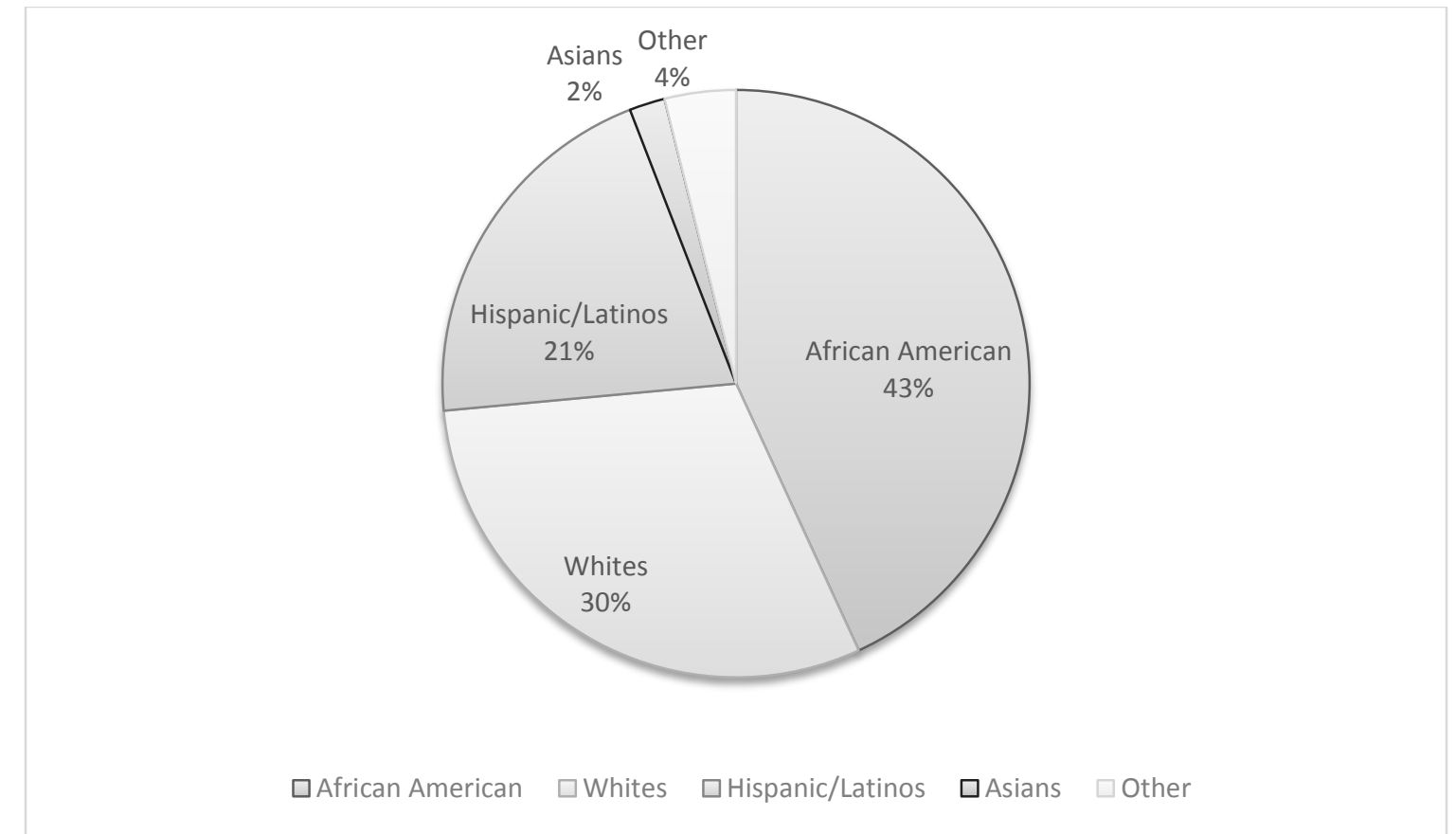

Figure 6. Estimated new HIV infections by race $(\mathrm{n}=47,500)$, CDC (2010)

African Americans also experience the most severe burden of persons living with HIV when compared to other race and ethnicities. They account for $46 \%$ of people living with HIV, and Hispanics/Latinos account for $17 \%$ of people living with HIV (CDC, 2012c). The prevalence of HIV among adults 50 years and older mimics that disproportionate burden among African Americans. The highest estimated prevalence rate of persons living with HIV who were older were among African Americans, at a rate of 1,255.5 per 100,000 population, making them 2.3 times the rate of Hispanics/Latinos (536.0) and 8.5 times the rate of whites (144.2) (CDC, 2013).

\section{Gender}

There are more men being diagnosed with HIV and living with HIV than women. More than half of all new infections (63\%) accounted for were among men (CDC, 2012c) and the rate of new HIV infections among men (30.7) was over four times that of women (7.3), as illustrated in Figure 7 (CDC, 2013c). Among older adult males, those aged 50- 
64 estimated rates of infection remained stable (13.6) yet was 3.2 times the rate of older females (4.2) (CDC, 2013).

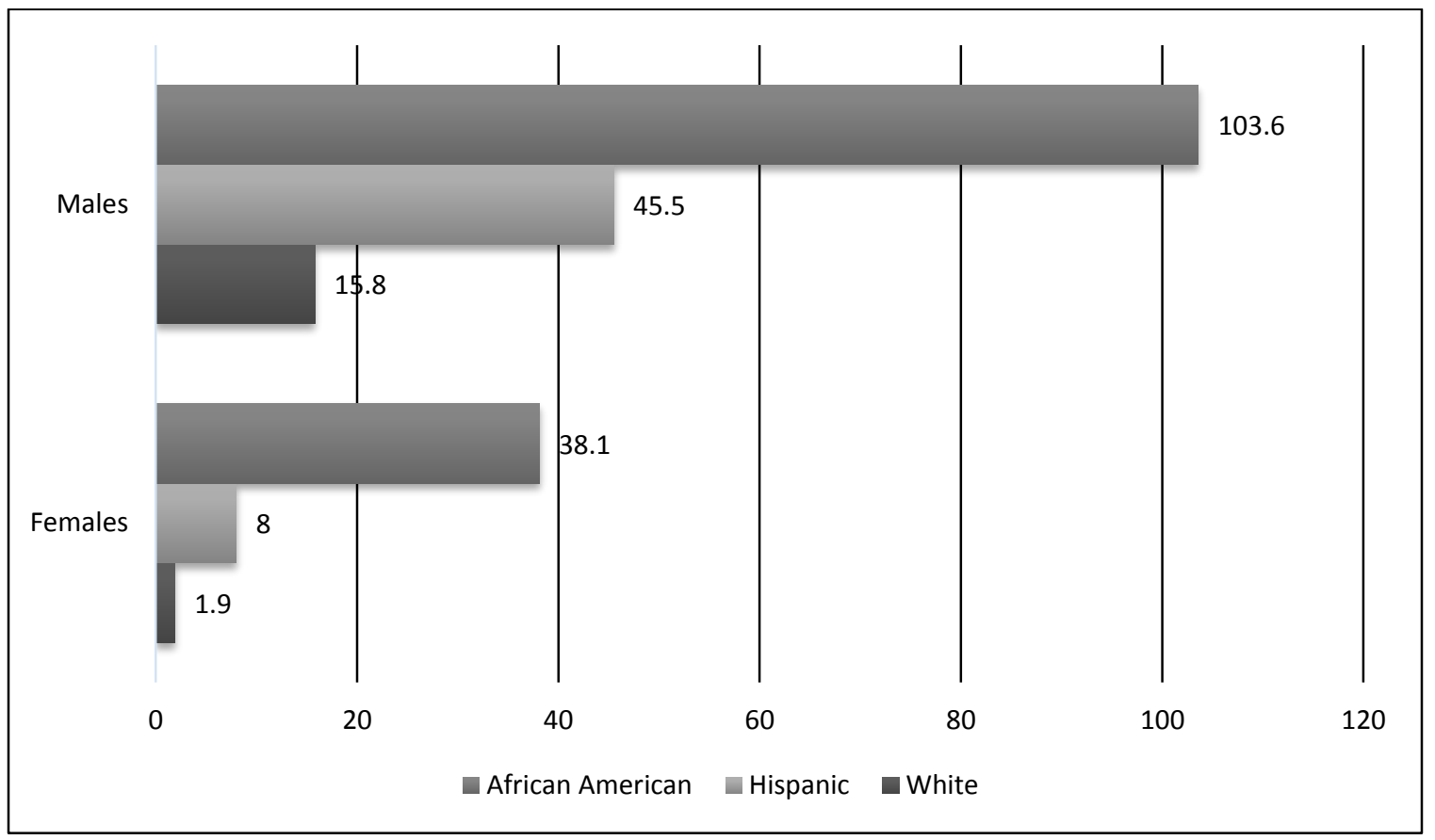

Figure 7. Estimated rate of new HIV infections per 100,000 individuals, 2010-United States (CDC, 2012c).

\section{Age}

It is estimated that adults aged 25-34 had the highest number of new HIV infections in 2010 (CDC, 2013c), and while infection remains a large issue for younger populations, it is a growing issue for aging populations as well. It has been projected that by 2015 , over half of all persons living with HIV/AIDS will be age 50 and older (U.S. Department of Health and Human Services, Administration on Aging, 2013). This age group has seen an increase in new cases over the years, growing $61 \%$ from 2001 to 2007, with younger Baby Boomers (aged 50-54) seeing the largest increase of diagnoses at $47 \%$ (CDC, 2013). 
This section looked at the nature of HIV/AIDS and its distribution by geographic location, race, gender, and age. Based on surveillance data, there are differences in HIV burden experienced in these distributions. The largest difference, or disparity, observed is by race, where African Americans are disproportionately affected by the disease given their size in the population. Another group that carries a significant amount of the HIV/AIDS burden is men who have sex with men. In the following section, there will be a detailed discussion of risk behaviors that lead to the transmission of HIV.

\section{Influences on Older Adults' HIV Risk Behaviors}

The issues facing older adults are three-fold in that they are 1) not identifying themselves as being at risk; 2) not identifying risk behaviors; and 3) are not largely being identified in the public realm as participating in risk behaviors. Much like younger adults, older adults are having unprotected sex and participating in intravenous drug use (CDC, 2008a). Identification and diagnosis is delayed (Waysdorf, 2002) because there is

a "false sense of security [that aging provides]... "some special immunity" (Hesselgrave, 1998,para.9). Blood transfusions were branded as the primary mode of transmission of HIV most common among older adults and accounted for over half of HIV infections at the onset of the disease (CDC,2006a). Since 1985, protocols to screen blood for HIV-1 antibodies were put into place. This concentrated focus on being a recipient of a blood transfusion or organ tissue infected with HIV as the mode of transmission for older adults decreased the awareness to the likelihood that older adults were also participating in risk behaviors. Additionally, clinical trials targeted designated "high-risk" populations, such 
as MSMs and injection drug users (IDUs), omitting aging persons who could have fit into any of the high-risk behavior groups.

For older adults already infected and who participated in risk behaviors, it was also difficult to discern between early HIV- related symptoms and signs of aging, as they can mimic some of those conditions. These conditions were weight loss or fatigue, as well as other conditions commonly found in older adults such as Parkinson's Disease or Alzheimer's (Inelman et al., 2005). Inelman et al. (2005) narrates a discussion about the first case report of persons over 60 diagnosed with AIDS which occurred in 1984. In each of the three cases reported, they all resulted in late diagnosis and acute death because AIDS was not suspected. In the 1990s, there was a gradual exploration into deaths of middle-aged persons from diseases such as tuberculosis, forms of pneumonia, and other co-morbidities, with autopsies later confirming the presence of HIV antibodies, further supporting that HIV infection was present in older adults and was going unrecognized. Another example of not identifying HIV risk among older adults revolved around HIV research. It was not until after 1993 that persons over the age of 60 were allowed to participate in clinical trials with AIDS vaccines, five years after the first human trials were conducted (Funnyé, Akhtar, \& Biamby, 2002). Early AIDS-related deaths among older adults' were misclassified, and once this connection was established, it created a new need to include adults over 50 in prevention and treatment efforts, furthermore including them as a group that participated in risk behaviors. (Calvet, 2000; Sharples, 2008). This highlighted the rising concern that HIV was, in fact, present and growing within aging populations. 


\section{Social Stigma}

The social construction of risk behaviors can aggravate outcomes for older adults. Older adults are more likely to not consider themselves as being at risk for HIV infection. The stigma of HIV, such as being homosexual or abusing drugs, carries a heavy stigma, which can lead to a decrease in testing or help-seeking behaviors among older adults. The public campaigns, including how President Reagan handled the presentation of the disease at its onset, set a tone for low disease perception among current day older adults who were younger, middle-aged adults when the disease first surfaced. The public presentation through media was that AIDS was a consequence of committing undesirable acts. A heavy stigma loomed around the idea that if one were to "catch" AIDS, they had been participating in some immoral activity as defined by dominant social groups (Cantwell, 1986), whether it be illicit drug use or having homosexual sex. Being that early cases primarily presented gay males and substance abusing persons as the face of AIDS, it was easy for adults who didn't fit that description to disassociate themselves from the disease. These types of beliefs were also oppressing to sexual minorities because it contributed to an environment that was already hostile in acceptance of alternative lifestyles to heterosexuality.

\section{Media Influence}

The media also played a pivotal role in shaping how current day older adults thought about HIV risk behaviors. During the early days of AIDS, there was a massive increase in films and news coverage with subject matter related to substance abuse, crime, corrupt systems, and race relations. During the Reagan administration, the War on 
Drugs created and passed strict laws during the era of crack cocaine. The promotion of select policies and laws were detrimental to impoverished areas as they were more susceptible to the crack cocaine epidemic (Austin \& Irwin, 2001), and also associated criminal acts such as these with race. This has been repeatedly attributed to the cause for the massive rates of African Americans incarcerated and as a possible source for why racial profiling exists (Katz, 2000; Welch, 2007).

Examples of such media coverage are the 1992 beating of Rodney King, an African American motorist, the L.A. riots, and the infamous and highly publicized criminal trial of O.J. Simpson, the African American former NFL- star and actor who was tried on two counts of murder of his ex-wife and another (whom were both White) and ultimately acquitted, were all landmark events that illuminated racial inequity in the criminal justice system. To date, criminal allegations among certain African American celebrities and entertainers, particularly men, are plastered throughout the public domain, reinforcing negative racial stereotypes (Dines, 2003). Even in the virtual world of film, movies were casting African Americans in controversial roles as drug lords, drug abusers, and active participants in prostitution and related illicit activity, which in the opinion of the author, unfavorably complemented everyday criminal acts and reinforced negative stereotypes and myths that already existed.

The media coverage of such events greatly shaped the presentation of race relations and dynamics of crime, contributing to public perception of risk behaviors for older adults (Gilens, 1996; Welch, 2007). Such presentations that focus on race/ethnic group membership can detrimentally imply that being a member of a race/ethnic group in of itself is a risk factor, instead of it being a variable that is associated with an increased 
risk of a disease or increases the vulnerability of the group to a disease. It also can imply that if one is not a member of a certain group (e.g., high-risk), then they can also be at increased risk because they are not seeing the risk for themselves and are not been seen by others as susceptible.

\section{Summary and Conclusion}

Understanding both environmental and individual factors and their unique influences on HIV risk behaviors among older adults is very important. It has been seen that similar to younger persons, older adults with HIV participated in HIV risk behaviors and have similar concerns in addition to age-related needs that should be addressed. If HIV risk behaviors are addressed specific to older adults, there are possibilities to revisit prevention strategies for this population and reduce HIV incidence among this group. As aforementioned, older adults are often diagnosed later in the disease course and have an increased mortality rate compared to younger persons. Additionally, older adults who are infected are at risk for not receiving adequate treatment and not being able to access services, resulting in a poorer quality of life and increased risk exposure to their peers. Social systems, ranging from family and friends to healthcare providers and federal programs, are ill-equipped to handle older persons with HIV.

The more that older adults are encouraged to test for HIV and other STDs, the demand for age-related provisions will increase in public policies and legislation. The shift in efforts will also be able to challenge systems of oppression because more people will be seeking out public assistance for HIV-related needs and services. A shift in those seeking help can reduce stigma and bring attention to medical and social barriers related 
to accessing care, mainstreaming issues, and increasing access to less visible and vulnerable populations. This attention will challenge old ideologies regarding HIV risk behaviors among older adults.

Geographically, HIV/AIDS is largely occupying the southern region, the same region that inhabits many older adults, in comparison to the other regions. HIV disproportionately affects persons who are ethnic minorities, with African Americans carrying a large burden of this disease compared to their smaller size in the general population, and older African Americans who are HIV positive bearing this strain as well. While it largely affects the population of men who have sex with men, increasingly heterosexual sex has led to increased incidence among women who are older and belong to ethnic minority groups.

If HIV risk is not investigated in this population in relation to their environmental context, the social, economic, and financial implications this nation will be left to deal with will be monumental as the number of infections and PLWA increases. If HIV risk is not investigated on an individual level, threats to interpersonal power and strength that older adults have been revered for will also be compromised. The study will examine both ends of this problem and contribute a unique perspective when discussing predictors of HIV risk behavior among older adults.

The following chapter will provide a review of literature, both empirical and theoretical, that relate to the multiple contexts in which HIV risk behavior occurs and how that context changes for different groups of older adults, deeming some groups being more vulnerable than others to risk exposure. In addition to this overview, a proposed 
conceptual model will be presented. The proposed conceptual model integrates both empirical and theoretical factors, setting forth how to best investigate this gap in knowledge about HIV risk behavior and older adults. 


\section{CHAPTER II: LITERATURE REVIEW}

"I have learned more about love, selflessness and human understanding in this great adventure in the world of AIDS than I ever did in the cut-throat, competitive world in which I spent my life."

$\sim$ Anthony Perkins

Understanding the context of how risk behavior occurs will help us settle the questions we have about the older population. Two theories have been identified for examining HIV risk behaviors, to help understand these contexts. The assumptions that are being made are that there are distinct gender differences in HIV risk behaviors and strong structural influences that increase participation in risk behaviors.

Connell's (1987) theory of gender and power and Ferraro and Shippee's (2009) cumulative inequality theory both identify factors which account for such life experiences and will guide the development of the proposed conceptual model. This proposed conceptual model incorporates both theories through a modified version of Andersen's Behavioral Model of Health Utilization (2007). This model is guided by behavioral ecological theory, which claims that hierarchical contingencies influence health decisions, depending on the interlocking patterns (nested systems) of individual, family and community, and environmental factors (Biglan \& Hayes, 1996;

Bronfenbrenner, 1979; Skinner, 1935). Finally, this chapter will operationalize the various variables in the proposed model that will be explored in the study. 


\section{Theory of Gender and Power}

The theory of gender and power has been used to explain gender roles and sexual scripts assumed by women and men (Card et al., 2007; Flowers, Sheeran, Beall, \& Smith, 1997), showcasing gender-based inequalities across labor, power, and affective attachments (i.e., social norms). Application of this theory has also been applied across individual, community, and structural levels and has been shown to address the amount of women's risk of HIV infection (Wingood et al., 2004) and sexually transmitted diseases (Sikkema et al., 2000) through their participation in HIV risk behaviors. This theory examines the context of HIV risk behavior and gendered dynamics in a way that helps identify and define social structures, which are typically challenging to define and operationalize.

The theory of gender and power has also been applied to create culturally sensitive HIV prevention interventions for women, which have been recognized and defined by the CDC as best-evidence HIV interventions (Crosby, Kegler, \& DiClemente, 2009; Lyles et al., 2007). Interventions for women such as SISTAS (Sistas' Informing Sistas' about Topics on AIDS), SIHLE (Sistas Informing, Healing, Living, and Empowering), and WILLOW (Women Involved in Life Learning from Other Women) have identified variables needed to assess the division of labor (economic exposures and socioeconomic risk factors), power (physical exposures and behavioral risk factors), and affective attachment (social exposures and personal risk factors) (DiClemente et al., 2009) that contribute to HIV risk behavior among women.

Robert Connell developed this theory in the late eighties to communicate that power differentials within relationships create and sustain a "global dominance of men 
over women"(DiClemente et al., 2009, p. 395). In other words, all is not fair in relationships between women and men and that men tend to have "the upper hand". To understand this 'uneven' distribution of power is essential in order to recognize environmental and individual factors that increase women's participation in HIV risk behaviors. The theory develops a position that women's risk is a function of interlocking patterns of individuals and systems, therefore, placing women at a disadvantage in different situations.

There are three domains related to women's risk, namely sexual division of labor, sexual division of power, and structure of cathexis, which will be referred to here on out as affective attachments (DiClemente et al., 2009). Sexual division of labor refers to women and men having certain occupations wherein women are constrained or limited due to the nature of their work. In other words, certain jobs associated with women have a negative connotation and less value, resulting in less pay or less opportunities for career advancement; conversely, men typically have higher incomes or easier access to resources such as education that create more opportunities for advancement (DiClemente et al., 2009). This speaks largely to the older population because there are such differences in access to resources that have affected them, such as education.

Women in the 1940s and 1950s pursued female-intensive jobs, jobs that did not require much advanced training or a college education. Post World War II, many of the Baby Boomers were born to these women, the same women who represented almost $73 \%$ of all teachers in the labor force at that time (Francis, n.d.). For the children born to these women, expectations were different and the nation saw a shift, as Baby Boomer women studied the sciences, elected to have careers versus jobs, and through the empowerment 
of the women's movement and reproductive rights, delayed marriage and beginning a family, placing women in positions to work in fields that were not traditionally occupied by women (Francis, n.d.). In regards to the division of labor and older women, women who are older inherently had less resources to place themselves in positions of having careers, career advancement, and higher incomes.

Older women are much different than their younger counterparts in terms of labor preparedness in which educational attainment can largely influence the quality and longevity of one's career and the types of economic exposures one experiences. While many women hold jobs comparable to men, instances such as unpaid caregiving and lower levels of education broaden the gap of economic inequity among women and can be observed by way of what Wingood et al., (2009) describe as "economic exposures...[and] socioeconomic risk factors" (p.396). An example of economic exposure, as presented by the same authors, includes women who have less education or live at the poverty level. Education has far reaching effects, and a decrease in education can create a context for increased risk exposures related to stable living conditions (having enough income and resources, able to maintain HIV-protective behaviors) (Logan et al., 2002) while growing workforce participation can decrease such risk exposures. This division, between women and men of all races, also occurs on an institutional level and can be seen through social institutions within the larger society. For example, sexual division of labor can be observed through the presence of women in the labor force.

Sexual division of power speaks to the gender negotiations that happen between women and men and how those transactions influence power in relationships. Within the 
context of relationships, power is used as a mechanism to exhibit authority and control. Women who are in power-imbalanced relationships experience adverse health outcomes compared to women who are not having this experience and are more likely to participate in HIV risk behaviors (DiClemente et al., 2009). For example, if a man brings to the relationship financial assets (i.e., money, status), then control can be exerted over the woman which creates an imbalance, and is further maintained through those mechanisms (Wingood \& DiClemente, 2000). This imbalance is observable through physical exposures (refusal of self or partner to use a condom) and behavioral risk factors (low self-efficacy to wield condom use or even discuss it with a partner) (DiClemente et al., 2009).

Relational contexts include incentives for engaging in relationships, interpersonal power, silencing, (Jacobs \& Kane, 2011; Longfield, Glick, Waithaka, \& Berman, 2004) intimate partner violence (IPV) (Rivara et al., 2007), gender differences regarding sexual acts (Birnbaum \& Laser-Brandt, 2002) and perceived risk (Cole, Logan, \& Shannon, 2008). Protective skills such as condom use, condom negotiation, communication, and strategies that address gender and power imbalances in relationships have been discussed and shown to influence African American women's sexual attitudes and participation in risk behaviors (Longfield et al., 2004; Oser et al., 2008). It is important to address how one ascertains what needs are being met by maintaining the relationship and what the exchange is in the relationship.

On an institutional level, socially constructed roles of women and men greatly influence the context of engaging in risk behaviors. The effect of media portrayal of women and how that influences the social context of sexuality is well documented and 
largely discussed. For example, while print media has received considerable backlash for provocative and risqué pictures, depicting women as sex objects, it continues to be a source of public displays of women. They include displays of women in unfavorable conditions, in bondage, fear, or in other forms of sexualized victims, which can perpetuate the cycles of violence that happen to women (Stankiewicz \& Rosselli, 2008). Societal definitions of gender roles are reinforced through media, and as the discussion has increased around the portrayal of young women in music videos since the $80 \mathrm{~s}$, it has been shown that such forms of media continue to show men in positions of power over women (Ward, Disch, Schensul, \& Levy, 2011). Because African American culture dominates the hip hop and rap genres of music, it is very challenging for groups such as African Americans to withstand the heavy subjugation of this type of exposure. This exposure can unfortunately limit their perceived control in relationships and limit their negotiation skills, further increasing their participation in risk behaviors (Wingood \& DiClemente, 2000).

The structure of affective attachments refers primarily to how society and culture have constructed what it means to be a woman or man within the context of relationships by way of social norms and gender stereotypes. There are stereotypes that women want to be with older men and that men prefer younger women. Additionally, studies have shown that safer sex practices such as condom use are influenced by the amount of attraction partners have for one another, with less use occurring among those who are more attracted to their partner (Crosby et al., 2009; Sheer \& Cline, 1994). There are social norms based on women and their desire to have children (no need to use protection, which after child bearing age can still be a expected practice; related to 
motherhood and having unprotected sex, this can reflect a status that is particularly strong in ethnic/minority cultures such as upholding traditional or religious practices) (Connell, 1987). Social exposures such as family influence (living in a single parent home, having siblings that abuse drugs; family networks where HIV risk exposure is prevalent) can increase participation in risk behaviors (Amaro, Zuckerman, \& Cabral, 1989; Connell, 1987; Newcomer \& Udry, 1987). Mistrust of the medical and public health systems (very high among African Americans, Hispanic, and Native Americans; persons in these groups may adopt alternative practices that can actually increase their risk of exposure) (Aral, Mosher, \& Cates, 1992; Davis, 1981; Snow, 1983; Thomas \& Quinn, 1991) can also increase participation in risk behaviors.

Social exposures such as holding a conservative belief about sex due to religion or cultural norms can create personal risk factors such as having limited knowledge about protecting oneself from HIV or feeling invincible to HIV infection. Premarital sex, having multiple partners, and masturbation were all once thought of as taboos, particularly for women. This created social biases about women, leading to the shaping of social norms and gender stereotypes about women's sexuality. These oppressive gender narratives are still alive and well among older adults from the Traditional Generation (born 1922- 1945) and among some of the older Baby Boomers (born 19461964) and are, thus, very relevant to the discussion of the role of gender in HIV risk behaviors among women over the age of 50 .

Many of the gender dynamics are changing for the current generation of Millenials (born 1980-2000) in that they have more education, more career opportunities, and have asserted more control in family planning. What was once thought of as 
'woman's work', such as unpaid caregiving, has long been sidelined as an option. The belief of sex for only procreation has long been cast away, and that challenges more traditional, older beliefs about sexual behavior. Younger persons (those under 50) are more likely to engage in using HIV-protective behaviors due to the different views about sex within their culture.

\section{Cumulative Inequality Theory}

A frequent occurrence in HIV-related research is to examine risk behaviors on a micro-level, looking at actions and relationships between individuals. A disadvantage of this perspective is that it limits the integration of population-level and social structural issues, especially when investigating risk behaviors among groups of persons who are adversely affected by those issues. These types of factors influence social, physical, and economic exposures, all of which influence the participation in HIV risk behaviors among older adults (Bowleg, Lucas, \& Tschann, 2004; Estes, 2001) .

Life course theory provides a framework for conceptualizing how people experience situations and events, and how those events socially construct the reality of those persons (Elder, 1995). This theory was used to guide the development of cumulative inequality theory, which begins with an examination of inequality across the life course in order to understand its impact on the developmental processes regarding sexual identity and sexual behavior. As a theoretical framework, cumulative inequality theory solely or in combination with other sociological theories is used to analyze and gain a better understanding of the process of aging within different contexts, with the ability to assess future needs of populations. 
Cumulative inequality theory is a contemporary extension of Dale Dannefer's (1998) cumulative advantage/disadvantage theory, a salient perspective that introduced a way to understand how social structures influence human behavior and interpersonal relationships. Cumulative inequality theory, here on out referred to as CIT, states that inequality accumulates over the life course. More precisely, "inequality is not primarily the result of individual choices and actions but is structurally generated" (Ferraro \& Shippee, 2009, p. 334). Themes of diversity and poverty among older adults reinforced a growing body of evidence that showed that with age there was indeed increased variability and inequality in their life experiences (Dannefer \& Sell, 1988; Maddox \& Douglass, 1974; Rowe \& Kahn, 1987). Estes (2001) also examines inequality and aging from a political economic perspective, and uses Walker's (1980) analysis of this issue to posit that "many complex social, political, and economic forces...may contribute to the production of dependency (rather than a reduction in dependency) in old age" (p.139). This dependency, or exposure, has also manifested as forms of institutional disadvantage with dire consequences for groups such as older persons of color and women (Estes, 2001, p. 139). The five domains of this theory are useful in order to understand and describe behavioral processes in aging populations, particularly women of color, and can be instrumental when trying to understand how systems of oppression have unfavorably affected certain populations, increasing their exposure to and participation in HIV risk behaviors.

\section{The Five Domains of Cumulative Inequality Theory}

The first of the five domains states that social systems generate inequality and that this experience manifests over the course of one's life. This can be used to 
understand how behavior in later life is shaped by events experienced in early-life, or childhood (Ferraro \& Shippee, 2009, p.335). Risk factors of HIV transmission for older African American women have progressively been accompanied by the examination of such individual and socio-cultural factors within a historical context.

The historical politics of African American women's sexuality, referred to as the politicization of sexuality (Mitchem, 2004) and the development of a sexual self, is based on an understanding of the messages and meanings an individual is given about sexual roles and behaviors, especially over time (Stephens \& Phillips, 2003;2005). This point was alluded to in the discussion of the theory of gender and power, where African American women have been over-sexualized in the media and in the cultural discourse among the dominant group, thus making them more vulnerable to childhood sexual abuse, early sexual experimentation, exploitation by older males and a greater risk of early childbearing and disease contraction (Ward et al., 2011). The negative consequence of early childbearing has been known to reduce educational attainment and income and has led to further sexual exploitation of young African American women who may be coerced into the sex trade as a means of income production further making them vulnerable to diseases and unwanted pregnancies. By the time these exploited women have reached their older years, they have had a lifetime of inability to fend off aggressive males or defend themselves against disease through the use of condoms, which involves cooperation from their oppressors.

The second domain is that "disadvantage increases exposure to risk, and advantage increases exposure to opportunity" (p.335), and can be used to look at an issue of poverty or low educational attainment among older populations, such as women, as 
factors that are associated with participating in HIV risk behaviors for sustainment. Poverty rates have fluctuated alongside AIDS cases over the past decade, implicating that the financial environment for women may present barriers to HIV protective behaviors. Not having the income to purchase condoms resulting in no condom use or decreased likelihood of using condoms, alongside being victims of intimate partner violence place these women at increased likelihood of HIV risk behaviors to present(Logan et al., 2002). Less education may limit women's perception of HIV risk behaviors, how to avoid situations that perpetuate that type of lifestyle, and how to have safer sex.

Underemployment and unemployment has risen in the last few years, and has caused an increased burden on groups of women who are economically dependent on their male partners. For instance, Bowleg et al. (2004) discuss their finding in a qualitative study regarding sexual scripts between African American women and men and the association with condom use in that relationship. During their discussion about power in relationships, they pointed out that these same issues of power are influenced by other social systems and how African American women may be more likely to be in relationships for economic security, using sex as a part of the conditions of maintaining that security. In addition to this, other factors that impose a disadvantage to women as a whole and increase their participation in HIV risk behaviors are types of hazardous lifestyle patterns such as sex-trade work, (Nyamathi \& Shuler, 1990), sexual abuse (Lewis, Melton, Succop, \& Rosenthal, 2000) or having multiple sex partners (Wagstaff et al., 1995). Conversely, it would appear that advantages, or exposures to opportunity, would include women having more income, more education, and higher levels of 
employability. As women's risks increase through disadvantages, this is likely even truer for older women of color.

The third domain is that life course trajectories are dependent upon how risks are accumulated over time, and how resources and human agency shape how one deals with those risks. The way in which one responds to stimuli greatly differs, some being able to better tolerate harmful treatment more than others (Thoits, 1996). This domain has the capacity to address how older women, especially women of color, have responded to risks or opportunities, and how that influences their behavior. Hess (1990) points out that women's life experiences vary from men's life experiences, as well as the life experience of people of color varied from white people because of lifelong stratification systems that maintain gender and racial inequality. How older women and women of color access care (are they able to access STD-related care and preventative screenings), are positioned among poverty (are they able to provide for their survival needs, as higher poverty rates indicate that these needs are greater), and experience inequality across the life course (the ones who have a high-risk partner, limited access to HIV education and/or drug treatment, have a history of alcohol and drug abuse, have a history of abuse) are factors that the literature specified shaping and influencing one's quality of life as well as one's life experiences.

The fourth domain states that people use subjective norms to gauge whether they are on or off track in relation to others and the life course. Those who feel they are ahead may have more self-efficacy and conversely, those who feel they lag behind would have less self-efficacy when it comes to participating in HIV risk behaviors. For instance, the development of a sexual self is based on an understanding of the messages and meanings 
an individual is given about sexual roles and behavior over time (Stephens \& Phillips, 2003; 2005). Self-efficacy plays a primary role in communicating about one's own sexual health, being able to ask partners about their sexual practices, negotiating condom use and seeking out medical services.

Among older women of color, having information on whether they felt they were on track or not in comparison to their peers and life experiences, (i.e., reaching certain milestones, experiencing changes in health status related to aging) could be used as an indicator of certain behaviors. These milestones can be reflective of the attitudes of older women regarding sexually transmitted HIV, as their subjective norms, norms which regulate certain behaviors such as social memberships (religious communities, social referents), and perceived behavioral control take into account their past experiences and anticipated obstacles to perform safer sex behavior. Wyatt (2009) suggests that African Americans have an adaptive duality from their slavery lineage, and that as a cultural factor, it should be included when the goal is behavior change. Identification of such variables are important because they can be used to determine if "a given background factor is related to the behavior of interest [and trace] differences in behavior-relevant beliefs, attitudes, subjective norms, [and] perceptions of behavioral control and intentions" (Ajzen \& Albarracin, 2007, p. 7). Being mindful of the heterogeneity of African American experiences is important in order to assess salient beliefs that influence those subjective norms used to gauge whether or not they are on track with their peers.

Finally, the last domain in this theory states if studying limited age ranges (e.g., focusing on people over 50), to be considered is that population truncation has occurred; 
in other words, one may miss some accumulation of risk factors that has occurred if they begin their investigation later in life because factors that accurately reflect accumulated inequality may be left out. For example, the question was posed if gerontologists should only study older people, because there are limitations set by not having data on the accumulation of risk factors up until the age of interest, which would be considerably older. Limiting a study by age can limit the consideration of the experienced disadvantage at different points over the life course. While focusing on older adults can be viewed as objectionable according to this domain, the benefit in looking at older cohorts is that those within that cohort share a common experience at the same time, allowing for insight about the relationship of age cohorts of older adults and social structures over time (Levy et al., 2003).

These theories have been used to examine gender and power imbalances as well as sexual inequalities that greatly influence participation in HIV risk behaviors. They have also taken up the task of accounting for risk exposures over the life course, which creates new options for exploring HIV risk taking among older populations in the context of sexual risk. They are perspectives that have been applied and empirically tested when assessing for predictors of HIV risk behavior and have determined variables to consider when studying this population. These combined perspectives have the ability to account for their socially constructed-experiences and lived experiences with regard to risk behaviors.

An assumption that can be made from analyzing these theories is that in comparison to older adults who experience exposures to advantages, older adults, particularly those of color, who have exposure to disadvantage, accumulate more inequality over their life 
span than other groups, and that it is structurally generated and not simply a result of choices and actions of that individual. This accumulation over time and sustainment by power imbalances is greatly associated with an increase to HIV risk exposure through participation in risk behaviors and explains why over time the nation has seen an increase in HIV infections in the older populations, in older ethnic minorities, and older women of color.

\section{Andersen's Behavioral Model of Health Utilization}

Originating in the 1960s and evolving over time, Andersen's Behavioral Model of Health Utilization depicts environment and population characteristics as having an influence on health behaviors and health outcomes (Andersen, 1995; Andersen \& Davidson, 2007). This allows for a population-level assessment of individual behaviors, while accounting for the multiple systems that are also related to the individual, such as influences of culture, family, community. Community level interventions began to appear more frequently in the literature, challenging the limitation of focusing on individual-level factors as predictors of HIV risk behavior to assessing for larger-scale, more contextual factors that affect exposure to HIV risk situations. Examples of contextual variables that were examined in both national and international studies were the pathways between violence, particularly against women, substance abuse (Wechsberg, Luseno, \& Lam, 2005), social inequality, and drug use (Sanders-Phillips, Liezille, \& Priscilla, 2009) on individual HIV risk behaviors.

Continuing on a systems-oriented trajectory, the application of ecological frameworks offers a comprehensive view of risk factors that drive the HIV/AIDS epidemic, and more importantly, how these risk factors impact groups that are 
disproportionately affected, for instance African Americans and women (Aronowitz, Todd, Agbeshie, \& Rennells, 2007; El-Bassel, Caldeira, Ruglass, \& Gilbert, 2009). Taking this type of approach allows for consideration of how community and social institutions have influenced their lives and how social systems can work together to control or limit HIV exposure. This is illustrated further in Figure 8 below.

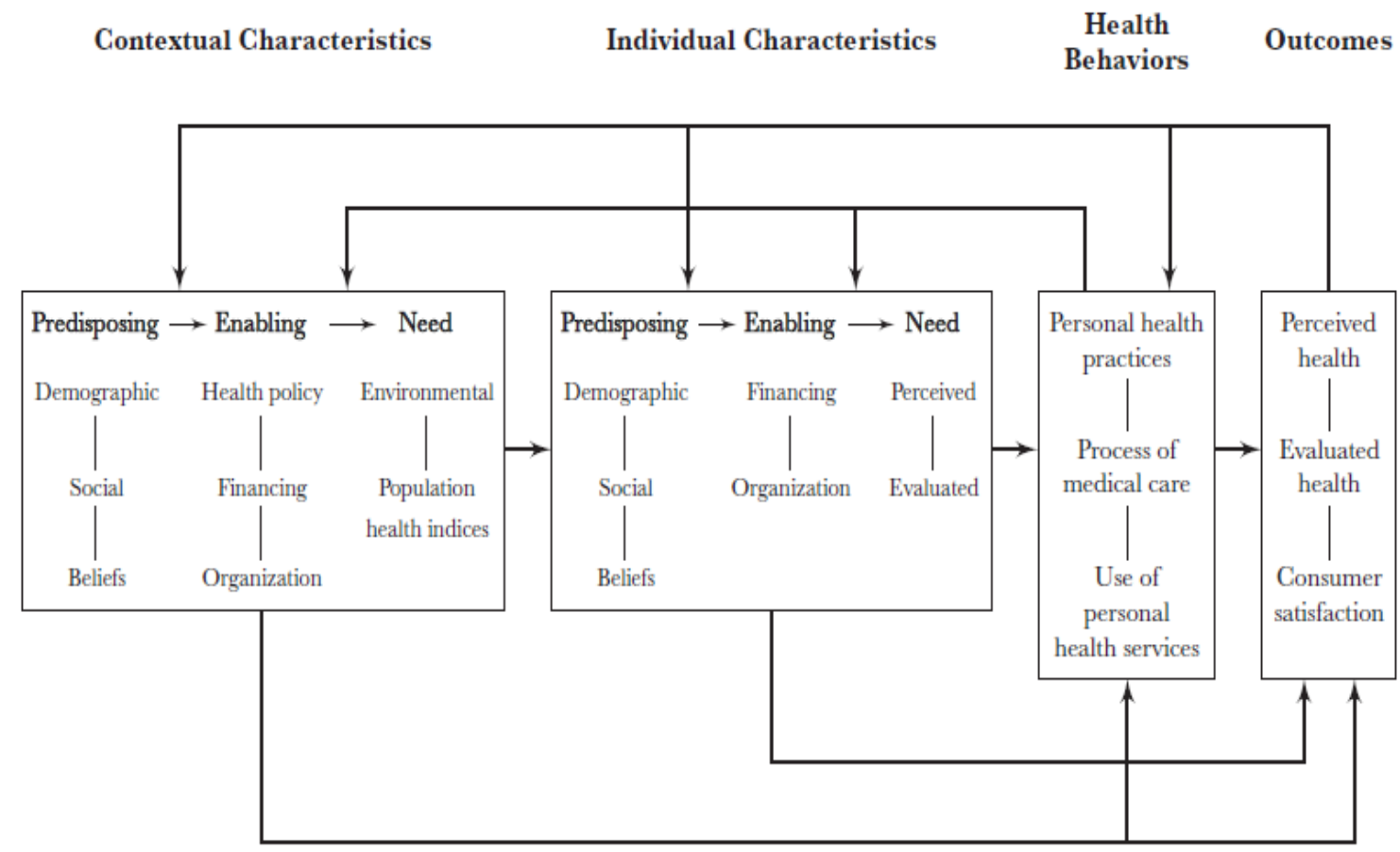

Figure 8. Behavioral Model of Health Utilization (Andersen \& Davidson, 2007).

In addition to traditional measures used to consider health behavior and outcomes (i.e., race, education, having health insurance), it has been identified that certain individuals or groups experience more socially structured disadvantages than other groups, therefore making them more vulnerable to poorer health status and outcomes when compared to those who do not share these experiences (Gelberg, Andersen, \& 
Leake, 2000). This approach takes into account the unique life experiences of groups who have been identified as vulnerable to HIV/AIDS and has wide transferability to other vulnerable populations. Identifying the specific factors related to this vulnerability would explain the negative impact on health behaviors and outcomes. In order to look at a group that is increasingly experiencing a rapid growth of sexually transmitted HIV such as African Americans, women, and now, older adults, Andersen's (2007) model is warranted, as these groups typically encounter a myriad of social issues that make them unique. For those more vulnerable groups like older African American women, it will show how social structures can truncate their ability to access certain resources, cope with presenting problems, or have the resources to deal with those problems, reflecting their social or economic position in their communities (Andersen \& Davidson, 2007).

Andersen's (2007) model captures how HIV risk behavior is influenced by environmental and individual factors. When examining the scope of risk associated with sexually transmitted HIV/AIDS in the aging population, contextual variables that take into consideration individual and community level needs have been identified in various research studies (e.g., Ark, Hull, \& Husaini, 2006; Cronholm \& Bowman, 2009; Logan et al., 2002). Placing individuals within a historical context, examining how inequality can accumulate over the life course through the social construction of social institutions, and how gender-based inequalities increase HIV exposure or risk taking behaviors can be illustrated through the use of cumulative inequality theory, as it helps to explain the interaction of the contextual variables on individuals. In order to investigate these phenomena, the next section proposes a conceptual model that hypothesizes what variables will predict HIV risk behavior among older adults. 


\section{Proposed Conceptual Model}

The proposed conceptual model is based on the assumption that older adults' HIV risk behavior is driven by certain characteristics. Therefore, when assessing for what predicts risk behavior, one must look at not only the individual -level factors but also the environmental-level factors. Environmental and individual variables were identified based on their prevalence in theoretical and empirical literature and serve as a basis for the variables included in the proposed conceptual model.

\section{State Characteristics as Environmental-level Predictors}

In order to place the condition of HIV risk behavior within a larger context, which is an aim of this study, environmental characteristics are explored because they describe the composition of the environment and allow for an understanding of how multiple influences beyond the individuals control or determine such behaviors. In order to examine this composition, state level indicators are used as environmental measures.

There are three categories of environmental characteristics that will be used to examine HIV risk behavior. These categories are environmental predisposing characteristics, which is the composition of the environment and how supportive or unfavorable it may be to the persons in that environment (demographic and social structure factors), environmental enabling resources through public policies, financial characteristics, and per capita expenditures for health services, which can increase or decrease what resources are available to individuals, and environmental need characteristics, health-related measures, both perceived and evaluated, of how healthy the environment might be that influence individuals. Environments that are resource rich 
provide more protection against risk behaviors and exposure to advantage for those living in that environment when compared to those not living in such an environment (Andersen \& Davidson, 2007).

\section{Individual Characteristics as Individual-level Predictors}

The previous three categories are divided the same way among individual characteristics used to examine HIV risk behavior. These categories are individual predisposing characteristics, which include demographic and social structure characteristics, enabling resources, and need characteristics. Predisposing characteristics are factors that represent one's status in society and suggest that people will participate, or not, in a health behavior (Andersen, 1995; Andersen \& Davidson, 2007). Additionally, social structural characteristics represent people's predisposition to a health behavior in the form of roles and social norms, which serve as representations of community and cultural values. Enabling resources are available personal and social resources that facilitate or deter one from participating in HIV risk behaviors. In other words, can individuals seek care if they need it based on the resources that they have? In previous studies, enabling resources have strong associations with health behavior and outcomes (Andersen, 1995; Andersen \& Bozzette, 2000). Personal enabling resources are variables such as income and having health insurance. Earlier examples have provided illustrations how not having financial resources can increase one's risk exposure because they may not have the income to pay for health services, a regular source of care, or the ability to purchase condoms. Examples of social enabling resources are the presence or absence of cost barriers to care, or being seen by a medical provider in the 
past year, both which largely affect one being able to self-identify risk behaviors, as well being identified by a health professional as participating in risk behaviors.

Individual need factors account for behaviors that lead to a decision about whether or not to seek care through perceived need (i.e., self-rated health) or the kind of treatment that a healthcare provider presents to a patient through evaluated need (i.e., being diagnosed as having a health condition, such as an alcohol problem or an STD). In terms of HIV risk behavior, how a person perceives how well they are, or are not, can influence their participation in risk behaviors. Quality of life, emotional well-being, and satisfaction with one's life directly influence perceived need among older adults. Coping mechanisms, such as drinking alcohol, affect one's perception about their well-being and functional state, and therefore have been included to account for its effect on the careseeking process, falling under evaluated need.

\section{HIV Risk Behavior as the Outcome Variable}

This study will examine HIV risk behavior as defined by the Behavioral Risk Factor Surveillance System (BRFSS); has one participated in any of the following behaviors in the past year: used intravenous drugs, been treated for an STD, given or received money for sex, or had anal sex without a condom. While unprotected sex is not

directly measured, there is enough epidemiological support to make a strong correlation between STDs and unprotected sex (Calvet, 2000; Kelly, 2011; Sormanti, Wu, \& ElBassel, 2004). Important to note is that STDs illustrate that a person had sex with at least one partner who was infected with an STD. Almost three dozen diseases are transmitted sexually, and HIV/AIDS is one of the most common, alongside chlamydia, gonorrhea, syphilis, and genital herpes (CDC, 2012c). Therefore, this allows for STDs 
to serve as a proxy measure for unprotected sex because it makes those infected more susceptible to HIV infection. Based on this line of research, a conceptual model is proposed that will provide a context for understanding factors that affect older adults, as shown in Figure 9 below: 


\begin{tabular}{|c|c|c|}
\hline $\begin{array}{l}\text { State Predictors } \\
\text { State Characteristics }\end{array}$ & $\begin{array}{l}\text { Individual Predictors } \\
\text { Individual } \\
\text { characteristics }\end{array}$ & $\begin{array}{l}\text { Individual Health Behaviors } \\
\text { HIV Risk Behaviors }\end{array}$ \\
\hline Predisposing Characteristics & $\begin{array}{l}\text { Predisposing } \\
\text { Characteristics }\end{array}$ & \multirow{9}{*}{$\begin{array}{l}\text { In past year: } \\
\text { 1) Intravenous drug use } \\
\text { 2) STD } \\
\text { 3) Money or drugs in exchange } \\
\text { for sex } \\
\text { 4) Anal sex without a condom }\end{array}$} \\
\hline Demographic & Demographic & \\
\hline$\%$ adults $65+$ & $\begin{array}{l}\text { Age } \\
\text { Gender }\end{array}$ & \\
\hline Social Structure & Social structure & \\
\hline $\begin{array}{l}\% \text { females } \\
\% \text { ethnic minorities } \\
\% \text { in labor force } \\
\% \text { female minorities in labor force } \\
\% \text { married } \\
\% \text { female minorities married } \\
\% \text { with college degree } \\
\% \text { female minorities with college degree } \\
\% \text { IPV/Sexual assault } \\
\text { Crime rate } \\
\text { Peace Index ranking } \\
\% \text { very religious }\end{array}$ & $\begin{array}{l}\text { Marital Status } \\
\text { Ethnicity } \\
\text { Education } \\
\text { Employment } \\
\text { Urban/Rural }\end{array}$ & \\
\hline Enabling Resources & Enabling Resources & \\
\hline $\begin{array}{l}\text { \% people annually in poverty } \\
\% \text { female minorities in poverty } \\
\text { Gini index by state } \\
\% \text { people annually without health } \\
\text { insurance } \\
\% \text { female minorities without health } \\
\text { insurance } \\
\text { Spending per capita on entitlement } \\
\text { programs (Medicare/Medicaid) } \\
\text { Spending per capita on Medicaid enrollees } \\
\text { with HIV } \\
\text { Federal HIV/AIDS grant funding for } \\
\text { PLWA per person } \\
\text { Total ADAP budget } \\
\text { Physicians in patient care per } 10,000 \\
\text { Metropolitan distribution }\end{array}$ & $\begin{array}{l}\text { Health insurance } \\
\text { Cost as a barrier to care } \\
\text { Personal doctor } \\
\text { Length of time since last } \\
\text { checkups } \\
\text { Income }\end{array}$ & \\
\hline Need & Need & \\
\hline $\begin{array}{l}\text { Rate of STD's } \\
\text { Rate of minorities with STD's } \\
\text { Rate of females with STD' } \\
\text { Rate of people with HIV } \\
\text { Rate of minorities with HIV } \\
\% \text { of AIDS diagnoses } \\
\% \text { of AIDS transmission routes }\end{array}$ & $\begin{array}{l}\text { General Health } \\
\text { Quality of Life } \\
\text { Emotional support } \\
\text { Life Satisfaction } \\
\text { Alcohol use }\end{array}$ & \\
\hline
\end{tabular}

Figure 9. Conceptual framework for determining HIV risk behavior.

The following sections will explain variables chosen for this study based upon the literature review and previous clinical experience of the author as a geriatric care manager. These variables were determined to give the best representation of environmental and individual characteristics that are associated with HIV risk behaviors. 


\section{Environmental Predisposing Demographic Characteristics}

Percentage of older adults by state. Identifying which states have a higher proportion of older adults (persons 65 and older) places them as individuals into a context for understanding levels of knowledge about HIV risk. Areas with a higher concentration of older adults experience lower socioeconomic status and lower levels of education (Issa \& Zedlewski, 2011), higher degrees of psychosocial issues, such as depression (Murrell, Himmelfarb, \& Wright, 1983), and less knowledge about HIV prevention information (Jacobs \& Kane, 2009). More people will have the potential of being widowed or divorced and available for sexual encounters with peers, some of which may be unprotected. By living in an area with a higher proportion of older adults, there is higher likelihood that there will be less knowledge about prevention methods of HIV as it relates to their age group, therefore more acceptance and participation in risk behaviors.

\section{Environmental Predisposing Social Structure Characteristics}

Percentage of females by state. Gender influences the distribution of resources in general and power and access through social institutions and social mechanisms (Greig \& Koopman, 2003; Jacobs, 2011). States that have a higher percentage of women will have more of an imbalance in the male-to-female ratio, which influences partner status for women, presenting a gendered issue that can increase women's exposure to HIV risk behaviors. Women are more likely to accept "sharing" a partner and engage in risk behaviors even if that is not the preferred interaction as a means to attract males and sustain relationships for maintaining an economic or social status (Crosby et al., 2009). While women have regained a significant number of jobs since the recession, they makeup over three-quarters of the workers in the lowest wage-earning occupations, 
another factor related to sustaining relationships for maintaining their economic and social status ("National Women's Law Center", 2013). Women also carry the burden of caregiving tasks, estimated at $66 \%$ of caregivers being female and $34 \%$ caring for two or more people ("Family Caregiver Alliance", 2012). Based on these estimates, it is believed that states with more women may experience higher percentages of underemployment or unemployment, as women tend to be primary caregivers to children and other family members or hold lower paying jobs.

Percentage of racial/ethnic minorities by state. Membership in a racial/ethnic minority group influences access to health services, income, educational attainment, and differences in community support systems (Heckman, 2000). States that have a higher percentage of racial/ethnic groups are more likely to experience income gaps, higher levels of poverty, poor health conditions, and low levels of educational attainment, all of which are socioeconomic risk factors that can influence participation in HIV risk behaviors (CDC, 2010b;2012d;2013d). There are competing needs that have to be dealt with for immediate survival and these risk factors may present fewer economic resources for HIV preventive behaviors among racial/ethnic minorities (Wingood \& DiClemente, 2000). The majority of older ethnic minorities live in the southern region of the country, where sexually transmitted HIV has the highest prevalence. By looking at the number of ethnic minorities by state, it is believed that states with more ethnic minorities may experience more risk factors that create an environment where there is an increase in acceptance and participation in risk behaviors than other geographic areas (Logan et al., 2002; Greig \& Koopman, 2003). 
Percentage of persons in the labor force by state. Identifying which states have a higher proportion of persons who are employed places individuals into a context for understanding levels of exposure to HIV risk. Participation in HIV risk behaviors is associated with economic dependence, especially related to gender effects. As mentioned previously, those states where there are lower rates of employment can be seen as environments that have a decreased ability to reduce the effects of economic dependence. The theories discussed earlier very clearly identified how unequal access to financial resources and power imbalances in relationships where women are sustained by a male partner create power issues, thus increasing their exposure to HIV risk situations. Higher rates of employment can also illustrate a strain on individuals as they may be in areas that have workers in high demand and low control (Hall, 1991), which in turn, can increase rates of psychological distress (Baker, 1985). This is an important perspective as the study is looking at groups of older adults, and topics related to economic dependency are key in understanding their over well-being and quality of life. By looking at the distribution of those of who participate in the labor force, it is believed that states with lower labor participation create an environment that increase economic exposures that can increase personal risk factors of HIV risk behaviors.

Percentage of female minority groups in the labor force by state. Identifying which states have a higher proportion of women of color who are employed places those individuals into a context for understanding their levels of exposure to HIV risk. It is beneficial to examine this context based on the disproportionate rate that women of color experience HIV risk exposures. Women of color are increasingly susceptible to HIV (CDC, 2013a), therefore states that have more women of color in the labor force will 
likely have more ability to reduce the effects of economic dependence, and those with less women of color in the labor force will increase that economic exposure to HIV risk.

Percentage of married persons by state. While marital status has been viewed as a protective factor, cited by Jessor, Turbin, \& Costa (1996) as enhancing the "likelihood of positive outcomes and lessen[ing] the likelihood of negative consequences from exposure to risk" (World Health Organization [WHO], 2004), it can also falsely link the social institution of marriage as a shield from exposure to risk, especially HIV infection (WHO, 2004). The risk that extramarital affairs can create is paramount and has been investigated globally. There are fewer stigmas on men who have extramarital affairs through their social networks, especially if they continue to provide financial support for their family. States that have a higher percentage of persons married should also be examined alongside social and economic contexts; states that have more poverty, more women who are uninsured, and lower educational attainment of women create environments that can facilitate gender inequality in relationships, thus, women may be sustaining themselves in these relationships for economic purposes, which influences their participation in HIV risk behaviors.

\section{Percentage of female ethnic minority groups who are married by state. As}

previously discussed, economic exposures such as living in poverty, being underemployed or unemployed, having less education, or marrying at a younger age can restrict or prevent women of color from accessing services or prevention education related to reducing HIV risk. It can also keep this group of women involved in relationships that are unhealthy and abusive for financial sustainment. Additionally, the ideal that their spouse is remaining faithful to them as they are to them as sole protection 
from the virus falls short of preventing the spread of HIV from men to women in committed relationships ("Guttmacher Institute", n.d.). Unprotected heterosexual sex has also been found to be the only HIV risk factor for HIV-infected women who were married (Newmann et al., 2000). By examining the percentage of ethnic women who are married by state, in conjunction with the social and economic contexts of that state, it will help us better understand the role of that state as a context of ethnic women's risk and their exposure in HIV risk behaviors.

Percentage of persons who have a college degree by state. States that have a larger percentage of people with low levels of educational attainment creates an environment wherein it can be more difficult to function. Such an environment fosters higher rates of substance abuse, victimization, lower incomes, and limited access to health service (Logan et al., 2002). States that have more education show more earning capacity, empowerment, and property ownership, all which can empower groups, especially women, and reduce vulnerability because it gives them more bargaining power at different levels and reduces the likelihood that they will engage in HIV risk behaviors as a means to maintain themselves (Dworkin, 2009). States that have more education provide an environment that increases one's ability to negotiate power and economic independence with social and interpersonal relationships (Whyte, 2006; Paranjape et al., 2006; Kamble et al., 2008) and influences the discussion-making processes regarding risk behavior and knowledge of how to remain safe.

\section{Percentage of female minority groups who have a college degree by state.}

States that have a higher percentage of women of color who have a college degree place those individuals into a context for understanding levels of exposure to HIV risk. While 
a significant association between educational attainment and vulnerability to HIV and STDs has been found among women of color, HIV risk behaviors can be reduced through more educational attainment for this group of women, as higher levels of education have been shown to increase their earning potential, employability, and decision making skills regarding gender roles (Jukes, Simmons, \& Bundy, 2008). It has also been found that when compared to women of color who did not have a college degree, those that had a college degree demonstrated higher self-efficacy regarding asking a partner about STD testing and less issues related to condom use negotiations, reflective of power issues that have been outlined in the theory of gender and power (Painter, Wingood, DiClemente, Depadilla, \& Simpson-Robinson, 2012f). They also had more knowledge about STDs and less multiple sex partners in the past year. It is beneficial to examine this context based on the disproportionate rate that women of color are experiencing HIV risk exposures. States that have a lower percentage of women of color with a college degree will likely have more women of color who are less knowledgeable about HIV prevention programs and behavior. This condition perpetuates the economic and social dependency cycle resulting in more women of color that do not have the means to participate in riskreduction behaviors. By examining the percentage of ethnic women who have college degrees by state, it will help us better understand the role of that state as a context of ethnic women's risk and their exposure in HIV risk behaviors.

\section{Percentage of lifetime prevalence of victimization (including rape, physical} violence, and stalking). States that have a higher percentage of lifetime victimization places those individuals into a context for understanding levels of exposure to HIV risk. The more experiences of victimization, the increased likelihood there is of sexual and 
physical abuse. This abuse is a gendered issue as four out of five victims are women (U.S. Department of Justice [DOJ], 2012a). Abuse can result in fewer negotiations about protective behaviors, such as using condoms and being forced to participate in high risk behaviors (e.g., prostitution, drug use). Higher percentages indicate that there are more community conditions of low power for women, greater divisions of power, and increased exposure to HIV risk behaviors, especially unprotected sex. Reports show higher rates of intimate partner violence (IPV) among women who are single with children when compared to married women or single women with no children. Overall, IPV rates are higher for women (at 85\%); also higher rates for those who are African American, have lower incomes, live in rental properties, and live in an urban area. Stigma related to being a victim can influence access and use of health services because women who experience sexual violence may not have received sufficient post-trauma care, which can result in coping mechanisms that can lead to repeat trauma (Gómez, 2011). By examining lifetime prevalence of victimization by state, it will help us better understand the role of that state as a context of how it contributes to an increase to social, economic, and physical exposures to HIV risk behaviors, particularly for women.

Rate of crime by state. States that have a higher crime rates place those individuals into a context for understanding levels of exposure to HIV risk. Crime rates include offenses reported to law enforcement. These offenses are murders, rape, robbery, and aggravated assault (U.S. Department of Commerce, n.d.). Several conditions apply to looking at the rate of crimes based on state reports. Rates should be examined alongside other demographic and geographic measures (U.S. Department of Justice, 2012) such as the percentage of people in the labor force, percentage of people in 
poverty, and metropolitan distribution of each state and are looked at in this study. After this is done, looking at the rate of crime by state within these contexts allows for understanding levels of exposure to HIV risk. Areas that are economically disadvantaged are associated with higher crime rates. Earlier mentioned was the connection between economic disadvantage and HIV risk, as persons are more likely to participate in behaviors for economic gain. Living in an environment that is economically or socially disadvantaged can lead to risky coping mechanisms and behaviors (Egerter, Barclay, Grossman-Kahn, \& Braveman, 2011), including participation in HIV risk behaviors. Regionally, the South has the highest rates of violent and property crime, compared to Northeast, Midwest, and West (U.S. Department of Justice, n.d.); HIV infection rates are also highest in the south. By examining crime rates by state, in conjunction with the social and economic contexts of that state, it is believed that states with higher crime rates are strong indicators of communities that are at an increased risk for HIV risk behaviors.

Peace Index ranking by state. According to the Institute for Economics and Peace (IEP), the United States Peace Index is used as an indicator of peace, and the noted advantages are found in states that have a higher ranking of peace. IEP (2011) states that peace is the "absence of violence" (p.3). In the discussion of crime rates, it was recommended to look at crime rates in conjunction with other relevant factors that have a significant impact on crime yet are not readily measured in all jurisdictions. The peace index offers an appropriate and alternative geographic measure of level of danger that exists in environments.

The peace index is quantified using data collected from the FBI Uniform Crime Reports, the U.S. Bureau of Justice Statistics from 1991-2009, and the CDC's National 
Center for Injury Prevention and Control, Fatal Injury Reports from 1991-2007. The indicators were number of homicides per 100,000 people, number of violent crimes (excluding homicides) per 100,000 people, number of jailed population per 100,000, number of police officers per 100,000 people, and availability of small arms per 100,000 people. Each indictor was scored from 1 to 5 , with 1 being the most peaceful and 5 the least peaceful. States that have lower rankings on the peace index should have lower crime rates as well, signaling environments that have a low prevalence of violence. It is believed that states with higher rankings of the peace index will likely have a higher prevalence of violence, which presents physical, economic, and social exposure to HIV risk.

Percentage of very religious by state. In terms of religiosity, states that indicate that they have a higher percentage of being very religious, as opposed to moderately religious or non-religious, may create a context for understanding levels of exposure to HIV risk. Religion has been seen as a product of coping, influencing how people appraise and participate in life activities (Pargament et al., 2004). It has also been a long recognized influencing factor of behaviors including sex and drug use (Hasnain, Sinacore, Mensah, \& Levy, 2005). While it has been viewed as a protective factor is several studies (i.e., Siegel \& Schrimshaw, 2002; Tix \& Frazier, 1998), religion has been conversely linked to generating thoughts on being invincible to becoming infected with HIV (e.g., Ark et al., 2006). In a separate study of religiosity and HIV risk behaviors among active injection drug users, belief in a higher power lead to a sense of protection that negated the need to be safe (Hasnain et al., 2005). Hasnain et al. (2005) also saw that there was an increased willingness to ignore risk behaviors (i.e., having unprotected sex) 
due to less fear of consequences because of the protective nature of religion as perceived by the participant.

It has also been established that religiosity plays a more significant role in lives of older adults and their well-being than the general population and that the majority of older adults' social networks can be found within their religious networks (Pickard, 2006). As older adults age, their perception of vulnerability to HIV and STDS may decline with age and reduced sexual activity (Ward, Disch, Levy, \& Schensul, 2004). Among groups of older adults, particularly those who are of the Silent Generation, there are heavy stigmas and norms about sexual activity, and that having sex outside of the context of marriage is unacceptable. For those who were married and are without a spouse due to divorce, death, or for those who were never married, the socialization of how to have sex has been largely driven by religious practices and beliefs. As there are mixed results and even some that contradictory in studies about using a sociodemographic variable such as religion to predict HIV risk (Ward et al., 2004), it has been deemed important to investigate because of its role in the lives of older adults. The direction of the relationship between religion and engaging in HIV risk behaviors is unclear due to competing evidence, and will be further investigated with this study.

\section{Environmental Enabling Resources}

Percentage of poverty by state. States that have a higher percentage of poverty place those individuals into a context for understanding levels of exposure to HIV risk. By living in a state that has higher levels of poverty, one is more likely to engage in HIV risk behaviors than those who do not reside in poorer states based on other social and economic conditions that drive the nature of maintaining relationships. Social conditions 
such as living in high poverty areas can expose populations to risk factors, such as not having adequate health insurance, which can lead to engaging in health behaviors that are unfavorable due to lack of screening or other preventative efforts, and limited access to care and medications that can lower levels of HIV and help prevent transmission (Crosby et al., 2009CDC, ; 2013e). Members of ethnic groups experience more adverse health outcomes due to the cumulative inequality experienced over their lifetime, and in combination with living in an environment that is impoverished, it can produce patterns of risk behaviors (Ferraro \& Shippee, 2009; Susser, 1996). This also interacts with low education levels of peers, which contributes to lack of knowledge about how to prevent STD transmission. The CDC also reports that poverty is the "single most important demographic factor associated with HIV infection among inner-city heterosexuals"(2013f). By looking at the distribution of those in poverty, it is believed that states with poverty create an environment that increase social and economic exposures that can increase personal risk factors of HIV risk behaviors.

Percentage of poverty among female minority groups by state. By examining states that have a higher percentage of women of color in poverty places those individuals into a context for understanding levels of exposure to HIV risk based on their environment. It is beneficial to examine this context based on the disproportionate rate that women of color experience HIV risk exposures. Women of color are increasingly susceptible to HIV, and living in poverty can exacerbate that condition. Women of color who live in poverty will be less likely to withstand the social, physical, and economic exposures to HIV risk behaviors as previously mentioned. An analysis conducted by the National Women's Law Center, who look at the effect of laws and policies for women 
and children, noted that both the poverty rate and extreme poverty rate (an income below half of the federal poverty line) for women increased from 2009 to 2010, being the highest in 17 years (“National Women's Law Center”, 2011). The rate of poverty was higher for African American and Hispanic women than for women in general. States that have more women of color that have economic insecurity, or live in poverty, will have more economic and physical exposures that will increase HIV risk behaviors.

Gini index by state. In the same line of thinking with crime rate and the peace index, the Gini index is an economic tool and summary measure that can be used to examine poverty on a macro level as a measure of inequality of incomes (DOC, 2012). To further explore the distribution of income, cumulative percentages of incomes are plotted against the number of individual incomes from poorest to richest on the Lorenz curve, and between that curve and a hypothetical line of absolute equality, lies the Gini Index. It ranges from 0 to $1 ; 0$ being perfect equality (all incomes being the same) to 1 (one individual has all the wealth) (Central Intelligence Agency, n.d.). In the South, there are more cases of HIV compared to the other regions (CDC, 2012d). The South also has a large number of counties that have a disproportionately high income inequality, with lower levels of income inequality found in Midwest counties (CDC, 2012). This type of difference is illustrative of an economic stress that can be placed on individuals who live in areas with high income inequality, that it can create environments that have more economic and physical exposures that will increase HIV risk behaviors.

Percentage of persons without medical insurance by state. Examining states and the percent of those individuals who do not have medical insurance will indicate the level of burden on that state's health system to provide screenings and treatment to those 
individuals. In terms of preventative screenings and treatment, states with more persons without health insurance will likely result in less prevention efforts able to reduce HIV risk behaviors, and it is likely that there will be more undiagnosed and untreated STDs including HIV, especially in communities where people select partners who are from the same community and ethnicity (CDC, 2013e), which can increase the risk of acquiring and transmitting HIV.

Percentage of female minority groups without medical insurance by state. There is a disproportion in accessing and using health services, especially among women of color (Estes, 2001; Marmot, 2007). For certain groups, particularly among older ethnic minority populations, this widens the gap to meeting health-related needs (Klitsch, 1990). For reasons mentioned above, women of color may delay or not seek out preventative treatment versus women who have private insurance. Therefore, states that have more women of color uninsured create an environment that is more susceptible to HIV risk behaviors.

Spending per capita on Medicaid. As the safety net for those who need assistance with healthcare, including who are disabled or are low-income, Medicaid is the largest public health insurance program in the nation (HKFF, 2013c). Examining the cost per person by state serves as an indicator of resource availability. This presence of medical support presents an environment that can decrease exposures to HIV risk behaviors.

Spending per capita on Medicare. As a federal health insurance program for older adults (those over 65), persons under 65 with permanent disabilities, and kidney failure, Medicare is an important source of coverage (HKFF, 2009). Examining the cost 
per person by state serves as an indicator of resource availability for adults age 65 and older. This presence of medical support presents an environment that can decrease exposures to HIV risk behaviors, as it helps with the cost of health care such as doctor services, other medical services, and prescription drug coverage.

Medicaid spending per capita on enrollees with HIV by state. For persons living with HIV, Medicaid provides a range of services including medication, a critical part of their care, as it is able to help maintain low levels of the virus which will reduce transmission risks (HKFF, 2013c). This can create a lower risk environment for both persons with HIV and those without HIV, and a supportive environment through treatment and medication adherence for those living with HIV/AIDS through increased healthcare access. The directions of HIV spending per capita and HIV risk are unclear, yet it is believed that by looking at the distribution of spending, states that have greater spending for enrollees who have HIV present environments with greater resources that will decrease risk exposure.

Federal HIV/AIDS grant funding for PLWA per person. Environments that have more federal financial support for programs and services for persons with AIDS (care, housing and cash assistance, prevention, research, and global/international support) are areas that will decrease the social and economic burdens that can present barriers to HIV care. The divisions of these programs are among the CDC, Housing Opportunities for Persons with AIDS (HOPWA), Substance Abuse and Mental Health Services Administration (SAMHSA), Office of Minority Health (OMH), and the Ryan White Program. While these funding streams have been established, historically federal and state level programs for HIV/AIDS has been underfunded (HRSA, 2010). Recent budget 
cuts and reallocations have stressed these funding streams. States that have lower funding, in conjunction with their HIV/AIDS burden, will likely have fewer resources for care and are less able to present environments that have less HIV risk because they will not be able to offer the necessary medical and social assistance to those living with HIV/AIDS.

Spending on AIDS Drug Assistance Program (ADAP) by state. To reduce transmission rates and maintain the health status of persons living with HIV/AIDS (PLWHA), medication intervention is essential. The federal funds provided through ADAP are allotted based on the proportion of PLWHA by region. Up until 2006, only persons living with AIDS received ADAP funds, leaving out those who were living with HIV. Additionally, cities that had populations of over 500,000 (metropolitan areas) were declared as Emergency Relief Areas (ERAs), and this did not allow for a spread of the funds around the country. The 2006 reauthorization of the Ryan White Care Act included persons who were living with HIV and revised an ERA to be a city with a population greater than 50,000 (HKFF, Reichmann, 2006; 2006). This change to the ERA definition increased support for those living with HIV and increased support for urban and suburban areas, as AIDS was no longer just a big city problem. States that have ADAP resources proportionate to their rate of persons living with HIV/AIDS will present environments that decrease exposures related to HIV risk behaviors.

Physicians in patient care per 100,000 by state. According to Andersen and Davidson (2007), it is important to understand how medical access is organized in order to understand how ratios affect people's receipt of care. States that have higher physicians per capita have higher median incomes, with the wealthiest states having the 
most practicing physicians per capita. This trend is opposite for poorer states (Weigley, Hess, \& Sauter, 2012). States with more physicians have lower rates of persons who are uninsured, have more medical facilities, and more practicing medical residents (Weigley et al., 2012). These states are healthier states, have longer life expectancies, and overall lower rates of chronic disease. Physicians are charged with conducting assessment of risk factors for HIV infection. Environments that have more physicians improve overall health conditions of persons living in that environment (i.e., individuals are seen by a medical provider, are given treatment regimens, are exposed to preventative measures). Environments where this ratio is lower can signal strain on medical access, thus a decrease in health conditions of persons living in that area. States with a higher physician in care per capita are more likely to be able to provide treatment and medical interactions that can reduce both the impact and exposure to HIV risk.

Metropolitan status within the state. The U.S. Census Bureau defines a state as rural based on their location to population centers of 50,000. If a state has a higher proportion of rural area outside of urban areas, or has large frontier areas, it is considered to be rural (Kelly, 2011). Among the 32 states that are considered rural, less than onethird has four of six recommended policies established by the CDC to reduce the spread of HIV (Kelly, 2011). Only one state, Maine, has adopted all six policies (screen for HIV and chlamydia infections, Medicaid coverage for routine HIV screening, state lab reporting on HIV, syringe exchange programs, partner therapy, and health education for adolescents) (Kelly, 2011). Up until the 2006 Reauthorization Act, federal dollars for ADAP ERAs (metropolitan areas) consisted of populations of 500,000 or more. In order to decrease the burden placed on areas that were being under-funded due to size, the ERA 
criteria were changed to 50,000 in order to be categorized as metropolitan areas. AIDS is still largely seen in metropolitan areas of 500,000 or more, and increasingly it is being seen in rural areas (CDC, 2006a).

Environments that are considered to be metropolitan have more cases of AIDS and warrant more funding support. However, rural areas are increasing in numbers and should be viewed as a marker to watch. The low adaptation of the recommended policies in rural states could have a large influence on the low prevalence that is observed in rural areas. It is still unclear in the literature how metropolitan status directly influences HIV exposure, as many who live in rural areas travel to urban areas for testing and services (Rural Center for AIDS/STD Prevention, 1996) and that skews their representation. There is the possibility that states that are considered to be more rural are at an increased risk for HIV exposure due to the lack of resources allocated for those areas, through education and prevention efforts, further decreasing the environment's resiliency to HIV risk behavior.

\section{Environmental Need Factors}

Rate of STDS by state. States that have higher percentages of STDs present environments which are less healthy, because they increase the risk of both acquiring and transmitting HIV. The environment determines the availability of sexual partners, and STDS are more prevalent in some communities than others. Some communities select partners who are from the same community and ethnicity, or have less available partners, increasing the individual risk of infection with each sexual encounter (IOM, 1997; CDC, 2013e) (IOM, 1997CDC, ; 2013e). By examining the rate of STDs by state, it is believed 
that states with higher rates present environments which make those individuals more susceptible to HIV risk behaviors.

Rate of minority groups with STDs by state. In communities of color, African Americans and Hispanics have a higher rate of chlamydia, gonorrhea, and syphilis compared to whites (National Center for HIV/AIDS, Viral Hepatitis, STD, \& TB Prevention, 2012). There is also an increased risk due to inner-community partnering that occurs, especially in African American communities as aforementioned. Social and economic conditions that have been mentioned throughout this chapter, such as rates of poverty, income inequality, and low levels of education can make it increasingly difficult for people of color to protect their sexual health (CDC, 2011d). By examining the rate of STDs among minority groups by state, it is believed that states with higher rates present environments which make those individuals more susceptible to HIV risk behaviors.

Rate of females with STDs by state. Similar to communities of color, women's risk of STDs are partly a function of their environment. As there is an increased risk due to imbalances in sex ratio, there are more opportunities for alternative relationships, where men have bargaining advantages (Logan et al., 2002). Additionally, there may be reluctance to discuss history of STDs and safer sex practices when the goal is to sustain a relationship, increasing risk to exposure. States with a higher rate of STDs among females present unhealthy environments and present environments which make females with STDs more susceptible to HIV risk behaviors.

Rate of HIV diagnoses by state. Similar to states with high STD rates, states with high rates of HIV greatly increase the risk of exposure to individuals in that state because there are more people living in that state with HIV, creating more opportunities 
for risk exposures to occur, such as it increases the likelihood that a sexual or drug-using partner has HIV (CDC, 2013d). States that have higher rates of HIV present unhealthy environments and exposure for one to participate in HIV risk behaviors.

Rate of HIV diagnoses among minority groups by state. HIV is a large burden among people of color, especially African Americans. Due to inner-community partnering among ethnic minorities and higher prevalence among ethnic minorities, this can lead to a disproportionate amount of risk placed on ethnic minorities, because there is an increased probability that they will come into contact with sexual or drug-using partner has HIV. States that have more people of color with HIV present environments that increase the risk of exposure to HIV for those groups in HIV risk behavior.

Percentage of AIDS diagnoses in each state. Similar to HIV infection rates, states with high percentages of AIDS greatly increase the risk of exposure to individuals in that state because there are more people living in that state with AIDS, creating more opportunities for risk exposures to occur, such as it increases the likelihood that a sexual or drug-using partner has AIDS and contact will expose one the virus. States that have higher percentages of AIDS present unhealthy environments and increased risk exposure for one to participate in HIV risk behaviors.

Percentage of transmission categories of AIDS in each state. Examining the percentage of AIDS by transmission categories in each state places those individuals into a context for understanding levels of exposure to HIV risk based on their environment. The category of men who have sex with men (MSM) account for over half of all new infections compared to the other transmission categories of heterosexual contact, injection drug use (IDU), and MSM who have a history of IDU (CDC, 2010d). 
Compared to the other transmission categories, MSMs have additional factors that increase the spread of HIV, such as increased alcohol and drug use, (as maladaptive coping mechanisms to deal with discrimination, violence, or mental health issues) which have been linked to high-risk sexual activity with non-steady partners, multiple partners, or high-risk activity while under the influence (CDC, 2013g;2013h). Among this group, African Americans are disproportionately affected, and young African American gay and bisexual men who were newly infected with HIV increased 20\% from 2008 to 2010 (CDC, 2013g). By examining the percentage of MSM as the transmission category of AIDS compared to the other categories by state, it is believed that states with higher percentages of AIDS transmitted through MSM present environments which make those individuals more susceptible to participate in HIV risk behaviors with persons who are at an increased risk.

\section{Individual Predisposing Demographic Characteristics}

The following section will review the individual level characteristics that will be included in the proposed conceptual model.

Age. Increased life expectancy allows persons aging to live longer and healthier. For older adults, age is seen as a barrier to knowledge and risk reduction behaviors (Stephens \& Phillips, 2003; 2005; Lindau et al., 2007). Persons 50 and older have been shown to have more challenges communicating sexual health issues to medical providers (IOM, 2010), sexual issues with partners (Lindau et al., 2007), and most importantly, higher frequency of not using a protective barrier during heterosexual sex occurs among older adults (Otto-Salaj, 2010). Based upon these reasons, it is believed that persons 50 and older have an increased likelihood to engage in HIV risk behaviors. 
Gender. Female gender is associated with increased exposure to HIV risk behaviors based on the notion that women are defined by their function to men in this society; therefore, this "view" extends inequality across major structures in society-labor, power, and social norms, increasing burden and barriers for women. For those who experience high degrees of structural and social disenfranchisement (Fullilove et al., 1990; Logan et al., 2002; Dworkin, 2009) this increases the likelihood that these women will be in more situations to engage in HIV risk behaviors than men. There are noted examples of gender differences in accessing and using resources that support the growing concern of gender disparities in health (Cameron, Song, Manheim, \& Dunlop, 2010). Another noted difference in health access is that women with safety concerns reported fewer preventive healthcare services (Cronholm, 2009). In the absence of an environment that increases women's exposure to equality and equitable experiences, this will increase women's exposure to situations that contribute to HIV risk behaviors.

\section{Individual Predisposing Social Structure Characteristics}

Marital status. Within the institution of marriage, it is acceptable that there are no or minimal uses of protective barriers such as condoms when comes to sexual encounters, as it is reflective of people's values about sex within marriage (Chimbiri, 2007). Additionally, condom use has been seen as a part of family planning and STD prevention, and should also be noted that within the institution of marriage, there is a decrease in risk perception of STDs because of the monogamous nature that marriage represents (Chimbiri, 2007; Hagedoorn et al., 2006). Among adults over 50 who are married, there were patterns of marrying at younger ages for this generation, and that marriage in their youths served as a protective factor against STDs because of the 'social 
contract' between partners to resist infidelity (Hagedoorn et al., 2006). Additionally, among older adults, gendered differences (roles taken on by women and men) tend to decrease over time because their roles become more alike over time, as companionship becomes increasingly important later in life (Chimbiri, 2007). This may reduce some of the issues related to gendered power in relationships in older couples that are issues in younger couples. Overall, it is believed that marriage offers a protection of environmental, social, and psychological factors (Levenson, Carstensen, \& Gottman, 1993). It is believed that for older adults, being in a committed relationship such as marriage serves as a protective factor against engaging in HIV risk behaviors.

Race/ethnicity. Belonging to an ethnic minority group has been strongly correlated with increased risk exposure (e.g., Ark, Hull, Husaini, \& Craun, 2006; Musa et al., 2009) and engagement in sexual risk behaviors (e.g., Shain et al., 1998; Winningham et al., 2004). As a social determinant of health, it has been substantiated in the literature that those belonging to ethnic minority groups experience more cumulative disadvantage over the life course when compared to non-ethnic minorities, which influences social and physical exposures (i.e., having lower socio-economic status, maintaining imbalanced relationships (e.g., Andersen \& Bozzette, 2000; DiClemente et al., 2009). Based on the relationship of race and HIV risk behaviors (Logan et al., 2002) it believed that that belonging to a racial/ethnic minority will contribute to participation in HIV risk behaviors.

Education. Having more education is seen as a protective factor, resulting in overall better health outcomes and reducing the likelihood of one participating in HIV risk behaviors (Whyte, 2006). The level of education affects resources such as 
understanding and engaging in non-HIV risk behaviors. A greater burden of those participating in HIV risk behaviors is found in those who are less educated (Hasnain, Levy, Mensah, \& Sinacore, 2007). There is a protective association between education and participating in risk behaviors, therefore it is believed that persons that have more education will have greater influence in decision-making processes regarding risk behavior and have more knowledge of how to remain safe in their social and interpersonal relationships (Whyte, 2006).

Employment. Persons who are employed generally have increased access to financial independence and medical benefits, substantially affecting the material condition of their life (IOM, 2001). This also reduces the need to maintain relationships for sustainment or those that are harmful because of the likelihood that being employed encourages financial independence (Kang, Deren, Andia, Colón, \& Robles, 2004). Being employed also affects decision making skills, components of human life which are heavily exercised in a work environment, where one has to examine and compare choices and challenges, selectively examine information, and depending on motivation, time, and other pressures, results in choices that are made ("Mindtools", n.d.). These cognitive processes play a significant role in self-regulating behaviors (Bandura 1990). Persons who exercise these behaviors are likely to be better equipped to resist engaging in HIV risk behaviors because of increased self-efficacy in those self-regulating behaviors (Kang et al., 2004). Persons who are employed are likely to have more protective factors against participating HIV risk behaviors.

Urban/rural residence. While HIV has long been an issue in urban areas, it is a growing issue in rural areas (Cene et al., 2011). Urban areas that have economically 
disadvantaged groups carry a larger burden of HIV risk because they have a higher HIV prevalence rate and lower socioeconomic status which can lead to increases in risk exposure (Denning \& DiNenno, 2013). Challenges that face persons who live in rural areas, such as distance, having limited healthcare resources, and cultural stigma about HIV and risk behaviors increase one's vulnerability to risk of exposure (Kelly, 2011). Non-urban areas have fewer resources that help with early detection and treatment of STDs such as low cost or free STD/HIV screenings, scarcity in condoms due to a lower number of retail stores, and decreased access to prevention information thru high speed internet (Kelly, 2011).

Additionally, persons who reside in rural areas and participate in HIV risk behaviors tend to do so in larger cities where there is increased availability of sexual partners and drug activity. While this is done away from families and friends and other social networks, those persons travel back home where there is hesitancy in seeking services, further contributing to the spread of disease (Heckman, Silverthorn, Waltje, Meyers, \& Yarber, 2003). Because there is a higher prevalence of HIV in Southern states, this warrants further exploration into urban and rural residence of individuals given what is known about the prevalence of HIV and HIV risk behaviors.

\section{Individual Enabling Resources}

Health insurance. While there have been provisions made to both Medicaid and Medicare through the Affordable Care Act (ACA), there are still a number of barriers that are present for individuals that do not have any health care coverage or qualify for healthcare assistance. This is a major public health concern, as many STDs are 
preventable, yet due to them remaining unrecognized and untreated, their impact on health statuses can be detrimental. Individuals who are uninsured are in a position to be at an increased risk of exposure to infection transmission because they are less likely to have a healthcare provider, participate in health screenings, or may not be receiving other services such as substance abuse or mental health treatment that can also identify HIV risk behaviors (Kelly, 2011).

Cost as a barrier to care. If a person does not have insurance, then out of pocket cost for care can present a barrier because they will have trouble affording care (Ahmed, Lemkau, Nealeigh, \& Mann, 2001). For people who cannot afford to visit a doctor or skip recommended treatment due to cost, this presents both a personal and social risk exposure as they may be experiencing symptoms related to HIV risk behaviors yet are unable to access care.

Personal doctor. Persons who have a personal doctor or a team of physicians access care better than those who do not, resulting in increased patient empowerment regarding healthcare decisions, continuity of care, and the establishment of a therapeutic relationship which can promote trust and communication about behaviors (Ridd, Shaw, \& Salisbury, 2006). Groups of older adults access health services differently, and having a personal doctor can account for some of the health disparity that is seen among older adults. For example, it has been found that older ethnic minorities use health department settings and emergency rooms more than older white adults (Dunlop, Manheim, Sohn, Liu, \& Chang, 2002). There are also reports in the difference of quality of care received by older adults of color (Fitzpatrick, Powe, Cooper, Ives, \& Robbins, 2004). African Americans who are older are more inclined to have feelings of mistrust about the medical 
community, and may steer away from traditional one-on-one visits, getting their needs met in a clinic setting versus doctor's office (Wingood \& Diclemente, 2000). This can present a challenge because if there is no personal doctor, it can be difficult to access health history, which is important when assessing for risk behaviors (Ridd et al., 2006). As a result, risk behaviors may go unnoticed (Jacobs \& Kane, 2011; Longfield et al., 2004). It is believed that those who do not have a medical provider, an important external support, increases the odds that any HIV risk behavior can go unnoticed.

Length of time since last checkup. As a prevention tactic, having regularly scheduled checkups with a healthcare provider or team of providers is a way to identify problems at the onset. Some research supports that seeing a physician increases the likelihood of receiving preventive care and within recommended time frames (McIsaac, Fuller-Thomson, \& Talbot, 2001). A delay in care largely influences HIV risk behavior because persons with unrecognized HIV may forego timely clinical intervention, which increases risk exposure to other persons participating in those risk behaviors. An important health consequence is that these persons are not being seen and assessed on a regular basis, therefore behaviors and symptoms may go unnoticed and untreated (McCoy et al., 2009).

Income. Having lower income can present economic and social exposures that are associated with participating in HIV risk behaviors because it is likely that those who cannot afford basic necessities in life will be exposed or participate in risk situations such as maintaining unhealthy relationships or participate in behaviors for competing survival needs (Dworkin \& Blankenship, 2009). Having lower income has been linked to poorer health and fewer resources for daily living which can influence behaviors related to 
survival (IOM, 2001; Kang et al., 2004). Those with higher incomes have increased access to resources which contribute to their over wellbeing and functioning (Killien et al., 2000). Highlighted in Connell's theory of gender and power, economic independence can alleviate a relational burden on women who are in relationships for financial dependence. Having more income also increases healthcare access, utilization, and better living conditions, exposure to advantages that support living in a healthy environment. Women with more income will be less likely to engage in HIV risk behaviors than women with less income due to the reduced need to maintain a risky relationship for economic support (Dworkin \& Blankenship, 2009). They also have higher self-efficacy in communicating and negotiating about sexual practices due to increased independence that is associated with being economically secure because they have overall improved autonomy (Dworkin \& Blankenship, 2009; Jacobs \& Kane, 2011). Given these reasons it is believed that lower levels of income are associated with increased exposure to HIV risk behaviors, especially for groups who experience economic disadvantage.

\section{Individual Need Factors}

General Health. General health, referred to as self-rated health status, includes both objective information as well as the subjective interpretation of that information (Foti \& Eaton, 2010). Self-rated health status is a valuable predictor of health utilization and among risk behaviors that have been studied, a lower rating of one's health status has been associated with risk behaviors. The association between self-rated health and risk behaviors such as cigarette smoking (e.g., Vingilis, Wade, \& Adlaf, 1998) and violence exposure (e.g., Boynton-Jarrett, Ryan, Berkman, \& Wright, 2008) have been

documented, but not sexual risk behaviors directly. In Foti and Eaton's (2010) study, of 
the 29 questions they asked related to risk behaviors, they included questions related to sexual activity were asked to assess lifetime sexual activity (i.e., lifetime sexual activity and current sexual activity), presenting the first of a paucity of empirical observations of self-rated health and sexual activity. A major finding of the study was that among racial/ethnic groups, not only were more non-sexual risk behaviors associated with poor or fair ratings of health compared to excellent ratings of health, but sexual risk behaviors was associated with worse ratings of self-rated health status (Foti \& Eaton, 2010). Based on the positive association between healthy behaviors and optimal self-rated health status (Tsai et al., 2010), it is believed that worse self-rated health will be associated with HIV risk behaviors.

Quality of life. Subjective well-being affects individuals socially, physically, and economically, influencing their physical and mental health (Pangman \& Seguire, 2000) and in terms of HIV risk behavior, can dictate the dynamics of relationships (Jacobs \& Kane, 2011), gender role context (Logan et al., 2002), and interpersonal power (Jacobs $\&$ Kane, 2011). It has been suggested that those who report experiencing a lower quality of life engage in more risk taking behaviors, and in combination with other vulnerable characteristics, that risk is higher (Aronowitz et al., 2007; El-Bassel et al., 2009).

Emotional support. Social networks play a major role in shaping affective attachments and facilitating risk reduction behaviors. Emotional supports indicate if a person feels they have that level of attention from persons in their social networks if they need it, largely affecting psychological and physical wellbeing. To be considered are the roles of social supports and how they influence one participating in HIV risk behaviors, because they shape social norms that tell people how one should act. In a study that 
looked at a group of middle-aged black women, the HIV risk behavior of having unprotected sex with a person of unknown status was predicted by increased emotional distress, avoidant coping, and less active coping (Neblett, Davey-Rothwell, Chander, \& Latkin, 2011; Nyamathi \& Shuler, 1990), each reflective of social and emotional supports, or the lack thereof.

Differences in perceived emotional support and health outcomes have also been investigated in sub-groups of older adults. For instance, it was documented that older African American men tend to underutilize both formal and informal support systems more than white men, that they do not access assistance as much as white men, and that they face more economic, social, and cultural complications that white males do (Chou et al., 2007). This adds to the point that there are variations in groups of older adults when it comes to emotional support that should be considered, especially when considering how perceived satisfaction with emotional support influences behaviors. When an individual feels that they do not have social or emotional support, these feelings can influence HIV risk behavior. Individuals who indicate that they have social and emotional supports are more likely to have better coping skills and support mechanisms, which will likely decrease their vulnerability in participating in HIV risk behaviors (Mino, Deren, \& Yeon-Kang, 2006).

Life satisfaction. Results from studies that looked at populations at risk for HIV suggested that in order to prevent HIV infection, it was important to build on the psychosocial factors that contribute to life satisfaction, as it was found that those that had a less positive outlook on life did not maintain risk reduction behaviors (Kalichman, Kelly, Morgan, \& Rompa, 1997; Somlai et al., 2000). The level of satisfaction that is 
experienced by individuals is reflective of the psychosocial climate that person is living in. Differences in attitudes, decreased behavioral intentions, and decreased risk reduction activities have been observed for groups that indicate lower current life satisfaction (Logan et al., 2002; Somlai et al., 2000). Based on these findings of groups at risk for HIV infection, it is believed that higher levels of life satisfaction will provide a protective factor against participating in HIV risk behaviors.

Alcohol use. The use of alcohol has been seen as a risk factor for participating in HIV risk behavior, particularly sexual risk behaviors (Kalichman, Simbayi, Kaufman, Cain, \& Jooste, 2007; Rees, Saitz, Horton, \& Samet, 2001). Alcohol has been identified as a behavioral risk factor because it can promote multiple partnering, unprotected sex, and money in exchange for sex among drinkers more than non-drinkers (Kalichman et al., 2007). There are very strong associations that have been found between alcohol consumption and HIV infection (Zablotska et al., 2006). Among older adults, this phenomena has yet to be investigated, however based on existing knowledge, it is proposed that increased alcohol consumption is associated with HIV risk behaviors.

\section{Individual Health Behavior}

HIV risk behaviors. Intravenous drug use (IDU) among older adults as a risk behavior has not been widely investigated, though HIV transmission of this risk behavior constitutes almost $16 \%$ of HIV infections in people over 50 (CDC, 2008a). Older adults who inject drugs engage in the same risk behaviors that young adults who inject drugs do and they typically have less social support and are poorer (Kral, Lorvick, \& Edlin, 2000). With the increase in methamphetamine use, there has been an observed increase in IDUs 
over time, with them presenting as older and having more years as IDUs (Cheng et al., 2010; Coady et al., 2007). Additionally, other vulnerable populations such as persons who are homeless and ex-convicts have a positive correlation with IDU rates and STDs (Kral et al., 2000; Nyamathi et al., 2008).

A personal history of STDS increases vulnerability to transmitting or contracting HIV. This is particularly because of the physiological and biological compromise that diseases and infections pose to the genital area and immune system (IOM, 1997). Persons who use protective barriers such as condoms greatly reduce the risk of transmission of STDs, therefore having a history of STDs is a strong indicator of one engaging in unprotected sex (Wingood et al., 2004). Among older women and men, there are physiological changes that can increase their susceptibility to STDs including HIV when they engage in unprotected sex (HKFF, 2011). Anatomically, women are more susceptible to transmission than men with vaginal-to-penile penetration because physiologically, more of the mucous membranes are exposed in women (i.e., the vaginal walls) as opposed to men, serving as a conductor of harboring the virus. This can occur through tears in the vagina during intercourse, size of the cervix, and its positioning with the urethra upon penile penetration (Sharts-Hopko, 1997). Unprotected vaginal to penile penetration is the primary route of STD and HIV transmission among heterosexual older adult women. Consensual or by force, this has been seen as a factor related to risk exposure (Gilbert \& Cunningham, 1986; Lewis et al., 2000). Because there is limited research on older adults and incidence of STDs, this should be approached with caution because of lower reporting and surveillance of STDs among older adults. However, in 
order to assess who is having unprotected sex, looking at self-reports of STDs are helpful in assessing unprotected sexual activity (Wingood \& DiClemente, 2000).

Paying for sex or any other forms of sex exchange practice is predictive of STD incidence and HIV transmission (Bonomi, Anderson, Rivara, \& Thompson, 2009; Logan \& Leukefeld, 2000). Women who have reported sex exchange practices are associated with participating in other high risk activities, such as substance and alcohol abuse (Logan et al., 2002; Logan \& Leukefeld, 2000) as well as men who report sex exchange practices (Kalichman et al., 1997; Logan \& Leukefeld, 2000; Mino et al., 2006; Nyamathi et al., 2008; Whyte, Whyte, \& Cormier, 2008). Sex exchange can facilitate substance abuse habits, as sex is used as a bartering mechanism when money is not an alternative (Exner, Dworkin, Hoffman, \& Ehrhardt, 2003). For men alike, having sex with a sex worker while maintaining a relationship with other partners is high risk, because there is the likelihood that within a relationship with a primary partner, no protection will be used. As previously mentioned, it is hypothesized that due to no concern for pregnancy, payment for sex increases the opportunities to have sex among older adult women, and that sex will be unprotected.

Anal sex is the primary route of transmission route for MSM. Similarly, the lining around the anus can be compromised as there is decreased elasticity and little natural lubricant in that area, increasing risk exposure. Equally, receptive partners of anal sex acts without condoms are also at increased risk for disease transmission (Card et al., 2000). 


\section{Summary and Conclusions}

In conclusion, theories that discuss how the larger context of an environment can influence individual behavior have been insightful in examining culturally and socially structured experiences. The theory of gender and power looks at gender and power imbalances in order to explain women's health behavior and outcomes. Cumulative inequality theory also helps to identify and explain socially structured factors that occur over the life course, and how systems of oppression have adversely affected certain populations. Andersen's (2007) model provides a population-level assessment of behaviors, while accounting for the influences of culture, family, and community. HIV risk behavior in the aging population is a growing body of study, and as it continues to grow, the review and analysis of current theoretical frameworks and their application will come under close examination for their flexibility and applicability to the diverse needs of this population.

This discussion was filled with literature related to the predictive ability of both environmental and individual characteristics and HIV behavior, identifying significant factors for the 50-plus population. There is a limited amount of evidence that exists about what predicts HIV risk behaviors among this population, and that is the gap that this dissertation aims to address. Exploring factors that increase participation in risk behaviors will provide insightful information directly related to older adults. 


\section{CHAPTER III: METHODOLOGY}

"HIV does not make people dangerous to know, so you can shake their hands and give them a hug. Heaven knows they need it."

\section{$\sim$ Princess Diana}

This chapter will be divided into several sections. First the research goals and hypotheses will be introduced. Then the research design, sample and power will be described. Following that, the operationalization of the state-level variables, individuallevel variables, and outcome variable described. Finally, the analysis plan will be discussed in detail.

As risk behaviors are a major determinant of disease susceptibility and exposure, the National Institutes of Health (NIH) support the use of multilevel studies of health across disciplines (Luke, 2004). The goal of multilevel modeling is to "predict values of some dependent variable based on a function of predictor variables at more than one level" (Luke, 2004, p. 9). The argument for utilizing multilevel modeling techniques in this study is that HIV risk behavior is multilevel in nature. Health behaviors in general are influenced not only by individual exposures and actions, but also social and cultural exposures. Along those same lines, HIV risk behaviors are not just contingent upon the individual as was discussed in chapter 2 , because social and environmental factors largely dictate how an individual acts or reacts within their environment. A vast majority of past studies of HIV risk behaviors, perceptibility, or susceptibility have examined risk on the individual level of analysis. 


\section{Research Goal and Hypotheses}

The purpose of this study was to develop an understanding of both environmental and individual factors that predict HIV risk behavior among older adults. More specifically, this study tested a conceptual model that integrated Connell's (1987) theory of gender and power domains and cumulative inequality theory in the population-level framework created by Andersen (2007). The model investigated the predictive ability of environmental characteristics and individual characteristics on HIV risk behaviors across four years of respondents (from 2008 to 2011) ages 50 and older living in different states in the U.S. The following research questions guided this study:

Specific Aim 1: To determine if the states have different levels of individual HIV risk behaviors.

Hypothesis 1: States have different levels of individual HIV risk behaviors with some states having more older adults participating in risk behaviors than other states.

Specific Aim 2: To determine if the states change differently in their individual HIV risk behavior over a period of four years.

Hypothesis 2: States change differently in their levels of individual HIV risk behaviors over a period of four years, where some states' individual HIV risk behaviors become less prevalent over time and other states' individual HIV risk behavior becomes more prevalent over time or don't change at all. 
Specific Aim 3: To determine what the most important state characteristics and individual characteristics are that predict individual HIV risk behavior within and between states over a four-year period.

Hypothesis 3: Some state and individual level characteristics related to gender and power and cumulative inequality (those that are predisposed social structure characteristics, enabling resources, and need factors) will be more important in predicting individual HIV risk behaviors in states over a four-year period than others.

\section{Research Design}

The research design for the study was a multilevel repeated cross sectional design with a three level nested structure. This trend study used secondary data retrieved from the Behavioral Risk Factor Surveillance System (BRFSS) from respondents who were 50 and older who completed the BRFSS survey in 2008, 2009, 2010, and 2011. Trend studies are used to determine if a population has changed over time (Engel \& Schutt, 2013). A trend study looks at samples that are drawn at different points in time from a group of potential participants (Yegedis, Weinbach, \& Myers, 2012). This trend study was used to answer the following question: Do states have more or less HIV risk behaviors over a period of four years? With this design, individual differences cannot be investigated over time due to different samples being investigated at various measurement points. Therefore, the focus is on changes at the yearly level, investigating the profiles of different groups with some possible explanations for these differences. 
This study is multilevel because it includes data at the individual level (level 1), nested within state cohorts over a four-year period (level 2), and nested within states (level 3). The multilevel structures are shown in Figure 10: 


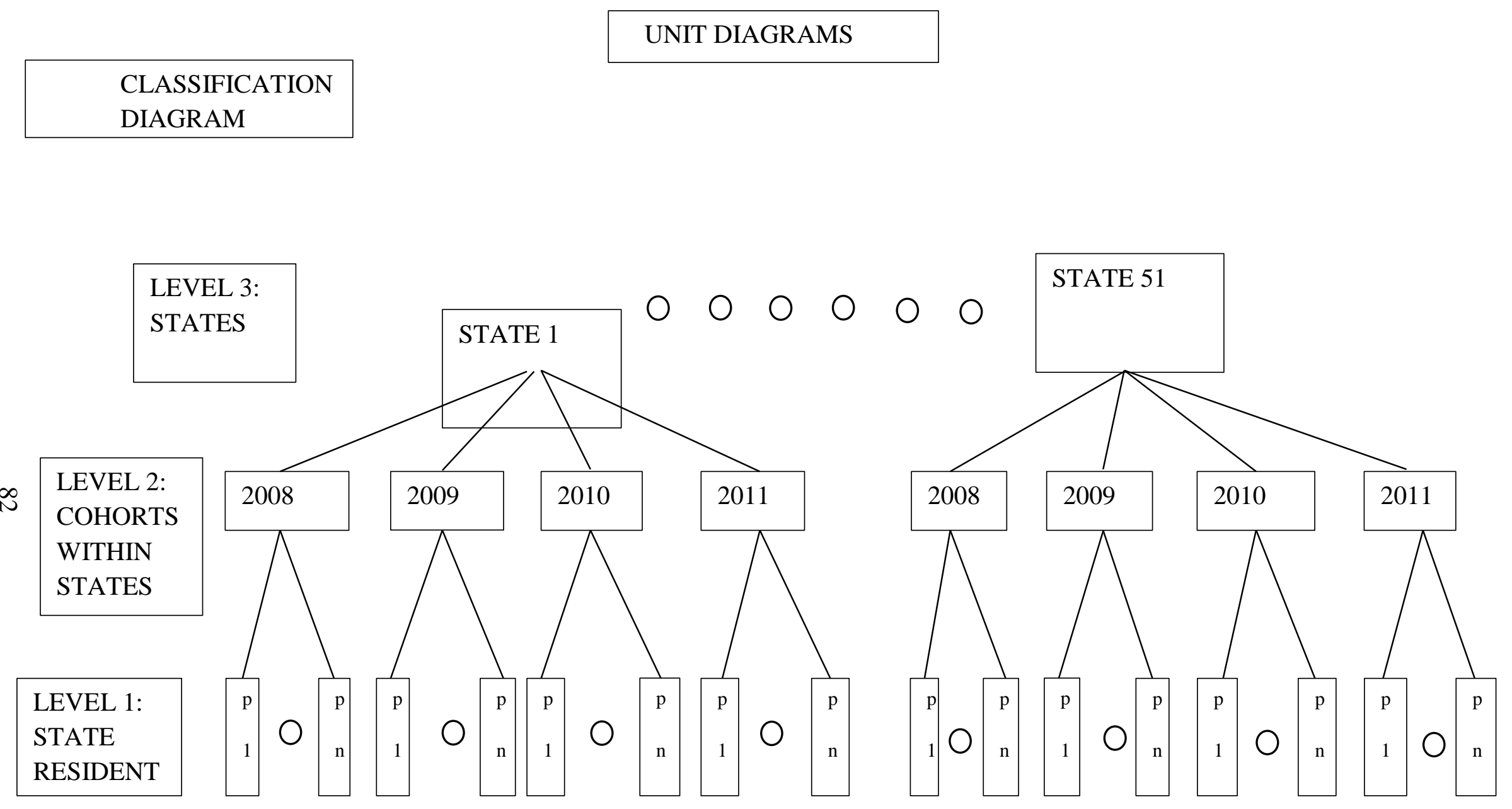

Figure 10. Multilevel structures and classifications. 


\section{Multilevel Modeling}

Existing datasets from nationally representative studies tend to be comprehensive and have a large sample, increasing the external validity of the findings for practitioners. Standard inferential statistics provide preliminary information about the data and in the advent of higher-level analytic techniques, such as multilevel modeling, investigation can go beyond just the individual, and into the community or context of their environment. Constructs at both levels are defined differently at those respective levels, and 'these types of 'multilevel' theoretical constructs require special analytic tools to properly evaluate" (Luke, 2004, p.1) their effects. Hence, we have multilevel modeling, which examines the cluster or group effect on individual outcomes (Asparouhov \& Muthen, 2006.).

The rationale for using a multilevel model has three aspects: theoretical, empirical, and statistical. Andersen's (2007) model provide theoretical justification for a multilevel model; empirical justification comes from potential state-to-state variability in the dependent variable that is assumed; and statistical justification comes from recognizing that the individuals in the sample are not independent, but clustered within a specific state context (Luke, 2004).

Limitations related to the design of the study are acknowledged. While data was collected on previous behavior, being confined to the data restricted the development and investigation of certain research questions and hypotheses. Random errors, whose effects are unpredictable, may have occurred due to respondents feeling a certain way on the day they participated in the telephone survey. Unlike longitudinal studies, it will not be able 
to examine changes over time for individuals; however, it can examine changes over time for states only (Yegedis et al., 2012). Recall bias (respondents having to recall retrospective events which can be less accurate as false memories or forgotten altogether) is another limitation to the study.

\section{Data Sources}

In order to accomplish this study, state level estimates of social determinants of health were used to examine environmental characteristics on the state level (level 3). The estimates included data collected from the U.S. Department of Commerce, Economics and Statistics Administration [ESA] (2012;2013;2011;2011a;2011b;2012a;2010;2011c); Health Resources and Services Administration [HRSA] (2010; 2010a); CDC (2011; 2009a; 2010a; 2011b;2011c;2012b;2010c); Federal Bureau of Investigations (2012;n.d.); Bureau of Labor Statistics (2010); National Intimate Partner and Sexual Violence Survey (Black et al., 2011); the Henry J. Kaiser Family Foundation State Health Facts [HKFF] (2009b;2011b;2011c;2012c;2012d;2013;2013a;2013b); the Gallup poll (Newport, 2013); and the Institute for Economics and Peace [IEP] (2011). Cohorts within states' data (level 2) were also based on data collected from the CDC and ESA. All estimates were based on data from 2010, except for crime rate data (2009) and peace index ratings (2011).

For individual population characteristics (level 1), the BRFSS (CDC, 2008c) was used to analyze the population characteristics as outlined in the conceptual model. The BRFSS has been collecting data about health behaviors by telephone since the early 1980's, redefining its methodology and expanding its reach to all 50 states of the United 
States, the District of Columbia, Puerto Rico, the U.S. Virgin islands, Guam, American Samoa, and Palau. It is the largest, ongoing public health survey in the world, and has adopted methods to account for cell phone use in data collection and improved its methods of statistical weighting (CDC, 2012d). The BRFSS implores geographic stratification sampling to gain access to smaller areas within states. Most importantly, it provides information about adult populations that are state specific, which allows the ability to look at conditions of individuals related to their state.

The BRFSS began as a monthly survey among 15 states back in 1984, collecting individual-level data. It evolved into a national surveillance system in 1993, redefining its questionnaire to include core questions and state-specific questions on selected health behaviors. In 2011, it conducted over 500,000 surveys and because of its advanced weighting methodology and ability to reach segments of the population that had previously been challenging, it is considered the gold standard of behavioral surveillance.

\section{Sample}

The data for this study represents a nationally representative sample of 23,950 individuals across all 50 states and the District of Columbia over the four year period, as seen in Table 1 . Washington had the most participants $(n=1,165 ; 4.8 \%)$ and Alaska had the least $(n=146 ; 0.6 \%)$. The study year of 2008 had the least amount of participants $(n=4,596 ; 19.1 \%)$ and the year 2011 had the most $(n=9,130 ; 38.1 \%)$. 
Table 1

Study Participants per Year

\begin{tabular}{|c|c|c|c|c|c|c|c|c|c|c|}
\hline & \multicolumn{2}{|c|}{2008} & \multicolumn{2}{|c|}{2009} & \multicolumn{2}{|c|}{2010} & \multicolumn{2}{|c|}{2011} & \multicolumn{2}{|c|}{ Total } \\
\hline & Frequency & Percent & Frequency & Percent & Frequency & Percent & Frequency & Percent & Frequency & Percent \\
\hline Alabama & 78 & 1.7 & 88 & 1.7 & 90 & 1.7 & 179 & 2 & 435 & 1.82 \\
\hline Alaska & 19 & 0.4 & 28 & 0.6 & 30 & 0.6 & 69 & 0.8 & 146 & 0.61 \\
\hline Arizona & 68 & 1.5 & 69 & 1.4 & 60 & 1.2 & 127 & 1.4 & 324 & 1.35 \\
\hline Arkansas & 69 & 1.5 & 44 & 0.9 & 54 & 1 & 107 & 1.2 & 274 & 1.14 \\
\hline California & 51 & 1.1 & 191 & 3.8 & 215 & 4.2 & 271 & 3 & 728 & 3.04 \\
\hline Colorado & 134 & 2.9 & 160 & 3.2 & 130 & 2.5 & 234 & 2.6 & 658 & 2.75 \\
\hline Connecticut & 71 & 1.5 & 58 & 1.1 & 82 & 1.6 & 133 & 1.5 & 344 & 1.44 \\
\hline Delaware & 44 & 1 & 48 & 0.9 & 56 & 1.1 & 65 & 0.7 & 213 & 0.89 \\
\hline District of Columbia & 63 & 1.4 & 75 & 1.5 & 71 & 1.4 & 107 & 1.2 & 316 & 1.32 \\
\hline Florida & 117 & 2.5 & 128 & 2.5 & 375 & 7.3 & 255 & 2.8 & 875 & 3.65 \\
\hline Georgia & 69 & 1.5 & 75 & 1.5 & 72 & 1.4 & 205 & 2.2 & 421 & 1.76 \\
\hline Hawaii & 89 & 1.9 & 91 & 1.8 & 87 & 1.7 & 193 & 2.1 & 460 & 1.92 \\
\hline Idaho & 49 & 1.1 & 64 & 1.3 & 73 & 1.4 & 118 & 1.3 & 304 & 1.27 \\
\hline Illinois & 54 & 1.2 & 55 & 1.1 & 64 & 1.2 & 104 & 1.1 & 277 & 1.16 \\
\hline Indiana & 47 & 1 & 118 & 2.3 & 129 & 2.5 & 146 & 1.6 & 440 & 1.84 \\
\hline Iowa & 58 & 1.3 & 73 & 1.4 & 65 & 1.3 & 109 & 1.2 & 305 & 1.27 \\
\hline Kansas & 88 & 1.9 & 223 & 4.4 & 113 & 2.2 & 414 & 4.5 & 838 & 3.50 \\
\hline Kentucky & 98 & 2.1 & 141 & 2.8 & 88 & 1.7 & 163 & 1.8 & 490 & 2.05 \\
\hline Louisiana & 74 & 1.6 & 95 & 1.9 & 72 & 1.4 & 209 & 2.3 & 450 & 1.88 \\
\hline Maine & 87 & 1.9 & 109 & 2.1 & 105 & 2 & 264 & 2.9 & 565 & 2.36 \\
\hline Maryland & 102 & 2.2 & 104 & 2.1 & 90 & 1.7 & 178 & 1.9 & 474 & 1.98 \\
\hline Massachusetts & 223 & 4.9 & 190 & 3.7 & 172 & 3.3 & 394 & 4.3 & 979 & 4.09 \\
\hline Michigan & 107 & 2.3 & 119 & 2.3 & 114 & 2.2 & 142 & 1.6 & 482 & 2.01 \\
\hline Minnesota & 53 & 1.2 & 82 & 1.6 & 92 & 1.8 & 247 & 2.7 & 474 & 1.98 \\
\hline Mississippi & 99 & 2.2 & 134 & 2.6 & 108 & 2.1 & 190 & 2.1 & 531 & 2.22 \\
\hline Missouri & 63 & 1.4 & 61 & 1.2 & 62 & 1.2 & 119 & 1.3 & 305 & 1.27 \\
\hline Montana & 84 & 1.8 & 79 & 1.6 & 83 & 1.6 & 185 & 2 & 431 & 1.80 \\
\hline Nebraska & 142 & 3.1 & 160 & 3.2 & 163 & 3.2 & 407 & 4.5 & 872 & 3.64 \\
\hline Nevada & 56 & 1.2 & 51 & 1 & 35 & 0.7 & 87 & 1 & 229 & 0.96 \\
\hline
\end{tabular}




\begin{tabular}{|c|c|c|c|c|c|c|c|c|c|c|}
\hline New Hampshire & 83 & 1.8 & 78 & 1.5 & 73 & $\overline{1.4}$ & 120 & 1.3 & 354 & 1.48 \\
\hline New Jersey & 126 & 2.7 & 126 & 2.5 & 144 & 2.8 & 243 & 2.7 & 639 & 2.67 \\
\hline New Mexico & 89 & 1.9 & 127 & 2.5 & 96 & 1.9 & 201 & 2.2 & 513 & 2.14 \\
\hline New York & 120 & 2.6 & 77 & 1.5 & 113 & 2.2 & 140 & 1.5 & 450 & 1.88 \\
\hline North Carolina & 197 & 4.3 & 147 & 2.9 & 122 & 2.4 & 200 & 2.2 & 666 & 2.78 \\
\hline North Dakota & 38 & 0.8 & 48 & 0.9 & 57 & 1.1 & 78 & 0.9 & 221 & 0.92 \\
\hline Ohio & 161 & 3.5 & 115 & 2.3 & 122 & 2.4 & 182 & 2 & 580 & 2.42 \\
\hline Oklahoma & 84 & 1.8 & 100 & 2 & 106 & 2.1 & 188 & 2.1 & 478 & 2.00 \\
\hline Oregon & 67 & 1.5 & 43 & 0.8 & 73 & 1.4 & 117 & 1.3 & 300 & 1.25 \\
\hline Pennsylvania & 142 & 3.1 & 111 & 2.2 & 110 & 2.1 & 184 & 2 & 547 & 2.28 \\
\hline Rhode Island & 51 & 1.1 & 69 & 1.4 & 73 & 1.4 & 123 & 1.3 & 316 & 1.32 \\
\hline South Carolina & 152 & 3.3 & 141 & 2.8 & 109 & 2.1 & 276 & 3 & 678 & 2.83 \\
\hline South Dakota & 68 & 1.5 & 54 & 1.1 & 66 & 1.3 & 148 & 1.6 & 336 & 1.40 \\
\hline Tennessee & 39 & 0.8 & 60 & 1.2 & 68 & 1.3 & 104 & 1.1 & 271 & 1.13 \\
\hline Texas & 126 & 2.7 & 124 & 2.4 & 191 & 3.7 & 291 & 3.2 & 732 & 3.06 \\
\hline Utah & 52 & 1.1 & 104 & 2.1 & 96 & 1.9 & 176 & 1.9 & 428 & 1.79 \\
\hline Vermont & 87 & 1.9 & 91 & 1.8 & 87 & 1.7 & 154 & 1.7 & 419 & 1.75 \\
\hline Virginia & 72 & 1.6 & 61 & 1.2 & 70 & 1.4 & 115 & 1.3 & 318 & 1.33 \\
\hline Washington & 275 & 6 & 290 & 5.7 & 262 & 5.1 & 338 & 3.7 & 1165 & 4.86 \\
\hline West Virginia & 44 & 1 & 46 & 0.9 & 46 & 0.9 & 90 & 1 & 226 & 0.94 \\
\hline Wisconsin & 75 & 1.6 & 64 & 1.3 & 50 & 1 & 104 & 1.1 & 293 & 1.22 \\
\hline Wyoming & 92 & 2 & 83 & 1.6 & 68 & 1.3 & 137 & 1.5 & 380 & 1.59 \\
\hline Total & 4596 & 100 & 5072 & 100 & 5152 & 100 & 9130 & 100 & 23950 & 100 \\
\hline
\end{tabular}


Inclusion criteria were that each respondent had to be 50 years of age or older at the time of the survey. To be included in the HIV risk behavior cases sample, respondents had to have answered yes to the question which asked if they had participated in any of the HIV risk behaviors. To be included in the non-HIV risk behavior cases, respondents had to have answered no to the question which asked if they had participated in any of the HIV risk behaviors. All of the "risk" cases that were 50 and older were selected for the study for a final total of 7,655 risk cases. From the remaining "non-risk" cases ( $\mathrm{n}=685,058)$, a random sample was drawn, accepting a 1 percent margin of error and a 99 percent confidence interval ("The Research Advisors", 2006). Based on these parameters, a sample of 16,195 non-risk cases was randomly selected. To allow for missingness, in the event that cases had to be deleted, the non-risk cases were oversampled by 100 , with a final sample size of 16,295 .

\section{Power}

Power depends on sample size and other design aspects—effect size or parameter values and the level of significance. With multilevel modeling, statistical power must be addressed on all levels. Power for level 1 was based on the number of individual cases $(n=23,950)$, power for level 2 on the number of state cohorts $(n=204)$, and power for level 3 on the number of states $(n=51)($ Snijders, 2005). Statistical power issues in multilevel modeling are complicated as the power differs for fixed effects versus random effects as a function of effect size, intraclass correlation, and the number of groups and cases per group (Cohen, Cohen, West, \& Aiken, 2003). 
In this study, there was sufficient power in terms of sample size. Based on convention, the significance level was set at .05 and the model sought to detect at least a medium effect size (0.4) and achieve at least 80 percent power. Additionally, the intraclass correlation was set to the convention, a minimum size of .05 .

Simulation studies, according to Kreft \& de Leeuw (1998), suggest that large samples are needed for adequate power in multilevel models and the number of groups is more important than the number of cases per group. According to Snijders (2005), it is desirable to have as many units as possible at the top level of the multilevel hierarchy. It is suggested to have at least 20 groups to detect cross-level interactions when group sizes are large (Kreft \& de Leeuw, 1998), and this assumption is met in this study with 51 states at level 3.

\section{Operationalization of Variables}

Study variables were selected based on a review of the literature that implicated their influence on HIV risk behavior among older adults.

\section{Environmental Predictor Variables}

Environmental characteristics include the context of where people live (states) and were measured on level 3 unless otherwise noted with two asterisks, indicating level 2 (state cohorts). Table 2 indicates the standardized measures used to operationalize these variables for the study and how the values were changed after data screening. 
Table 2

Environmental Characteristics (Level 2)

\begin{tabular}{|c|c|c|}
\hline Variable & Operationalization & $\begin{array}{l}\text { Data } \\
\text { Source }\end{array}$ \\
\hline & Predisposing Demographic Characteristics & \\
\hline \multirow[t]{2}{*}{$\begin{array}{l}\text { Percentage } \\
\text { of older } \\
\text { adults }\end{array}$} & $\begin{array}{l}\text { Total resident population estimates based for personsover } \\
65 \text { based on the last published decennial census as a } \\
\text { percentage of the total state population }\end{array}$ & $\begin{array}{l}\text { ESA } \\
(2011 a)\end{array}$ \\
\hline & Predisposing Social Structure Characteristics & \\
\hline $\begin{array}{l}\text { Percentage } \\
\text { of females }\end{array}$ & $\begin{array}{l}\text { Total estimates for females based on the last published } \\
\text { decennial census as percentage of the total state population }\end{array}$ & $\begin{array}{l}\mathrm{HKFF} \\
(2011 \mathrm{~b})\end{array}$ \\
\hline $\begin{array}{l}\text { Percentage } \\
\text { of ethnic } \\
\text { minorities }\end{array}$ & $\begin{array}{l}\text { Total estimates for civilians who are of Hispanic/Latino } \\
\text { origin or belong to one of OMB's defined race categories, } \\
\text { excluding those who are non-Hispanic white }\end{array}$ & $\begin{array}{l}\text { ESA } \\
(2011 b)\end{array}$ \\
\hline $\begin{array}{l}\text { Percentage } \\
\text { of civilians } \\
\text { in labor force }\end{array}$ & $\begin{array}{l}\text { Total estimates for non-institutional civilians who are } \\
\text { employed based on the last published decennial census as } \\
\text { a percentage of the total state population }\end{array}$ & $\begin{array}{l}\text { BLS } \\
(2010)\end{array}$ \\
\hline $\begin{array}{l}\text { Percentage } \\
\text { of female } \\
\text { minorities in } \\
\text { labor force }\end{array}$ & $\begin{array}{l}\text { Total estimates for NH African American female civilian } \\
\text { non-institutional persons who are employed based on the } \\
\text { last published decennial census as a percentage of the total } \\
\text { state population }\end{array}$ & $\begin{array}{l}\text { ESA } \\
(2010 a)\end{array}$ \\
\hline $\begin{array}{l}\text { Percentage } \\
\text { of females } \\
\text { married }\end{array}$ & $\begin{array}{l}\text { Total estimates for females who are married based on the } \\
\text { last published decennial census as percentage of the total } \\
\text { state population }\end{array}$ & $\begin{array}{l}\text { ESA } \\
(2012 a)\end{array}$ \\
\hline $\begin{array}{l}\text { Percentage } \\
\text { of minority } \\
\text { females } \\
\text { married }\end{array}$ & $\begin{array}{l}\text { Total estimates for minority females who are married } \\
\text { based on the last published decennial census as percentage } \\
\text { of the total state population }\end{array}$ & $\begin{array}{l}\text { Census } \\
(2010 a)\end{array}$ \\
\hline $\begin{array}{l}\text { Percentage } \\
\text { of persons } \\
\text { with a } \\
\text { college } \\
\text { degree }\end{array}$ & $\begin{array}{l}\text { Total resident population estimates for persons with a } \\
\text { college degree based on the last published decennial } \\
\text { census as a percentage of the total state population }\end{array}$ & $\begin{array}{l}\text { Census } \\
(2010 a)\end{array}$ \\
\hline
\end{tabular}




\begin{tabular}{|c|c|c|}
\hline $\begin{array}{l}\text { Percentage } \\
\text { of female } \\
\text { minorities } \\
\text { with a } \\
\text { college } \\
\text { degree }\end{array}$ & $\begin{array}{l}\text { Total resident population estimates for female minorities } \\
\text { with a college degree based on the last published } \\
\text { decennial census as a percentage of the total state } \\
\text { population }\end{array}$ & $\begin{array}{l}\text { Census } \\
\text { (2010a) }\end{array}$ \\
\hline $\begin{array}{l}\text { Percentage } \\
\text { of intimate } \\
\text { partner } \\
\text { violence/sex } \\
\text { ual assault }\end{array}$ & $\begin{array}{l}\text { State-level prevalence } \\
\text { estimates of violence for all states }\end{array}$ & $\begin{array}{l}\text { Black et } \\
\text { al. ( 2011) }\end{array}$ \\
\hline Crime rate & $\begin{array}{l}\text { Rates per } 100,000 \text { of offenses (murder, forcible rape, } \\
\text { robbery, and aggravated assault) reported to law } \\
\text { enforcement }\end{array}$ & $\begin{array}{l}\text { Census, } \\
\text { (n.d.) }\end{array}$ \\
\hline $\begin{array}{l}\text { Peace } \\
\text { Ranking } \\
\text { Index }\end{array}$ & $\begin{array}{l}\text { Each indicator was ranked from } 1 \text { to } 5 \text { and calculated to } \\
\text { two decimal points ( } 1=\text { most peaceful to } 5=\text { least } \\
\text { peaceful). Each was weighted, as indicated in the } \\
\text { parentheses. } \\
\text { Indicators: } \\
\text { - number of homicides per } 100,00 \text { people (4); } \\
\text { - number of violent crimes per } 100,000 \text { people (4); } \\
\text { - number of jailed population per } 100,000 \text { people } \\
\text { (3); } \\
\text { - number of police officers per } 100,000 \text { people (3); } \\
\text { availability of small arms (1) }\end{array}$ & $\begin{array}{l}\text { IEP } \\
(2011)\end{array}$ \\
\hline
\end{tabular}

Percentage Religion an important part of my daily life, and I attend of religiosity religious services every week or almost every week (1); Religion is an important but I do not attend services Newport (2013) regularly OR Religion is not important but I still attend services (2);

Religion is not an important part of my life and I seldom or never attend religious services (3)

Enabling Resources Level 2 indicated by

$* *$

Percentage of Percent of people living below the poverty level

ESA poverty $* *$

1c) 


\begin{tabular}{|c|c|c|}
\hline $\begin{array}{l}\text { Percentage of } \\
\text { female } \\
\text { minorities in } \\
\text { poverty }\end{array}$ & $\begin{array}{l}\text { Percent of female minorities living below the poverty } \\
\text { level }\end{array}$ & $\begin{array}{l}\text { Census } \\
(2010 a)\end{array}$ \\
\hline $\begin{array}{l}\text { Gini } \\
\text { coefficient }\end{array}$ & $\begin{array}{l}\text { Income inequality: values range from } 0 \text { to } 1 \text {, where } 0 \\
\text { indicates perfect equality (all households have equal } \\
\text { income) to } 1 \text {, which indicates perfect inequality (only one } \\
\text { household has any income) }\end{array}$ & $\begin{array}{l}\text { ESA } \\
(2011)\end{array}$ \\
\hline $\begin{array}{l}\text { Percentage of } \\
\text { persons } \\
\text { without health } \\
\text { insurance } * *\end{array}$ & $\begin{array}{l}\text { Total resident population estimates for persons without } \\
\text { insurance based on the last published decennial census as } \\
\text { a percentage of the total state population }\end{array}$ & $\begin{array}{l}\text { Census } \\
(2010 a)\end{array}$ \\
\hline $\begin{array}{l}\text { Percentage of } \\
\text { female } \\
\text { minorities } \\
\text { without health } \\
\text { insurance }\end{array}$ & $\begin{array}{l}\text { Total resident population estimates for Hispanic females } \\
\text { without insurance based on the last published decennial } \\
\text { census as a percentage of the total state population }\end{array}$ & $\begin{array}{l}\text { Census } \\
(2010 a)\end{array}$ \\
\hline $\begin{array}{l}\text { Spending per } \\
\text { capita on } \\
\text { entitlement } \\
\text { programs } \\
\text { (Medicare/Me } \\
\text { dicaid) }\end{array}$ & Cost per beneficiary & $\begin{array}{l}\text { HKFF } \\
(2011 \mathrm{c} ; 20 \\
12 \mathrm{~d})\end{array}$ \\
\hline $\begin{array}{l}\text { Spending per } \\
\text { capita on } \\
\text { Medicaid } \\
\text { enrollees with } \\
\text { HIV }\end{array}$ & Spending per capita of enrollees with HIV & $\begin{array}{l}\text { HKFF } \\
(2012 \mathrm{a})\end{array}$ \\
\hline $\begin{array}{l}\text { Federal } \\
\text { HIV/AIDS } \\
\text { grant funding } \\
\text { for PLWA } \\
\text { per person }\end{array}$ & Cost per beneficiary & $\begin{array}{l}\text { HKFF } \\
(2013 b)\end{array}$ \\
\hline $\begin{array}{l}\text { Total ADAP } \\
\text { budget }\end{array}$ & Total ADAP budget, federal and state sources per state & $\begin{array}{l}\text { HKFF } \\
\text { (2013d) }\end{array}$ \\
\hline
\end{tabular}




\begin{tabular}{|c|c|c|}
\hline $\begin{array}{l}\text { Physicians in } \\
\text { patient care } \\
\text { per } 100,000\end{array}$ & Rates per 100,000 civilians reported & $\begin{array}{l}\text { CDC } \\
(2010 \mathrm{c})\end{array}$ \\
\hline \multirow[t]{2}{*}{$\begin{array}{l}\text { Metropolitan } \\
\text { distribution }\end{array}$} & $\begin{array}{l}\text { Metropolitan Statistical Area must include at least one } \\
\text { city with } 50,000 \text { or more inhabitants, or a Census-Bureau } \\
\text { defined urbanized area of at least } 50,000 \text { inhabitants and } \\
\text { a total metropolitan population of } 100,000 \text { or more } \\
\text { ( } 75,000 \text { in New England). Non-Metropolitan includes } \\
\text { both respondents living in non-metropolitan areas and } \\
\text { areas not classified in either category }\end{array}$ & $\begin{array}{l}\text { HKFF } \\
(2012 \mathrm{c})\end{array}$ \\
\hline & Need Factors & Level 2 indicated by $* *$ \\
\hline $\begin{array}{l}\text { Rates of } \\
\text { STDs } \\
\text { (chlamydia, } \\
\text { gonorrhea, } \\
\text { syphilis) per } \\
100,000 \text { by } \\
\text { state** }\end{array}$ & Rates per 100,000 civilians as reported & $\begin{array}{l}\text { CDC } \\
(2009 a ; \\
2010 a ; \\
2011 c ; 201 \\
2 b)\end{array}$ \\
\hline $\begin{array}{l}\text { Rates of } \\
\text { minorities } \\
\text { with STDs } \\
\text { (chlamydia, } \\
\text { gonorrhea, } \\
\text { syphilis) per } \\
100,000 \text { by } \\
\text { state }\end{array}$ & Rates per 100,000 minorities as reported & $\begin{array}{l}\text { CDC } \\
(2011 b)\end{array}$ \\
\hline $\begin{array}{l}\text { Rate of HIV } \\
\text { diagnoses }\end{array}$ & Estimated rates per 100,000 population of HIV diagnoses & $\begin{array}{l}\text { CDC } \\
(2011)\end{array}$ \\
\hline $\begin{array}{l}\text { Percentage } \\
\text { of minorities } \\
\text { with AIDS } \\
\text { diagnoses }\end{array}$ & $\begin{array}{l}\text { Estimated cumulative percent of AIDS diagnoses by } \\
\text { ethnic minority group }\end{array}$ & $\begin{array}{l}\text { CDC } \\
(2011)\end{array}$ \\
\hline $\begin{array}{l}\text { Percentage } \\
\text { of females } \\
\text { with AIDS } \\
\text { diagnoses }\end{array}$ & $\begin{array}{l}\text { Estimated cumulative percent of AIDS diagnoses among } \\
\text { females }\end{array}$ & $\begin{array}{l}\text { CDC } \\
(2011)\end{array}$ \\
\hline
\end{tabular}




\begin{tabular}{|c|c|c|}
\hline $\begin{array}{l}\text { Rate of } \\
\text { cumulative } \\
\text { AIDS } \\
\text { diagnoses }\end{array}$ & Estimated rate of cumulative AIDS diagnoses & $\begin{array}{l}\text { HKFF } \\
(2013 a)\end{array}$ \\
\hline $\begin{array}{l}\text { Percentage } \\
\text { of AIDS } \\
\text { transmission } \\
\text { categories of } \\
\text { AIDS } \\
\text { (MSM, } \\
\text { heterosexual, } \\
\text { IDU, other, } \\
\text { and } \\
\text { MSM_IDU) }\end{array}$ & $\begin{array}{l}\text { Estimated numbers of AIDS diagnoses among adolescents } \\
\text { and adults by men-who-have-sex-with-men, heterosexual } \\
\text { sex, IDU, other transmission, and MSM and injection drug } \\
\text { use category, cumulative through } 2010\end{array}$ & $\begin{array}{l}\text { HKFF } \\
(2013)\end{array}$ \\
\hline
\end{tabular}

\section{Individual Predictor Variables}

Table 3 indicates which variables were included in the analysis, the way they operationalized, and how the data were changed after data screening. 
Table 3

Individual Characteristics (Level 1)

\begin{tabular}{|c|c|c|}
\hline Variable & Operationalization & Value in analysis \\
\hline \multicolumn{3}{|c|}{ Predisposing Demographic Characteristics } \\
\hline Age & What is your age? & $\begin{array}{l}\text { Reported age in } \\
\text { years }\end{array}$ \\
\hline Gender & Indicate sex of respondent. & $\begin{array}{l}\text { 1-Male } \\
\text { 2-Female }\end{array}$ \\
\hline \multicolumn{3}{|c|}{ Predisposing Social Structure Characteristics } \\
\hline $\begin{array}{l}\text { Marital } \\
\text { Status }\end{array}$ & $\begin{array}{l}\text { Are you...? } \\
\text { 1Married } \\
2 \text { Divorced } \\
3 \text { Widowed } \\
4 \text { Separated } \\
5 \text { Never married } \\
6 \text { A member of an unmarried couple }\end{array}$ & $\begin{array}{l}\text { 1-In a committed } \\
\text { relationship } \\
\text { 2-Not in a } \\
\text { committed } \\
\text { relationship }\end{array}$ \\
\hline Ethnicity & $\begin{array}{l}\text { Are you Hispanic or Latino? } \\
1 \text { Yes } \\
2 \text { No }\end{array}$ & $\begin{array}{l}3 \text { (in the Race } \\
\text { variable) }\end{array}$ \\
\hline Race & $\begin{array}{l}\text { Which one of these groups would you say best } \\
\text { represents your race? } \\
\text { Please read: } \\
1 \text { White } \\
2 \text { Black or African American } \\
3 \text { Asian } \\
4 \text { Native Hawaiian or Other Pacific Islander } \\
5 \text { American Indian or Alaska Native } \\
\text { Or } \\
6 \text { Other [specify] }\end{array}$ & $\begin{array}{l}\text { 1-Non-Hispanic } \\
\text { White } \\
\text { 2-Non-Hispanic } \\
\text { Black } \\
\text { 3-Hispanic } \\
\text { 4-Other }\end{array}$ \\
\hline Education & $\begin{array}{l}\text { What is the highest grade or year of school you } \\
\text { completed? }\end{array}$ & $\begin{array}{l}\text { 1-Less than high } \\
\text { school } \\
\text { 2-High school }\end{array}$ \\
\hline
\end{tabular}




\begin{tabular}{|c|c|c|}
\hline & $\begin{array}{l}\text { 1Never attended school or only attended } \\
\text { kindergarten } \\
2 \text { Grades } 1 \text { through } 8 \text { (Elementary) } \\
3 \text { Grades } 9 \text { through } 11 \text { (Some high school) } \\
4 \text { Grade } 12 \text { or GED (High school graduate) } \\
5 \text { College } 1 \text { year to } 3 \text { years (Some college or } \\
\text { technical school) } \\
6 \text { College } 4 \text { years or more (College graduate) }\end{array}$ & $\begin{array}{l}\text { 3-Some college } \\
\text { education or more }\end{array}$ \\
\hline $\begin{array}{l}\text { Employ- } \\
\text { ment }\end{array}$ & $\begin{array}{l}\text { Are you currently...? } \\
1 \text { Employed for wages } \\
2 \text { Self-employed } \\
3 \text { Out of work for more than } 1 \text { year } \\
4 \text { Out of work for less than } 1 \text { year } \\
5 \text { A Homemaker } \\
6 \text { A Student } \\
7 \text { Retired } \\
8 \text { Unable to work }\end{array}$ & $\begin{array}{l}\text { 1-Employed } \\
\text { 2-Self-employed } \\
\text { 3- } \\
\text { Homemaker/Student } \\
\text { 4-Unemployed } \\
\text { 5-Retired }\end{array}$ \\
\hline $\begin{array}{l}\text { Urban/ } \\
\text { Rural } \\
\text { designation }\end{array}$ & $\begin{array}{l}\text { Metropolitan Status Code } \\
\text { 1-In the center of an MSA } \\
\text { 2-Outside the center of an MSA but inside the } \\
\text { county containing the center city } \\
\text { 3-Inside a suburban county of the MSA } \\
\text { 4-In an MSA that has no center city } \\
\text { 5-Not in an MSA }\end{array}$ & $\begin{array}{l}\text { 1-Urban } \\
\text { 2-Suburban } \\
\text { 3-Rural }\end{array}$ \\
\hline \multicolumn{3}{|c|}{ Enabling Resources } \\
\hline $\begin{array}{l}\text { Health } \\
\text { care } \\
\text { coverage }\end{array}$ & $\begin{array}{l}\text { Do you have any kind of health care coverage, } \\
\text { including health insurance, prepaid plans } \\
\text { such as HMOs, or government plans such as } \\
\text { Medicare or Indian Health Services? }\end{array}$ & $\begin{array}{l}\text { 1-Yes, has health } \\
\text { coverage } \\
\text { 2-No, does not have } \\
\text { health coverage }\end{array}$ \\
\hline $\begin{array}{l}\text { Cost as a } \\
\text { barrier to } \\
\text { care }\end{array}$ & $\begin{array}{l}\text { Was there a time in the past } 12 \text { months when you } \\
\text { needed to see a doctor but could not } \\
\text { because of cost? }\end{array}$ & $\begin{array}{l}\text { 1-Yes, could not see } \\
\text { doctor because of } \\
\text { cost barrier } \\
\text { 2-No, was able to } \\
\text { see doctor }\end{array}$ \\
\hline $\begin{array}{l}\text { Personal } \\
\text { doctor }\end{array}$ & $\begin{array}{l}\text { Do you have one person you think of as your } \\
\text { personal doctor or health care provider? } \\
\text { If "No," ask: "Is there more than one, or is there no } \\
\text { person who you think of as your personal doctor or } \\
\text { health care provider?" }\end{array}$ & $\begin{array}{l}0 \text {-No regular } \\
\text { healthcare provider } \\
\text { 1-Regular healthcare } \\
\text { provider }\end{array}$ \\
\hline
\end{tabular}


Length of About how long has it been since you last visited a time doctor for a routine checkup? A routine checkup is a since last general physical exam, not an exam for a specific checkup injury, illness, or condition.

Income
0-Never

1 -Within past year

2-Within past 2

years

3-Within past 5

years

4-5 or more years

ago

1-Less than $10 \mathrm{k}$

2-Less than $25 \mathrm{k}$

3 -Less than $20 \mathrm{k}$

4-Less than $25 \mathrm{k}$

5 -Less than $35 \mathrm{k}$

6 -Less than $50 \mathrm{k}$

7 -Less than $75 \mathrm{k}$

8-75k or more

\section{Need Factors}

General Would you say that in general your health is-? health

Quality of life

Now thinking about your physical health,
includes physical illness and injury, for

how many days during the past 30 days was your physical health not good?

Emotional How often do you get the social and emotional Support support you need?

1-Always

2-Usually

3-Sometimes

4-Rarely

5-Never

1-Very satisfied

2-Satisfied

3-Dissatisfied

4-Very satisfied 


\begin{tabular}{|c|c|c|}
\hline $\begin{array}{l}\text { Alcohol } \\
\text { ase }\end{array}$ & $\begin{array}{l}\text { During the past } 30 \text { days, how many days per week } \\
\text { or per month did you have at least one drink of any } \\
\text { alcoholic beverage such as beer, wine, a malt } \\
\text { beverage or liquor? }\end{array}$ & $\begin{array}{l}1-\text { Yes, had alcoholic } \\
\text { beverages in the past } \\
30 \text { days } \\
2-\text { No, did not have } \\
\text { alcoholic beverages } \\
\text { in the past } 30 \text { days }\end{array}$ \\
\hline
\end{tabular}

\section{Outcome Variable: HIV Risk Behavior}

The outcome variable was measured on Level 1. Table 4 indicates the variable that was included in the analysis, the way it was operationalized, and how the data were changed after data screening. 
Table 4

Health Behavior (Level 1)

\begin{tabular}{|c|c|c|}
\hline Variable & Operationalization & $\begin{array}{l}\text { Value in } \\
\text { analysis }\end{array}$ \\
\hline $\begin{array}{l}\text { HIV risk } \\
\text { behavior }\end{array}$ & $\begin{array}{l}\text { Do any of the high risk situations apply? } \\
\text { I'm going to read you a list. When I'm done, please } \\
\text { tell me if any of the situations apply to you. You do } \\
\text { not need to tell me which one. } \\
\text {-You have used intravenous drugs in the past year. } \\
\text {-You have been treated for a sexually transmitted or } \\
\text { venereal disease in the past year. } \\
\text {-You have given or received money or drugs in } \\
\text { exchange for sex in the past year. } \\
\text {-You had anal sex without a condom in the past year. }\end{array}$ & $\begin{array}{l}\text { 1-Yes, HIV risk } \\
\text { behaviors apply } \\
\text { 2-No HIV risk } \\
\text { behaviors apply }\end{array}$ \\
\hline
\end{tabular}

\section{Analysis Plan}

The most appropriate analysis for this type of study is multilevel modeling because it allows for the identification of patterns between individuals and between states. The use of this advanced statistical technique also allows for the identification of patterns between and within state cohorts, testing the interactions between both levels of predictors and time. After obtaining institutional review board approval to review and report on these data, IBM SPSS Statistics 21 was used for data management. For preliminary analyses, three separate conventional data files were created to organize and sort data, with level 3 data comprising of state-level estimates, level 2 data comprising of state cohort data (data for each study year), and level 1 data comprising of individual level data. Final model variables were inspected for form by examining the distribution of state-level variables and recoding individual-level data. After conducting descriptive 
analyses for individual, cohort, and state levels, the data were merged into one file and uploaded to MLwiN version 2.27, a specialized multilevel software package (Rabash, Steele, Browne, \& Goldstein, 2009; Steele, 2008).

Because the outcome variable in this study is a binary variable, indicating the presence or absence of risk behavior, a Hierarchical Generalized Linear Model (HGLM) was tested (Lee \& Nelder, 2001). In a Hierarchical Generalized Linear Model, a nonlinear transformation of the predicted value is needed using a logit link function, which provides the relationship of a linear predictor and the mean of the distribution function (Raudenbush \& Bryk, 2005). The analysis is of similar form to a logistic regression analysis for non-nested data and will be discussed in detail in Chapter 4.

Model fit was accomplished by Bayesian modeling, first making use of Iterative Generalized Least Squares (IGLS) followed by Markov Chain Monte Carol (MCMC) estimation. Unlike classical methods that converge to a point, MCMC methods are stochastic converging to a distribution. MLwiN utilizes a Metropolis Hastings sampling method to sample diffuse preceding distributions. In order for chains to converge to the distribution of interest a "burning" period is used. The chains are subsequently a dependent sample of values from the distribution of interest. As a result of dependence, a suggested effective sample size (ESS) of 250 is advised for model convergence. ESS values exceeded 250 with 20,000 iterations (Jones, 2012; Steele, 2008).

After preliminary analyses were conducted to investigate the structure of each variable on each level, the analytic model for the dependent variable (participating in HIV risk behaviors or not) was developed in three steps, using HGLM (Raudenbush \& Bryk, 
2008). The first step consisted of (a) fitting the unconditional model. This step described the probability of participating in HIV risk behavior or not (Model A) (b) fitting the unconditional growth model depicting the probability of engaging in HIV risk behavior over time across states (Model B) (c) fitting the main effects of the individual predictors to explain the change in the dependent variable (Model C); and (d) fitting the individual and state main effects to explain the change in the dependent variable (Model D). Each model was first estimated using the IGLS estimation and followed by the MCMC estimation. In the interest of parsimony, predictor variables that did not contribute to the model fit were excluded from the final model (Model D).

\section{Summary and Conclusion}

This chapter detailed the methodological plan of this study by discussing the proposed research questions, research design, sampling procedure, data sources, operationalization of variables, and analytic strategy for studying the environmental and individual variables and how they influence HIV risk behaviors. The following chapter provides the detailed results of the statistical analyses of the research questions and hypotheses. 


\section{CHAPTER IV: RESULTS}

"We can't look at HIV in isolation from the environment in which people live"

Jonathan Mermin, M.D., director of CDC's Division of HIV/AIDS Prevention.

The purpose of this study was to develop an understanding of both environmental and individual predictors of HIV risk behaviors among adults 50 and older in the United States during the years 2008 to 2011 . Findings related to the three research questions are described in this chapter, namely, (1) Do states have different levels of individual HIV risk behaviors? (2) Over a period of four years, do states change differently in their individual HIV risk behavior? (3) Over a period of four years, which state and individual characteristics, specifically those related to gender and power and cumulative inequality, will be more important in predicting individual HIV risk behaviors than others? This chapter will explain data preparation activities and preliminary analyses, describe the study sample and the model building process, and present the results.

\section{Data Preparation}

\section{Retrieving and Merging Data}

In order to draw the sample for the three levels represented in study, data were retrieved from multiple data sources. The publicly available BRFSS data from the CDC was downloaded from http://www.cdc.gov/brfss/data_documentation/index.htm for individual level data (level 1) for 2008 to 2011 (CDC, 2008c). Appropriate variables 
related to this dissertation study were extracted. State cohort data (level 2) and state data (level 3) were downloaded from the publicly available data archives as previously discussed in Chapter 3 under Data Sources.

\section{Data Screening}

\section{State and State Cohort Level Data Screening}

State cohort level data (level 2) were restructured to a vertical data file, transposed, and merged into the state dataset (level 3). Then the state dataset was merged with the final individual dataset. All state data were taken directly from the data sources and consisted of percentages, rankings, and rates.

Missing values. To be noted is that in some states, ethnic groups such as African Americans, Hispanics, and Asians have very low or zero representation, which was the reason for much of the missing data for variables identified based on race/ethnic composition, particularly when looking at these groups among females (i.e., percent of African American females in the labor force or Native American females in poverty) (HKFF, 2009c). Two actions were taken to address this issue of missingness. The first action was to create a minority female variable using the mean value of all female ethnic groups for each state. This was done for the variables labor force, marital status, education, poverty, and uninsured. These variables were to be used in preliminary analysis to see if they were better suited for the model than each of the individual female ethnic groups per variable.

The second action taken was to address the missingness in the individual female ethnic groups. African American females were consistently missing in the same 11 
states $^{2}$, with Hispanics females missing in a range of 3 to 10 same states $^{3}$, followed by Asian females missing in over a third of states. Missingness was a huge issue for Native Hawaiian and American Indian groups being that these groups had data missing in almost all states, with the exception of Alaska, Hawaii, and a couple of western states like Oklahoma and Kansas. For this reason, states that had no representation were entered a value of 0 for the variables of labor, marital status, education, poverty, and uninsured by female ethnic group status. Intimate partner violence data was missing for D.C. and was replaced with the mean value, 36.04. Forcible rape data, part of the overall crime rate data value, was missing for Illinois and Minnesota. In order to have crime date for these two states, the missing data were replaced with the mean rate of forcible rape resulting in values of 651.4 and 247.2, respectively. For females with chlamydia, there was one missing value in D.C., and the mean was used to replace that value, 583.05.

Multicollinearity. Correlation analyses were run between the outcome variable and state predictors to determine if multicollinearity was present between the different predictors. If multicollinearity was detected (correlation between predictors exceeded 0.80 ), the decision of final variables to include was made based upon which predictors had the highest correlation with the outcome variable.

Environmental predisposing variables. Based on correlations between all the different predisposing demographic and social structure variables (Table 5), the following predictors were deleted: ethnic minorities, Hispanic females, Asian females, Native Hawaiian females, American Indian females, persons in the labor force, females in the

\footnotetext{
${ }^{2}$ ID,OR,HI,ME,MN,UT,WY,AK,VT,SD,ND

${ }^{3} \mathrm{ME}, \mathrm{MT}, \mathrm{AK}, \mathrm{VT}, \mathrm{SD}, \mathrm{ND}, \mathrm{WV}, \mathrm{MS}, \mathrm{AR}, \mathrm{LA}$
} 
labor force, white females in the labor force, African American females in the labor force, Hispanic females in the labor force, Asian females in the labor force, other females in the labor force, people with a college degree, females with a college degree, other females with a college degree, people who were married, females who were married, white females who were married, and percentage of lifetime prevalence of female victimization. 
Table 5

Correlation Matrix for State Predisposing Demographic and Social Structure Variables ${ }^{4}$

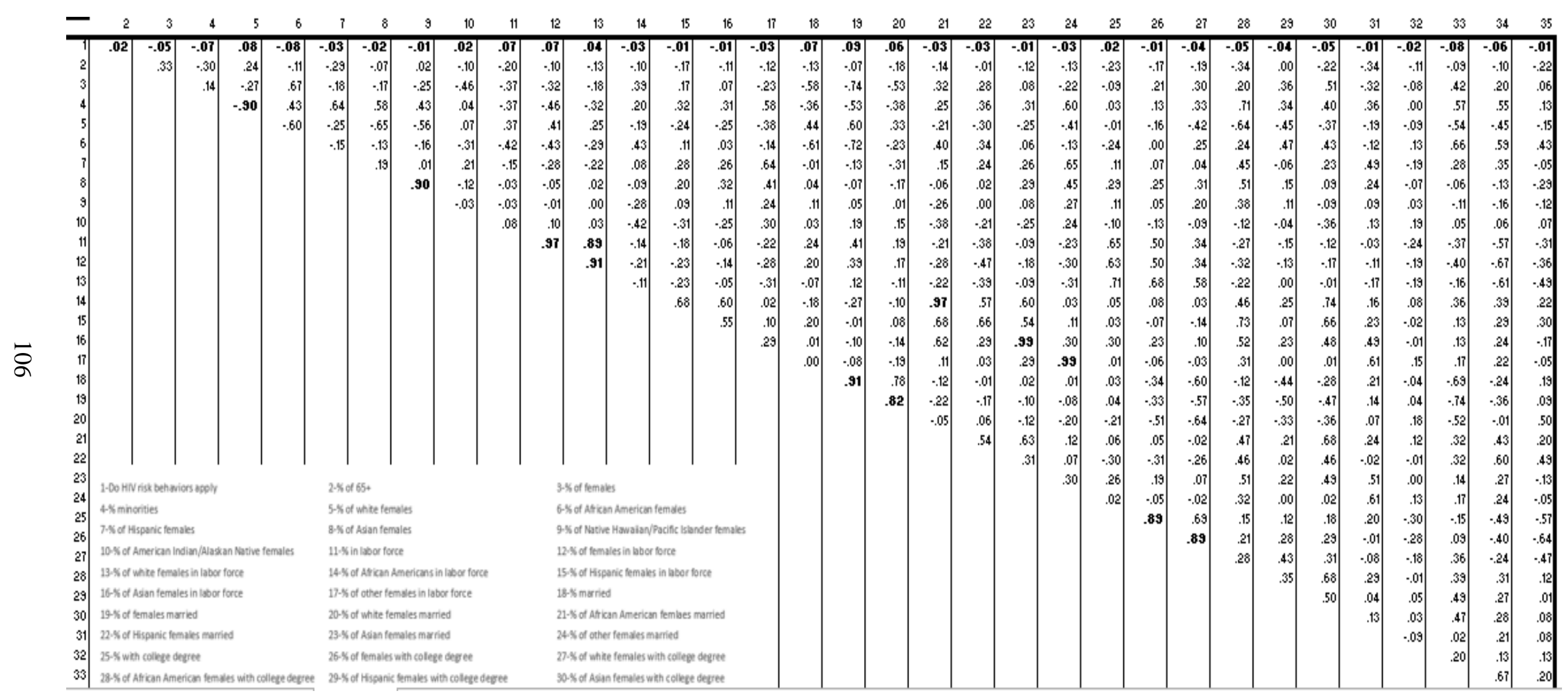

\footnotetext{
${ }^{4}$ See Appendix A for a larger table depicting the key
} 
Environmental enabling variables. Once the final state predisposing variables were identified, the enabling variables were added, and a correlation analysis was run. Based on the correlation of both predisposing and social structure variables (Table 6), the following enabling predictors were deleted: females in poverty, white females in poverty, African American females in poverty, Hispanic females in poverty, Asian females in poverty, other females in poverty, Gini index (income inequality), females who were uninsured, white females who were uninsured, African American females who were uninsured, Asian females who were uninsured, other females who were uninsured, and spending per capita on Medicaid enrollees with HIV. 
Table 6

\section{Correlation Matrix with Enabling Variables Added ${ }^{5}$}

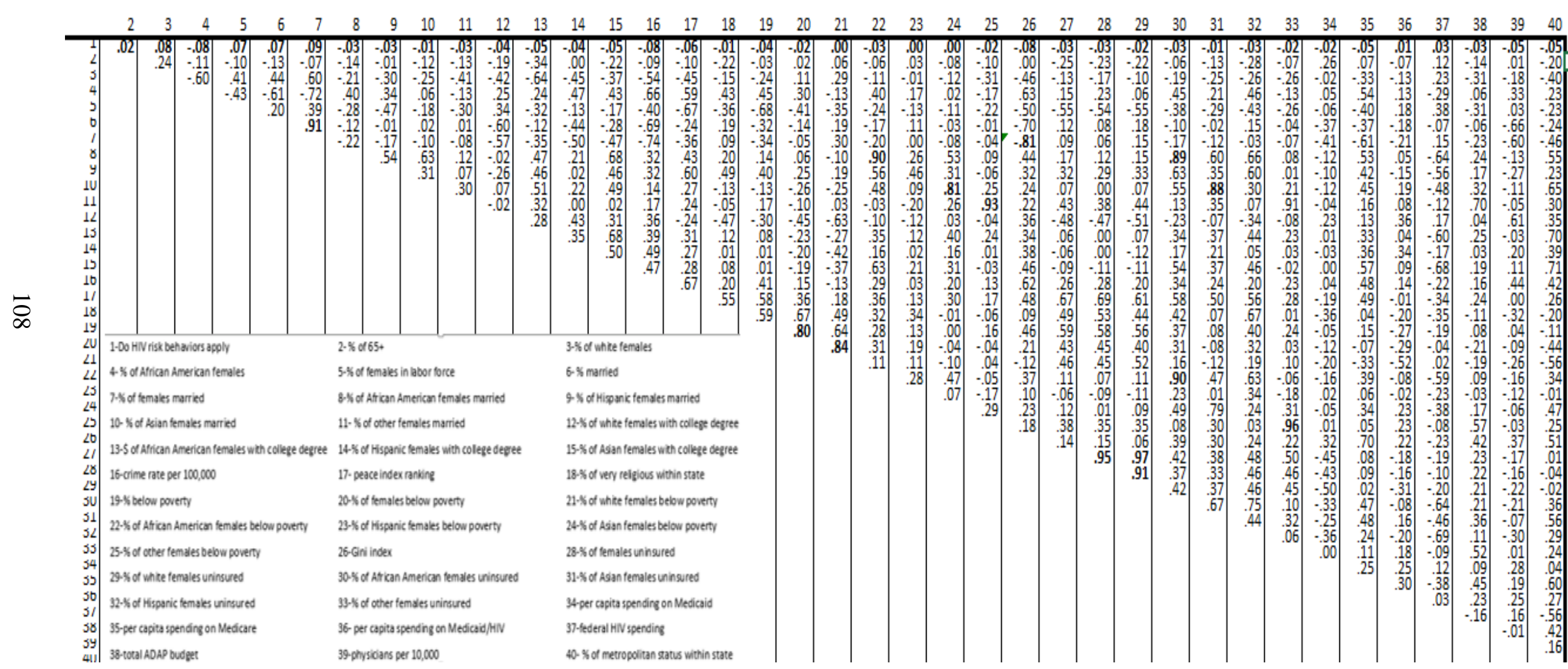

\footnotetext{
${ }^{5}$ See Appendix B for a larger table depicting the key
} 
Environmental need variables. Once the final state enabling variables were identified, the need variables were added and correlation analysis was run. Based on the correlation of the remaining variables (Table 7), the following need predictors were deleted: rate of gonorrhea for females, rate of chlamydia for females, rate of HIV, cumulative persons with AIDS, cumulative African Americans living with AIDS, and cumulative AIDS diagnoses among females, transmission by MSM, transmission by IDU, and other transmission route. 
Table 7

\section{Correlation Matrix with Need Variables Added ${ }^{6}$}

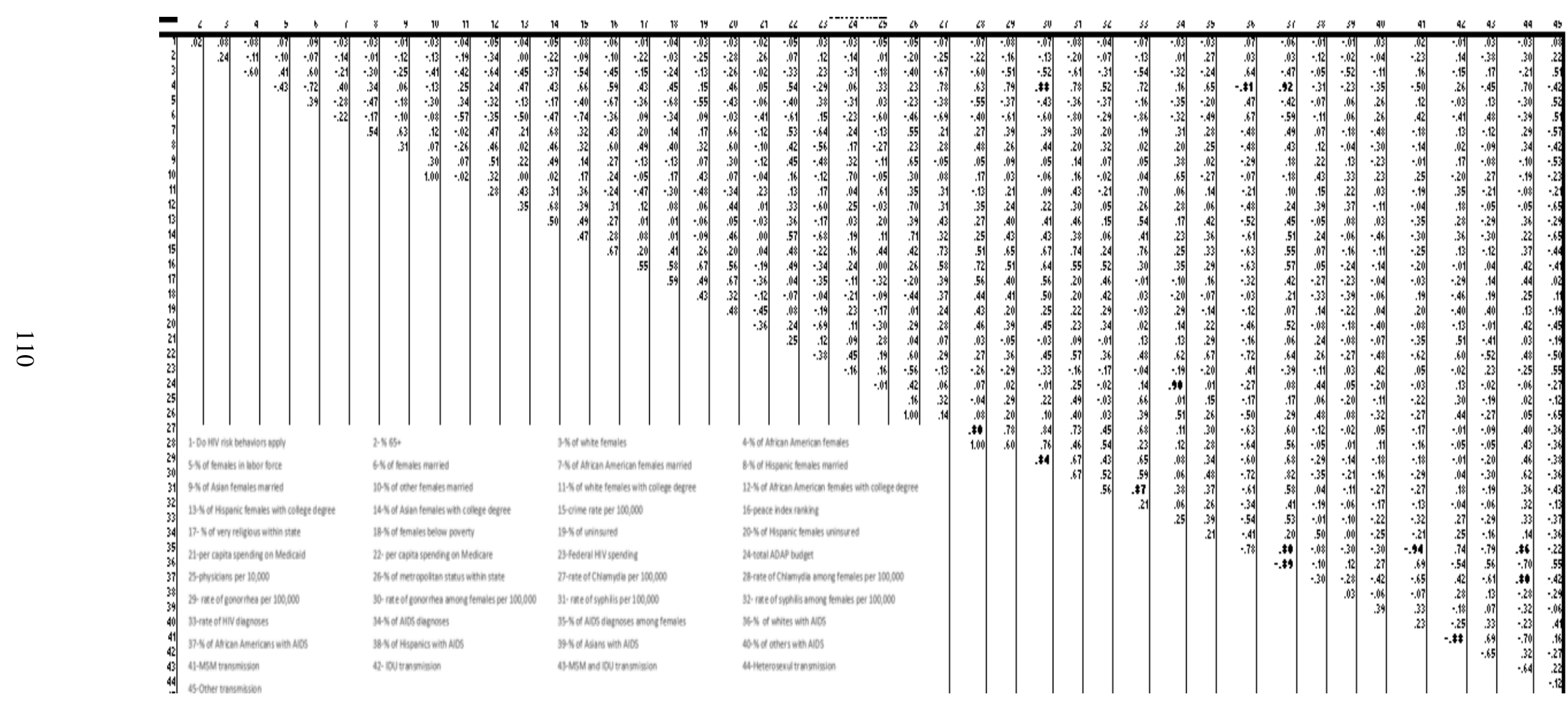

\footnotetext{
${ }^{6}$ See Appendix $\mathrm{C}$ for a larger table depicting the key
} 
Transformations. To normalize positively skewed data, transformations were computed to correct violations of functional form using square root, logarithmic, and inverse transformations. To normalize negatively skewed data, reflect and square root transformations were performed (Tabachnick \& Fidell, 2007, p. 89). For log transformations that had 0 's in the base values, a constant was added in the transformation (Tabachnick \& Fiddell, 2007, p. 89). Table 8 illustrates the variables, direction of skewness, and transformation used to correct the form of the variable. 
Table 8

Skewness Transformations

\begin{tabular}{|c|c|c|}
\hline Variable & Skewness & Transformation used \\
\hline$\%$ of white females & Negative & Reflected square root \\
\hline African American females & Positive & Square root \\
\hline Females married & Negative & Reflected square root \\
\hline Other females married & Positive & Square root \\
\hline $\begin{array}{l}\text { White females with college } \\
\text { degree }\end{array}$ & Positive & Inverse \\
\hline $\begin{array}{l}\text { Asian females with college } \\
\text { degree }\end{array}$ & Negative & Reflected square root \\
\hline Crime rate & Positive & Square root \\
\hline $\begin{array}{l}\text { Spending per capita, } \\
\text { Medicaid }\end{array}$ & Positive & Square root \\
\hline $\begin{array}{l}\text { Federal HIV/AIDS grant } \\
\text { funding }\end{array}$ & Positive & Inverse \\
\hline Total ADAP budget & Positive & $\log 10$ \\
\hline Physicians in patient care & Positive & Inverse \\
\hline Rate of chlamydia & Positive & Square root \\
\hline Rate of gonorrhea & Positive & Square root \\
\hline Rate of syphilis & Positive & $\log 10$ \\
\hline Rate of syphilis of females & Positive & Log10+ Constant \\
\hline Rate of HIV diagnoses & Positive & $\log 10$ \\
\hline $\begin{array}{l}\text { Percentage of AIDS } \\
\text { diagnoses }\end{array}$ & Positive & $\log 10$ \\
\hline $\begin{array}{l}\text { Asians with AIDS } \\
\text { diagnoses }\end{array}$ & Positive & Inverse \\
\hline $\begin{array}{l}\text { Others with AIDS } \\
\text { diagnoses }\end{array}$ & Positive & Inverse \\
\hline $\begin{array}{l}\text { Other transmission of } \\
\text { AIDS }\end{array}$ & Positive & $\log 10$ \\
\hline
\end{tabular}

\section{Individual Level Data Screening}

Responses of don't know, not sure or refused to answer were all recoded to system missing. Cases that contained missing data on a nominal level of measurement were removed from the dataset. Due to missingness (over 30\%), emotional support and 
life satisfaction were not used in the model. For general health, missing values were replaced with the median value of 3 . For income, missing values were replaced with the median value of 6 . For urban/rural designation, missing values were replaced with the median value of 2 .

Univariate analyses were conducted to inspect the distribution of each variable in order to meet the assumptions of normality. Only one form correction ( $\log 10)$ was necessary for the age variable. Correlation analysis was run on the individual-level predictors to check for multicollinearity, and there was no issues identified.

\section{Description of Sample}

The final sample included 23,950 individuals on level 1, 204 yearly cohorts for 2008 to 2011 on level 2 , and a total of 51 states on level 3. This section will describe the study sample for each level presented in the multilevel structure of the study that was included in the final analysis.

\section{State-level Predictors}

\section{Predisposing Characteristics}

Descriptive statistics for level three predisposing, enabling, and need predictors, are presented in Table 9. 
Table 9

Level 3 State Predictors

\begin{tabular}{|c|c|c|c|}
\hline Variable & $\begin{array}{l}\text { Stat } \\
(\mathrm{N})\end{array}$ & & Range \\
\hline \multicolumn{4}{|c|}{ Predisposing Factors } \\
\hline$\%$ over age 65 & 51 & $13.2 \%(1.6)$ & $7.7-17.3 \%$ \\
\hline \multicolumn{4}{|l|}{ Social Structure } \\
\hline$\%$ of white females & 51 & $77.0 \%(13.8)$ & $25.0-95.6 \%$ \\
\hline$\%$ of African American females & 51 & $11.0 \%(11.1)$ & $0.4-52.9 \%$ \\
\hline$\%$ of Females married & 51 & $47.9 \%(4.3)$ & $22.8-56.6 \%$ \\
\hline $\begin{array}{l}\% \text { of African American females } \\
\text { married }\end{array}$ & 51 & $20.5 \%(11.0)$ & $0.0-33.4 \%$ \\
\hline$\%$ of Hispanic females married & 51 & $33.9 \%(19.4)$ & $0.0-52.7 \%$ \\
\hline$\%$ of Asian females married & 51 & $37.5 \%(28.6)$ & $0.0-65.5 \%$ \\
\hline$\%$ of Other females married & 51 & $11.9 \%(20.6)$ & $0.0-85.1 \%$ \\
\hline $\begin{array}{l}\text { White females with college } \\
\text { degrees }\end{array}$ & 51 & $29.5 \%(7.8)$ & $17.4-81.2 \%$ \\
\hline $\begin{array}{l}\% \text { of African American females } \\
\text { with college degrees }\end{array}$ & 51 & $17.0 \%(7.2)$ & $0.0-35.2 \%$ \\
\hline $\begin{array}{l}\% \text { of Hispanic females with } \\
\text { college degrees }\end{array}$ & 51 & $14.5 \%(5.5)$ & $0.0-33.8 \%$ \\
\hline $\begin{array}{l}\% \text { of Asian females with } \\
\text { college degrees }\end{array}$ & 51 & $41.0 \%(17.0)$ & $0.0-78.2 \%$ \\
\hline Crime rate, per 100,000 & 51 & $429.8(196.5)$ & 119.4-1437.7 \\
\hline Peace index & 51 & $2.5(0.6)$ & 1.3-3.9 \\
\hline$\%$ of very religious & 51 & $39.0 \%(8.9)$ & $19.1-58.4 \%$ \\
\hline$\%$ of Metropolitan status & 51 & $76.0 \%(17.9)$ & $30.0-100.0 \%$ \\
\hline \multicolumn{4}{|c|}{ Enabling Factors } \\
\hline $\begin{array}{l}\% \text { of Hispanic females } \\
\text { uninsured }\end{array}$ & 51 & $27.2 \%(14.4)$ & $0.0-65.2 \%$ \\
\hline Medicaid spending & 51 & $\$ 1,125.87(387.15)$ & $\$ 471.00-\$ 2,595.00$ \\
\hline Medicare spending & 51 & $\$ 9,777.72(1,241.31)$ & $\$ 7,576.00-\$ 11,903.00$ \\
\hline $\begin{array}{l}\text { Federal HIV/AIDS grant } \\
\text { funding }\end{array}$ & 51 & $\$ 4,137.70(1,584.37)$ & $\$ 2,728.00-\$ 10,053.00$ \\
\hline ADAP budget & 51 & $\begin{array}{l}\$ 42,892,375.19 \\
(82,434,981.99)\end{array}$ & $\begin{array}{r}\$ 289,092.00- \\
\$ 436,930,287.00\end{array}$ \\
\hline Physicians in patient care & 51 & $25.0(6.7)$ & $17.0-65.9$ \\
\hline $\begin{array}{l}\% \text { of HIV testing in health } \\
\text { departments }\end{array}$ & 51 & $52.2 \%(28.7)$ & $0.0-100.0 \%$ \\
\hline \multicolumn{4}{|c|}{ Need Factors } \\
\hline Rate of Syphilis among females & 51 & $0.9(1.7)$ & $0.0-10.9$ \\
\hline Rate of HIV diagnoses & 51 & $16.6(20.8)$ & $2.3-177.9$ \\
\hline $\begin{array}{l}\text { Rate of cumulative AIDS } \\
\text { diagnoses }\end{array}$ & 51 & $2.3(3.7)$ & $0.0-17.3 \%$ \\
\hline
\end{tabular}




\begin{tabular}{lcrr}
\hline $\begin{array}{l}\text { \% whites with AIDS diagnoses } \\
\% \text { of Hispanics with AIDS }\end{array}$ & 51 & $52.0 \%(19.0)$ & $17.0-90.0 \%$ \\
$\begin{array}{l}\text { diagnoses } \\
\text { \% of Asians with AIDS }\end{array}$ & 51 & $11.0 \%(8.9)$ & $1.0-41.0 \%$ \\
$\begin{array}{l}\text { diagnoses } \\
\begin{array}{l}\% \text { of Others with AIDS } \\
\text { diagnoses }\end{array}\end{array}$ & 51 & Less than $1.0 \%$ & $0.0-15.0 \%$ \\
$\begin{array}{l}\% \text { of MSM_IDU transmission } \\
\% \text { of Heterosexual transmission }\end{array}$ & 51 & $1.6 \%(3.7)$ & $0.0-26.0 \%$ \\
$\%$ of Other transmission & 51 & $8.1 \%(2.6)$ & $4.0-15.0 \%$ \\
& 51 & $17.3 \%(7.0)$ & $7.0-34.0 \%$ \\
\end{tabular}

Descriptive statistics for level two enabling and need predictors are presented in Table 10. 
Table 10

Level 2 State Cohort Predictors

\begin{tabular}{|c|c|c|c|c|c|}
\hline Variable & Year & States $(\mathbf{N})$ & $f$ & $\bar{\chi}(\mathrm{SD})$ & Range \\
\hline \multicolumn{6}{|c|}{ Enabling Factors } \\
\hline \multirow{4}{*}{ Percentage in Poverty } & 2008 & 51 & 4596 & $12.85(2.8)$ & $7.5-21.4$ \\
\hline & 2009 & 51 & 5072 & $13.9(3.0)$ & $8.5-21.9$ \\
\hline & 2010 & 51 & 5152 & $14.8(2.9)$ & $8.3-22.4$ \\
\hline & 2011 & 51 & 9130 & $15.2(3.2)$ & $8.8-22.6$ \\
\hline \multirow{4}{*}{$\begin{array}{l}\text { Percentage of } \\
\text { Uninsured }\end{array}$} & 2008 & 51 & 4596 & $13.54(4.3)$ & $4.10-23.5$ \\
\hline & 2009 & 51 & 5072 & $13.9(4.1)$ & $4.2-23.8$ \\
\hline & 2010 & 51 & 5152 & $14.59(4.4)$ & $4.4-23.7$ \\
\hline & 2011 & 51 & 9130 & $13.8(4.4)$ & $4.3-23.0$ \\
\hline \multicolumn{6}{|c|}{ Need Factors } \\
\hline \multirow{4}{*}{ Rate of Chlamydia } & 2008 & 51 & 4596 & $389.8(142.6)$ & $160.3-1177.0$ \\
\hline & 2009 & 51 & 5072 & $400.1(149.0)$ & $159.7-1106.0$ \\
\hline & 2010 & 51 & 5152 & 407 (128.8) & 185.9-932.0 \\
\hline & 2011 & 51 & 9130 & $436.2(138.0)$ & 228.6-1094.0 \\
\hline \multirow{4}{*}{ Rate of Gonorrhea } & 2008 & 51 & 4596 & $102.3(75.0)$ & $6.0-451.0$ \\
\hline & 2009 & 51 & 5072 & $108.3(90.9)$ & $7.2-432.7$ \\
\hline & 2010 & 51 & 5152 & $89.3(59.8)$ & $7.3-350.9$ \\
\hline & 2011 & 51 & 9130 & $91.9(65.0)$ & $7.7-426.9$ \\
\hline \multirow{4}{*}{ Rate of Syphilis } & 2008 & 51 & 4596 & $11.2(11.0)$ & $0.6-62.9$ \\
\hline & 2009 & 51 & 5072 & $11.1(11.7)$ & $0.2-72.8$ \\
\hline & 2010 & 51 & 5152 & $12.3(12.3)$ & $0.5-82.5$ \\
\hline & 2011 & 51 & 9130 & $11.6(12.4)$ & $0.5-91.7$ \\
\hline
\end{tabular}

Figures 11, 12, and 13 illustrate the distribution of the state-level predictors among the states. 


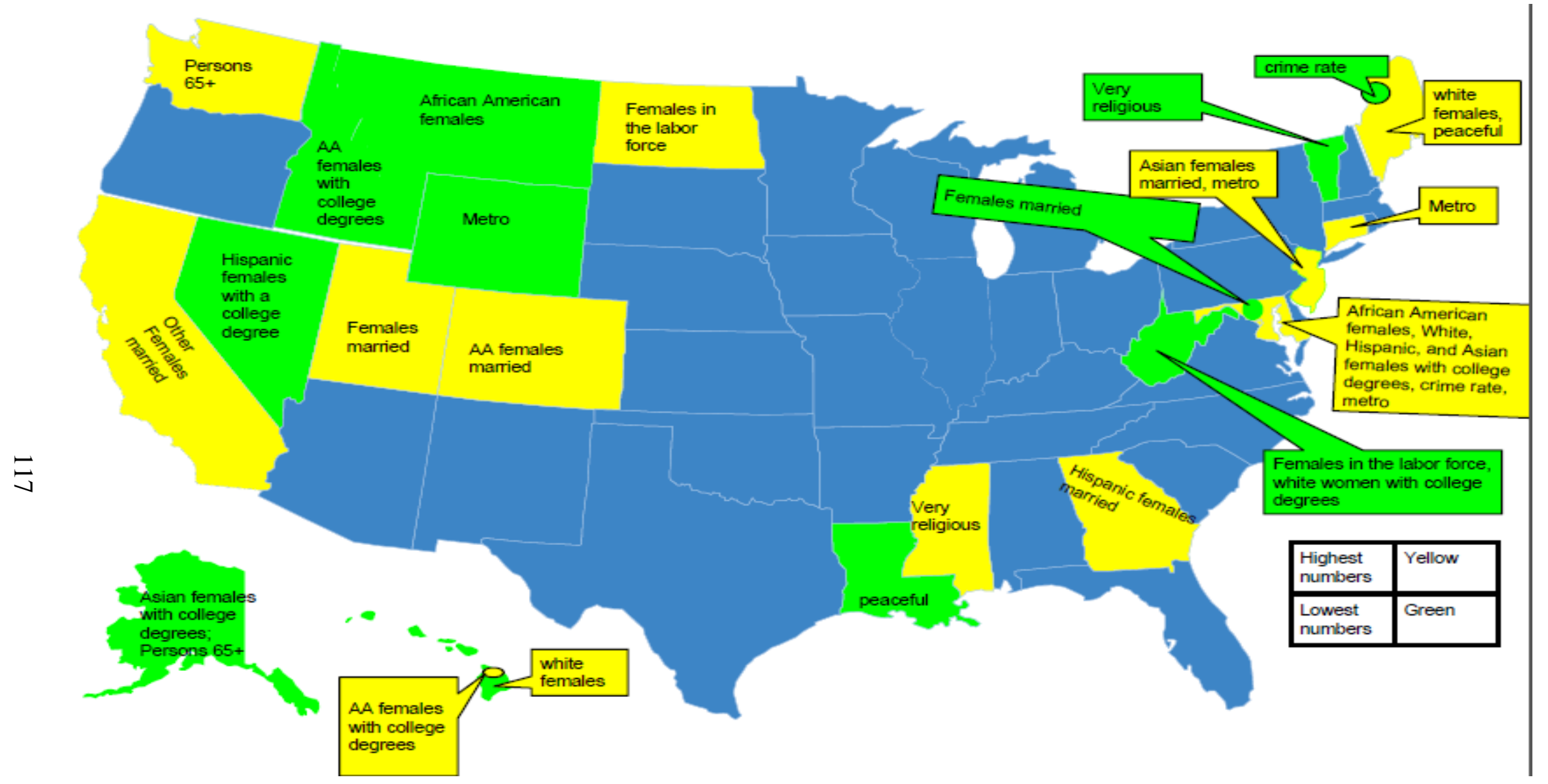

Figure 11. State-level predisposing demographic and social structure variables, highest and lowest states. 


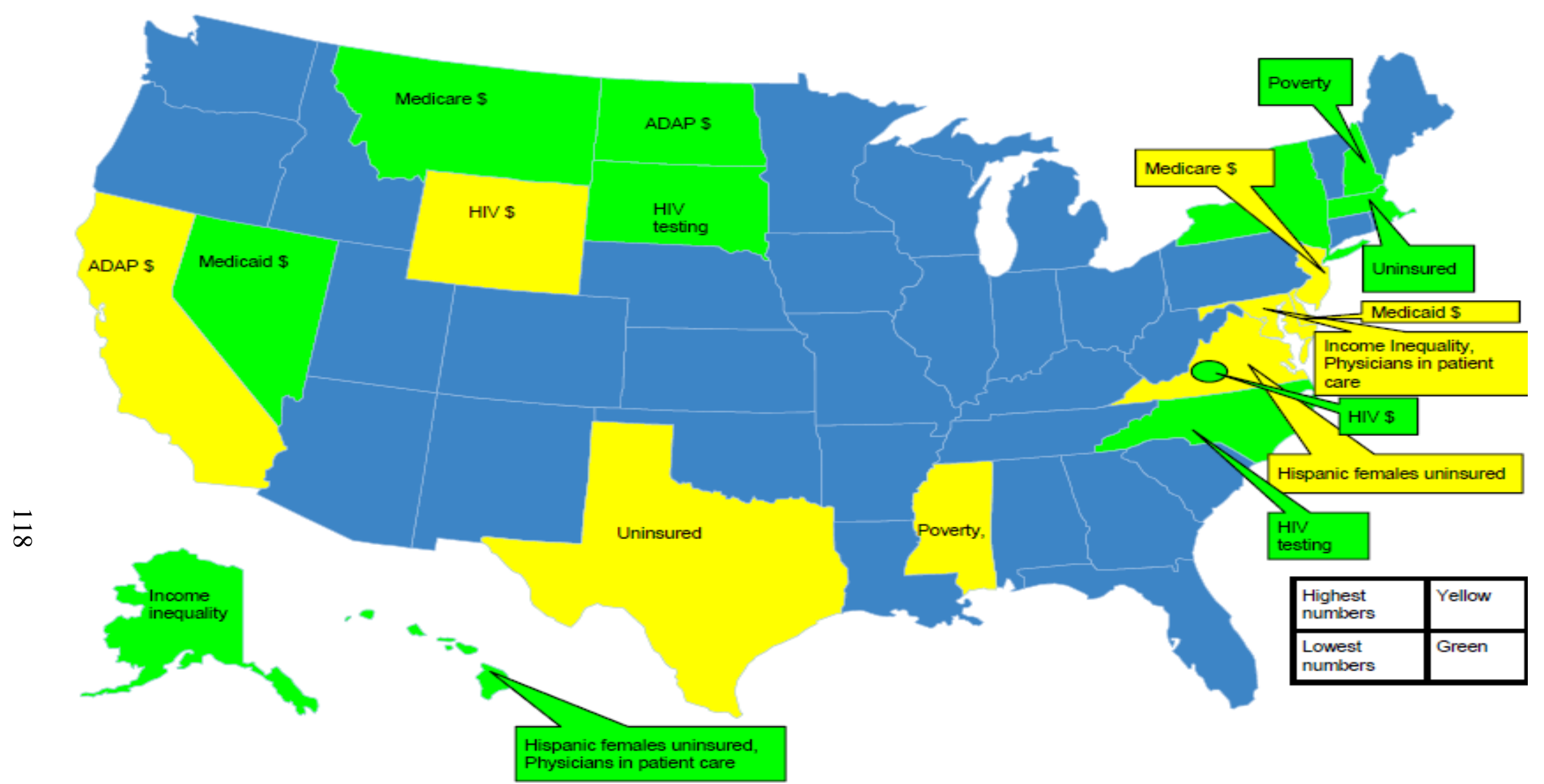

Figure 12. State-level enabling variables, highest and lowest states. 


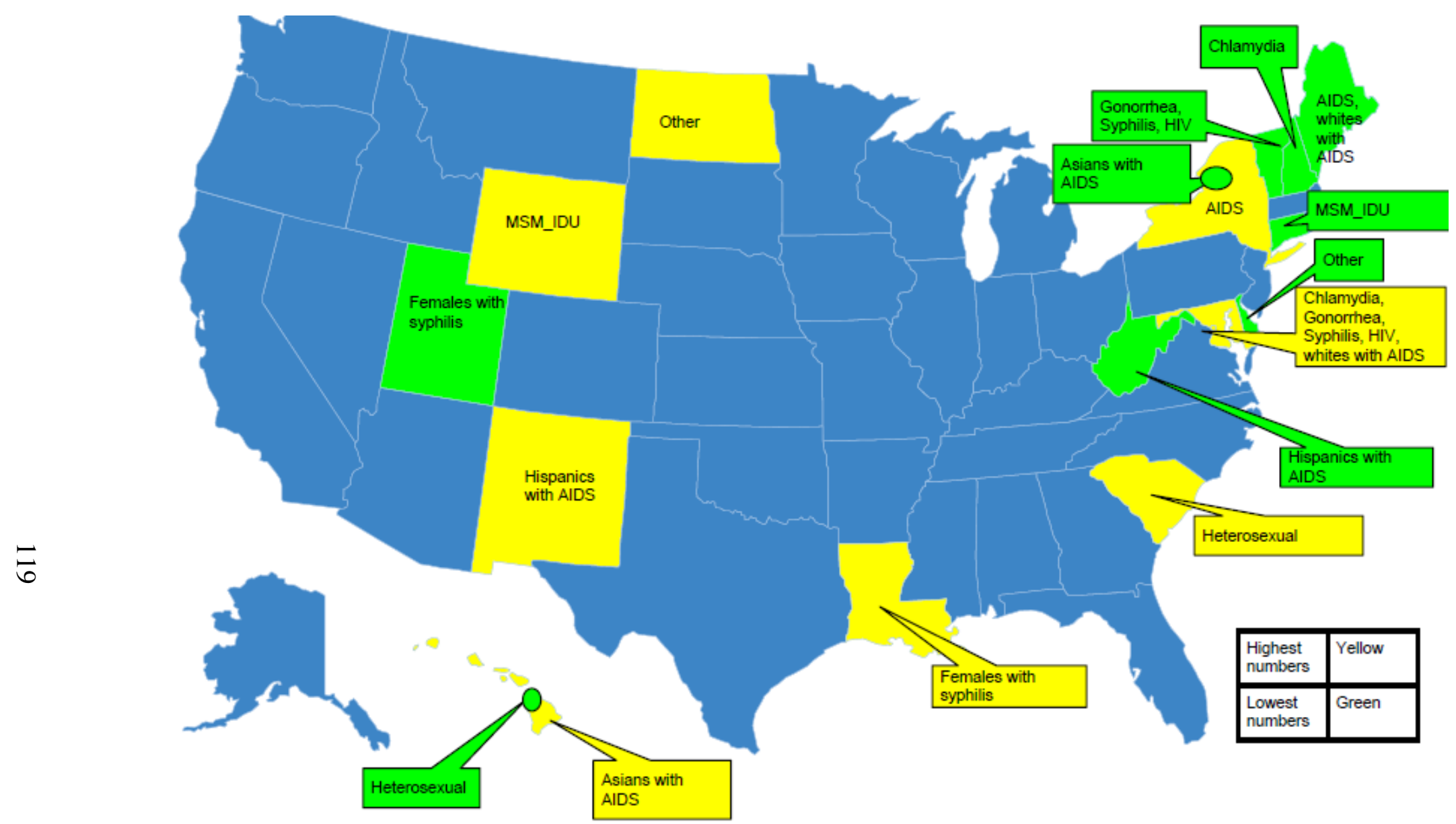

Figure 13. State-level need variables, highest and lowest states. 


\section{Individual Predictors}

\section{Predisposing Characteristics}

Tables 11 and 12 present both demographic and social structure characteristics of the sample on level 1. Over half of the sample consisted of females (56\%) with an average age of $59.2(\mathrm{SD}=7.7)$, ranging from 50 to 99 . Over half of the sample was in a committed relationship (55.6\%), non-Hispanic white $(80.2 \%)$, and over half $(63 \%)$ had some college education or more. Over half were either employed (43.4\%) or selfemployed (10.3\%) and lived in an urban area (54.6\%).

Of those that participated in HIV risk behaviors, slightly less than half (47\%) were female and on average 57.4 (6.5) years old. Just under half (44.7\%) were in a committed relationship and most where non-Hispanic white $(72.5 \%)$. Over half of this group had some college education or more (59.2\%), were employed or self-employed $(40.7 \% ; 10.0 \%)$, and lived in an urban area $(58 \%)$. 
Table 11

Level 1 Predisposing Demographic Characteristics $(\mathrm{N}=23,950)$

\begin{tabular}{lrrr}
\hline Variable & $\begin{array}{r}\text { Overall } \\
\mathbf{N = 2 3 , 9 5 0}\end{array}$ & $\begin{array}{r}\text { HIV risk } \\
\mathbf{n = 7 , 6 5 5}\end{array}$ & $\begin{array}{r}\text { Non-HIV risk } \\
\mathbf{n = 1 6 , 2 5 0}\end{array}$ \\
\hline & $\bar{x} / f(\mathrm{SD} / \%)$ & $\bar{x} / f(\mathrm{SD} / \%)$ & $\bar{x} / f(\mathrm{SD} / \%)$ \\
Age & $59.2(7.7)$ & $57.4(6.5)$ & $60(8.1)$ \\
Gender & & & \\
$\quad$ Females & $13,410(56.0)$ & $3,804(47.7)$ & $9,740(59.8)$ \\
$\quad$ Males & $10,540(44.0)$ & $3,851(52.3)$ & $6,510(40.2)$ \\
\hline
\end{tabular}

Table 12

Level 1 Predisposing Social Structure Characteristics $(\mathrm{N}=23,950)$

\begin{tabular}{lrrr}
\hline Variable & $\begin{array}{r}\text { Overall } \\
\mathbf{N = 2 3 , 9 5 0}\end{array}$ & $\begin{array}{r}\text { HIV risk } \\
\mathbf{n = 7 , 6 5 5}\end{array}$ & $\begin{array}{r}\text { Non-HIV risk } \\
\mathbf{n = 1 6 , 2 5 0}\end{array}$ \\
\hline Marital Status & & & \\
In a committed relationship & $13,308(55.6)$ & $3,418(44.7)$ & $9,890(60.7)$ \\
$\quad$ Not in a committed relationship & $10,642(44.4)$ & $4,237(55.3)$ & $6,360(39.3)$ \\
Race & & & \\
$\quad$ Non-Hispanic white & $19,203(80.2)$ & $5,547(72.5)$ & $13,656(83.8)$ \\
$\quad$ Non-Hispanic African American & $2,417(10.1)$ & $1,239(16.2)$ & $1,178(7.2)$ \\
Hispanic & $1,110(4.6)$ & $433(5.7)$ & $677(4.2)$ \\
$\quad$ Other & $1,220(5.1)$ & $436(5.7)$ & $784(4.8)$ \\
Education & & & \\
$\quad$ Less than high school & $2,060(8.6)$ & $931(12.2)$ & $1,129(6.9)$ \\
High school diploma & $6,784(28.3)$ & $2,190(28.6)$ & $4,594(28.2)$ \\
$\quad$ Some college or more & $15,106(63.1)$ & $4,534(59.2)$ & $10,752(64.9)$ \\
Employment status & & & \\
$\quad$ Employed & $10,385(43.4)$ & $3,118(40.7)$ & $7,267(44.6)$ \\
Self-employed & $2,476(10.3)$ & $764(10.0)$ & $1,712(10.5)$ \\
Homemaker/student & $1,088(4.5)$ & $273(3.6)$ & $815(5.0)$ \\
$\quad$ Unemployed & $4,549(19.0)$ & $2,180(28.5)$ & $2,369(14.5)$ \\
$\quad$ Retired & $5,452(22.8)$ & $1,320(17.2)$ & $4,132(25.4)$ \\
Residence & & & \\
$\quad$ Lived in an urban area & $13,072(54.6)$ & $4,441(58)$ & $8,631(53)$ \\
Lived in a suburban area & $2,913(12.2)$ & $847(11.1)$ & $2,066(12.7)$ \\
Lived in a rural area & $7,965(33.3)$ & $2,367(30.9)$ & $5,598(34.4)$ \\
\hline
\end{tabular}




\section{Enabling Resources}

Table 13 present the descriptive statistics for enabling resources of the sample on level 1 . The majority of the sample had healthcare coverage $(88.6 \%)$, no cost barriers to seek care (86\%), a regular healthcare provider (89.6\%), and had a checkup within the past year (74.7\%). Most had incomes between $\$ 30,000$ and $\$ 50,000$ annually $(56.9 \%)$.

Of those who participated in HIV risk behaviors, the majority also had healthcare coverage $(85.4 \%)$, no cost barriers to seek care $(80.3 \%)$, a regular healthcare provider (87.9\%), and had a checkup within the past year (73.5\%). Nearly one-fourth $(20.8 \%)$ had incomes between $\$ 35,000$ and $\$ 50,000$ annually. 
Table 13

Level 1 Enabling Resource Characteristics of Study Population $(\mathrm{N}=23,950)$

\begin{tabular}{|c|c|c|c|}
\hline Variables & $\begin{array}{r}\text { Overall } f(\%) \\
\mathrm{N}=23,950\end{array}$ & $\begin{array}{r}\text { HIV risk } f(\%) \\
n=7,655\end{array}$ & $\begin{array}{r}\text { Non-HIV risk } f \\
(\%) \\
n=16,250\end{array}$ \\
\hline \multicolumn{4}{|l|}{ Have any healthcare coverage } \\
\hline Yes & $21,226(88.6)$ & $6,540(85.4)$ & $14,686(90.1)$ \\
\hline No & $2,724(11.4)$ & $1,115(14.6)$ & $1,609(9.9)$ \\
\hline \multicolumn{4}{|l|}{$\begin{array}{l}\text { Cost was a barrier to seeking } \\
\text { care }\end{array}$} \\
\hline Yes & $3,354(14.0)$ & $1,509(19.7)$ & $1,845(11.3)$ \\
\hline No & $20,596(86.0)$ & $6,146(80.3)$ & $14,450(88.7)$ \\
\hline \multicolumn{4}{|l|}{$\begin{array}{l}\text { Has a regular healthcare } \\
\text { provider }\end{array}$} \\
\hline Yes & $21,459(89.6)$ & $6,730(87.9)$ & $14,729(90.4)$ \\
\hline No & 2,491 (10.4) & $925(12.1)$ & $1,566(9.6)$ \\
\hline \multicolumn{4}{|l|}{$\begin{array}{l}\text { Length of time since last } \\
\text { routine check up }\end{array}$} \\
\hline Never had a checkup & $198(0.8)$ & $69(0.9)$ & $129(0.8)$ \\
\hline $\begin{array}{l}\text { Checkup within the past } \\
\text { year }\end{array}$ & $17,897(74.7)$ & $5,623(73.5)$ & $12,274(75.3)$ \\
\hline Checkup within past 2 years & $2,677(11.2)$ & $865(11.3)$ & $1,812(11.1)$ \\
\hline Checkup within past 5 years & $1,521(6.4)$ & $511(6.7)$ & $1,010(6.2)$ \\
\hline $\begin{array}{l}\text { Checkup more than } 5 \text { years } \\
\text { ago }\end{array}$ & $1,657(6.9)$ & $587(7.7)$ & $1,070(6.6)$ \\
\hline \multicolumn{4}{|l|}{ Household Income } \\
\hline Less than $\$ 10,000$ & $1,536(6.4)$ & $731(9.5)$ & 805 (4.9) \\
\hline Less than $\$ 15,000$ & $1,554(6.5)$ & $641(8.4)$ & $913(5.6)$ \\
\hline Less than $\$ 20,000$ & $1,674(7.0)$ & $599(7.8)$ & $1,075(6.6)$ \\
\hline Less than $\$ 25,000$ & $2,062(8.6)$ & $649(8.5)$ & $1,413(8.7)$ \\
\hline Less than $\$ 35,000$ & $2,639(11.0)$ & 804 (10.5) & $1,835(11.3)$ \\
\hline Less than $\$ 50,000$ & $4,159(17.4)$ & $1,591(20.8)$ & $2,568(15.8)$ \\
\hline Less than $\$ 75,000$ & 3,801 (15.9) & $959(12.5)$ & $2,842(17.4)$ \\
\hline More than $\$ 75,000$ & $6,525(27.2)$ & $1,681(22.0)$ & $4,844(29.7)$ \\
\hline
\end{tabular}

\section{Need Factors}

Table 14 present the descriptive statistics for need factors of the sample on level

1. Most of the sample population reported being healthy, with $29.8 \%$ reporting good health, $30.5 \%$ reporting great health, and $16.1 \%$ reporting excellent health. Over half (58.1\%) also reported not having any days that their physical health was not good in the 
past month. Over half (53.4\%) reported consuming alcoholic beverages in the past month.

For those who participated in HIV risk behaviors, most of this group reported being healthy, with $30.1 \%$ reporting good health, $25.8 \%$ reporting great health, and $13.1 \%$ reporting excellent health. Nearly half $(49.4 \%)$ also reported not having any days that their physical health was not good in the past month. Over half (57.2\%) reported consuming alcoholic beverages in the past month. 
Table 14

Level 1 Need Characteristics of Study Population $(\mathrm{N}=23,950)$

\begin{tabular}{lrrr}
\hline Variables & $\begin{array}{r}\text { Overall f (\%) } \\
\text { N=23,950 }\end{array}$ & $\begin{array}{r}\text { HIV risk f (\%) } \\
\mathbf{n = 7 , 6 5 5}\end{array}$ & $\begin{array}{r}\text { Non-HIV risk } \\
\mathbf{f}(\%) \\
\mathbf{n = 1 6 , 2 5 0}\end{array}$ \\
\hline Mental health & & & \\
0 days not good & $15,385(64.2)$ & $4,100(53.6)$ & $11,285(69.3)$ \\
1-15 days was not good & $5,999(25.0)$ & $2,369(30.9)$ & $3,630(22.3)$ \\
16-30 days was not good & $2,566(10.7)$ & $1,186(15.5)$ & $1,380(8.5)$ \\
General health & & & \\
Excellent & $3,857(16.1)$ & $1,006(13.1)$ & $2,851(17.5)$ \\
Very good & $7,308(30.5)$ & $1,977(25.8)$ & $5,331(32.7)$ \\
Good & $7,128(29.8)$ & $2,305(30.1)$ & $4,823(29.6)$ \\
Fair & $3,728(15.6)$ & $1,480(19.3)$ & $2,248(13.8)$ \\
Poor & $1,929(8.1)$ & $887(11.6)$ & $1,042(6.4)$ \\
Physical health & & & \\
0 days not good & $13,924(58.1)$ & $3,781(49.4)$ & $10,143(62.2)$ \\
1-15 days was not good & $6,682(27.9)$ & $2,438(31.8)$ & $4,244(26.0)$ \\
16-30 days was not good & $3,344(14.0)$ & $1,436(18.8)$ & $1,908(11.7)$ \\
Alcoholic beverages in the past & & & \\
30 days & & & \\
Yes & $12,801(53.4)$ & $4,380(57.2)$ & $8,421(51.7)$ \\
No & $11,149(46.6)$ & $3,275(42.8)$ & $7,874(48.3)$ \\
\hline
\end{tabular}

\section{Outcome Variable}

Table 15 presents the descriptive statistics for HIV risk behavior of the sample on level 1 across the sample years. Of the entire sample, one-third (31.9\%) participated in HIV risk behaviors. Based on the results of the aforementioned tables, it can be seen that more males participated in HIV risk behaviors than women during the study years, less persons were in committed relationships, more persons were from racial minority groups, had less education, a lower percentage were employed, and more lived in urban areas when compared to those who did not participate in HIV risk behaviors. Those who participated in HIV risk behaviors usually had healthcare insurance, cost was not a barrier 
to seeking care, and they had a regular care provider. Most had a routine checkup in the past year and an income of less than $\$ 50,000$. They also reported that on average, their general health was good and had 1-15 days that their physical health was not good in the past month. Lastly, consumption of alcoholic beverages was higher for this group than for those who did not participate in HIV risk behaviors. These types of patterns reflect some of the dynamics related to gender and power and cumulative inequality.

Table 15

Study Participants per Year on the Outcome Variable

\begin{tabular}{lrrr}
\hline \multicolumn{4}{c}{ Study Participants Per Year } \\
\hline Year & Overall & HIV risk behavior & No HIV risk behavior \\
& $\boldsymbol{f}(\boldsymbol{\%})$ & $\boldsymbol{f}(\boldsymbol{\%})$ & $\boldsymbol{f}(\boldsymbol{\%})$ \\
2008 & $4,596(19.1)$ & $1,541(33.5)$ & $3,055(66.5)$ \\
2009 & $5,072(21.1)$ & $1,794(35.4)$ & $3,278(64.6)$ \\
2010 & $5,152(21.5)$ & $1,766(34.3)$ & $3,386(65.7)$ \\
2011 & $9,130(38.1)$ & $2,554(28)$ & $6,576(72.0)$ \\
& & & \\
Total & $23,950(100.0)$ & $7,655(31.9)$ & $16,295(68.0)$ \\
\hline
\end{tabular}

The next section describes the model building process. First preliminary considerations linked to multilevel structure of data are discussed. Following the considerations, the specifics of building several sub-models and the final model are defined. Discussion of the results is guided by the three research questions.

\section{Model Building}

\section{Assessing the Need for the Multilevel Model}

An easy way to initially assess patterns of change in a study population is to graph actual growth trajectories for a sample of cases and visually inspect them (Singer \& 
Willett, 2003). Based on the outcome variable the percentages of respondents who participated in HIV risk behavior were plotted for the 51 states. The percentage is represented in Figure 14. With the individual growth plots, several observations can be made. First, some states (e.g., Alabama, Arizona, Tennessee) displayed a steady increase in HIV risk behaviors over time. Others displayed a sharp increase after the first study year (e.g., California, Georgia, New Jersey). Others fluctuated (e.g., Colorado, North Carolina), and fewer decrease (e.g., Wyoming).
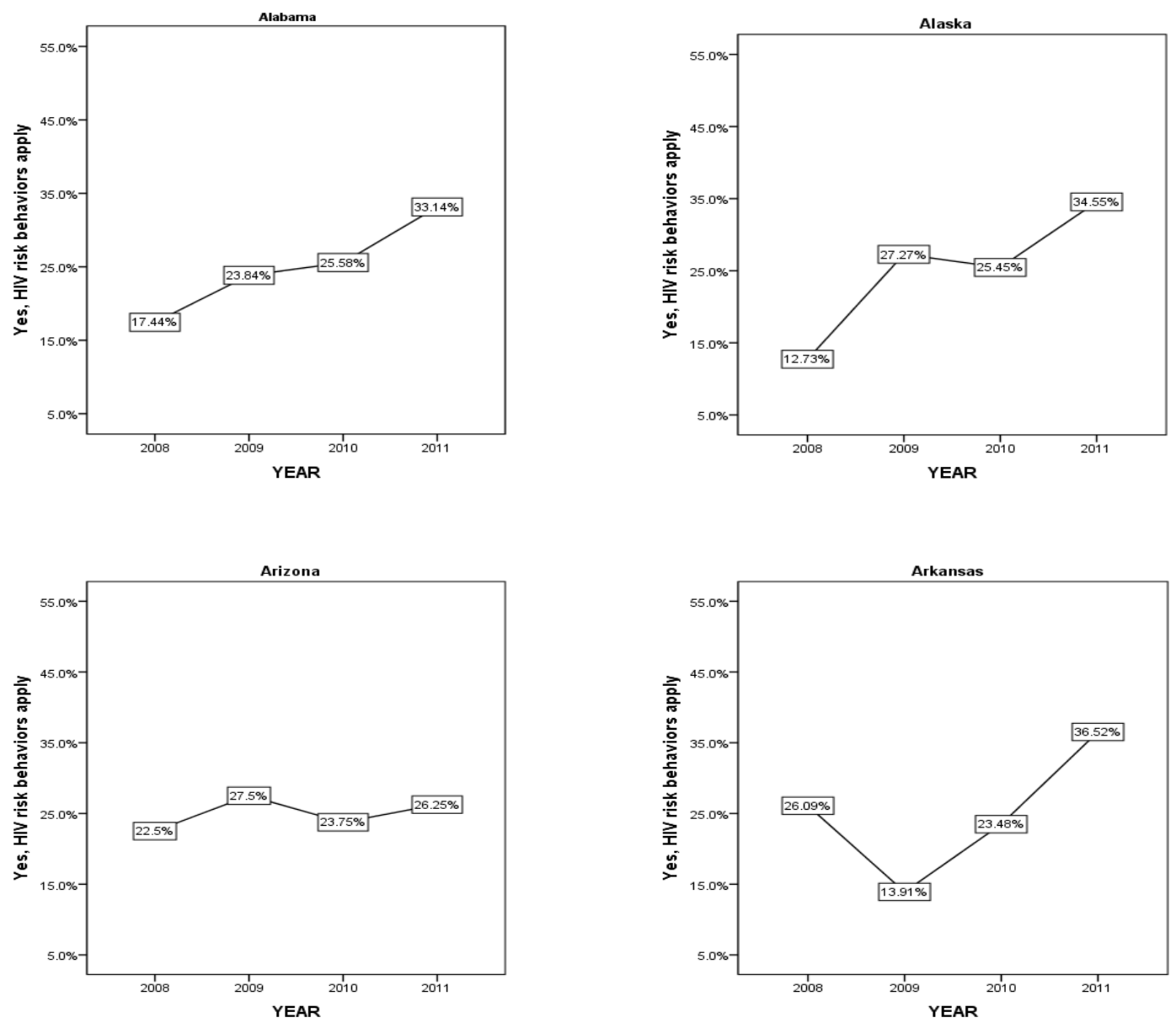

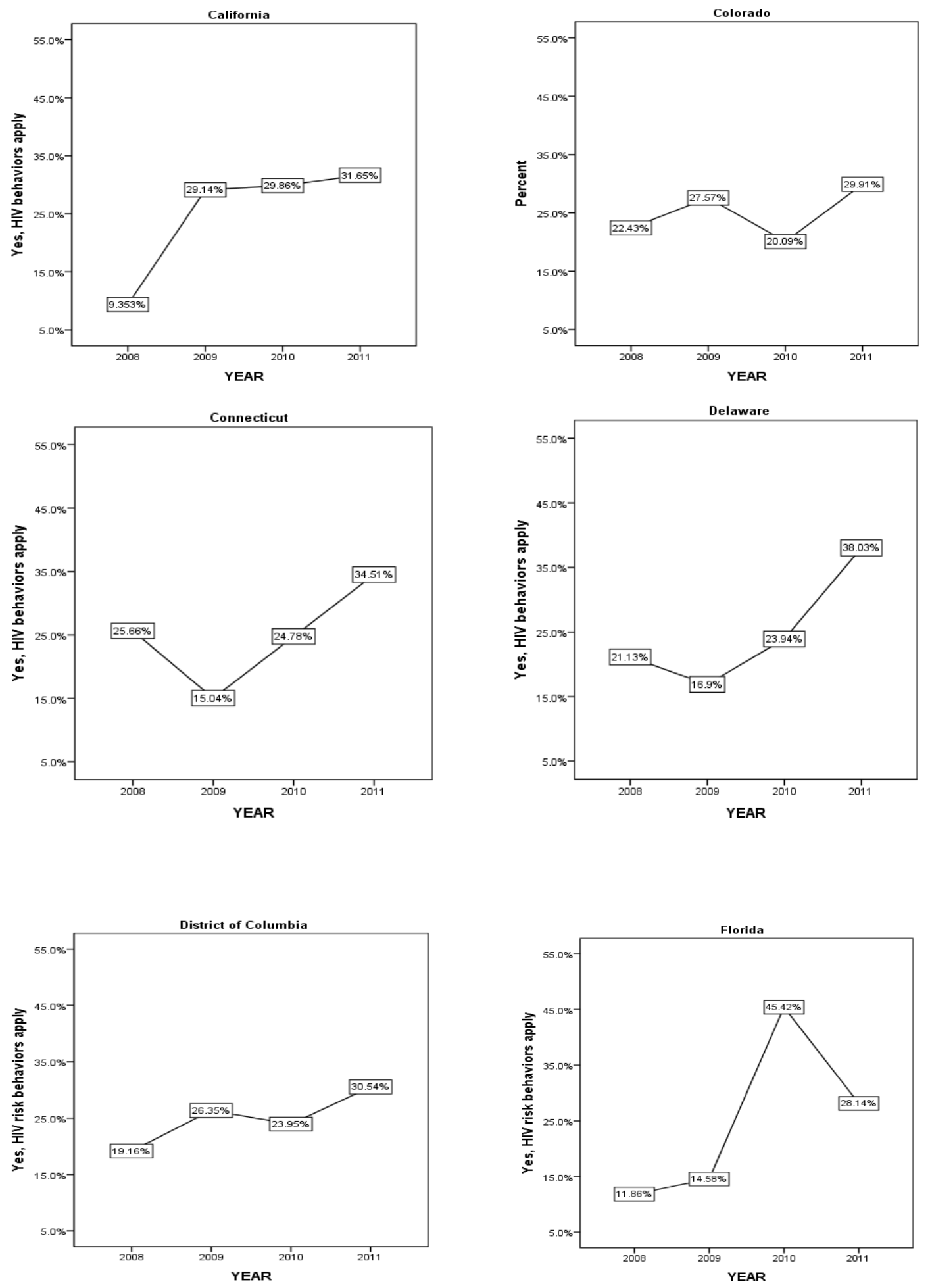

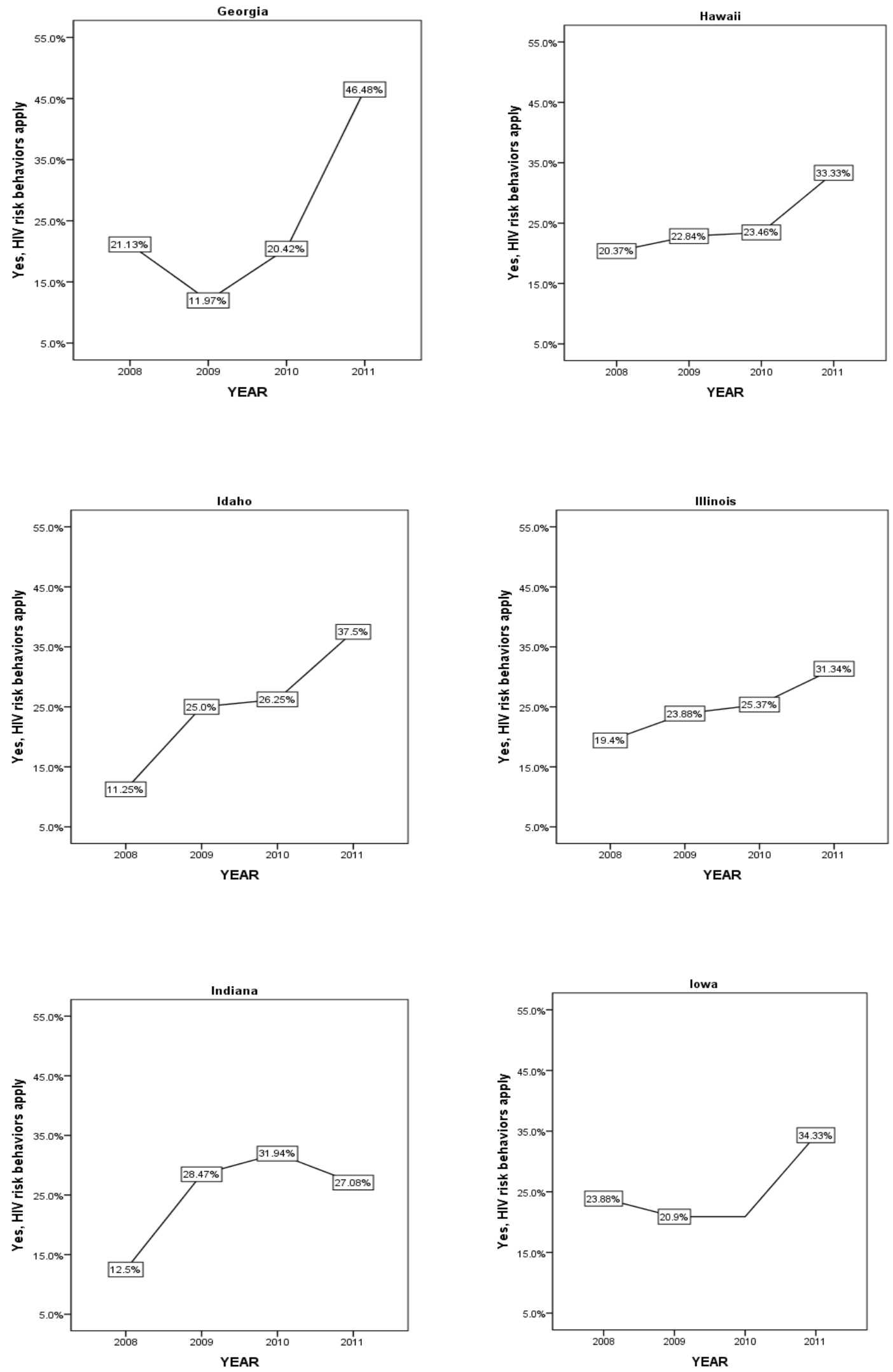

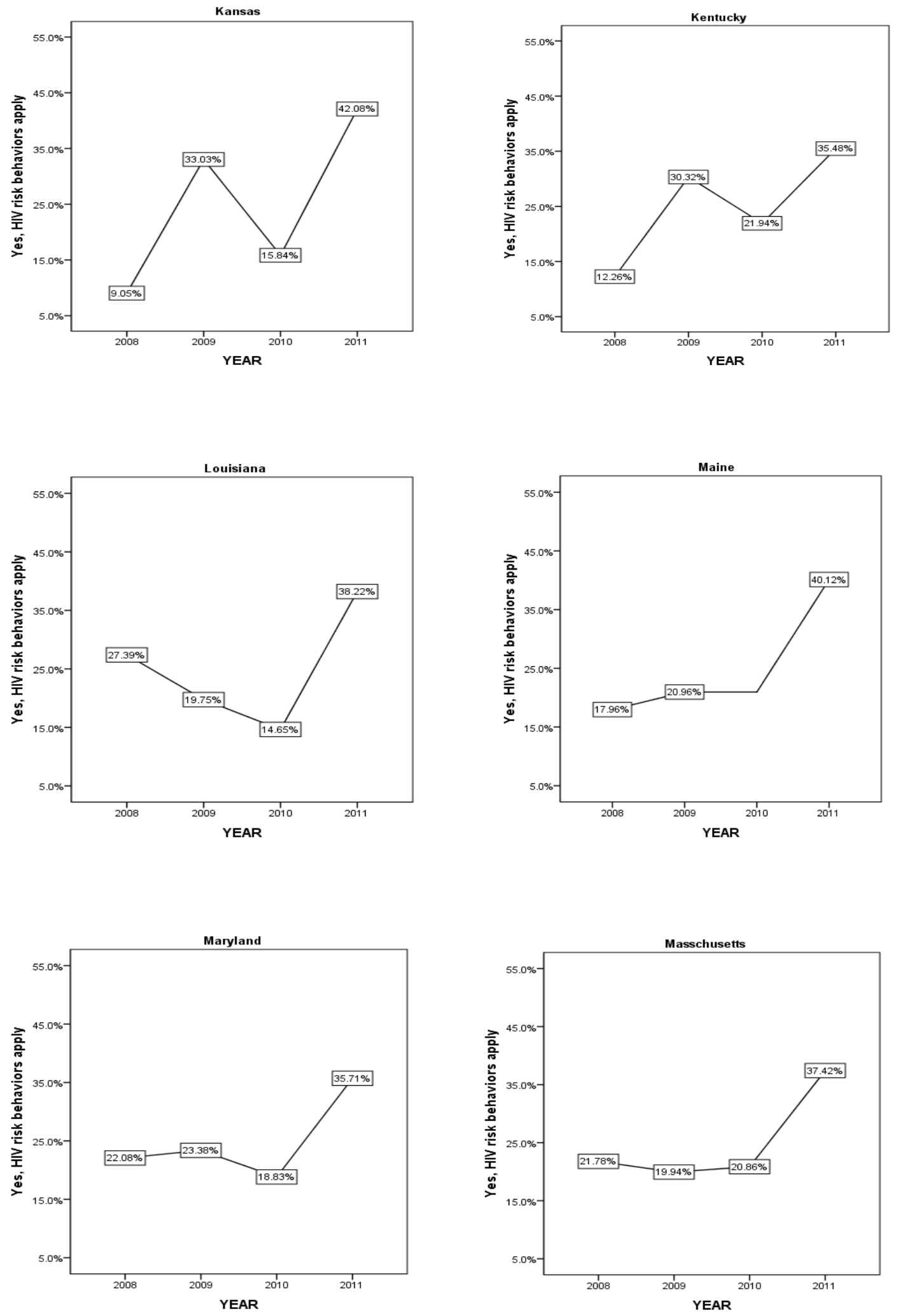

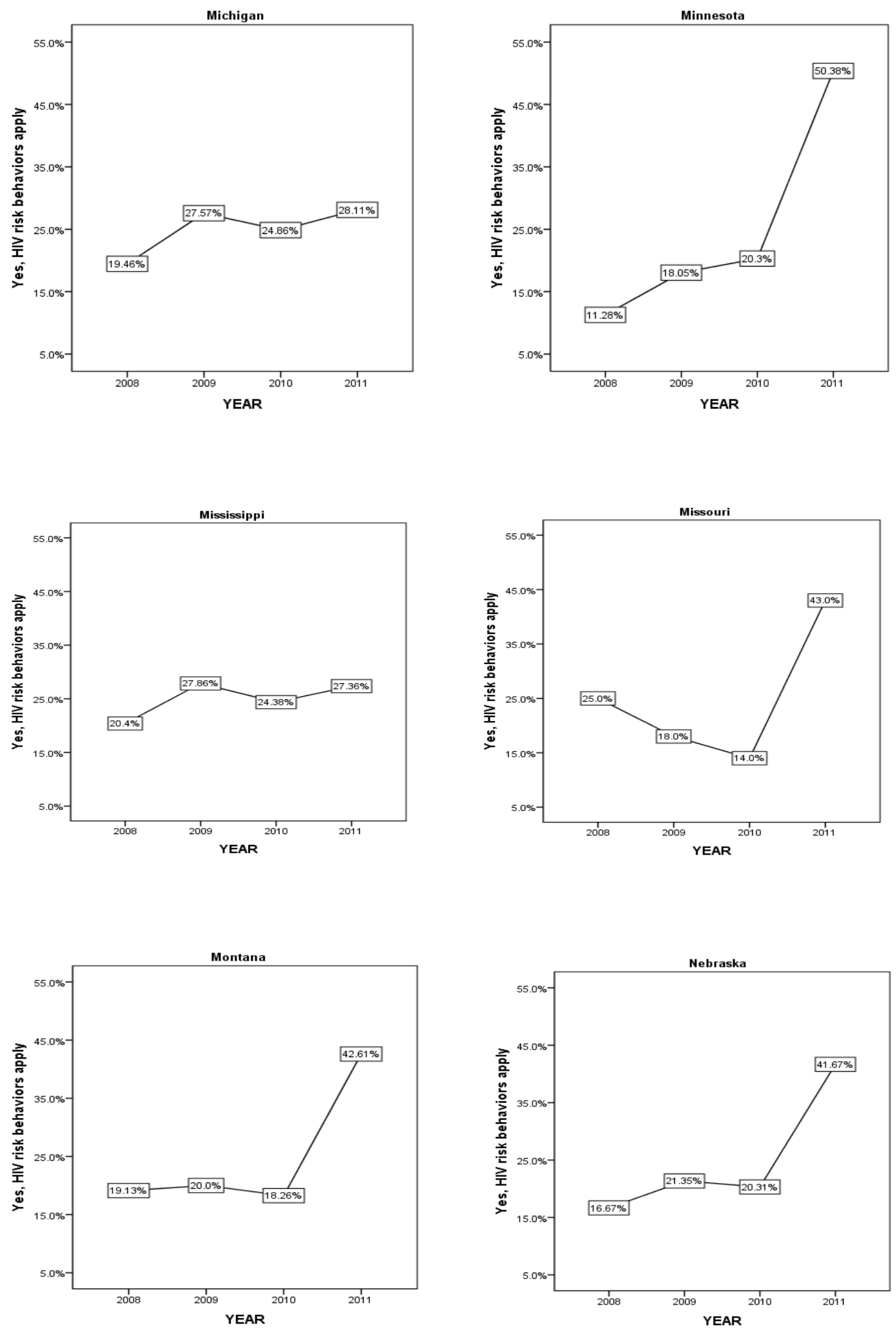

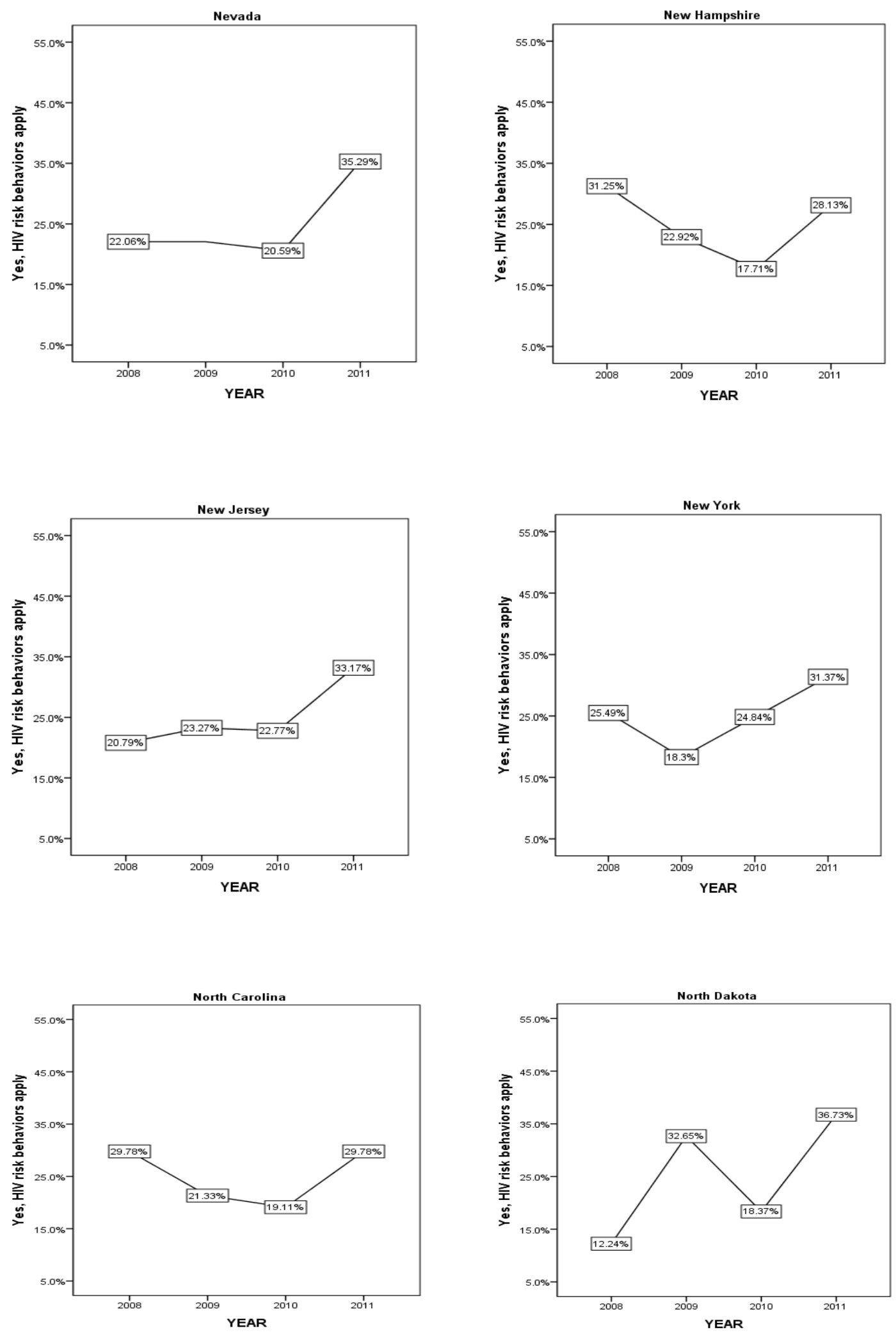

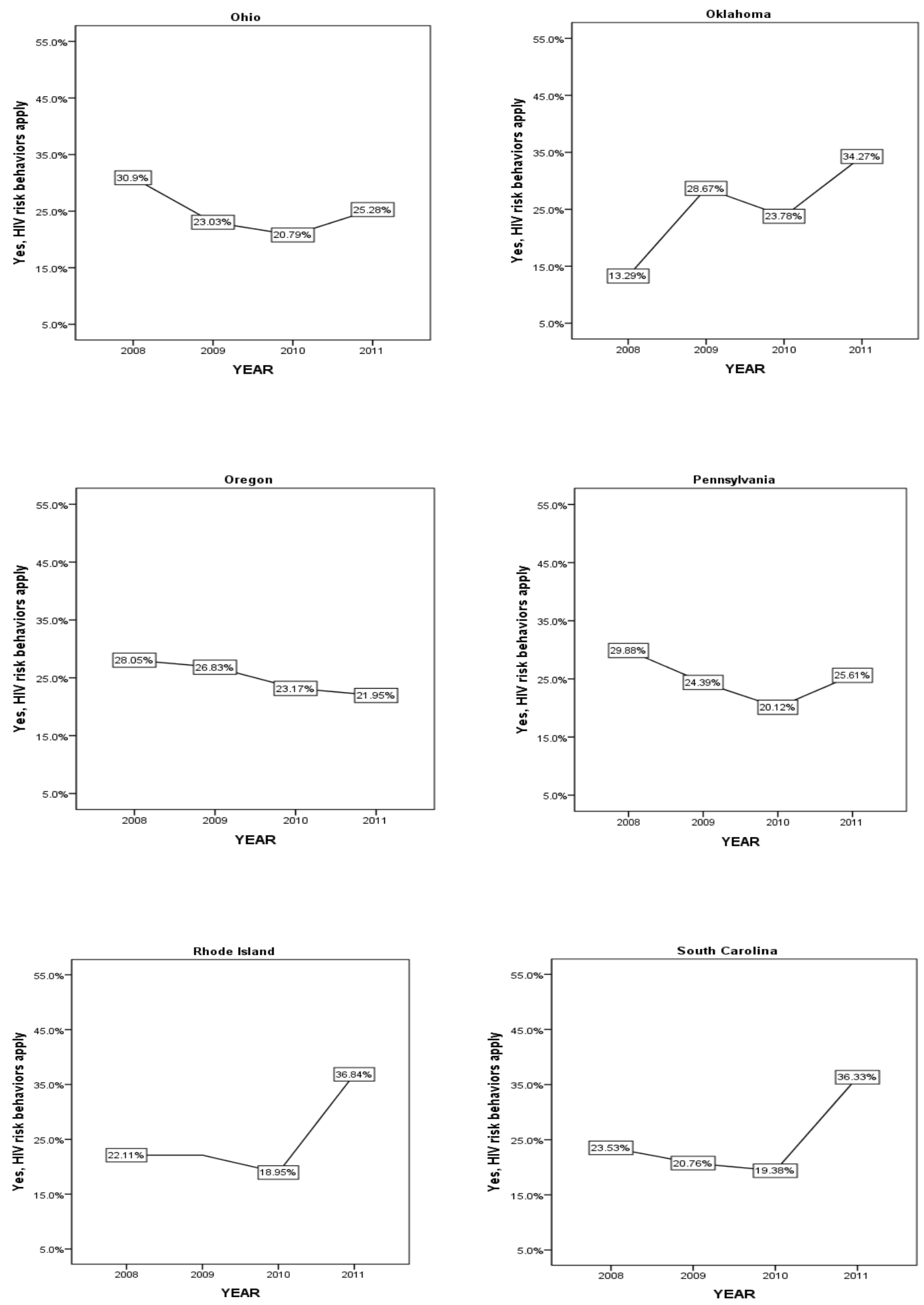

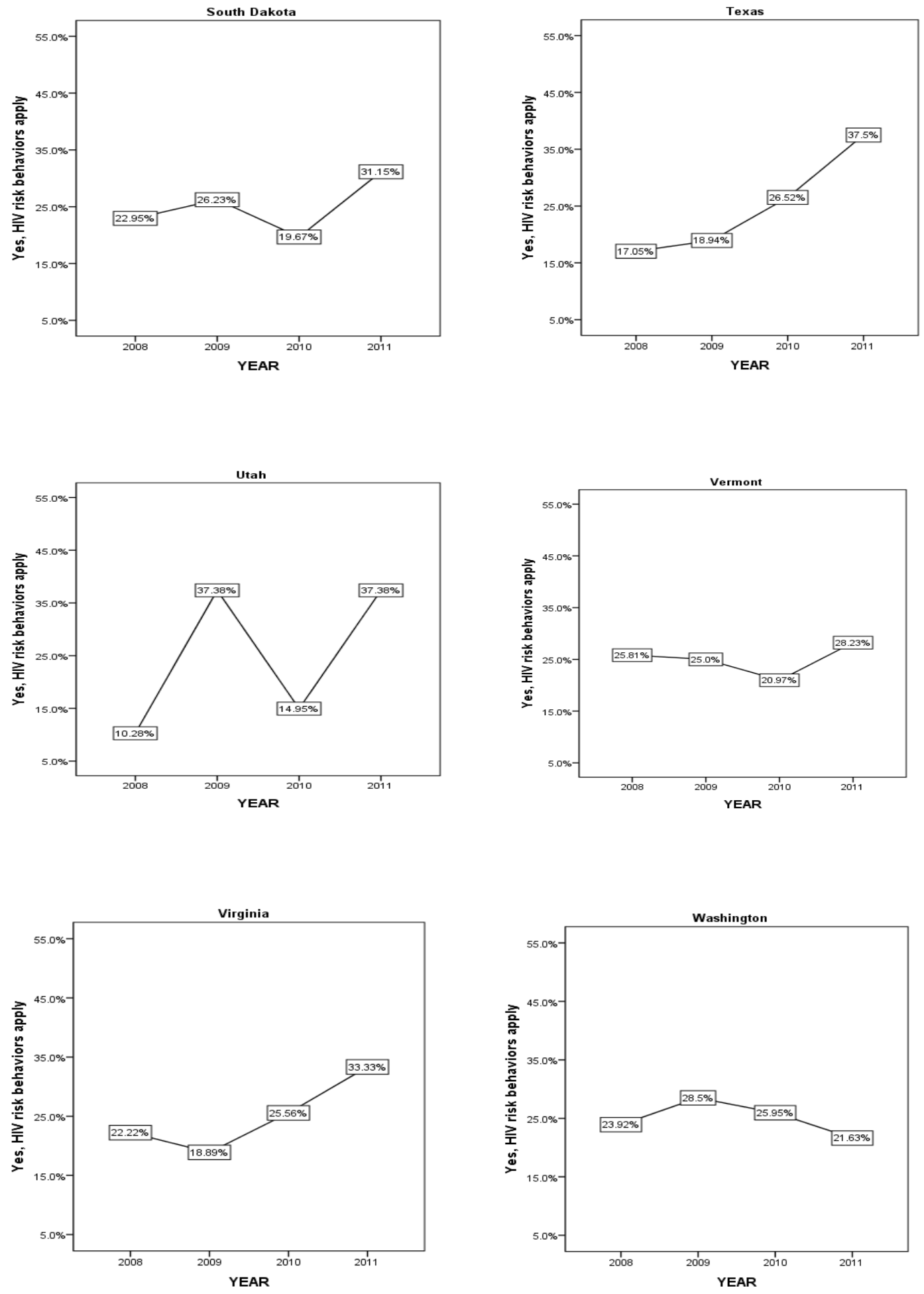

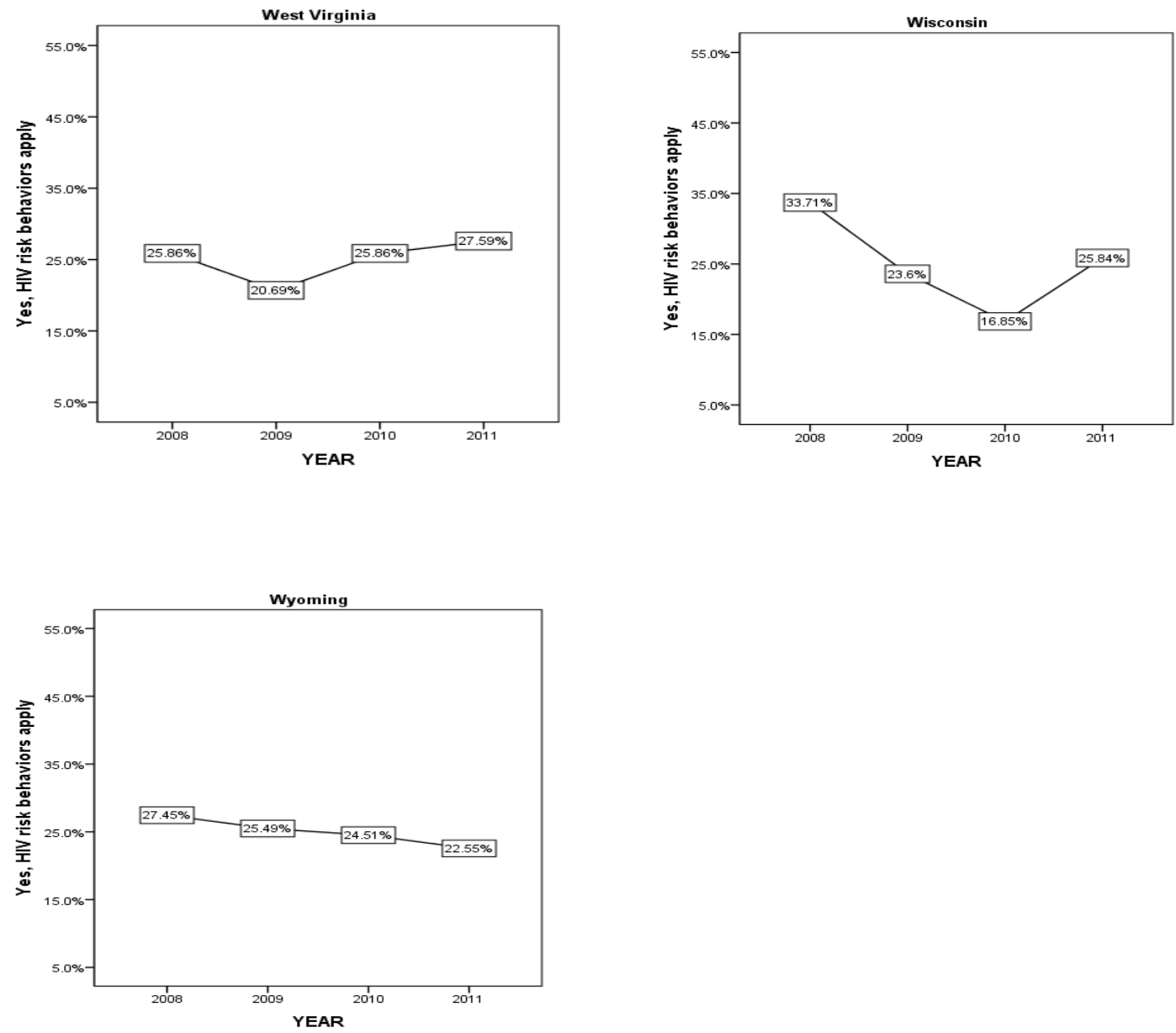

Figure 14. Empirical growth plots for state HIV risk behaviors over time.

\section{Unconditional Model}

Fitting the unconditional model (null), which describes the probability of expecting HIV risk behaviors across states (model A), was accomplished using the equation in Figure 15. 
HIVRISK $2_{i j} \sim$ Binomial $\left(\right.$ Constant $\left._{i j k}, \pi_{i j k}\right)$

$\operatorname{logit}(\pi i j k)=\beta_{0 j k}$ Constant

$\beta_{0 j k}=\beta_{0}+v_{o k}+u_{0 j k}$

$\left[v_{0 k}\right] \sim \mathrm{N}\left(0, \Omega_{v}\right): \Omega_{v}=\left[\sigma^{2} v_{0}\right]$

$\left[u 0_{0 j k}\right] \sim \mathrm{N}\left(0, \Omega_{u}\right): \Omega_{\underline{u}}=\left[\sigma^{2} u 0\right]$

$\operatorname{var}\left(\operatorname{HIVRISK} 2_{i j k} \mid \pi_{i j k}\right)=\pi_{i j k}\left(1-\pi_{i j k}\right) /$ Constant $_{i j k}$

Figure 15. Null model.

Table 16 provides details on the estimated intercept, standard errors, and model fit for the three level null model. As mentioned earlier, there were 23,950 individuals on level 1, 204 state cohorts on level 2, and 51 states on level 3.

Table 16

Unconditional model (null model)

\begin{tabular}{lrr}
\hline & & Model A \\
\hline & & Fixed effects \\
Constant & & (S.E.) \\
& Random Parameters & $-0.763 * * *(0.04)$ \\
Level 3: STATE & & \\
Constant/Constant & & $0.059 * * *(0.02)$ \\
Level 2: YEAR & & \\
Constant/Constant & & $0.040 * * *(0.01)$ \\
DIC: & 29682.69 \\
pD: & 114.13 \\
\hline
\end{tabular}

Note: Standard errors are in parentheses. DIC: Diagnostic Information Criterion; pD: estimated degrees of freedom; ${ }^{* * *} p<0.001 ; * * p<0.01$

With the null model (Model A, Table 16), the "success" being modeled is that of participating in HIV risk behavior. The results of the fixed part in Table 13 indicate that for the null model, without any predictors, the log-odds of engaging in HIV risk behavior 
is -0.76 , which corresponds to a probability of $\exp (-0.76) /[1+\exp (-0.76)]=0.32$.

An important aspect that should receive attention with model building is the intraclass correlation (ICC), as it measures the proportion of total variance that is due to differences in groups and estimates of the amount of variability at a specified level (e.g., level-3, level-2) (Steele, 2008). This is calculated by using the specified level variance divided by the total variance present in the model. With the use of a logistic model, the level one residuals are expected to follow the standard logistic distribution with a mean of 0 and a variance of $\pi^{2} / 3=3.29$ (O'Connell, 2010). Table 13 shows that the variance at level 3 (state level) was 0.059 . Therefore, about $1.8 \%$ percent of the total variance $[(0.059 / 3.29+0.059+0.040)=0.018]$ was between states, indicating that there were indeed some differences in individual HIV risk behaviors between the different states. Based on the Wald test, the Chi-square statistic for the variance component was 11.30 on 1 degree of freedom. The critical value for a chi square test at the $5 \%$ level is 3.84 , therefore, strong evidence was seen that the between-state variance was non-zero. In other words, it is concluded that there was significant variation between states in the probability of participating in HIV risk behaviors.

Table 13 shows that the variance at level 2 (state cohort level) was 0.040 . Therefore, about $1.2 \%$ of the total variance $[(0.040 / 3.29+0.059+0.040)=0.012]$ was between state cohorts, indicating that just over 1\% change took place between 2008 and 2011 within different states between the different cohorts in relation to their participation in individual HIV risk behaviors. Based on the Wald test, the Chi-square statistic for the variance component was 15.61 on 1 degree of freedom, providing strong evidence that 
the between-cohort variance was non-zero. In other words, it is concluded that there was significant variation within states between state cohorts in the probability of participating in HIV risk behaviors.

The Deviance Information Criterion (DIC) is used as an analytical method to assess the fit of models estimated with MCMC methods. DIC is utilized to determine the most parsimonious model based on both fit and complexity (Neelon, O'Malley, \& Normand, 2010). Therefore, this is a comparative number where lower values are indicative of a more parsimonious model. Since the DIC is already penalized for model complexity, it is not compared to a frequency distribution. Instead, the DIC values can be compared to one another. Lower values indicate a better and a more parsimonious model. There needs to be a decrease of at least ten points for a DIC value to be considered a significant improvement (Jones, 2012). The DIC value for the null model (Model A, Table 13) equals 29682.69.

Figure 16 plots and rank-orders the estimated residuals of the 51 states with $95 \%$ confidence intervals. The line represents the mean log-odds of participating in HIV risk behaviors, so those who do not overlap the line are said to differ significantly from the average at the 5\% level (Steele, 2009). 


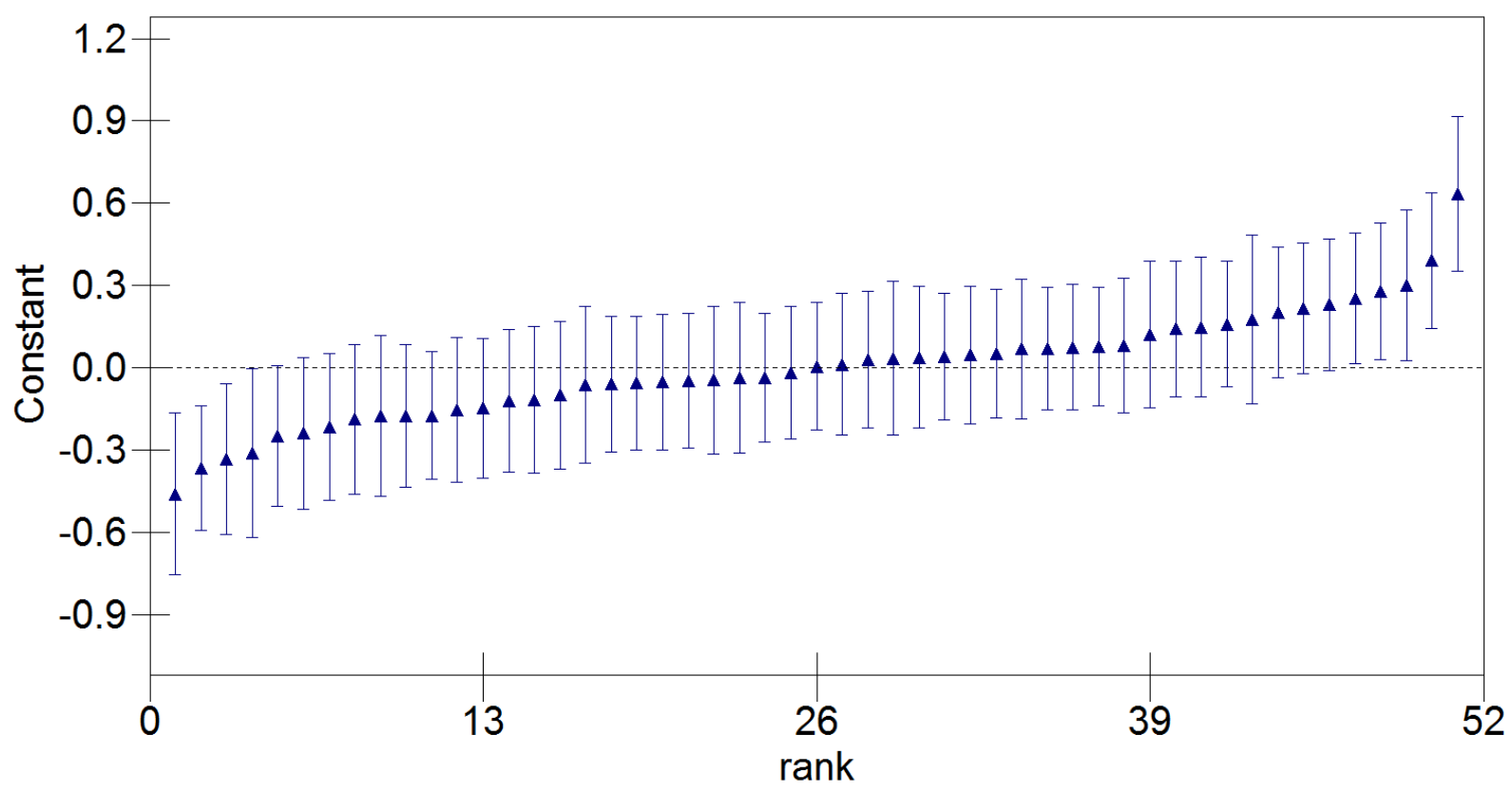

Figure 16. Caterpillar plot showing state residuals with $95 \%$ confidence intervals for log odds of participating in HIV risk behaviors.

Citizens in four states showed significantly lower probability than the average states of participating in HIV risk behaviors. Starting with the lowest, those states were South Dakota, Nebraska, Iowa, and North Dakota. Citizens in five states showed significantly higher probability than the average states of participating in HIV risk behaviors. Starting with the highest, those states were the District of Columbia, South Carolina, Arkansas, Alabama, and California.

\section{Unconditional Growth Model}

The unconditional growth model can be described as the unconditional model with the time variable added, as seen in Figure 17. Fitting the unconditional growth model, depicting the probability of experiencing individual HIV risk behavior over time, is shown in Model B, using the following expanded equation in which time was added. 


$$
\begin{aligned}
& \text { uHIVRISK } 2_{i j k} \sim \text { Binomial (Constant }_{i j k}, \pi_{i j k} \text { ) } \\
& \operatorname{logit}\left(\pi_{i j k}\right)=\beta_{0 j k} \text { Constant }+\beta_{1 j} \text { TIME }_{j k} \\
& \beta_{0 j k}=\beta_{0}+v_{0 k}+u_{0 j k} \\
& \beta_{1 j}=\beta_{0}+u_{1 j k} \\
& {\left[\mathrm{v}_{0 k}\right] \sim \mathrm{N}\left(0, \Omega_{v}\right): \Omega_{v}=\left[\sigma_{v}^{2}{ }_{v}\right]} \\
& {\left[\begin{array}{l}
u_{0 j k} \\
u_{1 j k}
\end{array}\right] \sim \mathrm{N}\left(0, \Omega_{u}\right): \Omega_{u}=\left[\begin{array}{l}
\sigma_{u}^{2}{ }_{u} \\
\sigma_{u} 01 \\
\sigma_{u}^{2} 1
\end{array}\right]} \\
& \operatorname{var}\left(\operatorname{HIVRISK} 2_{i j k} \mid \pi_{i j k}\right)=\pi_{i j k}\left(1-\pi_{i j k}\right) / \text { Constant }_{i j k}
\end{aligned}
$$

Figure 17. Unconditional growth model.

Table 17 shows both Model A and Model B, which includes the time variable.

Table 17

Comparison of Null Model to Growth Model

Model A

Fixed effects

Constant

TIME

$-0.763 * * *(0.04)$

$-0.600 * * *(0.05)$

$-0.090 * * *(0.02)$

Random parameters

Level 3: STATE

Constant/Constant

Level 2: YEAR

Constant/Constant

TIME/Constant

TIME/TIME

DIC:
$0.064 * * *(0.02)$

$0.040 * * *(0.01)$

$0.034 *(0.02)$

$-0.019 *(0.01)$

$0.013 *(0.01)$

29667.38

114.13

92.95

$\mathrm{pD}$ :

114.13

Note: Standard errors are in parentheses. DIC: Diagnostic Information Criterion; pD: estimated degrees of freedom; $* * * p<0.001 ; * * p<0.01 ; * \mathrm{p} \leq 0.05$. 
Adding the time variable to the model resulted in an improved model fit (DIC $=$ 29682.69 for the null model and 29667.38 for the growth model). As the case was with the null model, log-odds were transformed to probabilities using the customized predictions function in MLwiN. The probabilities for HIV risk behavior for the unconditional growth model are shown in Figure 18.

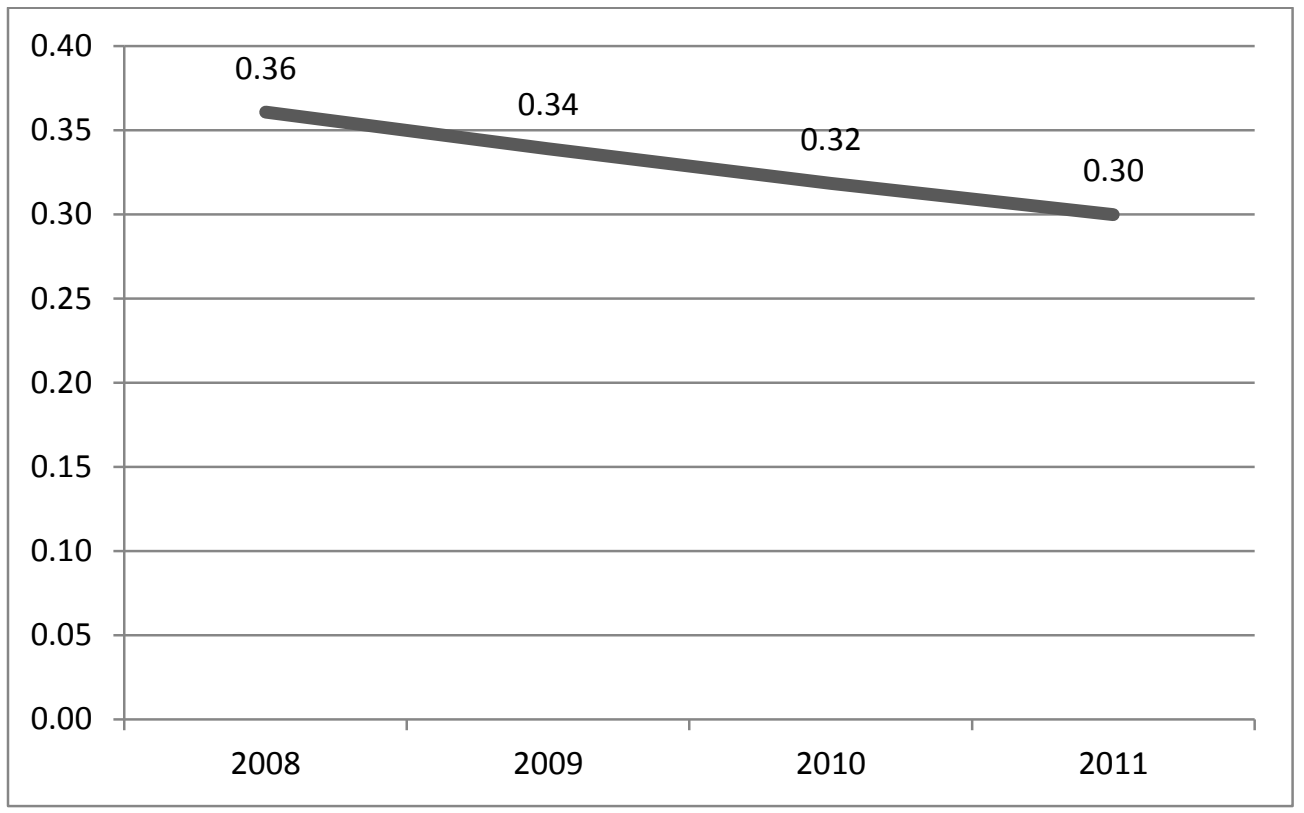

Figure 18. HIV risk behavior of the whole sample over time.

For the unconditional model, the probability of HIV risk behaviors was 0.32 , what the "average" state value would be. For the unconditional growth model, an overall decrease was seen in the level of HIV risk behavior between 2008 and 2011. The probability of an individual participating in HIV risk behaviors decreased from $36 \%$ in 2008 to $30 \%$ in 2011 . 


\section{Conditional Growth Model with Individual Predictors}

The conditional growth model was expanded by adding the individual- level predictors (Model C) to the equation as seen in Figure 19. Variables that were not included because they were not significant were health care coverage, having a personal doctor, household income, emotional support, and life satisfaction:

HIVRISK $2_{i j k} \sim$ Binomial $\left(\right.$ Constant $\left._{i j k}, \pi i j k\right)$

$\operatorname{logit}(\pi i j k)=\beta_{0 j k}$ Constant $+\beta_{1 j} \mathrm{TIME}_{j k}+\mathrm{Age}_{i j k}+\mathrm{Male}_{i j k}+$ Not in a committed relationship $_{i j k}+$ Black $_{i j k}+$ Hispanic $_{i j k}+$ Other race $_{i j k}+$ Less than $\mathrm{HS}_{i j k}+\mathrm{HS}_{i j k}+$ Employed $_{i j k}+$ Self-employed $_{i j k}+$ Homemaker/Student $_{i j k}+$ Unemployed $_{i j k}+$ Live in an urban area $_{i j k}+$ Live in a suburban area $a_{i j k}+$ Yes, could not see doctor because of cost ${ }_{i j k}+$ 1-15 days mental health was not $\operatorname{good}_{i j k}+16-30$ mental health was not $\operatorname{good}_{i j k}+$ General health ${ }_{i j k}+1-15$ days physical health was not $\operatorname{good}_{i j k}+16-30$ days physical health was not $\operatorname{good}_{i j k}+$ Yes, had alcoholic beverages in the past 30 days $i j k$

$\beta_{0 j k}=+\mathrm{v}_{0 k}+\mathrm{u}_{0 j k}$

$\beta_{1 j}=+u_{1 j k}$

$[\mathrm{V} o k] \sim \mathrm{N}(0, \Omega v): \Omega v=\left[\sigma^{2}{ }_{v}\right]$

$\left[\begin{array}{l}\mathrm{u}_{0 j k} \\ \mathrm{u}_{1 j k}\end{array}\right] \sim \mathrm{N}(0, \Omega u): \Omega u=\left[\begin{array}{l}\sigma_{u 0}^{2} \\ \sigma_{u} 01 \sigma^{2}{ }_{u}\end{array}\right]$

$\operatorname{var}\left(\right.$ HIVRISK $2_{i j k} \mid \pi i j k=\pi i k\left(1-\pi_{i j k}\right) /$ Constant $_{i j k}$

Figure 19. Growth model with individual variables added.

Table 18 compares the unconditional model (null model) with the unconditional growth model and the conditional growth model, with all the individual variables included. 
Table 18

Comparison of Null Model, Growth Model and Growth Model with Main Individual Effects

\begin{tabular}{|c|c|c|c|}
\hline & Model A & Model B & Model C \\
\hline \multicolumn{4}{|c|}{ Fixed effects } \\
\hline Constant & $-0.764 * * *(0.04)$ & $0.600 * * *(0.05)$ & $-1.888 * * *(0.07)$ \\
\hline TIME & & $-0.090 * * *(0.02)$ & $-0.086(0.02)$ \\
\hline \multicolumn{4}{|l|}{ Individual Predisposing Demographic Variables } \\
\hline Age & & & $-6.756 * * *(0.37)$ \\
\hline Male & & & $0.572 * * *(0.03)$ \\
\hline \multicolumn{4}{|c|}{ Individual Predisposing Social Structure Variables } \\
\hline Not in a committed relationship & & & $0.533 * * *(0.03)$ \\
\hline Black & & & $0.606 * * *(0.05)$ \\
\hline Hispanic & & & $0.157 *(0.07)$ \\
\hline Other & & & $0.081(0.07)$ \\
\hline Less than HS & & & $0.277 * * *(0.06)$ \\
\hline HS & & & $0.023(0.03)$ \\
\hline Employed & & & $-0.136 * * *(0.05)$ \\
\hline Self-employed & & & $-0.070(0.06)$ \\
\hline Homemaker/Student & & & $0.045(0.08)$ \\
\hline Unemployed & & & $0.225 * * *(0.05)$ \\
\hline Urban & & & $0.076 *(0.04)$ \\
\hline Suburban & & & $-0.066(0.05)$ \\
\hline \multicolumn{4}{|l|}{ Individual Enabling Variables } \\
\hline Yes, could not see a doctor because of cost & & & $0.160 * * *(0.04)$ \\
\hline 1-15 days mental health was not good & & & $0.378 * * *(0.04)$ \\
\hline 16-30 days mental health was not good & & & $0.398 * * *(0.05)$ \\
\hline
\end{tabular}




\begin{tabular}{|c|c|c|c|}
\hline \multicolumn{4}{|l|}{ Individual Need Variables } \\
\hline General health & & & $0.057^{* *}(0.02)$ \\
\hline 1-15 days physical health was not good & & & $0.255^{* * *}(0.04)$ \\
\hline 16-30 days physical health was not good & & & $0.239 * * *(0.05)$ \\
\hline \multicolumn{3}{|c|}{ Yes, had alcoholic beverages in the past 30 days } & $0.365^{* * *}(0.03)$ \\
\hline & & & \\
\hline \multicolumn{4}{|l|}{ Level 3: State } \\
\hline Constant/Constant & $0.059 * * *(0.02)$ & $0.065 * * *(0.02)$ & $0.023^{*}(0.01)$ \\
\hline \multicolumn{4}{|l|}{ Level 2: Year } \\
\hline Constant/Constant & $0.040 * * *(0.01)$ & $0.035 *(0.02)$ & $0.028 *(0.01)$ \\
\hline TIME/Constant & & $-0.020 *(0.01)$ & $-0.01(0.01)$ \\
\hline TIME/TIME & & $0.014(0.01)$ & $0.007 \sim(0.00)$ \\
\hline DIC: & 29682.69 & 29667.38 & 27300.15 \\
\hline pD: & 114.13 & 92.95 & 109.26 \\
\hline
\end{tabular}


Adding the individual-level predictors to the model resulted in an improved model fit (DIC= 29682.69 for the null model, 29667.38 for the growth model, and 27300.15 for the growth model with main effects). As with the null model and the unconditional growth model, log-odds were transformed into probabilities. In Figure 20, the probability of HIV risk behavior for the entire sample after adding all individual main effects was modeled between 2008 and 2011. The average probability of engaging in HIV risk behaviors only changed one percent between 2008 and 2011, after adding all individual main effects.

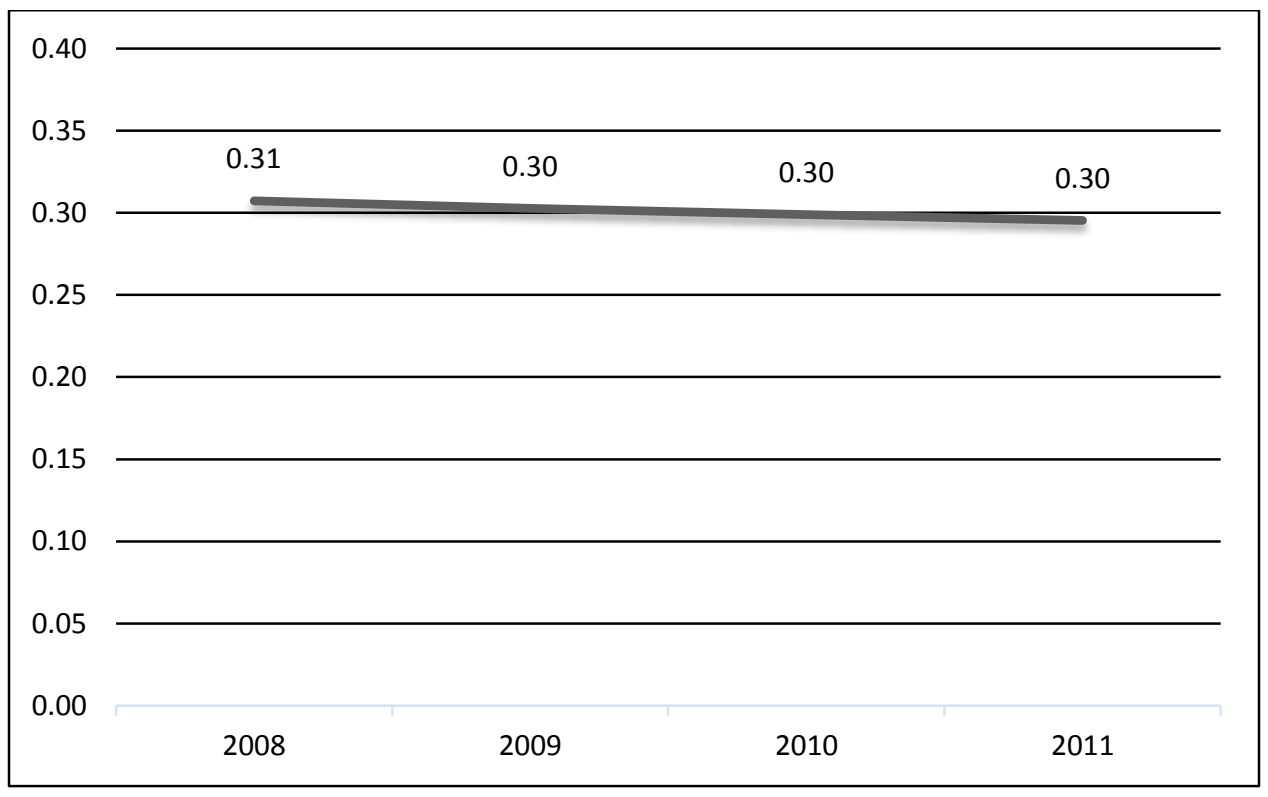

Figure 20. HIV risk behavior of the whole sample over time with individual predictors.

\section{Conditional Growth Model with State Effects}

The conditional growth model was expanded by adding state-level predictors to the model. State-level variables that were either not significant or did not contribute to overall model fit were deleted to create a parsimonious model. Five significant state variables remained in the final model, namely the percentage of white females in each 
state, percentage of uninsured persons in each state, and percentage of white persons with AIDS, Asians with AIDS, and other race groups with AIDS.

HIVRISK $2_{i j k} \sim$ Binomial $\left(\right.$ Constant $_{i j k}, \pi_{i j k}$ ) $\operatorname{logit}(\pi i j k)=\beta_{0 j k}$ Constant $+\beta_{1 j} \mathrm{TIME}_{j k}+\mathrm{Age}_{i j k}+$ Male $_{i j k}+$ Not in a committed relationship $_{i j k}+$ Black $_{i j k}+$ Hispanic $_{i j k}+$ Other race $i j k+$ Less than HS $_{i j k}+\mathrm{HS}_{i j k}+$ Employed $_{i j k}+$ Self-employed $_{i j k}+$ Homemaker/Student $_{i j k}+$ Unemployed $_{i j k}+$ Live in an urban area $_{i j k}+$ Live in a suburban $_{i j k}+$ Yes, could not see doctor because of cost $_{i j k}+1-15$ days mental health was not $\operatorname{good}_{i j k}+16-30$ mental health was not $\operatorname{good}_{i j k}+$ General health ${ }_{i j k}+1-15$ days physical health was not $\operatorname{good}_{i j k}+16-30$ days physical health was not $\operatorname{good}_{i j k}+$ Yes, had alcoholic beverages in the past 30 days $_{i j k}$ Percentage of white females $_{k}+$ Percentage of whites with $\operatorname{AIDS}_{k}+$ Percentage of Asians with AIDS $_{k}+$ Percentage of Other races with $\operatorname{AIDS}_{k}$

$\beta_{0 j k}=\beta_{0}+v_{0 k}+u_{0 j k}$

$\beta_{1 j}=\beta_{0}+u_{1 j k}$

$[\mathrm{V} o k] \sim \mathrm{N}\left(0, \Omega_{v}\right): \Omega_{v}=\left[\sigma^{2}{ }_{v o}\right]$

$\left[\begin{array}{l}\mathrm{u}_{0 j k} \\ \mathrm{u}_{1 j k}\end{array}\right] \sim \mathrm{N}(0, \Omega u): \Omega u=\left[\begin{array}{l}\sigma^{2}{ }_{u} 0 \\ \sigma_{u} 01 \sigma^{2}{ }_{u} 1\end{array}\right]$

$\operatorname{var}\left(\mathrm{HIVRISK} 2_{i j k} \mid \pi \mathrm{ijk}=\pi_{i j k}\left(1-\pi_{i j k}\right) /\right.$ Constant $_{i j k}$

Figure 21. Growth model with individual and state variables added.

Table 19 compares all four models. Adding the main effects of state-level predictors with the main effects of the individual- level predictors to the model resulted in an overall reduction in DIC, indicating a good fit (DIC $=29682.69$ for the null model versus DIC $=29667.38$ for the unconditional growth model versus DIC $=27300.15$ for the conditional growth model versus DIC $=27289.190)$. 
Table 19 shows that in the final model, the variance at level 3 (state level) was 0.007. Therefore, there was $0.2 \%$ variance between states $[(0.007 / 3.29+0.007+0.024)$ $=0.002]$, indicating that there remained almost no state differences after including all the predictors. Based on the Wald test, the Chi-square statistic for the variance component was 1.63 on 1 degree of freedom. The critical value for a chi square test at the $5 \%$ level is 3.84, therefore, evidence was seen that the between-state variance was zero. In other words, it is concluded that there was very little variation left between states in the probability of participating in HIV risk behaviors after adding in the predictors.

Figure 22 plots and rank-orders the estimated residuals of the 51 states with $95 \%$ confidence intervals. The line represents the mean log-odds of participating in HIV risk behaviors, and the plots illustrate that there are no more state differences.

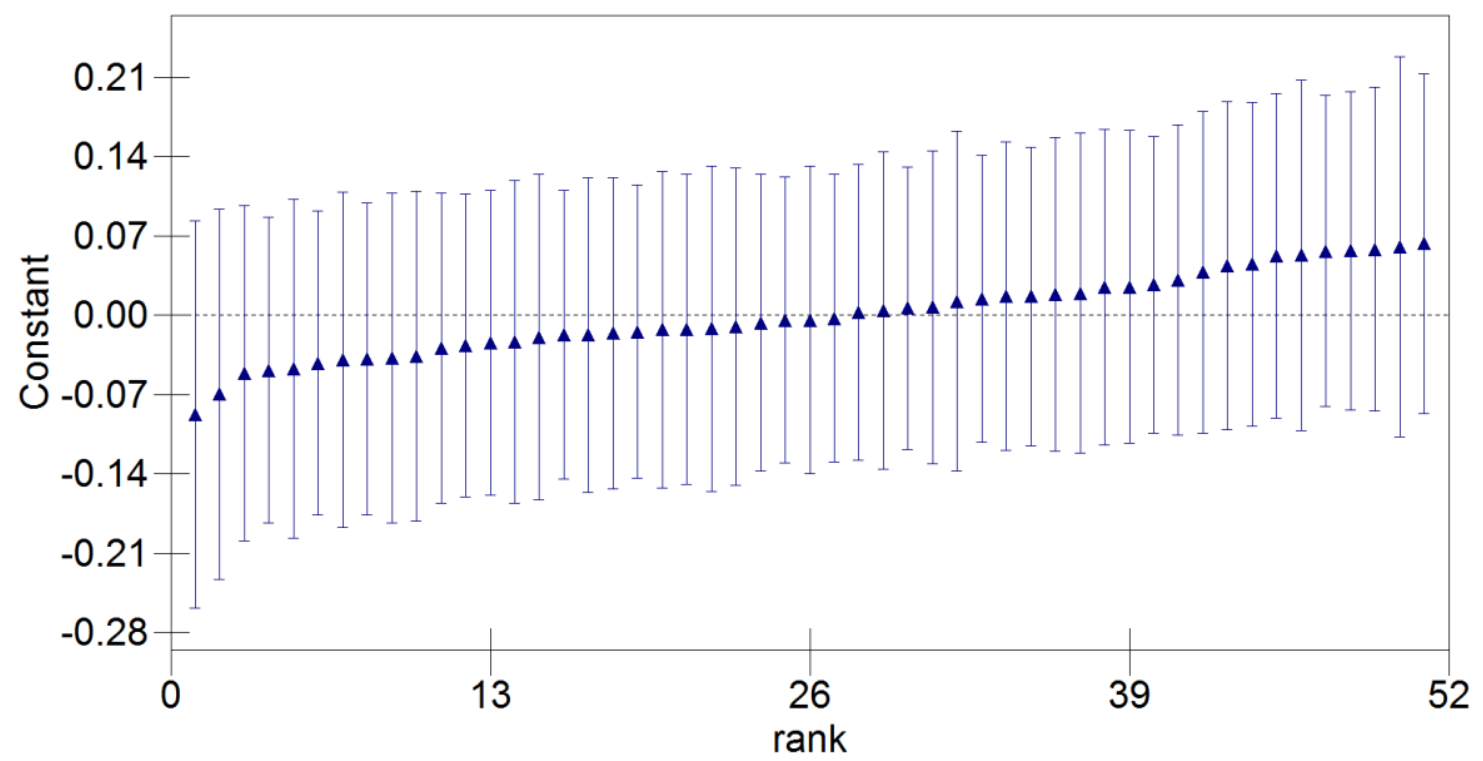

Figure 22 . Caterpillar plot showing state residuals with $95 \%$ confidence intervals for log odds of participating in HIV risk behaviors after adding in predictors.

Table 19 shows that in the final model, the variance at level 2 (state cohort level) was 0.024 . Therefore, there was $0.7 \%$ variance between state cohorts 
$[(0.024 / 3.29+0.007+0.024)=0.007]$, indicating that there remained some change that took place between 2008 and 2011 within states between the different cohorts after including all the predictors. Based on the Wald test, the Chi-square statistic for the variance component was 4.72 on 1 degree of freedom. The critical value for a chi square test at the $5 \%$ level is 3.84 , therefore, evidence was seen that the between-cohort variance was non-zero. In other words, it is concluded that there was still significant variation left within states between the different cohorts in the probability of participating in HIV risk behaviors that could not be explained by the variables in the model. 
Table 19

Comparison of All Models

\section{Model A}

Model B

Model C

Model D

Fixed effects

Constant

TIME

$-0.764 * * *(0.04)$

$-0.600 * * *(0.05)$
$-0.090 * * *(0.02)$

$-1.888 * * *(0.07)$

$-1.867 * * *(0.07)$

Individual Predisposing Demographic Variables

$-0.086(0.02)$

$-0.021(0.02)$

Age

Male

$-6.756 * * *(0.037) \quad-6.727 * * *(0.38)$

Individual Predisposing Social Structure Variables

$0.572 * * *(0.03) \quad 0.573 * * *(0.03)$

Not in a committed relationship

t) Black

Hispanic

Other races

Less than HS

HS

Employed

Self-employed

Homemaker/Student

Unemployed

Urban

Suburban

$$
\begin{array}{rr}
0.533 * * *(0.03) & 0.533 * * *(0.03) \\
0.606 * * *(0.05) & 0.572 * * *(0.05) \\
0.157 *(0.07) & 0.150 * *(0.07) \\
0.081(0.07) & 0.071(0.07) \\
0.277 * * *(0.06) & 0.271 * * *(0.06) \\
0.023(0.03) & 0.023(0.04) \\
-0.136 * * *(0.05) & -0.135 * *(0.05) \\
-0.070(0.06) & -0.071(0.06) \\
0.045(0.08) & 0.041(0.09) \\
0.225 * * *(0.05) & 0.223 * * *(0.05) \\
0.0762 *(0.04) & 0.061 \sim(0.04) \\
-0.066(0.05) & -0.088 \sim(0.05)
\end{array}
$$

Individual Enabling Variables

Yes, could not see doctor because of cost 


\begin{tabular}{|c|c|c|c|c|}
\hline \multicolumn{5}{|l|}{ Individual Need Variables } \\
\hline 1-15 days mental health was not good & & & $0.378 * * *(0.04)$ & $0.378 * * *(0.04)$ \\
\hline 16-30 days mental health was not good & & & $0.398 * * *(0.05)$ & $0.398 * * *(0.05)$ \\
\hline General health & & & $0.057 * *(0.02)$ & $0.060 * * *(0.02)$ \\
\hline 1-15 days physical health was not good & & & $0.255 * * *(0.04)$ & $0.255^{* * *}(0.04)$ \\
\hline 16-30 days physical health was not good & & & $0.239 * * *(0.05)$ & $0.238 * * *(0.05)$ \\
\hline $\begin{array}{l}\text { YES, had alcoholic beverages in the past } 30 \\
\text { days }\end{array}$ & & & $0.365 * * *(0.03)$ & $0.369 * * *(0.03)$ \\
\hline \multicolumn{5}{|l|}{ State Predisposing Social Structure Variable } \\
\hline Percentage of white females & & & & $0.141 * * *(0.03)$ \\
\hline \multicolumn{5}{|l|}{ State Enabling Variable } \\
\hline Percentage of persons uninsured & & & & $0.101 \sim(0.06)$ \\
\hline \multicolumn{5}{|l|}{ State Need Variables } \\
\hline Percentage of whites with AIDS & & & & $0.630 * * *(0.24)$ \\
\hline Percentage of Asians with AIDS & & & & $0.010 * *(0.00)$ \\
\hline \multirow[t]{2}{*}{ Percentage of other races with AIDS } & & & & $0.008 * *(0.00)$ \\
\hline & Random Parameters & & & \\
\hline \multicolumn{5}{|l|}{ Level 3: STATE } \\
\hline Constant/Constant & $0.059 * * *(0.02)$ & $0.065 * * *(0.02)$ & $0.023 *(0.01)$ & $0.007(0.01)$ \\
\hline \multicolumn{5}{|l|}{ Level 2: YEAR } \\
\hline Constant/Constant & $0.040 * * *(0.01)$ & $0.035^{*}(0.02)$ & $0.028 *(0.01)$ & $0.024(0.01)$ \\
\hline TIME/Constant & & $-0.020 *(0.01)$ & $-0.01(0.01)$ & $-0.007(0.01)$ \\
\hline TIME/TIME & & $0.014 *(0.01)$ & $0.007 \sim(0.00)$ & $0.006(0.00)$ \\
\hline DIC: & 29682.69 & 29667.38 & 27300.15 & 27289.190 \\
\hline pD: & 114.13 & 92.95 & 109.26 & 99.217 \\
\hline
\end{tabular}


As with Models A, B, C, and D, log odds were transformed into probabilities using the customized predictions functions in MLwiN. Figure 23 displays the probabilities modeled for HIV risk behavior for the whole sample after adding both individual and state predictors. The average probability of engaging in HIV risk behaviors changed two percent between 2008 and 2011, after adding all individual and state main effects.

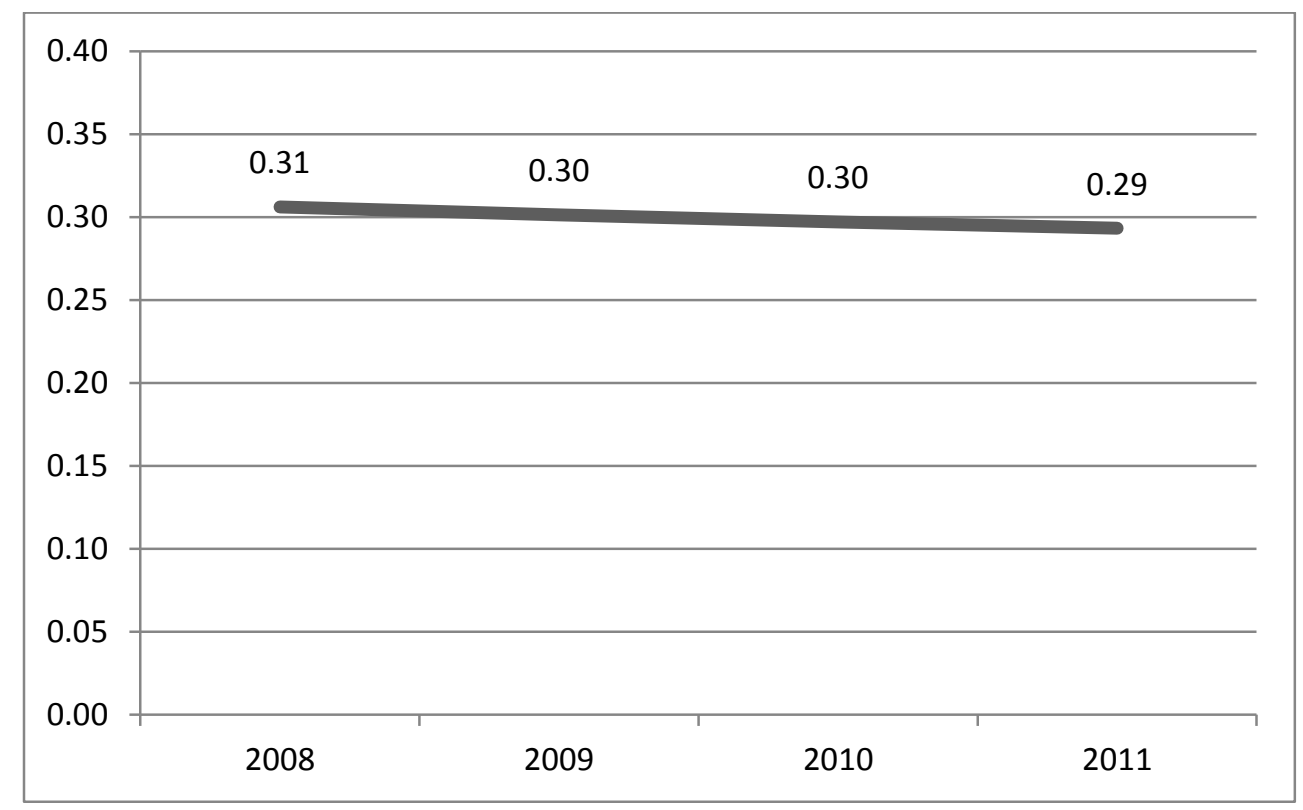

Figure 23. HIV risk behaviors of the whole sample over time with individual and state predictors.

\section{Individual Main Effects}

The next section details the probabilities of HIV risk behaviors as modeled for each of the significant individual main effects (see Figures 23-34).

Figure 24 highlights the probabilities for the main effect of age on participating in HIV risk behaviors. 


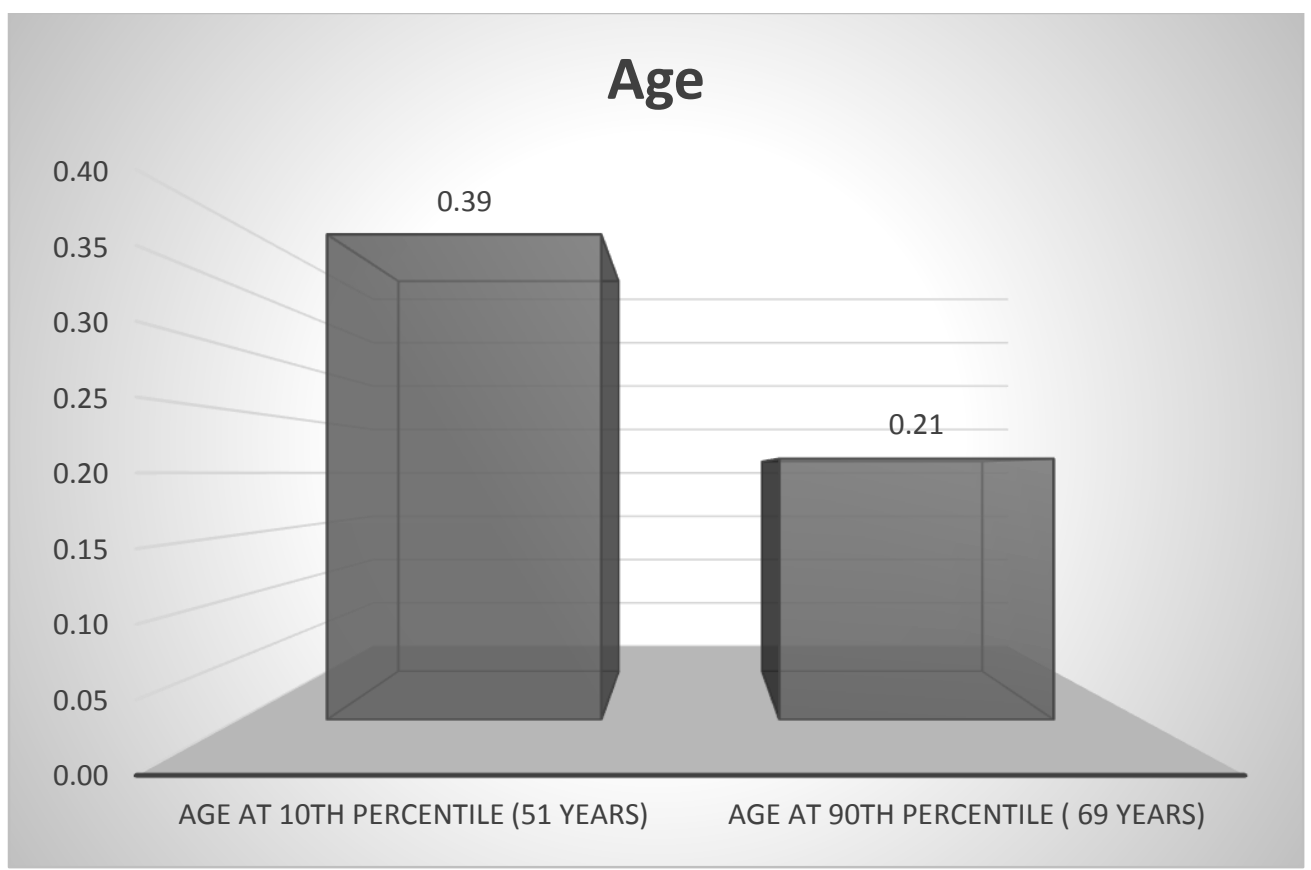

Figure 24. Predicted probabilities for age on participating in HIV risk behaviors.

Based on Figure 23 and the significance of these effects from Table 19, it is evident that persons who were younger $\left(10^{\text {th }}\right.$ percentile $=51$ years $)$ were more likely to participate in HIV risk behaviors than those who were older $\left(90^{\text {th }}\right.$ percentile $=69$ years $)$. Persons who are young older adults had a higher probability of participating in HIV risk behaviors than old older adults.

Figure 25 highlights the probabilities for the main effect of gender on participating in HIV risk behaviors. 


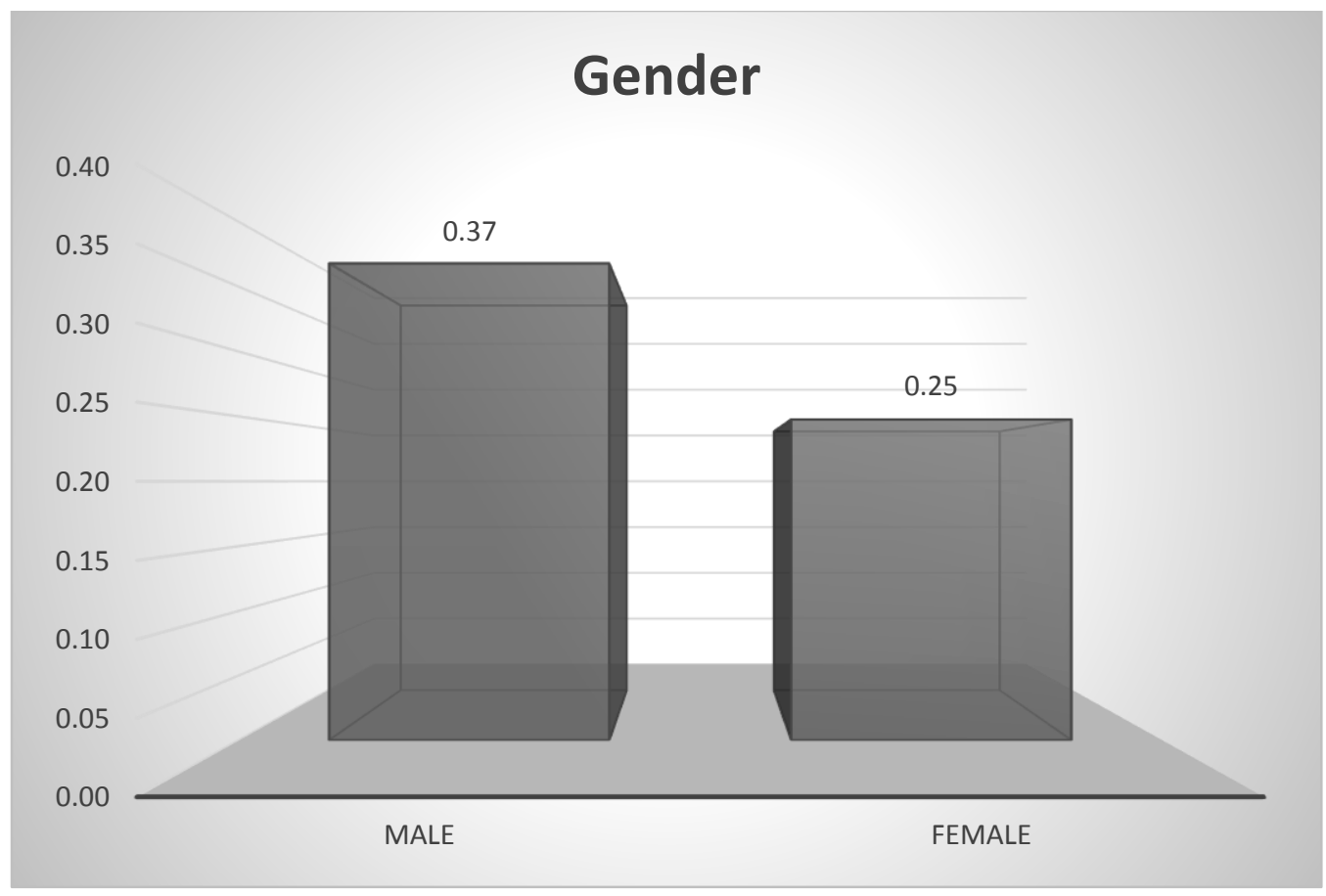

Figure 25. Predicted probabilities for gender on participating in HIV risk behaviors.

Based on Figure 24 and Table 19, it is evident that males had a higher probability of participating in HIV risk behaviors than females.

Figure 26 highlights the probabilities for the main effect of marital status on participating in HIV risk behaviors. 


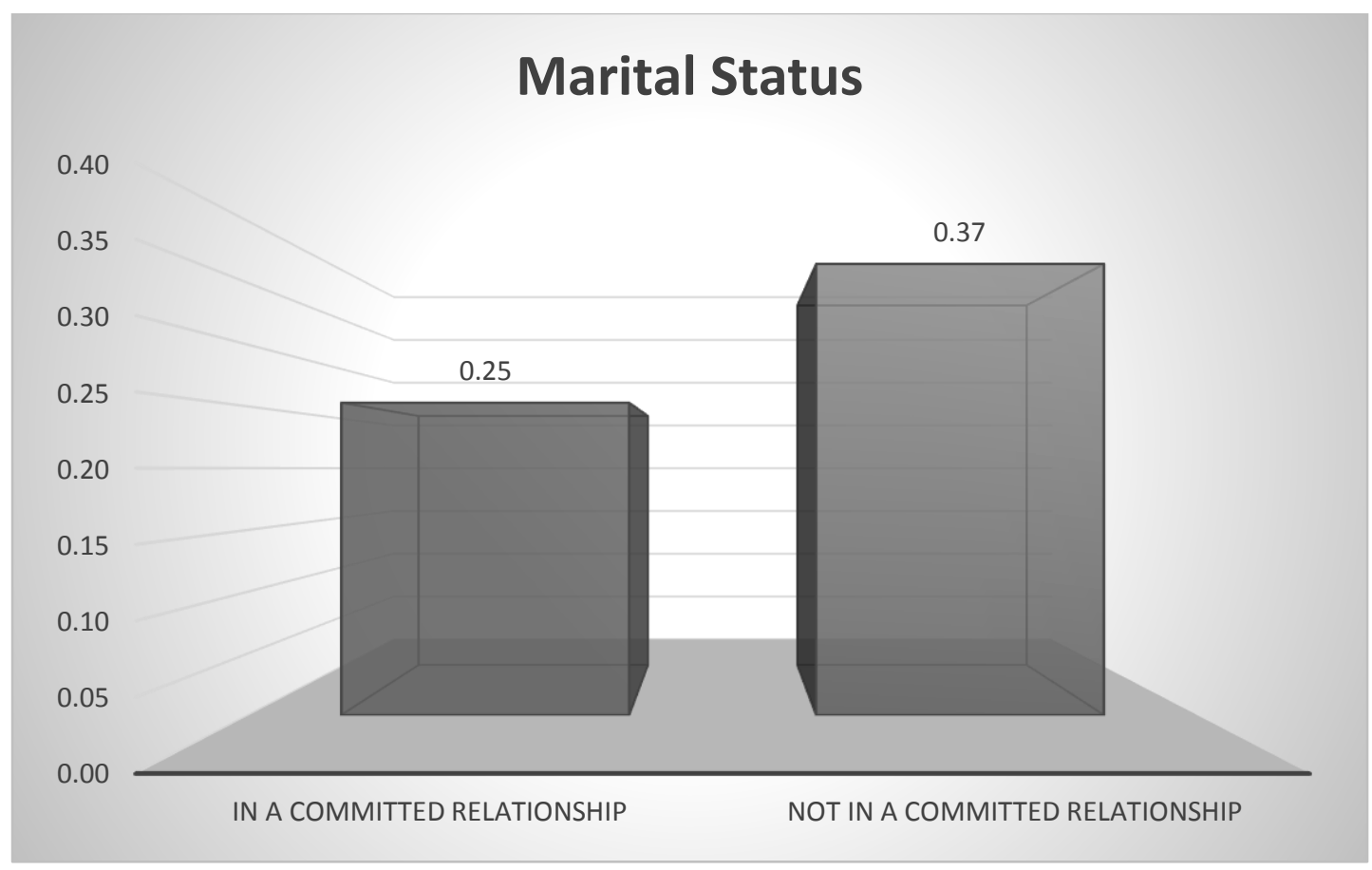

Figure 26. Predicted probabilities for marital status in participating in HIV risk behaviors.

Based on Figure 26 and Table 19, it is evident that persons who were not in committed relationships had a higher probability of participating in HIV risk behaviors than persons were in a committed relationship.

Figure 27 highlights the probabilities of the main effect of race participating in HIV risk behaviors. 


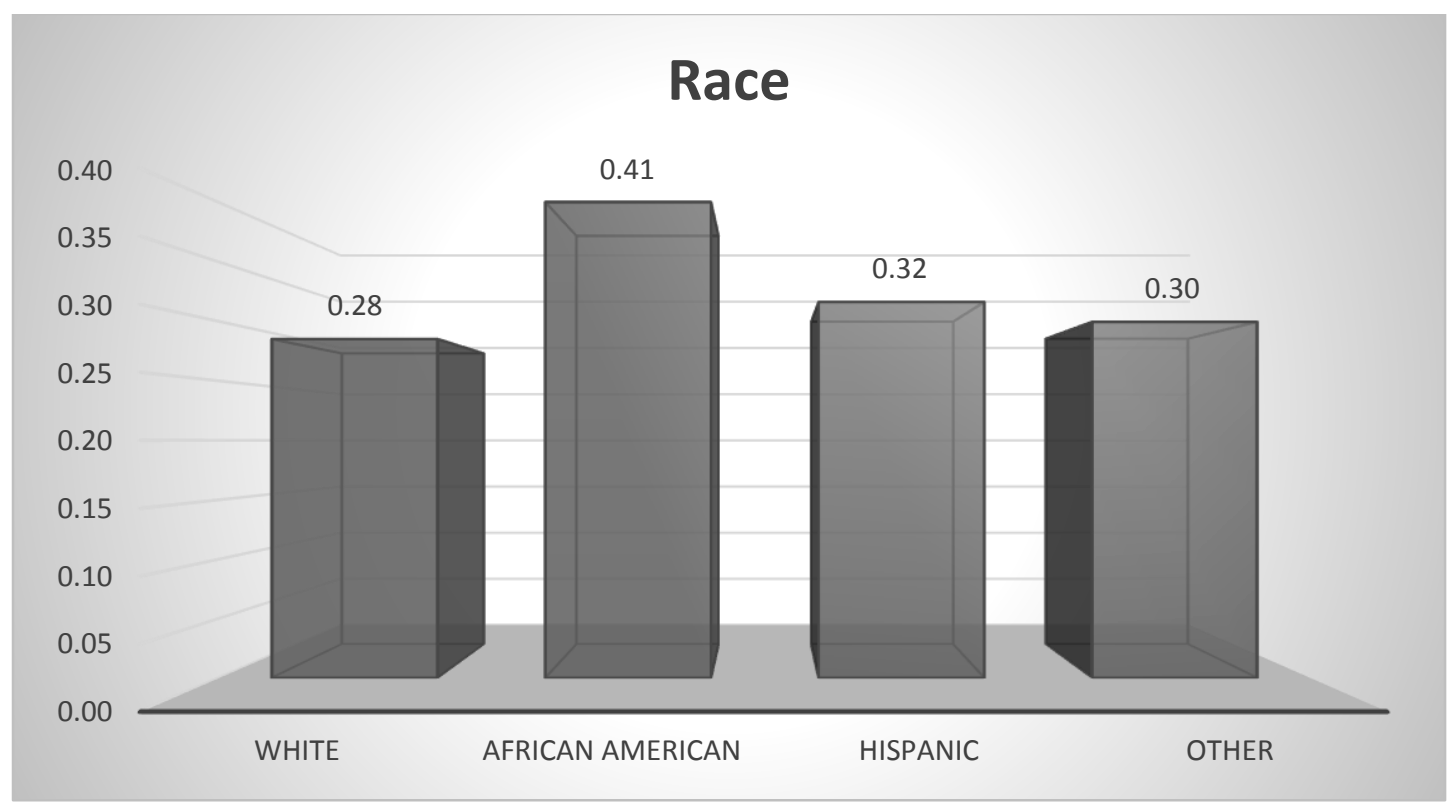

Figure 27. Predicted probabilities for race on participating in HIV risk behaviors.

Based on Figure 27 and Table 19, it is evident that persons who were white or belonged to other race groups were similar in their HIV risk behaviors compared to persons who were African American and Hispanic, with both these last two groups showing significantly higher probabilities of engaging in HIV risk behaviors. Persons who were African American had the highest probability of participating in HIV risk behaviors, followed by people who were Hispanic.

Figure 28 highlights the probabilities of the main effect of education on participating in HIV risk behaviors. 


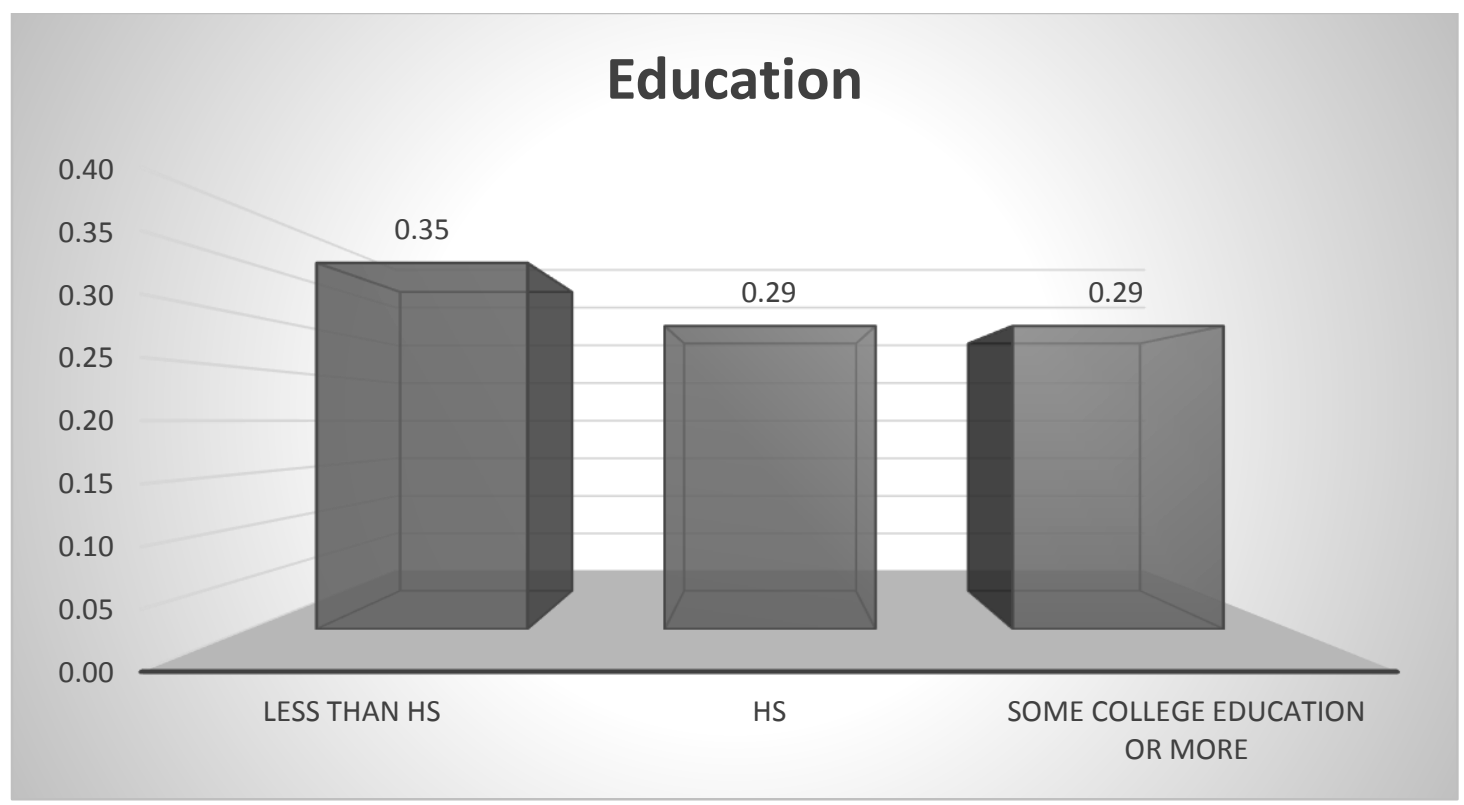

Figure 28. Predicted probabilities for education on participating in HIV risk behaviors.

Based on Figure 28 and Table 19, it is evident that persons who had a high school education or some college or more were similar in their HIV risk behaviors compared to persons who had less than a high school education. Persons with less than a high school education had a higher probability of participating in HIV risk behaviors.

Figure 29 highlights the probabilities of the main effect of employment status on participating in HIV risk behaviors. 


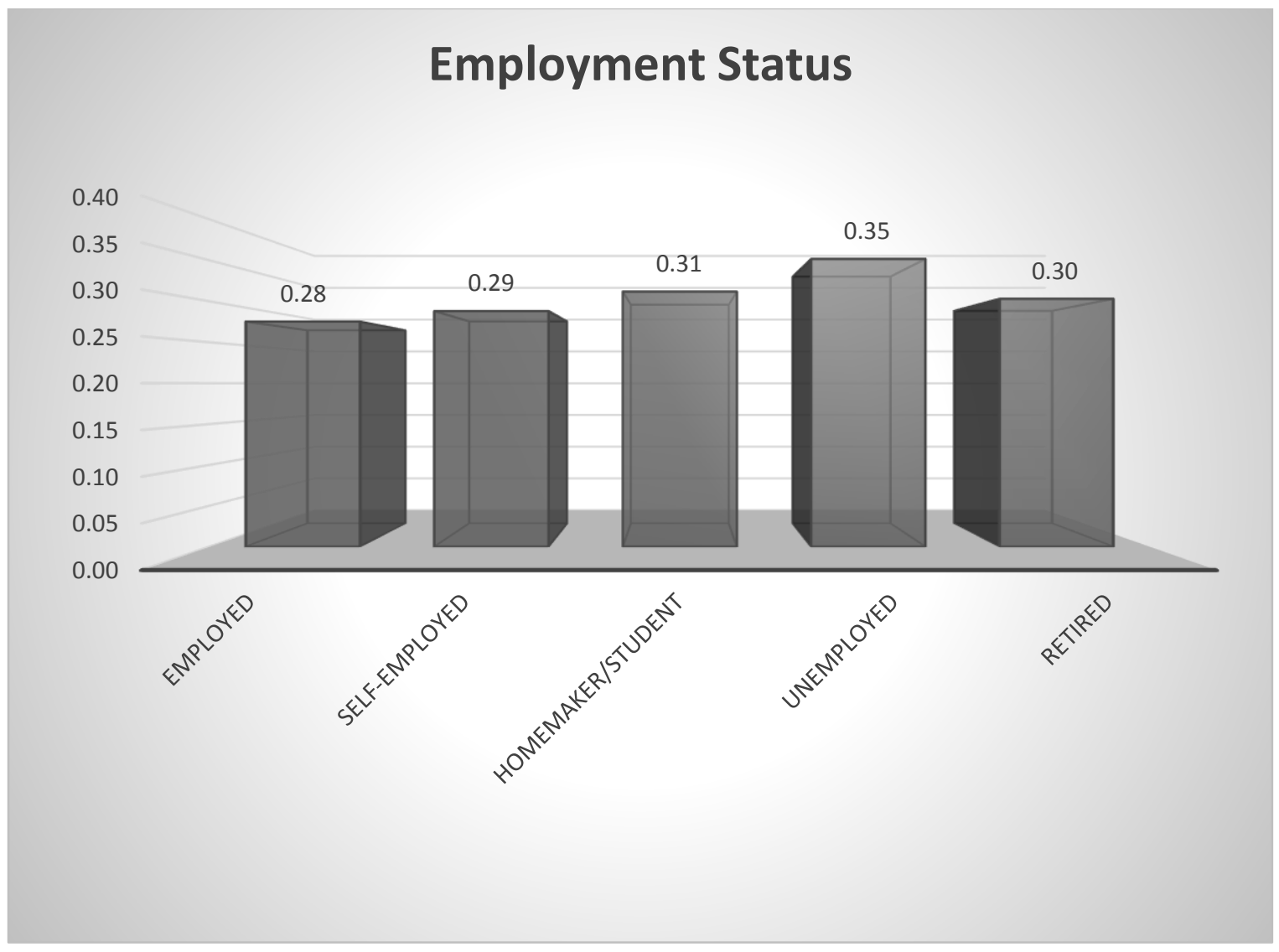

Figure 29. Predicted probabilities for employment status on participating in HIV risk behaviors.

Based on Figure 29 and Table 19, it is evident that persons who were selfemployed and homemakers or students were similar in their HIV risk behaviors compared to persons who were retired. Persons who were unemployed were significantly more at risk and persons who were employed were significantly less at risk than those were retired, self-employed, homemakers or students.

Figure 30 highlights the probabilities of the main effect of residence on participating in HIV risk behaviors. 


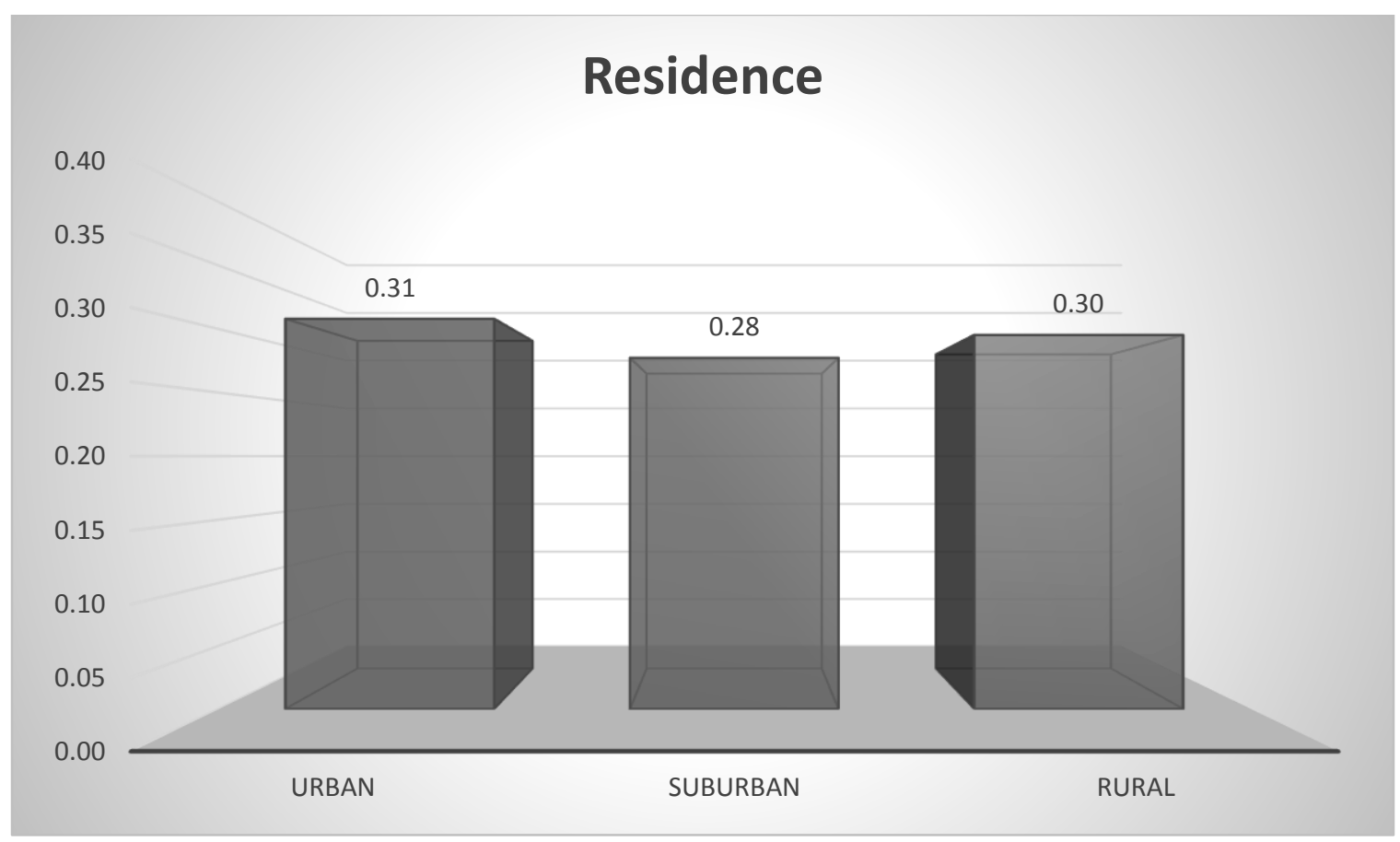

Figure 30. Predicted probabilities for residence status on participating in HIV risk behaviors.

Based on Figure 30 and Table 19, it is evident that persons who lived in suburban areas showed a trend toward less HIV risk behaviors compared to persons who lived in rural areas. Persons who lived in urban areas showed a trend toward higher risk of participating in HIV risk behaviors as compared to persons living in rural areas.

Figure 31 highlights the probabilities for the main effect of cost as a barrier to care on participating in HIV risk behaviors. 


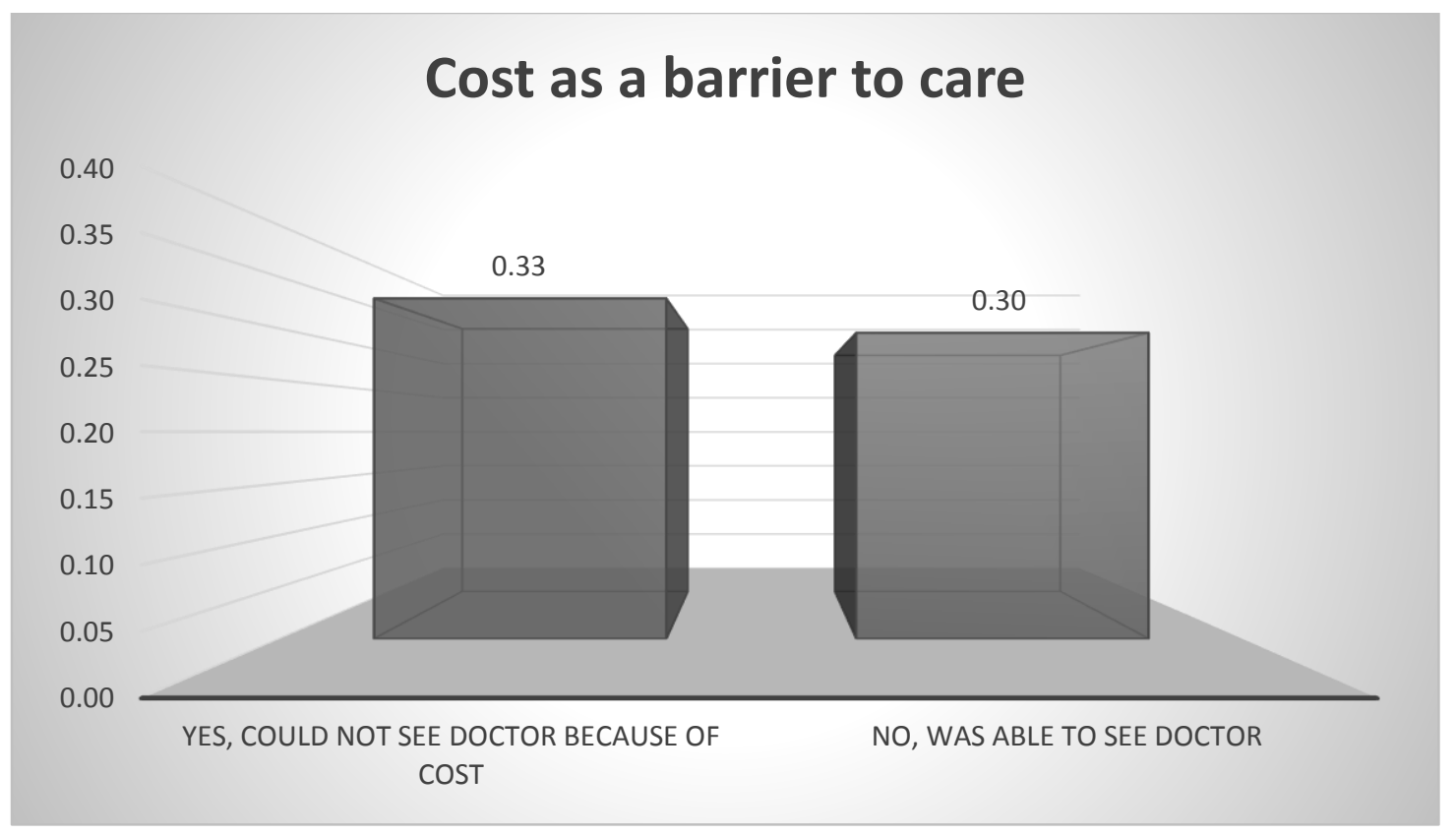

Figure 31. Predicted probabilities for cost as a barrier to care on participating in HIV risk behaviors.

Based on Figure 31 and Table 19, it is evident that persons who were not able to see a doctor because of cost had a higher probability of participating in HIV risk behaviors than persons who were able to see a doctor.

Figure 32 highlights the probabilities for the main effect of mental health status on participating in HIV risk behaviors. 


\section{Mental Health Status}

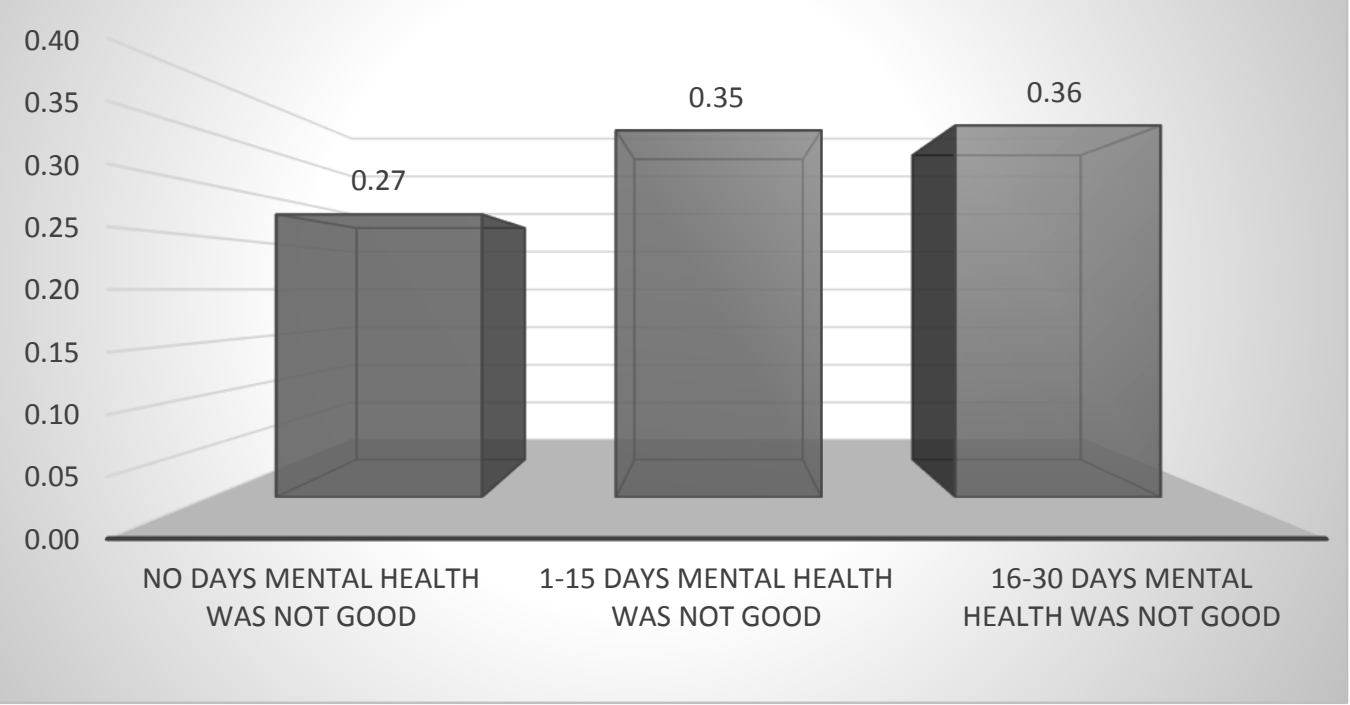

Figure 32. Predicted probabilities for mental health status on participating in HIV risk behaviors.

Based on Figure 32 and Table 19, it is evident that persons who had mental health concerns were different in their HIV risk behaviors compared to persons who did not have any mental health concerns. Persons who had 16-30 days of mental health issues had the highest risk of participating in HIV risk behaviors, followed by persons who had 1-15 days of mental health concerns.

Figure 33 highlights the probabilities for the main effect of general health status on participating in HIV risk behaviors. 


\section{Health Status}

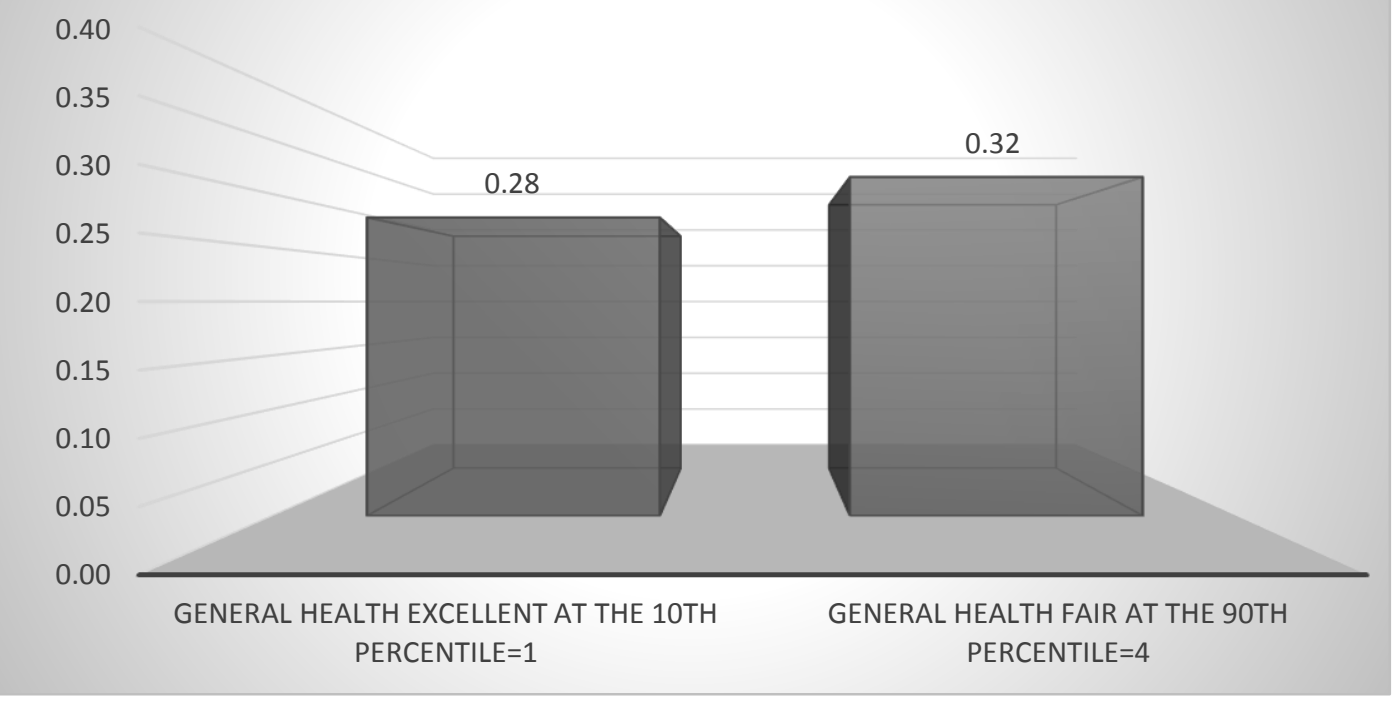

Figure 33. Predicted probabilities for general health status on participating in HIV risk behaviors.

Based on Figure 33 and Table 19, it is evident that persons who rated their health worse had a higher probability of participating in HIV risk behaviors than persons who rated their health better.

Figure 34 highlights the probabilities for the main effect of physical health status on participating in HIV risk behaviors. 


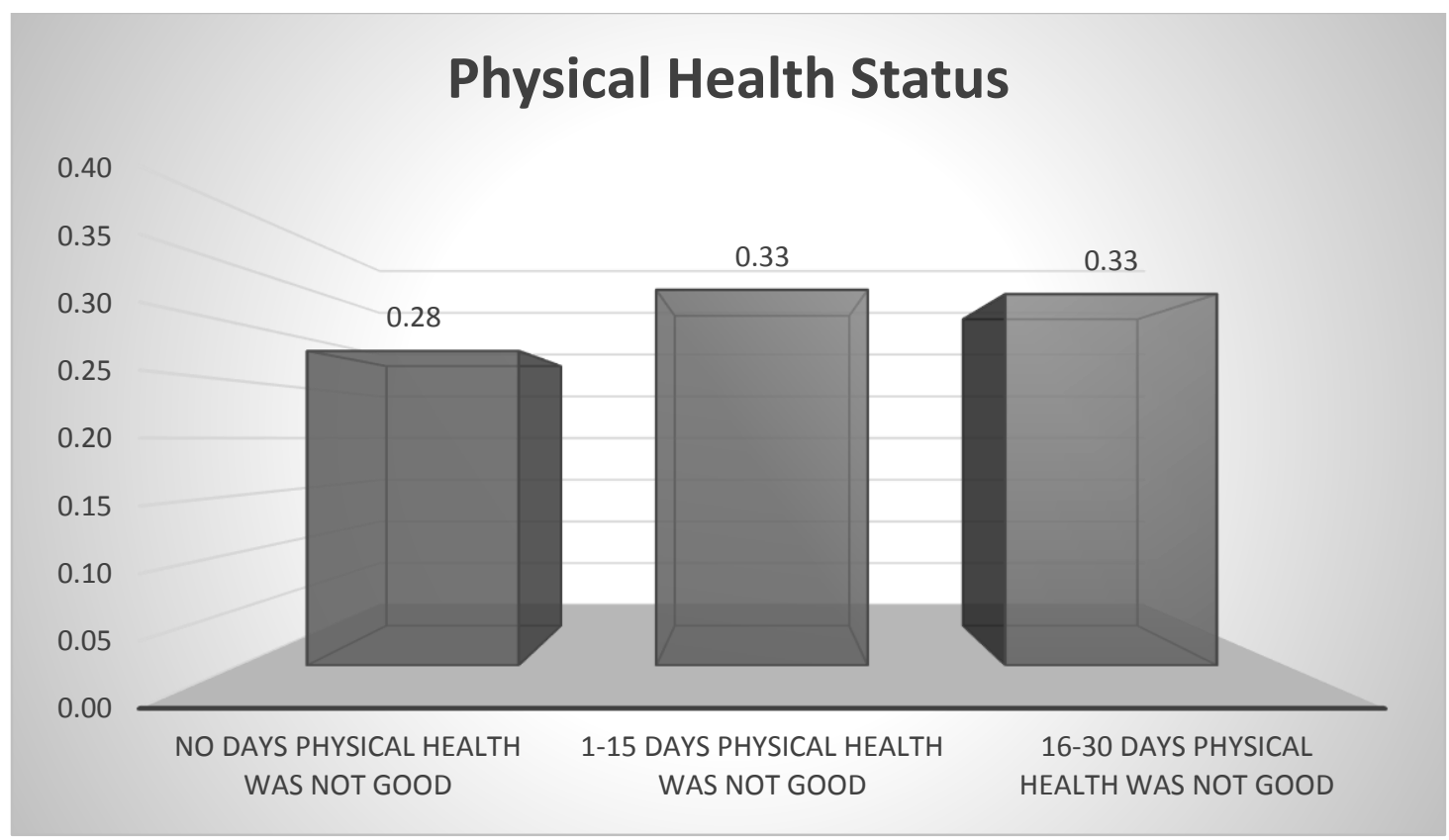

Figure 34. Predicted probabilities for physical health status on participating in HIV risk behaviors.

Based on Figure 34 and Table 19, it is evident that persons who had physical health concerns (both 1-15 days and 16-30 days groups) were significantly higher in their probabilities of participating in HIV risk behaviors as compared to persons who did not have any physical health concerns.

Figure 35 highlights the probabilities for the main effect of drinking alcohol on participating in HIV risk behaviors. 


\section{Drinking Alcohol}

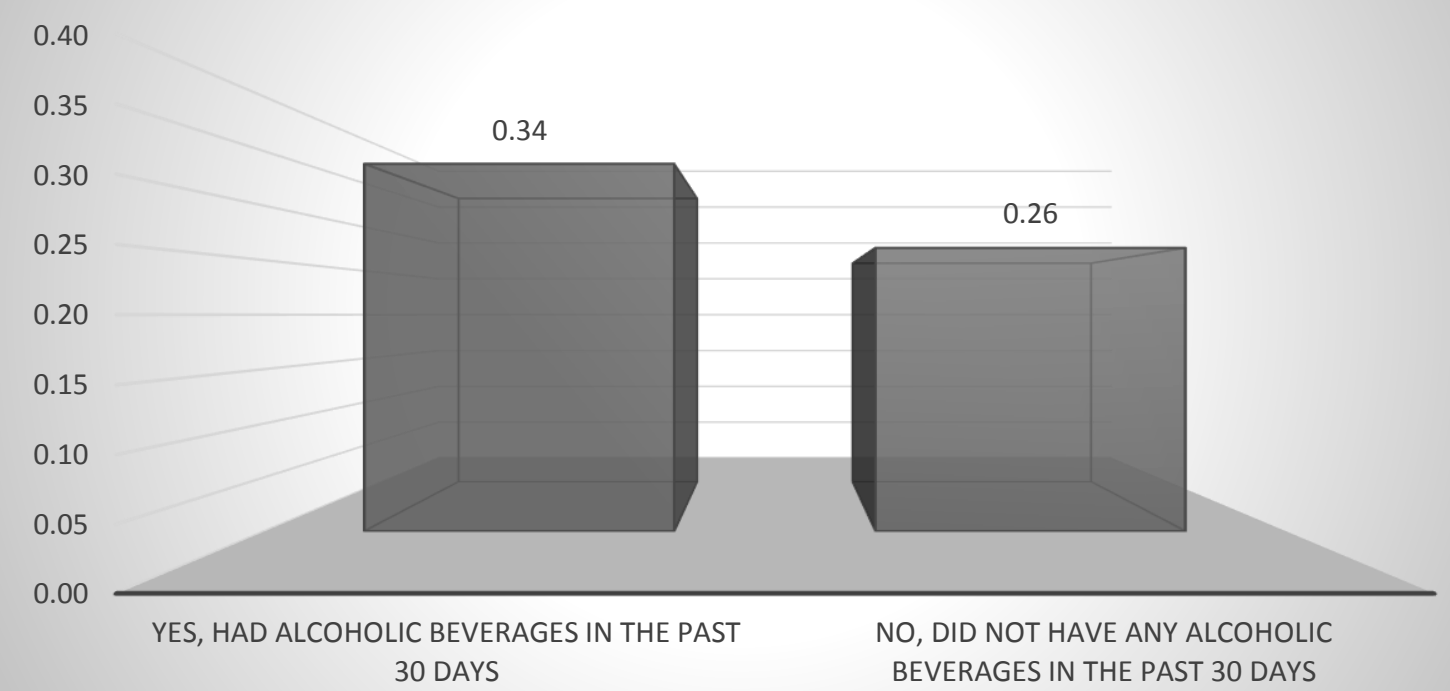

Figure 35. Predicted probabilities for drinking alcohol on participating in HIV risk behaviors.

Based on Figure 35 and Table 19, it is evident that persons who had any alcohol in the past 30 days were more likely to participate in HIV risk behaviors than persons who did not drink at all. Persons who drank alcohol had a higher probability of participating in HIV risk behaviors.

\section{State Main Effects}

The next section details the probabilities of HIV risk behaviors as modeled for each of the significant state main effects.

Figure 36 highlights the probabilities for the main effect of percentage of white females in a state on participating in HIV risk behaviors. 


\section{White Females in each State}

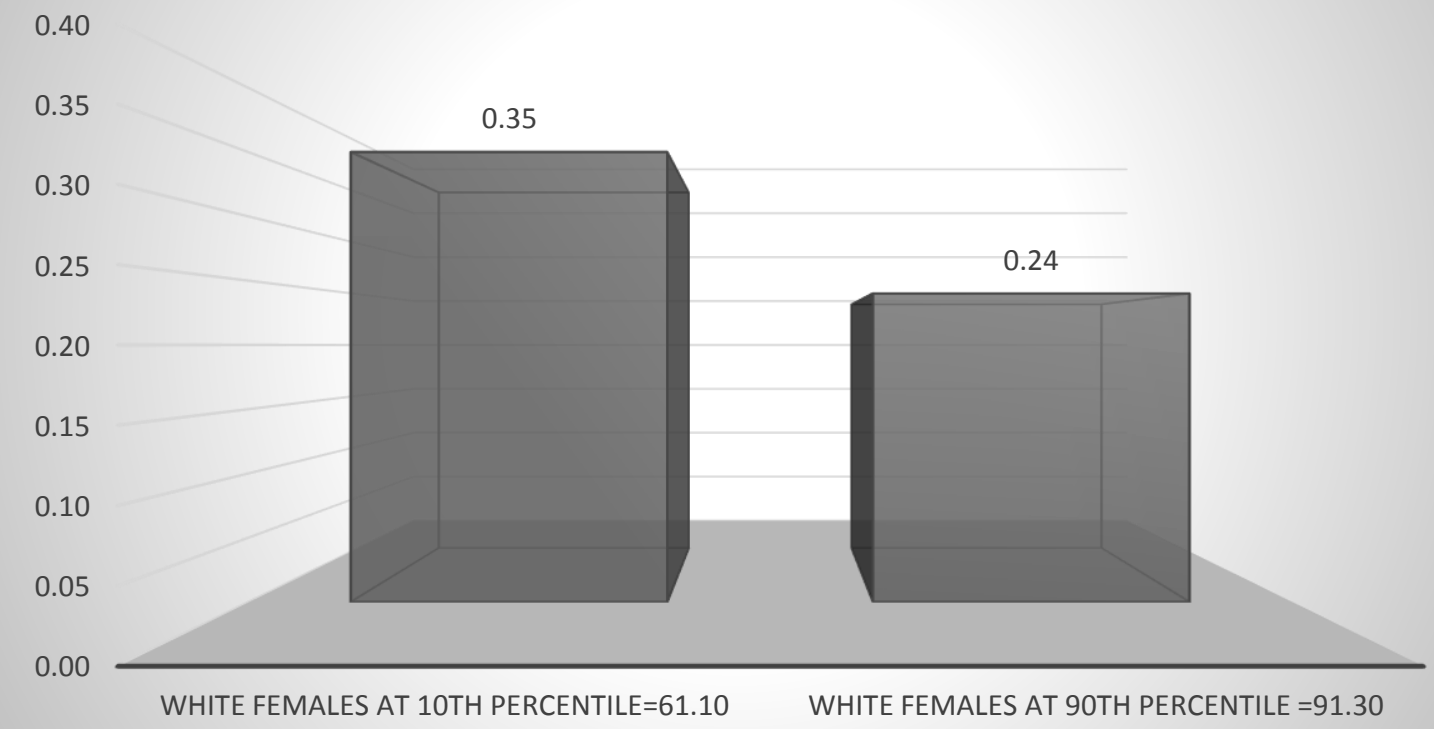

Figure 36. Predicted probabilities for percentage of white females in each state on participating in HIV risk behaviors.

Based on Figure 36 and Table 19, it can be seen that in states where there were less White females, the risk were higher for their citizens to engage in HIV risk behaviors as compared to states where there were more White females. It is important to note that the percentage of White females in a state were very highly negatively correlated with the percentage of minorities in a state $(r=-0.90)$, showing the advantage for citizens in states with more Whites and more White females.

Figure 37 highlights the probabilities for the main effect of percentage of persons uninsured in a state on participating in HIV risk behaviors. 


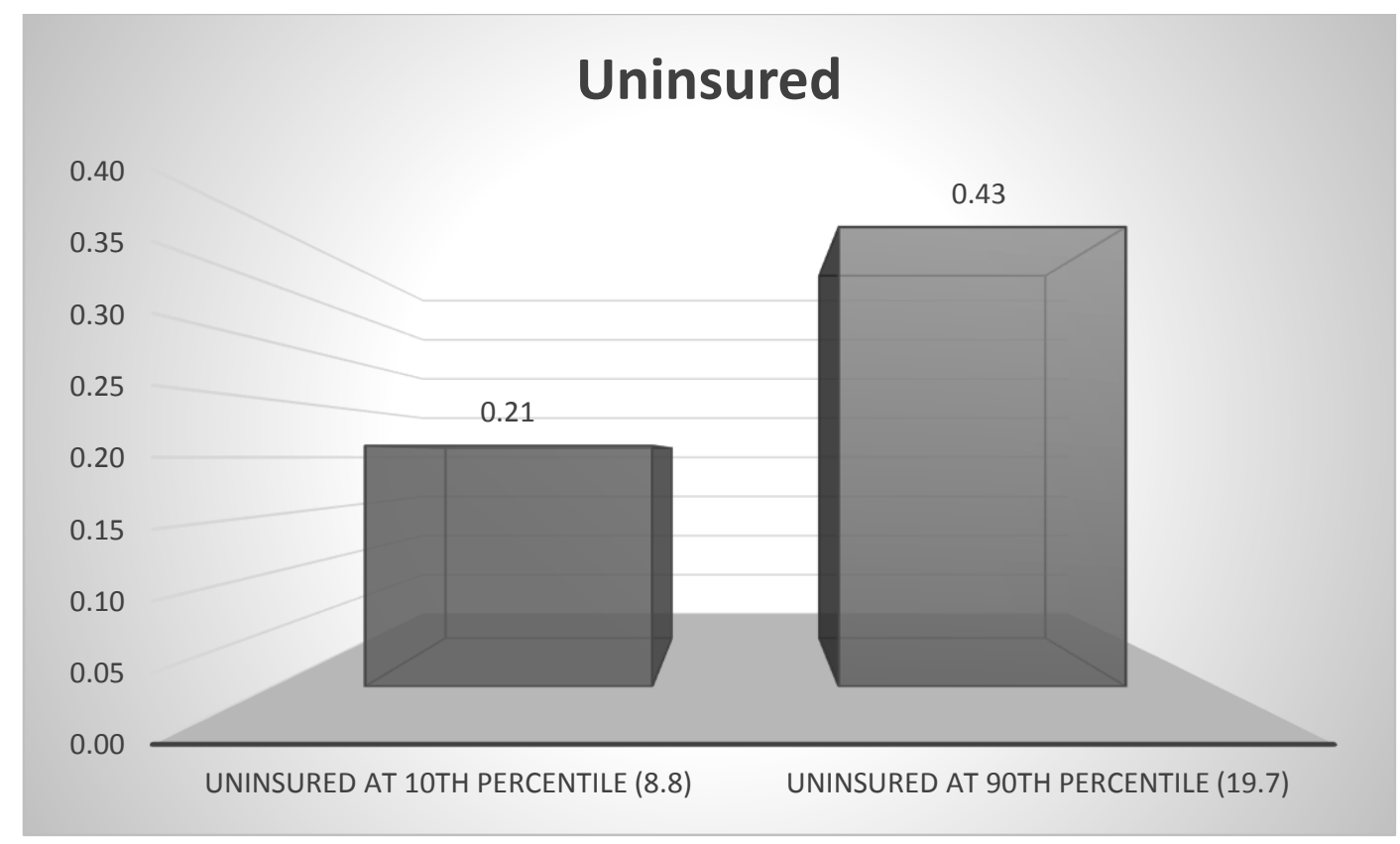

Figure 37. Predicted probabilities for percentage of persons uninsured in each state on participating in HIV risk behaviors.

Based on Figure 37 and Table 19, it can be seen that states that had more people who were uninsured had individuals who showed a trend toward higher probability of participating in HIV risk behaviors.

Figure 38 highlights the probabilities on the main effect for percentage of AIDS diagnosis among persons who were white in a state. 


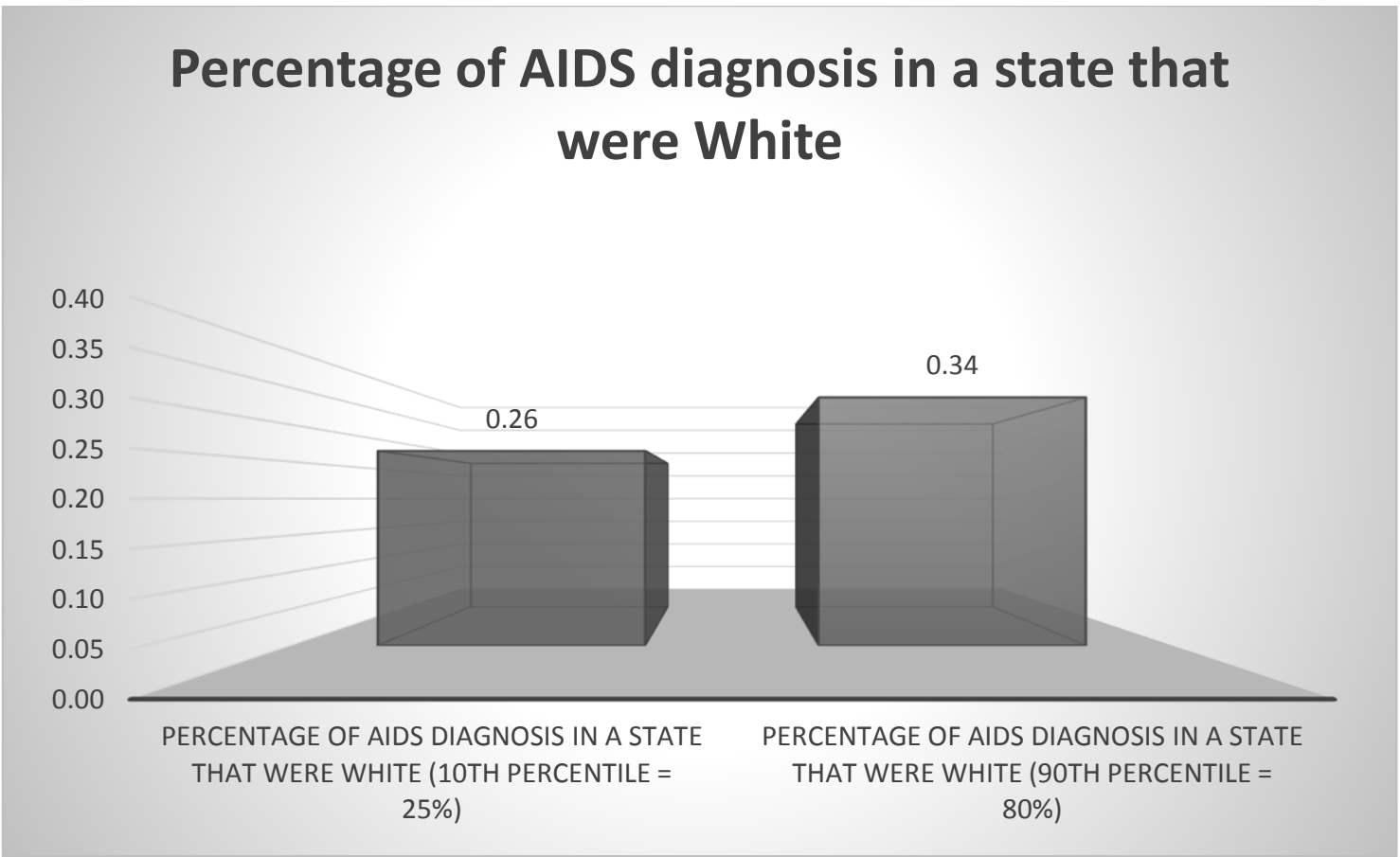

Figure 38. Predicted probabilities for percentage of AIDS diagnoses among persons who were white in each state on participating in HIV risk behaviors.

Based on Figure 38 and Table 19, it is clear that in states where there were higher percentages of people living with AIDS who were White, the higher the probability of their citizens to be engaged in HIV risk behaviors. It is important to also understand that the percentage of people living in a state with AIDS who were White, were highly negatively correlated with the percentage of African American females in a state (-0.81), the percentage of people living with AIDS who were African American (-0.89) and the percentage of females in a state living with AIDS (-0.78). It can therefore be assumed that the states with higher percentages of Whites diagnosed with AIDS, were also the states with less African American females in a state, less African Americans with an AIDS diagnosis and less females with an AIDS diagnosis. 
Figure 39 highlights the probabilities on the main effect for percentage of AIDS diagnosis in a state that were Asian.

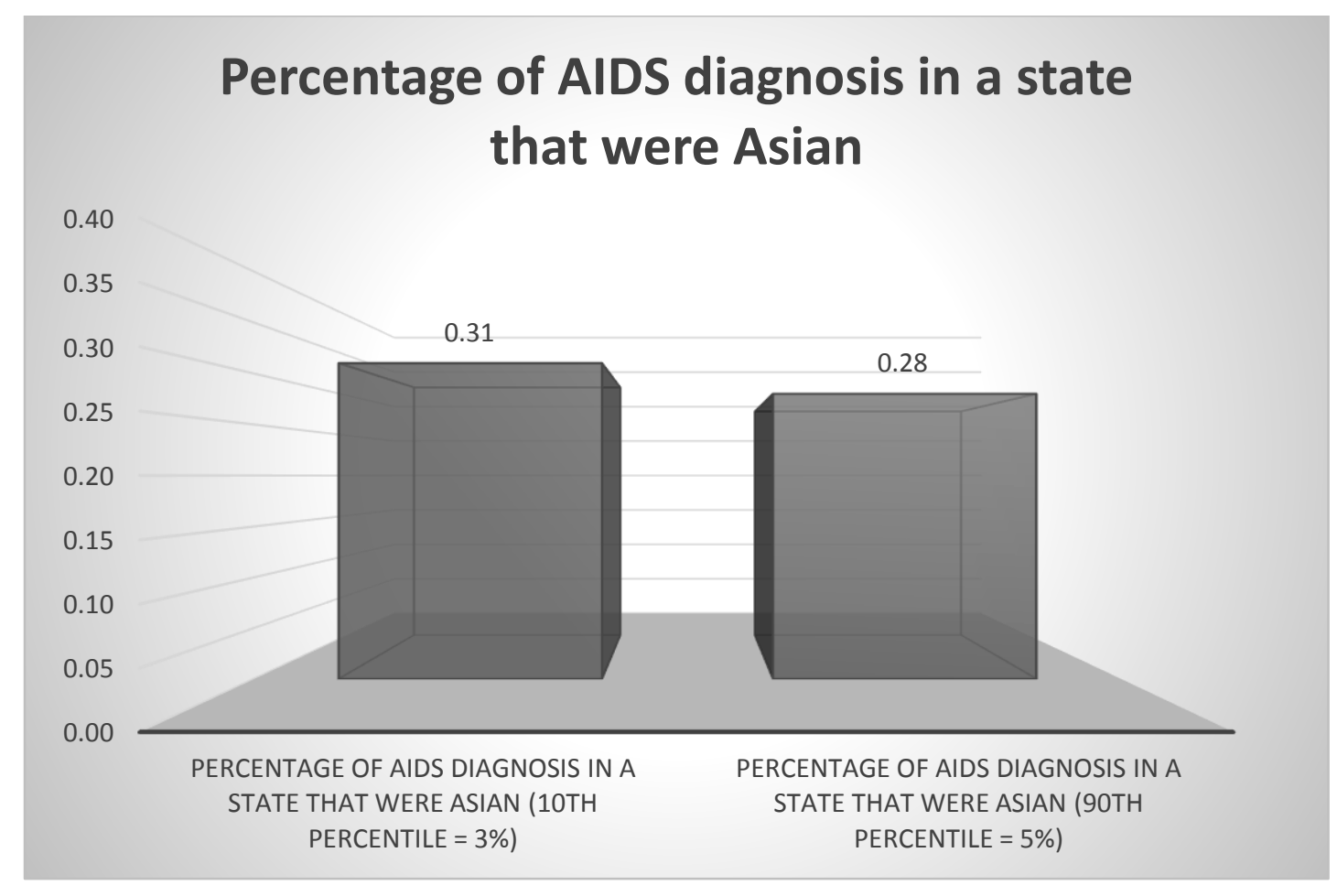

Figure 39. Predicted probabilities for percentage of AIDS diagnoses among persons who were Asian in each state on participating in HIV risk behaviors.

Based on Figure 39 and Table 19, it is clear that in states where there were higher percentages of people living with AIDS who were Asian, the lower the probability of their citizens to be engaged in HIV risk behaviors.

Figure 40 highlights the probabilities on the main effect for percentage of AIDS diagnosis in a state that were from the Other race group (including Native American/Pacific Islander, American Indian, and multiple races) than white, African American, Hispanic or Asian. 


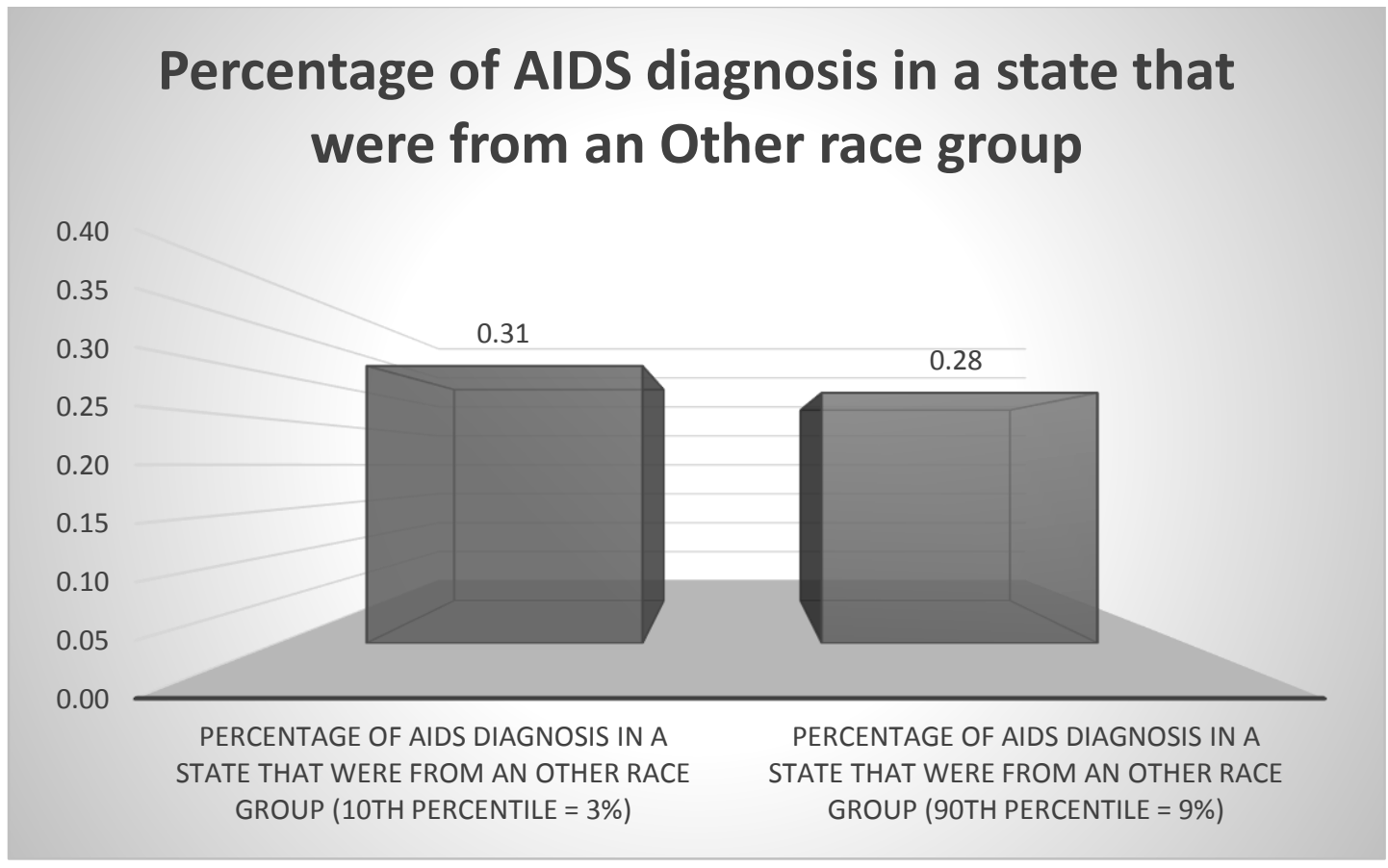

Figure 40. Predicted probabilities for percentage of AIDS diagnoses among persons who were in the Other race group in each state on participating in HIV risk behaviors. Other race group included Asians, Pacific Islanders, American Indians, and multiple races.

Based on Figure 40 and Table 19, it is clear that in states where there were higher percentages of people living with AIDS who were from an Other race group, the lower the probability of their citizens to be engaged in HIV risk behaviors.

\section{Summary and Conclusion}

In each step, the model fit improved using the DIC statistic. Overall, the probability for participating in HIV risk behaviors decreased from 2008 to 2011. In the overall sample, statistically significant individual predictors of HIV risk behavior were being younger, being male, being either African American or Hispanic, not being in a committed relationship, having less than high school education, being unemployed, living in an urban area, having cost as a barrier to health care, those with any health or mental health concerns, and having any alcoholic beverages in the past 30 days. 
Statistically significant environmental predictors that increased the probability of its citizens to be engaged in HIV risk behaviors were states that had less white females, states with more uninsured persons, and states with more white persons with AIDS, less Asians with AIDS, and less other race groups with AIDS.

In the next chapter, the relevance of these findings will be discussed, specifically addressing the implications for future research, social work practice, education, and policy. 


\section{CHAPTER V: DISCUSSION}

"We've got to keep pushing. We've got to make access to health care more available and affordable for folks living with HIV."

President Obama

This chapter will discuss the implications of the results in Chapter 4. First, the findings of the analyses will be discussed in reference to possible explanations of the findings and their convergence or divergence with previous literature. Next, practice and education implications of the study will be discussed followed by research and policy implications. Finally, limitations of the study are reviewed and suggestions made for future directions in social work research.

Using nationally representative data of adults over 50 from 2008 to 2011, a multilevel study using a repeated cross sectional methodology has responded to the research questions which asked if states had different levels of individual HIV risk behaviors, if there was change within states in their individual HIV risk behaviors over a period of four years, and lastly, which state and individual characteristics predicted HIV risk behaviors within and between states over a four year period. The study demonstrated that there were differences in states and their HIV risk behaviors, as seen in Figure 14 (Chapter 4) and differences between the state residuals for the log odds of participating in HIV risk behaviors, as seen in Figure 16 (Chapter 4). This study also revealed that there were changes, over time, in HIV risk behaviors, as illustrated in Figure 18 (Chapter 4). More importantly, this study showed the predictive ability of individual and state 
characteristics on participating in HIV risk behaviors, as seen in Tables 18 and 19 (Chapter 4).

Prior to adding in any predictors in the model, the probability of participating in HIV risk behaviors was $32 \%$, with $1.8 \%$ of the variance between states and $1.2 \%$ of the variance between state cohorts, illustrating that there was significant variation in individual HIV risk behaviors between states and between the state cohorts. States that identified as having the highest probability of participating in HIV risk behaviors were the District of Columbia, South Carolina, Arkansas, Alabama, and California. They differed significantly from those states with the lowest probability of participating in HIV risk behaviors, which were South Dakota, Iowa, Nebraska, Iowa, and North Dakota.

After adding time in, the probability of an individual participating in HIV risk behaviors decreased from $36 \%$ in 2008 to $30 \%$ in 2011, as seen in Figure 18 (Chapter 4). After adding in the individual main effects, the average probability of engaging in HIV risk behaviors only changed one percent between 2008 and 2011 as seen in Figure 20 (Chapter 4). After adding in the state main effects, average probability of engaging in HIV risk behaviors changed two percent between 2008 and 2011, as seen in Figure 22 (Chapter 4).

\section{Discussion of Hypothesis 1}

Based on the modeled data and the predictors of HIV risk behavior, the study supported research hypothesis \#1. This section will discuss the significant differences between the state with the lowest probability in participating in HIV risk behaviors (South Dakota) and the state with the highest probability in participating in HIV risk 
behaviors (District of Columbia), highlighting how the District of Columbia (D.C.)

followed most of the trends of predictors that had higher probabilities of participating in HIV risk behaviors.

\section{Individual Predisposing Characteristics}

The District of Columbia's mean age of older adults, which was 58.12 (SD=7.12), was lower than South Dakota's mean age of older adults, which was 60 (SD=8.2), indicating that persons who were younger were significantly more likely to participate in HIV risk behaviors compared to persons who were older. D.C. had more males $(n=178$; $56.3 \%)$ compared to South Dakota $(n=163 ; 48.5 \%)$ indicating that having more males in the state means there was a significantly higher probability of participating in HIV risk behaviors. D.C had more persons not in a committed relationship ( $\mathrm{n}=224 ; 70.9 \%)$ compared to South Dakota $(n=116 ; 34.5 \%)$, indicating that having more people not in committed relationships means there was a significantly higher probability of participating in HIV risk behaviors.

D.C had more persons who were African American ( $\mathrm{n}=142 ; 44.9 \%)$ and Hispanic $(8 ; 2.5 \%)$ compared to South Dakota $(n=1 ; 0.3 \%$ and $n=3 ; 0.9 \%$, respectively), indicating that people who were African American or Hispanic had a significantly higher probability of participating in HIV risk behaviors. D.C. had more people with less than a high school education $(n=30 ; 9.5 \%)$ compared to South Dakota $(n=19 ; 5.7 \%)$, indicating that people with less than a high school education had significantly higher probability of participating in HIV risk behaviors. D.C. had more people that were unemployed $(n=69$; $21.8 \%)$ compared to South Dakota $(n=23 ; 6.8 \%)$, indicating that people who were unemployed had a significantly higher probability of participating in HIV risk behaviors. 
All of D.C.'s sample lived in an urban area $(n=316 ; 100 \%)$ compared to South Dakota $(\mathrm{n}=72 ; 21.4 \%)$, indicating that people who live in an urban area had a significantly higher probability of participating in HIV risk behaviors.

\section{Individual Enabling Characteristics}

D.C. had more older adults who indicated that cost was a barrier to care $(n=40$; 12.7\%) compared to South Dakota $(\mathrm{n}=27 ; 8.0 \%)$, indicating that people who indicated cost as a barrier to receiving care had a higher probability of participating in HIV risk behaviors.

\section{Individual Need Characteristics}

D.C. had more older adults who indicated that they recently (in the past 30 days) had either 1-15 days ( $\mathrm{n}=100 ; 31.6 \%)$ of mental health concerns or 16-30 days $(\mathrm{n}=31 ; 9.8 \%)$. In comparison, South Dakota had less older adults who indicated that they recently (in the past 30 days) had either $1-15$ days $(n=65 ; 19.3 \%)$ of mental health concerns or 16-30 days $(n=20 ; 6.0 \%)$, indicating that people who had mental health concerns had a significantly higher probability of participating in HIV risk behaviors. On average, individuals that rated their health status worse had a higher probability of participating in HIV risk behaviors. In this instance, the data for these two states did not match the results of the study. A higher rating indicated worse health, where D.C. had a lower mean health status rating of 2.46, compared to South Dakota who had a higher mean health status of 2.54 .

D.C. had more older adults who indicated that they recently (in the past 30 days) had either $1-15$ days $(n=170 ; 33.9 \%)$ of physical health concerns or 16-30 days $(n=39$; 12.3\%). In comparison, South Dakota had less older adults who indicated that they 
recently (in the past 30 days) had either $1-15$ days $(n=83 ; 24.7 \%)$ of physical health concerns or $16-30$ days $(n=24 ; 7.1 \%)$, indicating that people with more physical health concerns had a significantly higher probability of participating in HIV risk behaviors. D.C. had more older adults who had alcoholic beverages in the past 30 days $(n=208$; $65.8 \%)$ compared to South Dakota $(n=185 ; 55.1 \%)$, indicating that persons who drank alcohol had a higher probability of participating in HIV risk behaviors.

\section{State Predisposing Characteristics}

On average, states that had less white females had a higher probability of participating in HIV risk behaviors. D.C. had a lower percentage of white females in the state $(38.1 \%)$ compared to South Dakota $(86.6 \%)$, indicating the context that the presence of less white females correlated with higher individual probability of participating in HIV risk behaviors.

\section{State Enabling Characteristics}

On average, states that had more persons who were uninsured had a higher probability of participating in HIV risk behaviors. Here is where D.C. and South Dakota differed from the findings. D.C. had a lower percentage of persons who were uninsured in the state (7.2\%) compared to South Dakota (12.4\%).

\section{State Need Characteristics}

On average, states that had more white persons with AIDS diagnoses had a higher probability of participating in HIV risk behaviors. Again, this is where D.C. and South Dakota differ from these findings; D.C. had fewer whites with AIDS (17\%) than South Dakota (64\%). A possible explanation for this difference observed is because of racial/ethnic composition in these states. D.C. is considered majority-minority, a term 
used to describe a state with over 50 percent of the population consisting of minorities (CDC, 2011b). D.C. did not have data available for AIDS diagnoses among Asians and subsequently reported $0 \%$, and South Dakota had $1.0 \%$, indicating the context that the presence of less Asians with AIDS diagnoses showed a higher individual probability of participating in HIV risk behaviors. D.C. had $1 \%$ of Other races with AIDS diagnoses compared to South Dakota at $19.0 \%$, indicating once again the context that the presence of less AIDS diagnoses among Other races showed a higher probability of participating in HIV risk behaviors.

With about 3\% of the D.C. population living with HIV (Magnus et al., 2010; HKFF; 2012g), there are several factors that contribute to an environment of increased risk exposure. D.C. is considered to be a "small, densely populated community with overlapping sexual networks that can fuel transmission” (HKFF, 2012, para.2). Additionally, there are healthcare access challenges, high rates of STDs, more men living with HIV/AIDS, more African American residents with HIV compared to the African American population in the District of Columbia, higher rates of drug use, and more poverty (HKFF, 2012g).

There is an understanding that most people contract HIV from participating in HIV risk behaviors such as having unprotected sex. In keeping with tenets of gender and power theory, factors such as poverty, having less education, being underemployed or unemployment, or having health concerns that are not addressed by a health professional sets up an environment that increases the possibility of exposure to HIV risk behaviors due to the relationships and social institutions they are involved in. These characteristics 
are relevant to the division of labor, wherein access to resources is based on educational attainment and opportunities for career establishment and advancement.

In addition to unprotected sex, D.C. has had struggles with public funding with regard to needle exchange programs, which have been shown to be highly effective in reducing HIV transmission among IDUs (McEnery, 2010). On an institutional level, the division of power in Connell's (1987) theory illustrates the context of dominant ideologies, how power is wielded, and how it perpetuates cycles of disadvantage among certain groups. As mentioned in Chapter 1, these and other social determinants of health are key to HIV prevention because they increase access to information about HIV transmission.

Comparing the differences in HIV risk behaviors across the states identified the strengths and shortcomings that are presented to older individuals within those states. By identifying what characteristics are related to HIV risk behavior relative to the state with the most risk and the state with the least risk allows for examination of the strengths and resiliency found in those environments. The first hypothesis of the study was supported by the findings and identified the states that had the lowest and highest probability of older adults participating in HIV risk behaviors.

\section{Discussion of Hypothesis 2}

Based on the modeled data and the predictors of HIV risk behavior, the study supported research hypothesis \#2. This discussion examines the second hypothesis tested, whether some states' individual HIV risk behaviors became less prevalent over time and other states' individual HIV risk behavior became more prevalent over time or did not change at all. 
It was seen in Figure 18 (Chapter 4) that overall, there was a decrease within states of HIV risk behaviors from 2008 to 2011. Some states experienced substantial growths in HIV risk behaviors and others substantial decreases in HIV risk behaviors. Figure 14 (Chapter 4) presented the growth plots for each state over time. The only state that experienced a continuous decrease in HIV risk behaviors over the four-year period was Oregon, going from $28.05 \%$ to $21.05 \%$ over the four years. Conversely, several states increased dramatically during 2009, 2010, and 2011. In 2009, two states increased sharply, tripling in their participation in HIV risk behaviors. California rose from $9.35 \%$ to $29.14 \%$, and Kansas rose from $9.05 \%$ to $33.03 \%$. In 2010, Florida had a dramatic growth, tripling from $14.58 \%$ to $45.42 \%$. In the final study year, several states saw significant increases, Georgia (20.425 to $46.48 \%$ ), Louisiana (14.65\% to $38.22 \%$ ), Minnesota (20.30\%-50.38\%), Missouri (14.0\% to 43.0\%) Montana (18.26\% to $42.61 \%$ ), and Nebraska (20.31\% to $41.67 \%)$. The mentioned states excluding Missouri doubled in HIV risk behaviors, whereas Missouri tripled in HIV risk behaviors among older adults.

A key trend that has been observed in the United States with regard to HIV incidence is that there has been a decline among individuals newly infected with HIV who are not MSMs (National Center for HIV/AIDS, 2010). HIV/AIDS reached its highest peak in the mid-eighties and then began to decline in the nineties after the introduction of anti-retroviral therapies (HKFF, 2013f). It is estimated that roughly $82 \%$ of people who have HIV have been diagnosed, $66 \%$ are linked to care, and one-fourth are virally-suppressed (HKFF, 2013f). What can be made of this observation of a decreased trend over time? In regards to older adults, it is possible that the nation is slowly realizing that older adults are not only living longer with HIV and AIDS, but they are also 
becoming infected later in life, raising additional awareness to some degree in the aging population, leading to a reduction in risk behaviors reported (Jacobs \& Thomlison, 2009; Levy-Dweck, 2005; Stall \& Catania, 1994; Winningham et al., 2004). There have been several HIV prevention programs geared at older adults that address knowledge about HIV and risk reduction behaviors (e.g., Cornelius, Moneyham, \& Legrand, 2008; Kral et al., 2000), and these could be attributed to the reduction of reported participation in HIV risk behaviors. The decrease could also be attributed to complacency; the issue that since people are living longer with HIV, the concern about it has faded. There exist the belief that because the concern has faded, it has led to people not reporting their participation in risk behaviors because they are not identifying those behaviors as risky (Jacobs \& Kane, 2011) and resulting in underreporting of actual behaviors or misidentification of risk behaviors (National Center for HIV/AIDS, 2010). There still remains a heavy stigma among older adults about HIV, therefore similar issues of underreporting may occur when asked about behaviors (Emlet, 2006). Because there is a paucity of literature on older adults and HIV risk behaviors, this limits the scope of discussing the trend observed in decreased HIV risk behaviors.

Using cumulative inequality theory (CIT), one can better understand the complexity of this issue. As mentioned by Estes (2001), there indeed are forces that contribute to the cycle of dependency as persons age, making it more challenging for persons who are at a disadvantage to withstand negative exposures. Inelman (2005) discusses that Western views on sexuality among older adults greatly contributed to stereotypes and ignorance, factors that can negatively influence the identification of risk behaviors among this population as well as helping professionals, especially groups 
considered high risk (i.e., homosexual, bisexual, and transgender). The first domain of CIT states that systems are responsible for generating inequality over the life course, adding to the notion that it would be challenging for older adults to withstand something so ingrained in society about gay lifestyles patterns or illicit drug use, and other behaviors associated with HIV risk. The third domain of CIT addressed how older adults are able to respond to risks or opportunities shapes their quality of life. Given the situation that older adults do not use condoms during sexual intercourse as much as younger populations is reflective of how their life was shaped with regard to sexual behavior, as older adults have attested to the fact that they have never used condoms and have never been tested for HIV (Stall \& Catania, 1994).

In terms of drug use, there has been an observed increase in heroin and methamphetamine use among Baby Boomer aged persons, which possibly can offer some accounting for what was observed in this study (Boeri, Sterk, \& Elifson, 2006). During 2006 to 2008 , about $4.7 \%$ of adults over 50 reported using an illicit drug in the past year, as seen in Figure 41. Drug use was found to be higher among the younger group (50-65) of older adults compared to older old adults (over 65) (Substance Abuse and Mental Health Services Administration [SAMHSA], 2010). Older old adults reported more nonmedical use of prescription drugs compared to the young old group, who reported more marijuana use. As a cohort that is the first in U.S. history with a majority having used illicit drugs, it is expected that substance abuse will be seen in this group (SAMHSA, 2009). This is reflective of the second domain of CIT, as it extends on the point that disadvantage can increase exposure to risk. 


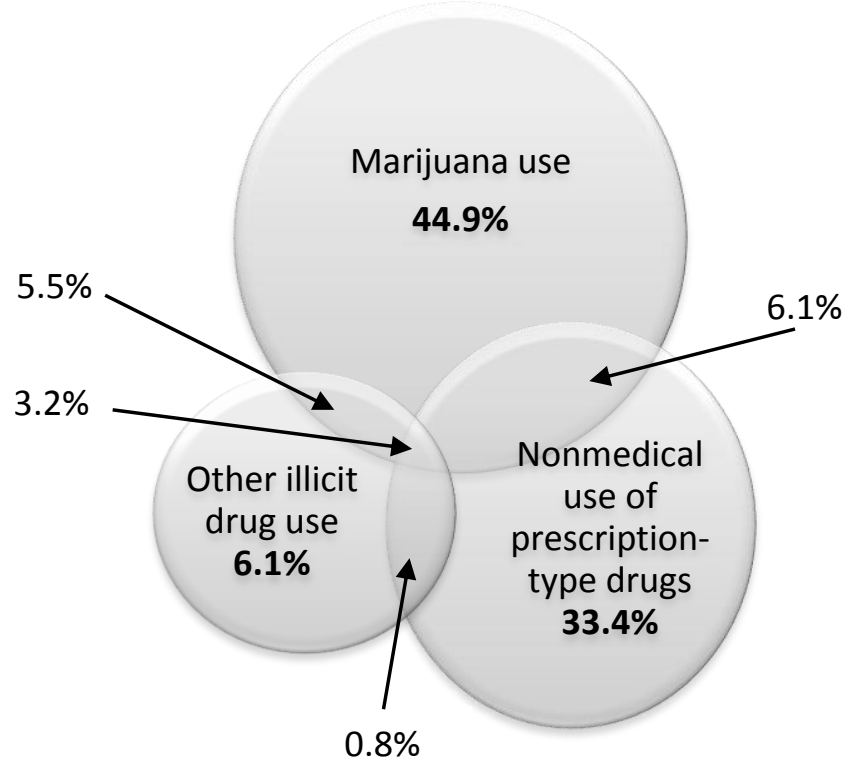

Figure 41. Type of illicit drugs used in the past year among adults age 50 or older who used illicit drugs in the past year: 2006 to 2008 (SAMHSA, 2009).

Additionally, some of the same predictors modeled in this study are also factors that have been associated with elevated rates of substance abuse among older adults, such as being male, not being in a committed relationship, and alcohol use (SAMHSA, 2009). Again, these are additional thoughts as to why an increase in HIV risk behaviors was observed in this study.

\section{Discussion of Hypothesis 3}

Based on the empirical findings made with this study, the third hypothesis was supported. The strong theoretical approaches used for this dissertation provided guidance in answering this final hypothesis. The discussion examines the third hypothesis tested, which individual and state level characteristics predicted HIV risk behavior.

Age. Younger groups of older adults are engaging in sexual activity at an increased frequency and with more people compared to groups of older old adults (those 65 and older) (Evans, 2011; Kral et al., 2000; Waysdorf, 2002). They are also more 
likely to engage in other risk behaviors, such as substance use, compared to older groups, further increasing their exposure to risk and participating in other HIV risk behaviors (Boeri et al., 2006; Kral et al., 2000).

Gender. Older men who have sex with men (MSM) have seen an increase with infection rates since 2007 (CDC, 2013), compared to older women who have experienced a decline in HIV infection rates (CDC, 2013). This has also been seen when looking at transmission routes, as being a MSM is the highest risk category for older adults, at $60 \%$, compared to heterosexual sex and being an IDU.

Marital status. Being in a committed relationship offers a protective factor for older adults against participating in HIV risk behaviors, as it greatly reduces the gendered power dynamics that can dictate social roles in a relationship (Chimbiri, 2007;

Hagedoorn et al., 2006). Those who are not in a committed relationship are likely to experience more encounters related to dating, which can increase potential sexual partners and exposure to other situations that are related to HIV risk behaviors due to the lack of having a steady partner in a committed relationship.

Race/ethnicity. Being an older person of color greatly increases risk exposure, as HIV/AIDS is disproportionately affecting African Americans and Hispanics compared to their size in this nation (Ward et al., 2011). The results of this study and other studies of people of color support claims that there exist additional barriers and cultural and gendered dynamics that make it difficult for people of color to be resilient against their HIV risk exposures (e.g., Ahmed et al., 2001; Bowleg et al., 2004; El-Bassel et al., 2009).

Education. Older adults with less education are less likely to be informed about risk behaviors and how to remain safe in interpersonal relationships (Whyte, 2006). It 
was found in this study that persons with less than a high school education had a higher probability of participating in HV risk behaviors. Having more education as an older adults means that they will have greater influence in decisions that they make for their lives and better understand HIV risk behaviors (Corneille, Zyzniewski, \& Belgrave, 2008; Hasnain et al., 2007; Jukes et al., 2008). It has been seen that in terms of protective factors, those who attended college reported higher HIV knowledge, more favorable attitudes about condoms, and had higher condom negotiation efficacy (Corneille et al., 2008).

Employment. Lack of employment or the benefits of employment can make it difficult for older adults to provide for some of their basic needs (Tugend, 2013), and while the effects of employment status of older adults and HIV risk behavior have yet to be explored, what was found in this study indicated that those unemployed had the greatest risk of participating in HIV risk behaviors. To be considered also is what is known from looking at younger populations, that there is the increased likelihood of participating in behaviors to gain resources, resulting in those challenges related to the balance of power within relationships and increased exposure to risk taking behaviors (Oser et al., 2008).

Residence. Urban areas are recognized as having more social issues related to housing, higher prevalence of STDs including HIV, and mental health issues compared to non-urban areas (Neblett et al., 2011). Additionally, more high-risk sexual practices have been accounted for in urban areas (Nyamathi et al., 2008; CDC, 2006a). In support of existing evidence, this study showed that for older adults, those in urban areas had the 
highest probability of participating in HIV risk behaviors when compared to suburban and rural areas.

Cost as a barrier to care. For older adults who cannot access healthcare because of out of pocket expenses, it presents a barrier to care that can be costly, especially in terms of screenings and treatment (Thorpe, Thorpe, Kennelty, \& Pandhi, 2011). In support of this aspect, this study found that those not being able to see a doctor because of cost had a higher probability of participating in HIV risk behaviors. Given the changing needs of older adults, access to care is a paramount issue and older adults who experience a barrier such as affordability are likely to experience other related access issues.

Mental health. Older adults experience more mental health issues as they age, and it is not uncommon that they also mistakenly assume that a condition such as depression is a normal part of getting older (National Institute of Mental Health [NIMH], n.d.). This can lead to additional mental and behavioral health concerns for this group. Groups of older adults who experience mental health issues are also less likely to get the care they need and resort to maladaptive coping mechanisms to deal with the issues (American Psychological Association [APA], n.d.). Observed in this study, and others (i.e., Jacobs \& Kane, 2011; Kok, Hospers, Harterink, \& De Zwart, 2007; Westerhof, Maessen, de Bruijn, \& Smets, 2008) was that persons who had more days (16-30) of mental health issues had the highest probability of participating in HIV risk behaviors.

General health. As an important measure of subjective well-being, general health status can dictate the dynamics of relationships and can a play a substantial role in participating in risk behaviors. This study revealed that those who reported a worse 
rating of health had a higher probability of participating in HIV risk behaviors. This is supported by previous evidence that states that a worse health status is associated with more risk taking behaviors (Aronowitz et al., 2007; Foti \& Eaton, 2010).

Physical health status. In looking at the physical health in the older community, there is evidence that shows that there are multiple health and well-being outcomes that stem from having a positive physical health status, such as seeing good physical health as a resource and being beneficial to the psychological and social aspects of life for community dwelling older populations (Conn, 2007). Anderson and Davidson's (2007) model capture this idea with the domain of need characteristics, as perceived need drives health behaviors and health outcomes. It was observed in this study that persons who had more days of physical health issues had the highest probability of participating in HIV risk behaviors.

Drinking alcohol. Abusing alcohol can impair judgment, which can lead to a person being involved in HIV risk behaviors (National Institute on Alcohol Abuse and Alcoholism [NIAAA], n.d.) . Understanding how alcohol influences HIV is critical, as it has been substantiated that nearly $50 \%$ of persons who have HIV also have histories of alcohol problems, further dictating how the disease is transmitted (Lefevre et al., 1995). Alcohol can increase the viral load in a person who is infected, and that greatly increases the transmission of HIV in communities (Samet, Horton, Meli, Freedberg, \& Palepu, 2004). Drinking is a social activity at times, and that means that alcohol consumption can draw people to places such as bars or clubs where they can meet potential sex and/or drug partners (NIAAA, n.d.). This study revealed that persons who had alcohol had a higher probability of participating in HIV risk behaviors, supporting the fact that alcohol 
use does in fact impair judgment, increasing the likelihood of participating in risk behaviors.

On the state level, this study found that in states that had less white females, more people who were uninsured, more whites with AIDS, less Asians with AIDS, and less people of other races with AIDS, there was a higher the probability for participating in HIV risk behaviors. A way to look at this result is to revisit the geographic distribution racial/ethnic groups. Urbanization eases the transmission of HIV, as seen in Figure 4 (Chapter 1). In terms of older adults, one-third reside in a very urban region of this nation, the South, who has not only the highest rate of HIV but the largest concentration of the African American population (CDC, 2013i). Tables 18 and 19 (Chapter 4) illustrated the negative relationship between white females and the percentage of ethnic minorities in a state. Additionally, being white with an AIDS diagnosis had a strong negative relationship with being African American, being African American with AIDS, and being a female with AIDS. Therefore, it is supported that being a member of an ethnic minority places persons in a context of having an increased risk to HIV risk behaviors. Lastly, states in the South have the highest number of residents who do not have health insurance (CDC, 2012g), again illustrating the context of being in an environment that increased risk to exposure.

\section{Implications of the Study}

As HIV/AIDS continues to evolve and challenge the way we see the disease, there are a number of steps that can be taken guide the work of practitioners, inform educators about training needs for students, propose scientific approaches that add a dimension to existing knowledge, and connect with current policies that can have a direct impact on 
the wellbeing on older adults when it comes to HIV/AIDS care. These intersecting pathways are envisioned for all levels of social work practice, as they entail working with client systems (micro), systems that affect client systems (mezzo), and involve the processes of social planning and community organizing (macro) (Hepworth, Rooney, Rooney, \& Strom-Gottfried, 2013).

\section{Practice Implications}

The results of this study have practice implications for understanding how to work with older adults and address issues related to HIV risk behavior using existing systems commonly associated with aging. Through the direct provision of services, social workers provide case management and counseling services that cover an array of older adults' needs. As coordinators and advocates, social workers who specialize in working with adults are in a prime position to serve as brokers of information about HIV risk behaviors. In a nutshell, the individual practitioner is in the position to make decisions, yet in that capacity has the difficult task of navigating through the complex web of systems and relationships that are involved when working with older adults (Gray, Plath, \& Webb, 2009).

While guided and mandated by interagency policies, practitioners remain in a position to act on behalf of clients to obtain resources and services that would otherwise, not be provided. The question remains, how many social work practitioners are running to give workshops to older adults in the community to educate them on identifying sexual risk behaviors, to talk about making a plan to discuss sexual health and preferences prior to engaging in sexual activity with a partner, or having the talk with a partner about getting an HIV test? Given the range of training that is provided to gerontological social 
workers, it is the thought of the author that the only practitioners who would take this on are those that have an exact interest and take it upon themselves to get additional training that better prepares them for these activities.

Practitioners can take several steps to maximize their position in older adults' lives to address this issue HIV risk. A primary step is for social workers to extend their evidence-based practices to other disciplines, using research evidence that is interdisciplinary in nature to inform them about best practices regarding behavior change, as it well known that behavior change is key to reducing participating in risk behavior (Crosby et al., 2009). There is some evidence of areas to focus on when working with older adults, such as focusing on psychosocial factors that are associated with HIV risk behaviors to increase things like self-efficacy and to educate on general knowledge about transmission and risks (Boeri et al., 2006; Winningham et al., 2004). HIV/AIDS is such a public health issue that social workers will need to be comfortable with reading public health literature and understand more complex interventions to really be able to consider what modifications would be necessary to carry out programs in older communities.

Discussed previously in this study was much of what exist in regards to best practice interventions is based on populations that are not older adults (Emlet, 2006; Waysdorf, 2002). A systematic review of literature conducted by the CDC HIV Prevention Research Synthesis Team identified interventions that demonstrated best practices in terms of reducing HIV risk. Of the 18 interventions, two had samples with mean ages over 40, and the oldest participants ages 59 and 89 (Lyles et al., 2007). What this signals is that while the evidence is limited when focusing on populations of older adults (Akers, Bernstein, Doyle, \& Corbie-Smith, 2008; Jacobs \& Kane, 2010;2011; 
Lindau et al., 2007; Ward et al., 2004), what currently is known is applicable for prevention efforts (CDC, 2008). Practitioners will have to use existing studies that have been conducted on other populations (DiClemente et al., 2009, Longfield, Glick, Waithaka, \& Berma, 2004; Magnus et al., 2010) and then with a close lens, use life course and cognitive behavioral theories to go back and modify for this population (Emlet, 2006; Ferraro \& Shippee, 2008; Fullilove, Fullilove, Haynes, \& Gross, 1990; Heckman, 2000).

Secondly, practitioners will need to request for trainings and continuing education efforts that cater to this topic. This will require practitioners to come together and host mini-workshops and luncheons for other interested practitioners, and carve out time for professional development to consider what it is they need to know and how to access that knowledge, whether it be through an online course or having a guest speaker from a local university come and give a training. To support this route, a third step is becoming familiar with and using public databases, such as the Campbell Collaboration, the Cochrane Collaboration, SAMHSA's National Registry of Evidence-based Programs and Practices, and the CDC Compendium of Evidence-Based HIV Behavioral Interventions. These databases and sites contain systematic reviews and behavioral interventions that have been deemed as best practices.

\section{Education Implications}

With the interest and emphasis on the Educational Policy and Accreditation Standards (EPAS) across the departments and schools of social nationwide, there is a precendent that universities are presenting students with curriculums that are not only 
sound but also rigourous, multi-faceted, and most importantly, have prepared them to be generalist or advanced practitioners. In keeping with the tenets of competent preparation standards, therein awaits an open door for a focus in HIV education for social work students. Having created and taught an elective that focuses on the connection between social work roles and HIV disease management, it has been observed by the author that there is a very high likelihood that students in social work will be exposed to some facet of HIV/AIDS during their career. From field placements to a job in the field where one is working with the homeless population, veterans, child welfare, substance abuse, aging, social justice, some part of HIV/AIDS may touch their educational experience.

Schools of social work have the opportunity to provide their students with a unique experience by offering electives that are cross-listed and interdiscplinary that have a focus on some aspect of HIV/AIDS. Common now is to have sessions in core curriculum courses dedicated to social issues, and HIV/AIDS can also be streamlined in. Additionally, as there is a growing trend in specializations, it would also be wise to investigate and invest in creating specialization tracks in HIV/AIDS, due to the growing number of PLWAs and their diverse needs in addition to policy-level changes that are going to open access to services for persons living with AIDS and require more social service agents to be able to provide service to them. Students will need training and support to learn about the policy and systems that regulate care for various groups of the population related to HIV/AIDS from the standpoint of an applied science such as social work. Also, the epidemic is intergenerational, as we see children, young families, and grandparents caught in the middle of providing care or needing care as it relates to some side of this disease. Students and working professionals need schools of social work to 
provide a heterogenous mix of course offerings and continuing education opportunities that relate to HIV/AIDS to be adequately prepared and competent to serve consumers and community. Educators who have interest in this field should be apart of curriculm committees and participate in outside departments activites as well that share the interest, building partnerships for student learning projects as well as academic collaborations. As an educator, it would imperative to identify a scholar in the field that has experience teaching about HIV/AIDS, possibly shaing ideas, readings, and syllabi. This will foster the growing interest and create a wider network of support for other educators who may be interested along the way. Faculty interests fuel student interest, and there is no limit to where that can take the social work profession as far a visibility about caring for people and their situations, and being recognized as leaders and experts about how to execute that.

\section{Research Implications}

This study has several methodological implications that can strengthen future research in the area of HIV/AIDS specific to aging and older populations. The purpose of this study was to 1) see if states changed in their HIV risk behavior, 2) see if within states, there was change over time in HIV risk behavior, and 3) identify the individual and environmental characteristics that predict HIV tisk behavior among adults over 50. The results of this study extend our understanding about predicts this behavior, yet further discussion of these areas and their implications for future research is warranted.

Individual characteristics matter. As illustrated in this study and others (Winningham et al., 2004; Wyatt, 2009) that have samples of older adults, individual characteristics matter. As the variables in this study were limited to the data used, there 
are other variables that reflect context that fit in these domains that should also be explored. In terms of social structure variables, or characteristics that reflect the social arrangements one holds in society, future research should include variables such as social networks, social support sytems, living arrangements, indicators of the presence of a secondary partner when in a committed relationship, being a survivor of sexual assault, being in survivor of domestic violence/intimate partner crime, and religious affliation and activities (Andersen \& Bozzette, 2000). Enabling resources, what enables or deters one from participating in risk behaviors, should also include communication with partners about sexual health, communication with medical professionals about sexual health, partner's health status, and being tested for HIV. A need factor that could be explored is if there was a history of being in substance abuse treatment, given the association of substance abuse and HIV risk behaviors and what is know about older adults with substance abuse issues and lifetime patterns of abuse (Boeri et al., 2006; Jyrkkä, Enlund, Korhonen, Sulkava, \& Hartikainen, 2009).

For studies that investigate women's risk, to also be investigated are these factors in addition to if they are post-menopausal or not, as it has been discussed the association between menopause and having unprotected sex among older adults (e.g., Levy-Dweck, 2005). For studies that investigate men's risk, in addition to the above stated factors is if they are taking sexual enhancements medications, as there is an association between increased sexual activity and HIV risk behaviors among older adults (Levy-Dweck, 2005). Emerging is the inclusion of transgendered populations in studies, and among older adults this should be accounted for as well, as there are challenges for aging LGBT groups that need further exploration. They are less likely to have a partner, be without stable housing 
(due to employment barriers), and will likely encounter healthcare access issues that the current healthcare industry is unprepared to deal with (i.e. if a transgender male has certain anatomical features of a female) (Herman, 2010). This group is also at risk for more substance abuse issues and attempting suicide as maladpative coping mechanisms for coping with mistreatment (Herman, 2010). This group has distinct vulnerabilities that need to be highlighted through dissemination of research to reach service providers and community organizers, as well as teaching institutions and policies that regulate service for populations deemed having the greatest social need (Auldridge, Tamar-Mathis, Kennedy, Ames, \& Tobin, 2012).

Context matters. Research that is inclusive of environmental factors add to the methodological quality of studies because they address the criticisms that say research has not paid enough attention to social interactions and culture, both associated with participation in HIV risk behaviors (Levy et al., 2003; Logan et al., 2002). In addition to what was explored in this study should be considered reactions to race, as older ethnic minorities are a population that have accumulated experiences related to race, which should be accounted for as it affects their quality of life (Ferraro \& Shippee, 2009). The prevalence of elder abuse should also be considered, as an additional indicator of a risky environment. To also be considered are those indicators that are reflective of resiliency among older adults, factors that provide strength and are protective. This could look like the percentage of adult day centers in a community, the percentage of agencies that serve older adults, and the proportion of services that are provided by state Area Agencies on Aging, to name a few. 
Design implications. Some things to be considered for future studies of older adults and HIV risk are examining different cohorts of older adults (i.e., Baby Boomers, the Silent Generation), longitudinal studies, using an appropriate level of analysis that considers the cultural and social aspects related to aging, replicating existing studies with diverse older populations to assess for fit and identify cultural adaptations, using more qualitative inquiry to identify concepts that need further investigation, and lastly, successfully disseminating study findings to academic and non-academic communities (Levy et al., 2003).

\section{Policy Implications}

System level developments are necessary to support all levels of practice and training for professionals who are working with older adults who are affected and/or infected with HIV. Moving beyond individually-focused intiatives, such as encouraging testing in older populations, support is needed to re-educate aging groups of all types about risk behaviors, risk exposures, and how to re-think how HIV can affect them. In order to achieve this, recognition of aging concerns is needed as well as support to pursue related research and education.

The National HIV/AIDS Strategy includes three goals: to reduce the number of people who are infected with HIV, improving access to care for those living with HIV, and reducing health disparities (HealthyPeople.gov, n.d.). Groups of interest are adolescents and adults, MSM, and pregnant women (those considered as high risk for infection). Examples of a few of the policies that will focus on improving outcomes are increasing healthcare coverage, maintaing support for federal programs that play a vital 
role in HIV care, such as the Ryan White Program, and very important to this study, focusing on prevention interventions that work and having funding for HIV/AIDS programs ("AIDS.gov", 2013).

The Affordable Care Act. As discussed in Chapter 3, Medicaid is a major source of health coverage to PLWA. As a bridge to healthcare access, this piece of legislation, once fully implemented, will provide healthcare to not only children with HIV or AIDS who were previously denied coverage due to a pre-existing condition, but it will also provide coverage for non-disabled persons infected with HIV who do not have dependent children (Kates, 2012). In terms of HIV risk behaviors, this means that people who are infected who have not had medical treatment can now receive care and medications that will reduce their viral load, suppressing the virus, delaying the development of AIDS, and for communities, reducing the amount of exposure to risk.

Prevention programs. While funding for prevention programs lies heavily upon the groups being categorized as high risk (National Center for HIV/AIDS, Viral Hepatitis, STD, \& TB Prevention, 2011), older adults are under the radar; this is where change is paramount. This study illuminated some of the characteristics that increase participation in HIV risk behaviors, therefore, given the rate of growth of the older population, older, ethnic minorities, and the ratio of professionals who are trained in gerontology and geriatrics, this identifies the need for older adults to become a priority population. It has been identified that there is more knowledge that is needed regarding older adults and HIV risk, that multilevel approaches should be used, and to also consider successful prevention interventions that have been used among younger populations (CDC, 2008). These programs include education to increase knowledge, skills training, 
culturally sensitive messages, and strategies for older women to negotiate safer sexual behavior (CDC, 2008). It is also the thought of the author that prevention strategies should include the exploration of risk behaviors, specifically among older communities of color, older women, older persons who identify as LGBT, because of the diverse and agespecific needs that are present yet unexplored. Prevention strategies should also be explored among health and helping professionals, as they can serve as educators and perform risk assessment to identify the need for interventions, referrals, and related services. Given what we know about mistrust of the medical community among populations of older adults (Ahmed et al., 2001; Cené et al., 2011), prevention strategies will need to expand to clinicians and medical professionals, providing training on issues of mistrust and how to maximize their interactions with consumers when it comes to risk assessments and education.

\section{Limitations}

Although great measures were taken to ensure a strong study, this study, like others, has several limitations due to its nature. Prior to listing the limitations, however, it is important to note a couple of strengths that are vital to the research: 1) the use of a nationally, representative sample of adults aged 50 and older, 2) the inclusion of individual and environmental characteristics, which is a small yet growing characteristic in HIV research, 3) using all 50 states and the District of Columbia, as several large scale studies select regions or specific states to concentrate on when examing issues related to HIV issues and older adults (e.g., Wigfall, Williams, Sebastiann, \& Glover, 2010), and to date, 4) the first study that has using a multilevel approach to explore HIV risk behaviors among adults 50 and older. 
The first limitation to be addressed is variable selection. Being that this study was limited to existing data, this limited the measures associated with the theories and framework used. For example, the National Social Life, Health, and Aging Project (NSHAP) is a population based-study that examines health and aging, specifically looking at social and intimate relationships of a nationally representative sample of 3,005 individuals ages 57-85 (Lindau et al., 2007). In addition to using questionnaires, this study also collected biomeasures which provided additional health information. The additional variables that were discussed earlier in this chapter could be explored using this data. This also applies to the outcome variable, HIV risk behavior, as it was limited to the categories presented in the BRFSS questionnaire. Additional ways to operationalize HIV risk behaviors include having multiple sex partners and having sex with someone whose HIV status is unknown (CDC, 2010d).

Another limitation is that this study was a trend study. While it revealed changes, it provided limited insight as to how the changes have taken place as well as revealing little change over time. In public health studies, a small amount of change can mean a lot practically, however, that is a strength in longitudinal studies. Longitudinal studies can detect changes over a period of time, providing researchers and consumers information about causal relationships between variables, pointing out the variation over time (Dudley, 2011). This allows for the detections of patterns and trends that can be monitored.

Important to note is that this study classified older adults as persons 50 and older, whereas the usual classification of age of older adults has been 65 and up. This is largely due to that age of 65 being a marker for receipt of benefits for the older population. The 
limitation this presents is that in terms of the findings of this study, one should interpret with caution because of that gap in age.

\section{Summary and Conclusion}

Results of this study support the hypotheses that HIV risk behaviors are different between states, that it changes over time within states, and that there are both individual and environmental predictors of participating in HIV risk behaviors among adults who are 50 and older in the United States. This study provides empirical support for the notion that for older adults, there are certain predisposing, enabling, and need factors relative to Andersen and Davidson's (2007) health utilization model, that predict their participation in HIV risk behaviors. Using a multilevel model analytic technique, significant predictors were identified and discussed in terms of their contribution to HIV risk behaviors for this group. It was concluded that this study has allowed for a change in how research should investigate HIV risk among older populations, serving as a catalyst for understanding the context in which older adults are exposed to HIV risk situations. This study is one that has great potential for future applied uses for practice, education, and research. 


\section{REFERENCES}

Ahmed, S., Lemkau, J., Nealeigh, N., \& Mann, B. (2001). Barriers to healthcare access in a non-elderly urban poor American population. Health \& Social Care in the Community, 9(6), 445-453.

AIDS.gov. (2013). Accelerating improvements in HIV prevention and care in the United States through the HIV Care Continuum Intitiative. Retrieved from AIDS.gov website: http://aids.gov/federal-resources/national-hiv-aids-strategy/hiv-carecontinuum-initiative-fact-sheet.pdf.

Ajzen, I., \& Albarracin, D. (2007). Prediction and change of health behavior: Applying the reasoned action approach. Mahwah, New Jersey: Lawrence Erlbaum Associates.

Akers, A. Y., Bernstein, L., Doyle, J., \& Corbie-Smith, G. (2008). Older women and HIV testing: examining the relationship between HIV testing history, age, and lifetime HIV risk behaviors. Sexually transmitted diseases, 35(4), 420-423.

Amaro, H., Zuckerman, B., \& Cabral, H. (1989). Drug use among adolescent mothers: Profile of risk. Pediatrics, 84(1), 144-151.

American Psychological Association. (n.d.). Mental and behavioral health and older Americans. Retrieved from http://www.apa.org/about/gr/issues/aging/mentalhealth.aspx.

Andersen, R. (1995). Revisiting the behavioral model and access to medical care: Does it matter? Journal of Health \& Social Behavior, 36(1), 1. 
Andersen, R., \& Bozzette, S. (2000). Access of vulnerable groups to antiretroviral therapy among persons in care for HIV disease in the United States. Health Services Research, 35(2), 389-416.

Andersen, R., \& Davidson, P. (2007). Improving access to care in America: Individual and contextual indicators. San Francisco, CA: Jossey-Bass.

Aral, S., Mosher, W., \& Cates, W. (1992). Vaginal douching among women of reproductive age in the United States: 1988. American Journal of Public Health, $82(2), 210-214$.

Ark, P., Hull, P., \& Husaini, B. (2006). Religiosity, religious coping styles, and health service use: Racial differences among elderly women. Journal of Gerontological Nursing, 32(8), 20-29.

Aronowitz, T., Todd, E., Agbeshie, E., \& Rennells, R. (2007). Attitudes that affect the ability of African American preadolescent girls and their mothers to talk openly about sex. Issues in Mental Health Nursing, 28(1), 7-20. doi:

$10.1080 / 01612840600996158$

Auldridge, A., Tamar-Mathis, A., Kennedy, S., Ames, E., \& Tobin, H. (2012). Improving the lives of transgender older adults: Recommendations for policy and practice. Retrieved from SAGE (Services and Advocacy for GLBT Elders) and National Center for Transgender Equality (NCTE) website: http://transequality.org/Resources/TransAgingPolicyReportFull.pdf.

Bandura , A. (1990). Perceived self-efficacy in the exercise of control over AIDS infection. Evaluation and Program Planning, 13, 9-17. 
Biglan, A., \& Hayes, S. (1996). Should the behavioral sciences become more pragmatic? The case for functional contextualism in research on human behavior. Applied and Preventive Psychology, 5(1), 47-57.

Birnbaum, G., \& Laser-Brandt, D. (2002). Gender differences innthe experience of heterosexual intercourse. Canadian Journal of Human Sexuality, 11(3/4).

Black, M., Basile, K., Breiding, M., Smith, S., Walters, M., Merrick, M., ... Stevens, M. (2011). The national intimate partner and sexual violence survey (NISVS): 2010 summary report. Retrieved from the National Center for Injury Prevention and Control, Centers for Disease Control and Prevention website: http://www.cdc.gov/violenceprevention/pdf/nisvs_executive_summary-a.pdf.

Boeri, M., Sterk, C., \& Elifson, K. (2006). Baby boomer drug users: Career phases, social control, and social learning theory. Sociological Inquiry, 76(2), 264-291.

Bonomi, A., Anderson, M., Rivara, F. P., \& Thompson, R. S. (2009). Health care utilization and costs associated with physical and nonphysical-only intimate partner violence. Health services Research, 44(3), 1052-1067.

Bowleg, L., Lucas, K., \& Tschann, J. (2004). The ball was always in his court: An exploratory analysis of relationship scripts, sexual scripts, and condom use among African American women. Psychology of Women Quarterly, 28(1), 70-82.

Boynton-Jarrett, R., Ryan, L., Berkman, L., \& Wright, R. J. (2008). Cumulative violence exposure and self-rated health: Longitudinal study of adolescents in the United States. Pediatrics, 122(5), 961-970.

Bronfenbrenner, U. (1979). The ecology of human development. Cambridge, MA: Harvard University Press. 
Cahill, S., Darnell, B., Guidry, J., Krivo-Kaufman, A., Schaefer, N., Urbano, L., . . . Valadex, R. (2010). Growing older with the epidemic: HIV and aging. Retrieved from http://www.gmhc.org/files/editor/file/a_pa_aging10_emb2.pdf.

Calvet, H. (2000). STDs in older adults: The need for increased awareness. Clinical Geriatrics, 8(8), 94-100.

Card, J., Amarillas, A., Conner, A., Akers, A., Solomon, J., \& DiClemente, R. J. (2007). The complete HIV/AIDS teaching kit. New York, NY: Springer Publishing Company, LLC.

Cené, C., Akers, A., Lloyd, S., Albritton, T., Powell Hammond, W., \& Corbie-Smith, G. (2011). Understanding social capital and HIV risk in rural African American communities. Journal of General Internal Medicine, 26(7), 737-744.

Central Intelligence Agency. (n.d.). Country comparison: Distribution of family incomeGini index. Retrieved from https://www.cia.gov/library/publications/the-worldfactbook/rankorder/2172rank.html.

Cheng, W., Garfein, R., Semple, S., Strathdee, S., Zians, J., \& Patterson, T. (2010). Increased drug use and sti risk with injection drug use among HIV- seronegative heterosexual methamphetamine users. Journal of Psychoactive Drugs, 42(1), 1118.

Chimbiri, A. M. (2007). The condom is an 'intruder' in marriage: Evidence from rural Malawi. Social Science \& Medicine, 64(5), 1102-1115.

Chou, A. F., Brown, A. F., Jensen, R. E., Shih, S., Pawlson, G., \& Scholle, S. H. (2007). Gender and Racial Disparities in the Management of Diabetes Mellitus Among Medicare Patients. Women's Health Issues, 17(3), 150-161. 
Coady, M., Latka, M., Thiede, H., Golub, E., Ouellet, L., Hudson, S., . . G Garfein, R. (2007). Housing Status and Associated Differences in HIV Risk Behaviors Among Young Injection Drug Users (IDUs). AIDS and Behavior, 11(6), 854-863.

Cohen, J., Cohen, P., West, S., \& Aiken, L. (2003). Applied multiple regression/correlation analysis for the behavioral sciences (3rd ed.). Mahwah, N.J: Lawrence Erlbaum Associates.

Cole, J., Logan, T., \& Shannon, L. (2008). Self-Perceived Risk of HIV among Women with Protective Orders against Male Partners. Health \& Social Work, 33(4), 287298.

Colello, K. (2007). Where do older Americans live? Geographic distribution of the older population. Retrieved from Congressional Research Service website: http://www.aging.senate.gov/crs/aging5.pdf.

Conn, V. (2007). Older women's beliefs about physical activity. Public Health Nursing, $15(5), 370-378$.

Connell, R. (1987). Gender and power. Stanford, CA: Stanford University Press.

Corneille, M. A., Zyzniewski, L. E., \& Belgrave, F. Z. (2008). Age and HIV Risk and Protective Behaviors among African American Women. Journal of Black Psychology, 34(2), 217-233.

Cornelius, J., Moneyham, L., \& Legrand, S. (2008). Adaptation of an HIV Prevention Curriculum for Use With Older African American Women. Journal of the Association of Nurses in AIDS care Journal of the Association of Nurses in AIDS care, 19(1), 16-27. 
Cronholm, P., \& Bowman, M. (2009). Women with Safety Concerns Report Fewer Gender-Specific Preventive Healthcare Services. Journal of Women's Health 18(7). doi: 10.1089=jwh.2008.0968

Crosby, R., Kegler, M., \& DiClemente, R. J. (2009). Understanding and applying theory in health promotion practice and research. San Francisco, CA: Jossey-Bass.

Dannefer, D., \& Sell, R. (1988). Age structure, the life course and 'aged heterogeneity': Prospects for research and theory. Comprehensive Gerontology B, 2, 1-10.

Davis, A. (1981). Women, Race and Class. New York, NY: Random House.

Denning, P., \& DiNenno, E. (2013). Communities in crises: Is there a generalized HIV epidemic in impverished urban areas of the United States? Retrieved from http://www.cdc.gov/hiv/pdf/statistics_poverty_poster.pdf.

Department of Health and Human Services, Centers for Disease Control and Prevention. (2008). Persons aged 50 and older. Retrieved from http://www.cdc.gov/hiv/topics/over50/index.htm.

Department of Health and Human Services, Centers for Disease Control and Prevention. (2011). Disparities in diagnoses of HIV infection between Blacks/African Americans and other racial/ethnic populations-37 states, 2005-2008. Morbidity and Mortality Weekly Report, 60(4), 93-98. Retrieved from http://www.cdc.gov/mmwr/pdf/wk/mm6004.pdf.

DiClemente, R., Wingood, G., Rose, E., Sales, J., Lang, D., Caliendo, A., . . Crosby, R. (2009). Efficacy of sexually transmitted disease/human immunodeficiency virus sexual risk-reduction intervention for African American adolescent females 
seeking sexual health services: a randomized controlled trial. Archives of Pediatrics \& Adolescent Medicine, 163(12), 1112-1121.

Dudley, J. (2011). Research methods for social work: Being producers and consumers of research (2nd ed.). Boston, MA: Allyn \& Bacon.

Dunlop, D., Manheim, L., Sohn, M., Liu, X., \& Chang, R. (2002). Incidence of functional limitation in older adults: The impact of gender, race, and chronic conditions. Archives of Physical Medicine and Rehabilitation, 83(7), 964-971.

Dworkin, S., \& Blankenship, K. (2009). Microfinance and HIV/AIDS prevention: Assessing its promise and limitations. AIDS and Behavior, 13(3), 462-469. doi: $10.1007 / \mathrm{s} 10461-009-9532-3$

Egerter, S., Barclay, C., Grossman-Kahn, R., \& Braveman, P. (2011). Violence, social disadvantage, and health (Issue Brief No.10). Retreived from the Robert Woof Johnson Foundation website: http://www.rwjf.org/content/dam/farm/reports/issue_briefs/2011/rwjf70452. El-Bassel, N., Caldeira, N., Ruglass, L., \& Gilbert, L. (2009). Addressing the Unique Needs of African American Women in HIV Prevention. American Journal of Public Health, 99(6), 996. doi: 10.2105/AJPH.2008.140541

Emlet, C. (2006). "You're awfully old to have this disease": Experiences of stigma and ageism in adults 50 years and older living with HIV/AIDS. The Gerontologist, 46(6), 781-790.

Emlet, C., \& Poindexter, C. (2004). Unserved, unseen, and unheard: Integrating programs for HIV-infected and HIV-affected older adults. Health \& Social Work, 29(2), 8696. 
Engel, R., \& Schutt, R. (2013). The practice of research in social work (3rd ed.). Los Angeles, CA: Sage.

Estabrooks, P., \& Carron, A. (1999). The Influence of the Group With Elderly Exercisers. Small Group Research, 30(4), 438-452.

Estes, C. (2001). Social policy \& aging : a critical perspective. Thousand Oaks, Calif.: Sage Publications.

Evans, S. (2011). Uncovering sexual risk behaviors: HIV-positive baby boomers speak out. Doctoral dissertation. ProQuest database. (UMI 3444140)

Exner, T., Dworkin, S. L., Hoffman, S., \& Ehrhardt, A. A. (2003). Beyond the male condom: The evolution of gender-specific HIV interventions for women. Annual Review of Sex Research, 14, 114-136.

Family Caregiving Alliance, National Center on Caegiving. (2012). Fact sheet: Selected caregiver statistics. Retrieved from http://www.caregiver.org/caregiver/jsp/content_node.jsp?nodeid=439.

Ferraro, K., \& Shippee, T. (2009). Aging and Cumulative Inequality: How Does Inequality Get Under the Skin? The Gerontologist, 49(3), 333-343.

Fitzpatrick, A., Powe, N., Cooper, L., Ives, D., \& Robbins, J. (2004). Barriers to health care access among the elderly and who perceives them. American Journal of Public Health, 94(10), 1788-1794.

Flowers, P., Sheeran, P., Beall, N., \& Smith, J. (1997). The Role of Psychosocial Factors in HIV Risk-Reduction among Gay and Bisexual Men: A Quantitative Review. Psychology \& Health, 12(2), 197-230. 
Foti, K., \& Eaton, D. (2010). Associations of selected health risk behaviors with selfrated health status among U.S. high school students. Public Health Reports, 125(5), 771-781.

Francis, D. (n.d.). Why do women outnumber men in college? . Retrieved from the National Bureau of Economic Research website: http://www.nber.org/digest/jan07/w12139.html.

Fullilove, M., Fullilove, R., Haynes, K., \& Gross, S. (1990). Black women and AIDS prevention: A view towards understanding the gender rules. The Journal of Sex Research, 27(1), 47-64.

Funnyé, A. S., Akhtar, A. J., \& Biamby, G. (2002). Acquired immunodeficiency syndrome in older African Americans. Journal of the National Medical Association, 94(4), 209-214.

Gelberg, L., Andersen, R. M., \& Leake, B. D. (2000). The behavioral model for vulnerable populations: Application to medical care use and outcomes for homeless people. Health Services Research, 34(6).

Gilbert, B., \& Cunningham, J. (1986). Women's postrape sexual functioning: Review and implications for counseling. Journal of Counseling \& Development, 65(2), 71-73.

Gómez, C. A. (2011). Preventing HIV in U.S. women and girls: A call for social action. Women's Health Issues, 21(6), 287-294. doi: 10.1016/j.whi.2011.07.012

Gray, M., Plath, D., \& Webb, S. (2009). Evidence-based social work: A critical stance. . New York, NY: Routledge.

Hagedoorn, M., Van Yperen, N., Coyne, J., van Jaarsveld, C., Ranchor, A., van Sonderen, E., \& Sanderman, R. (2006). Does marriage protect older people from 
distress? The role of equity and recency of bereavement. Psychology and Aging, 21(3), 611-620.

Hasnain, M., Levy, J., Mensah, E., \& Sinacore, J. M. (2007). Association of educational attainment with HIV risk in African American active injection drug users. AIDS Care, 19(1), 87-91.

Hasnain, M., Sinacore, J., Mensah, E., \& Levy, J. (2005). Influence of religiosity on HIV risk behaviors in active injection drug users. AIDS Care, 17, 892-901.

HealthyPeople.gov. (n.d.). HIV. Retrieved from

http://www.healthypeople.gov/2020/topicsobjectives2020/overview.aspx?topicid $=22$.

Heckman, T., Silverthorn, M., Waltje, A., Meyers, M., \& Yarber, W. (2003). HIV transmission risk practices in rural persons living with HIV disease. Sexually Transmitted Diseases, 30(2), 134-136.

Hepworth, D., Rooney, R., Rooney, G., \& Strom-Gottfried, K. (2013). Direct social work practice: Theory and skills (9th ed.). Belmont, CA: Brooks/Cole.

Herman, J. (2010). Transgender issues: The additional challenges of LGBT aging. Retrieved from http://www.huffingtonpost.com/joanne-herman/shining-thespotlight-on-_b_777551.html.

Hesselgrave, B. (1998). The over-50 crowd relearns the facts of life. Pacific Standard. Retrieved from http://www.miller-mccune.com/article/277

Inelman, E. M., Gasparini, G., \& Enzi, G. (2005). HIV/AIDS in older adults: a case report and literature review. Geriatrics, 60(9), 26-30. 
Institute for Economics \& Peace. (2011). United States peace index-2011. Retrieved from http://economicsandpeace.org/research/iep-indices-data/national-peaceindices.

Institute, G. (n.d.). Early marriage puts women at risk of HIV/AIDS. Retrieved from http://www.guttmacher.org/media/nr/2006/07/18/index.html.

Institute of Medicine. (1997). The Hidden Epidemic: Confronting Sexually Transmitted Diseases. Washington, D.C: National Academy Press.

Institute of Medicine. (2010). HIV screening and access to care: Exploring barriers and facilitators to expanded HIV testing. . Retrieved from http://www.nap.edu/openbook.php?record_id=12932\&page=R2.

Institute of Medicine, Committee on Health Behavior. (2001). Health and behavior: The interplay of biological, behavioral, and societal influences. Retrieved from http://www.ncbi.nlm.nih.gov/books/NBK43750/. Washington, D.C.: National Academy Press.

Issa, P., \& Zedlewski, S. (2011). Poverty among older Americans, 2009 (Number 1). . Retrieved from the Urban Institute Program on Retirement Policy website: http://www.urban.org/UploadedPDF/412296-Poverty-Among-OlderAmericans.pdf.

Jacobs, R., \& Thomlison, B. (2009). Self-silencing and age as risk factors for sexually acquired HIV in midlife and older women. Journal of Aging and Health, 21(1), 102-128. 
Jacobs, R. J., \& Kane, M. N. (2009). Theory-based policy development for HIV prevention in racial/ethnic minority midlife and older women. Journal of Women and Aging, 21(1), 19-32.

Jacobs, R. J., \& Kane, M. N. (2010). HIV-related stigma in midlife and older women. Soc. Work Health Care Social Work in Health Care, 49(1), 68-89.

Jacobs, R. J., \& Kane, M. N. (2011). Psychosocial predictors of self-esteem in a multiethnic sample of women over 50 at risk for HIV. Journal of Women \& Aging, 23(1), 23-39.

Jones, K. (2012). MCMC training manual. Bristol, UK: Centre of Multilevel Modeling. Jukes, M., Simmons, S., \& Bundy, D. (2008). Education and vulnerability: The role of schools in protecting young women and girls from HIV in southern Africa. AIDS, $22,41-56$.

Jyrkkä, J., Enlund, H., Korhonen, M. J., Sulkava, R., \& Hartikainen, S. (2009). Patterns of drug use and factors associated with polypharmacy and excessive polypharmacy in elderly persons: results of the Kuopio 75+ study: A crosssectional analysis. Drugs \& Aging, 26(6), 493-503.

Kalichman, S., Kelly, J., Morgan, M., \& Rompa, D. (1997). Fatalism, current life satisfaction, and risk for HIV infection among gay and bisexual men. Journal of Consulting and Clinical Psychology, 65(4), 542-546.

Kalichman, S., Simbayi, L., Kaufman, M., Cain, D., \& Jooste, S. (2007). Alcohol use and sexual risks for HIV/AIDS in sub-Saharan Africa: systematic review of empirical findings. Prevention Science, 8(2), 141-151. doi: 10.1007/s11121-006-0061-2 
Kang, S., Deren, S., Andia, J., Colón, H. M., \& Robles, R. (2004). Effects of changes in perceived self-efficacy on HIV risk behaviors over time. Addictive Behaviors, 29(3), 567-574. doi: 10.1016/j.addbeh.2003.08.026

Kates, J. (2012). How the ACA changes pathways to insurance coverage for people with $H I V$. Retrieved from the Henry J. Kaiser Family Foundation website : http://kff.org/hivaids/perspective/how-the-aca-changes-pathways-to-insurancecoverage-for-people-with-hiv/.

Kelly, A. (2011). HIV and STD prevention policies: Focus on rural areas. . Retrieved from Knowledge Center, The Council of State Governments at http://knowledgecenter.csg.org/kc/content/hiv-and-std-prevention-policies-focusrural-areas.

Klitsch, M. (1990). Subgroups of US women differ widely in exposure to sexual intercourse. Family Planning Perspectives, 22(2), 94-95.

Kok, G., Hospers, H. J., Harterink, P., \& De Zwart, O. (2007). Social-cognitive determinants of HIV risk-taking intentions among men who date men through the Internet. AIDS Care, 19(3), 410-417. doi: 10.1080/09540120600813137

Kral, A., Lorvick, J., \& Edlin, B. (2000). Sex- and drug-related risk among populations of younger and older injection drug users in adjacent neighborhoods in San Francisco. Journal of Acquired Immune Deficiency Syndromes 24(2), 162-167.

Kreft, I., \& De Leeuw, J. (1998). Introducing multilevel modeling. Thousand Oaks, CA: Sage Publications. 
Lee, Y., \& Nelder, J. (2001). Hierarchical generalised linear models: A synthesis of generalised linear models, random-effect models and structured dispersions. Biometrika, 88(4), 987-1006.

Lefevre, F., O'Leary, B., Moran, M., Mossar, M., Yarnold, P., Martin, G. J., \& Glassroth, J. (1995). Alcohol consumption among HIV-infected patients. Journal of General Internal Medicine, 10(8), 458-460.

Levenson, R., Carstensen, L., \& Gottman, J. (1993). Long-term marriage: Age, gender, and satisfaction. Psychology and Aging, 8(2), 301-313.

Levy-Dweck, S. (2005). HIV/AIDS fifty and older: A hidden and growing population. Journal of Gerontological Social Work, 46(2), 37-50.

Levy, J., Holmes, D., \& Smith, M. (2003). Conceptual and methodological issues in research on age and aging. Journal of Acquired Immune Deficiency Syndromes $33,206-217$.

Lewis, L., Melton, R., Succop, P., \& Rosenthal, S. (2000). Factors influencing condom use and STD acquisition among African American college women. Journal of American College Health, 49(1), 19-24.

Lindau, S., Schumm, P., Laumann, E., Levinson, W., O’Muirchertaigh, C., \& Waite, L. (2007). A Study of Sexuality and Health Among Older Adults in the United States and Health Among Older Adults in the United States. Obstetrics \& Gynecology, 110(5). doi: 10.1056/NEJMoa067423

Logan, T., Cole, J., \& Leukefeld, C. (2002). Women, sex, and HIV: social and contextual factors, meta-analysis of published interventions, and implications for practice and research. Psychological bulletin, 128(6), 851-885. 
Logan, T., \& Leukefeld, C. (2000). HIV risk behavior among bisexual and heterosexual drug users. Journal of Psychoactive Drugs, 32(3), 239-248.

Longfield, K., Glick, A., Waithaka, M., \& Berman, J. (2004). Relationships Between Older Men and Younger Women: Implications for STIs/HIV in Kenya. Studies in Family Planning Studies in Family Planning, 35(2), 125-134.

Luke, D. (2004). Multilevel modeling. Thousand Oaks, CA: Sage Publications.

Lyles, C., Kay, L., Crepaz, N., Herbst, J., Passin, W., Kim, A., . . Team, H. I. V. A. P. R. S. (2007). Best-evidence interventions: findings from a systematic review of HIV behavioral interventions for US populations at high risk, 2000-2004. American journal of public health, 97(1), 133-143. doi: 10.2105/AJPH.2005.076182

Maddox, G., \& Douglass, E. (1974). Aging and individual differences: A longitudinal analysis of social , psychological and physiological indicators. Journal of Gerontology, 29, 555-563.

Magnus, M., Kuo, I., Phillips, G., Shelley, K., Rawls, A., Montanez, L., . . Greenberg, A. (2010). Elevated HIV prevalence despite lower rates of sexual risk behaviors among black men in the District of Columbia who have sex with men. AIDS Patient Care STDS, 24(10), 615-622. doi: 10.1089/apc.2010.0111

McCoy, S., Miller, W., MacDonald, P., Hurt, C., Leone, P., Eron, J., \& Strauss, R. (2009). Barriers and facilitators to HIV testing and linkage to primary care: Narratives of people with advanced HIV in the Southeast. AIDS Care, 21(10), $1313-1320$. 
McEnery, R. (2010). Why is HIV ravaging DC. Retreived from http://www.iavireport.org/Back-Issues/Pages/IAVI-Report-14(6)WhyisHIVRavagingDC.aspx.

McIsaac, W., Fuller-Thomson, E., \& Talbot, Y. (2001). Does having regular care by a family physician improve preventive care? Canadian Family Physician, 47, 7076.

Mindtools. (n.d.). How good is your decision making? Retrieved from http://www.mindtools.com/pages/article/newTED_79.htm.

Mino, M., Deren, S., \& Yeon-Kang, S. (2006). Social support and HIV-related injection risk among Puerto Rican migrant and nonmigrant injection drug users recruited in New York City. AIDS Education and Prevention, 18(1), 81-90.

Mitchem, S. (2004). What's love got to do? (\& other stories of black women's sexualities). Cross Currents, 54(3), 72-84.

Murrell, S., Himmelfarb, S., \& Wright, K. (1983). Prevalence of depression and its correltes in older adults. American Journal of Epidemiology, 117(173-184).

National Center for HIV/AIDS, V. H., , STD, and TB Prevention,, Division of HIV/AIDS Prevention. (2011). Strategic plan: Division of HIV/AIDS prevention 2011 through 2015. Retrieved from the CDC website: http://www.cdc.gov/hiv/pdf/policies_DHAP-strategic-plan.pdf.

National Center for HIV/AIDS, V. H., STD, and TB Prevention,, Division of HIV/AIDS Prevention. (2010). Projecting possible future courses of the HIV epidemic in the United States. Retrieved from http://www.cdc.gov/hiv/pdf/prevention_epi_futurecourses.pdf. 
National Institute of Mental Health. (n.d.). Older adults and mental health. Retrieved from http://www.nimh.nih.gov/health/topics/older-adults-and-mentalhealth/index.shtml.

National Institute on Alcohol Abuse and Alcoholism, National Institutes of Health. (n.d.). Alcohol and HIV/AIDS: Intertwining stories. Retrieved from http://pubs.niaaa.nih.gov/publications/AA80/AA80.htm.

National Women's Law Center. (2013). 60 percent of women's job gains in the recovery are in the 10 largeset low-wage jobs. Retrieved from http://www.nwlc.org/resource/60-percent-women\%E2\%80\%99s-job-gainsrecovery-are-10-largest-low-wage-jobs.

Neblett, R. C., Davey-Rothwell, M., Chander, G., \& Latkin, C. A. (2011). Social network characteristics and HIV sexual risk behavior among urban African American women. J Urban Health, 88(1), 54-65. doi: 10.1007/s11524-010-9513-x

Neelon, B., O'Malley, A., \& Normand, S. (2010). A Bayesian model for repeated measures zero-inflated count data with application to outpatient psychiatric service use. Statistical Modelling, 10(4), 421-439.

Newcomer, S., \& Udry, J. (1987). Parental Marital Status Effects on Adolescent Sexual Behavior. Journal of Marriage and Family, 49(2), 235-240.

Newmann, S., Sarin, P., Kumarasamy, N., Amalraj, E., Rogers, M., Madhivanan, P., . . . Solomon, S. (2000). Marriage, monogamy and HIV: A profile of HIV-infected women in south India. International Journal of STD \& AIDS, 11(4), 250-253. 
Newport, F. (2013). Mississippi maintains hold as most religious U.S. state. Retrieved from http://www.gallup.com/poll/160415/mississippi-maintains-hold-religiousstate.aspx\#1.

Nyamathi, A., Dixon, E., Shoptaw, S., Marfisee, M., Gelberg, L., Williams, S., . . Leake, B. (2008). Profile of lifetime methamphetamine use among homeless adults in Los Angeles. Drug and Alcohol Dependence, 92(1-3), 1-3.

Nyamathi, A., \& Shuler, P. (1990). Focus group interview: A research technique for informed nursing practice. Journal of Advanced Nursing, 15(11), 1281-1288.

Oser, C., Havens, J., Mooney, J., Staton-Tindall, M., Knudsen, H., Duvall, J., \& Leukefeld, C. (2008). Racial differences in HIV/AIDS discussion strategies and sexual risk behaviors among drug-abusing female criminal offenders. Journal of psychoactive drugs, 40(4), 483-492.

Painter, J., Wingood, G., DiClemente, R., Depadilla, L., \& Simpson-Robinson, L. (2012f). College graduation reduces vulnerability to STIs/HIV among AfricanAmerican young adult women. Women's Health Issues 22(3).

Pangman, V., \& Seguire, M. (2000). Sexuality and the chronically ill older adult: A social justice issue. Sexuality \& Disability, 18(1), 49-59.

Pargament, K., McCarthy, S., Shah, P., Ano, G., Tarakeshwar, N., Wachholtz, A., . . Duggan, J. (2004). Religion and HIV: A review of the literature and clinical implications. Southern Medical Journal, 97(12), 1201-1209.

Pickard, J. G. (2006). The relationship of religiosity to older adults' mental health service use. Aging \& Mental Health, 10(3), 290-297. 
Poindexter, C. (2009). Handbook of HIV and social work: Principles, practice, and populations. New York, NY: John Wiley \& Sons, Inc.

Population Action International. (2012). Why population matters to infectious diseases and HIV/AIDS. Retrieved from the Healthy Families, Healthy Planet website: http://populationaction.org/policy-briefs/why-population-matters-to-infectiousdiseases-and-hivaids/.

Quinn, S. C. (1993). AIDS and the African American woman: The triple burden of race, class, and gender. Health Education Quarterly, 20(3), 305-320.

Rabash, J., Steele, F., Browne, W., \& Goldstein, H. (2009). A User's Guide to MLwiN, $v 2.10$.

Raudenbush, S., \& Bryk, A. (2005). HLM 6: Hierarchical Linear Models: Applications and data analysis methods Lincolnwood, IL: SSI Scientific Software International.

Rees, V., Saitz, R., Horton, N., \& Samet, J. (2001). Association of alcohol consumption with HIV sex- and drug-risk behaviors among drug users. Journal of Substance Abuse Treatment, 21(3), 129-134.

Reichmann, D. (2006). Bush signs 3 health care-related bills. Retrieved from http://www.washingtonpost.com/wpdyn/content/article/2006/12/19/AR2006121900797.html. The Washington Post.

Ridd, M., Shaw, A., \& Salisbury, C. (2006). 'Two sides of the coin'--the value of personal continuity to GPs: A qualitative interview study. Family Practice, 23(4), 461-468.

Rivara, F., Anderson, M., Fishman, P., Bonomi, A., Reid, R., Carrell, D., \& Thompson, R. (2007). Intimate partner violence and health care costs and utilization for 
children living in the home. Pediatrics, 120(6), 1270-1277. doi:

10.1542/peds.2007-1148

Rowe, J., \& Kahn, R. (1987). Human aging: Usual and successful. Science, 237, 143-149.

Rural Center for AIDS/STD Prevention. (1996). HIV/AIDS in Rural America. Retrieved from http://www.indiana.edu/ aids/factsheets/factsheets8.html

Samet, J., Horton, J., Meli, S., Freedberg, K., \& Palepu, A. (2004). Alcohol consumption and antiretroviral adherence among HIV-infected persons with Alcohol problems. Alcoholism: Clinical and Experimental Research, 28(4), 572-577. doi:

10.1097/01.ALC.0000122103.74491.78

Sanders-Phillips, K., Liezille, P., \& Priscilla, R. (2009). Building International Research Partnerships to Develop HIV Programs for Women of Color in the Context of Social Inequalities and Human Rights. Social Work in Public Health, 24(1/2). doi: $10.1080 / 19371910802569534$

Sharples, T. (2008). More midlife and (older) STDs. TIME. Retrieved from http://www.time.com/time/health/article/0,8599,1819633,00.html?xid=rsstopstories.

Sharts-Hopko, N. (1997). STDs in women: What you need to know. American Journal of Nursing, 97(4).

Sheer, V., \& Cline, R. (1994). The Development and Validation of a Model Explaining Sexual Behavior among College Students: Implications for AIDS Communication Campaigns. Human Communication Research, 21(2), 280-304. 
Siegel, K., \& Schrimshaw, E. (2002). The perceived benefits of religious and spiritual coping among older adults living with HIV/AIDS. Journal for the Scientific Study of Religion, 41(1), 91-102.

Sikkema, K., Kelly, J., Winett, R., Solomon, L., Cargill, V., Roffman, R., . . Merce, r. M. (2000). Outcomes of a randomized community-level HIV prevention intervention for women living in 18 low-income housing developments. American Journal of Public Health, 90(1), 57-63.

Singer, J., \& Willett, J. (2003). Applied longitudinal data analysis. Modeling change and event occurence. Oxford, NY: Oxford University Press.

Skinner, C. E. (1935). Readings in psychology. New York: Farrar \& Rinehart, Inc.

Snijders, T. (2005). Power and sample size in multilevel linear models (Vol. 3). Chicester: Wiley.

Snow, L. F. (1983). Traditional health beliefs and practices among lower class black Americans. The Western Journal of Medicine, 139(6), 820-828.

Somlai, A., Kelly, J. A., Heckman, T. G., Hackl, K., Runge, L., \& Wright, C. (2000). Life optimism, substance use, and AIDS-specific attitudes associated with HIV risk behavior among disadvantaged innercity women. Journal of Women's Health \& Gender-Based Medicine, 9(10), 1101-1111.

Sormanti, M., Wu, E., \& El-Bassel, N. (2004). Considering HIV Risk and Intimate Partner Violence Among Older Women of Color: A Descriptive Analysis. Women and Health, 39(1), 45-63. doi: 10.1300/J013v39n01_03 
Stall, R., \& Catania, J. (1994). AIDS risk behaviors among late middle-aged and elderly Americans. The National AIDS Behavioral Surveys. Archives of internal medicine, 154(1), 57-63.

Stankiewicz, J., \& Rosselli, F. (2008). Women as Sex Objects and Victims in Print Advertisements. Sex Roles, 58(7-8), 579-589.

Steele, F. (2008). Introduction to multilevel modelling concepts. Retrieved from http://www.bristol.ac.uk/cmm/learning/module-samples/5-concepts-sample.pdf.

Steele, F. (2009). Module 7: Multilevel models for binary responses. Retrieved from http://www.bristol.ac.uk/cmm/learning/module-samples/7-practicals-mlwinsample.pdf.

Stephens, D., \& Phillips, L. (2003). Freaks, gold diggers, divas, and dykes: The sociohistorical development of adoelscent African Amercan women's sexual scripts. Sexuality \& Culture, 7(1), 3-49.

Stephens, D., \& Phillips, L. (2005). Integrating Black feminist thought into conceptual frameworks of African American adolescent women's sexual scripting processes. Sexualities, Evolution \& Gender, 7(1). doi: 10.1080/14616660500112725

Substance Abuse and Mental Health Services Administration. (2009). Older adults and substance use: New data highlight concern. Retrieved from http://www.samhsa.gov/samhsaNewsletter/Volume_17_Number_1/OlderAdults.a $\underline{\operatorname{spx}}$.

Substance Abuse and Mental Health Services Administration. (2010). The aging population and drug use. Retrieved from 
http://www.samhsa.gov/samhsanewsletter/Volume_18_Number_1/OlderAdults.as

px.

Susser, I. (1996). The construction of poverty and homelessmess in US cities. Annual Review of Anthropology, 25, 411-435.

Szirony, T. (1999). Infection with HIV in the elderly population. Journal of Gerontological Nursing, 25(10), 25-31.

Tabachnick, B., \& Fidell, L. (2007). Using Multivariate Statistics. Boston, MA: Allyn and Bacon.

The Henry J. Kaiser Family Foundation. (2006). The Ryan White CARE act: A side-byside comparison of prior law to the newly reauthorized CARE act. Retrieved from http://kaiserfamilyfoundation.files.wordpress.com/2013/01/7531-03.pdf.

The Henry J. Kaiser Family Foundation. (2009). Medicare and HIV/AIDS. Retrieved from http://kff.org/hivaids/fact-sheet/medicare-and-hivaids/.

The Henry J. Kaiser Family Foundation. (2009b). The national HIV prevention inventory: The state of HIV prevention across the U.S. . Retrieved from http://kaiserfamilyfoundation.files.wordpress.com/2013/01/7932.pdf

The Henry J. Kaiser Family Foundation. (2011). The global HIV/AIDS epidemic. Retrieved from http://www.kff.org/hivaids/upload/3030-16.pdf. The Henry J. Kaiser Family Foundation. (2011b). Population distribution by gender. Retrieved from http://kff.org/other/state-indicator/distribution-by-gender/. 
The Henry J. Kaiser Family Foundation. (2011c). Total Medicare spending by state (in millions). Retrieved from http://kff.org/medicare/state-indicator/medicarespending-by-residence/.

The Henry J. Kaiser Family Foundation. (2012). Kentucky: Estimated numbers of AIDS diagnosis, all ages, cumulative through 2010. Retrieved from http://www.statehealthfacts.org/profileind.jsp?ind=502\&cat=11\&rgn=19.

The Henry J. Kaiser Family Foundation. (2012a). Medicaid enrollment and spending on $H I V$. Retrieved from http://kff.org/hivaids/state-indicator/enrollment-spendingon-hiv-fy2009/.

The Henry J. Kaiser Family Foundation. (2012c). Population distribution by metropolitan status. Retrieved from http://kff.org/other/stateindicator/metropolitan-distribution/.

The Henry J. Kaiser Family Foundation. (2012d). Why does Medicaid spending vary across states: A chart book of factors driving state spending. Retrieved from http://kff.org/medicaid/report/why-does-medicaid-spending-vary-across-states/. Washington, D.C.: Snyder, L., Rudowitz, R., Garfield, R., \& Gordon, T. The Henry J. Kaiser Family Foundation. (2012e). The HIV/AIDS epidemic in the United States. Retrieved from http://www.kff.org/hivaids/upload/3029-13.pdf.

The Henry J. Kaiser Family Foundation. (2012g). The HIV/AIDS epidemic in Washington, D.C. Retrieved from http://kaiserfamilyfoundation.files.wordpress.com/2013/01/8335.pdf.

The Henry J. Kaiser Family Foundation. (2013). Estimated numbers of adults and adolescents living with HIV diagnosis, by transmission category. Retrieved from 
http://kff.org/hivaids/state-indicator/estimated-numbers-of-adults-and-

adolescents-living-with-an-hiv-diagnosis-by-transmission-category/

The Henry J. Kaiser Family Foundation. (2013a). Estimated numbers of AIDS diagnoses, all ages, cumulative through 2011. Retrieved from http://kff.org/hivaids/stateindicator/estimated-numbers-of-aids-diagnoses-all-ages/\#

The Henry J. Kaiser Family Foundation. (2013b). Federal HIV/AIDS grant funding per person living with HIV/AIDS. Retrieved from http://kff.org/hivaids/stateindicator/federal-grant-funding-per-person/.

The Henry J. Kaiser Family Foundation. (2013c). Medicaid and HIV/AIDS. Retrieved from http://kff.org/hivaids/fact-sheet/medicaid-and-hivaids/.

The Henry J. Kaiser Family Foundation. (2013d). Total AIDS drug assistance program (ADAP) budget, federal and state sources, an percent change in total ADAP budget, FY2011 to FY2012. Retrieved from http://kff.org/hivaids/stateindicator/total-adap-budget/.

The Henry J. Kaiser Family Foundation. (2013f). The HIV/AIDS epidemic in the United States. Retrieved from http://kff.org/hivaids/fact-sheet/the-hivaids-epidemic-inthe-united-states/.

The Henry J. Kaiser Family Foundation, Center on Budget Reports and Policy Priorties, Kaiser Commission on Medicaid and the Uninsured. (2009c). A foundation for health reform: Findings of a 50 state survey of eligibility rules, enrollment and renewal procedures, and cost-sharing practices in Medicaid and CHIP for 
children and parents in 2009 (Publication No.8028). Retrieved from http://www.kff.org/medicaid/upload/8028.pdf.

The Research Advisors. (2006). Sample size table. Retrieved from http://www.researchadvisors.com/tools/SampleSize.htm.

Thoits, P. (1996). Managing the emotions of others. Symbolic Interaction, 2(85-109).

Thomas, S., \& Quinn, S. (1991). The Tuskegee Syphilis Study, 1932 to 1972:

Implications for HIV Education and AIDS Risk Education Programs in the Black Community. American Journal of Public Health, 81(11), 1498-1505.

Thorpe, J., Thorpe, C., Kennelty, K., \& Pandhi, N. (2011). Patterns of perceived barriers to medical care in older adults: A latent class analysis. BMC Health Services Research, 11 .

Tix, A., \& Frazier, P. A. (1998). The use of religious coping during stressful life events: Main effects, moderation, and mediation. Journal of Consulting and Clinical Psychology, 66(2), 411-422.

Tsai, J., Ford, E. S., Li, C., Zhao, G., Pearson, W. S., \& Balluz, L. S. (2010). Multiple healthy behaviors and optimal self-rated health: Findings from the 2007 Behavioral Risk Factor Surveillance System Survey. Preventive Medicine, 51(34), 268-274.

Tugend, A. (2013). Unemployed and older, and facing a jobless future. Retrieved from http://www.nytimes.com/2013/07/27/your-money/unemployed-and-older-andfacing-a-jobless-future.html?_r=0. 
U.S. Department of Commerce, Economics and Statistics Administration. (2012).

Household income inequality Within U.S. counties: 2006-2010. Retrieved from http://www.census.gov/prod/2012pubs/acsbr10-18.pdf.

U.S. Department of Commerce, Economics and Statistics Administration. (2013). The black population: 2010 . Retrieved from http://www.census.gov/prod/cen2010/briefs/c2010br-06.pdf.

U.S. Department of Commerce, Economics and Statistics Administration, U.S. Census Bureau. (2011). B19083 Gini Index of income inequality Universe: Households 2007-2011 American community survey 5-year estimates. Retrieved from http://factfinder2.census.gov/faces/tableservices/jsf/pages/productview.xhtml?src $=$ bkmk.

U.S. Department of Commerce, Economics and Statistics Administration, U.S. Census Bureau. (2011a). Age and sex composition: 2010. (C2010BR-03). Retrieved from http://www.census.gov/prod/cen2010/briefs/c2010br-03.pdf. Washington, D.C.: Howden, J., \& Meyer, J.

U.S. Department of Commerce, Economics and Statistics Administration, U.S. Census Bureau. (2011b). Overview of race and Hispanic origin: 2010. (C2010BR-02). Retrieved from http://www.census.gov/prod/cen2010/briefs/c2010br-02.pdf. Washington, D.C.: Humes, K., Jones, N., \& Ramirez, R.

U.S. Department of Commerce, Economics and Statistics Administration, U.S. Census Bureau. (2012a). Households and families: 2010. (C2010BR-14). Retrieved from http://www.census.gov/prod/cen2010/briefs/c2010br-14.pdf. 
U.S. Department of Commerce, Economics and Statistics Administration,, U.S. Census Bureau. (2010). Poverty: 2008 and 2009. (ACBR/09-1). Retrieved from http://www.census.gov/prod/2010pubs/acsbr09-1.pdf. Washington, D.C.: Bishaw, A., \& Macartney, S.

U.S. Department of Commerce, Economics and Statistics Administration,, U.S. Census Bureau. (2011c). Poverty: 2009 and 2010. (ACSBR/10-01). Retreived from http://www.census.gov/prod/2011pubs/acsbr10-01.pdf. Washington, D.C.: Bishaw, A.

U.S. Department of Commerce, United States Census Bureau. (2010a). American FactFinder, American Community Survey. Retrieved from http://factfinder2.census.gov/faces/nav/jsf/pages/index.xhtml.

U.S. Department of Commerce, United States Census Bureau (n.d.). Law enforcement, courts, \& prisons: Crimes and crime rates. Retrieved from http://www.census.gov/compendia/statab/cats/law_enforcement_courts_prisons/cr imes_and_crime_rates.html.

U.S. Department of Health and Human Services, Administration on Aging. (2013). Older adults and HIV/AIDS. Retrieved from http://www.aoa.gov/AoARoot/AoA_Programs/HPW/HIV_AIDS/.

U.S. Department of Health and Human Services, Centers for Disease Control and Prevention. (2006a). Cases of HIV infection and AIDS in urban and rural areas of the United States, 2006. Retrieved from http://www.cdc.gov/hiv/pdf/statistics_2008_HIV_Surveillance_Report_vol_13_n o2.pdf. 
U.S. Department of Health and Human Services, Centers for Disease Control and Prevention. (2006b). Morbidity and Mortality Weekly Reports from 1983. Retrieved from http://www.cdc.gov/hiv/resources/reports/mmwr/1983.htm. U.S. Department of Health and Human Services, Centers for Disease Control and Prevention. (2006b). HIV/AIDS among women who have sex with women. Retrieved from http://www.cdc.gov/hiv/topics/women/resources/factsheets/wsw.htm.

U.S. Department of Health and Human Services, Centers for Disease Control and Prevention. (2007). Drug-associated HIV transmission continues in the United States. Retrieved from http://www.cdc.gov/hiv/resources/factsheets/idu.htm.

U.S. Department of Health and Human Services, Centers for Disease Control and Prevention. (2008a). Persons aged 50 and older. Retrieved from http://www.cdc.gov/hiv/topics/over50/index.htm.

U.S. Department of Health and Human Services, Centers for Disease Control and Prevention. (2008c). Behavioral Risk Factor Surveillance System Survey Data, 2008-2011. Retrieved from http://www.cdc.gov/brfss/questionnaires.htm. U.S. Department of Health and Human Services, Centers for Disease Control and Prevention. (2009a). Sexually transmitted disease surveillance, 2008. Retrieved from http://www.cdc.gov/std/stats08/surv2008-complete.pdf.

U.S. Department of Health and Human Services, Centers for Disease Control and Prevention. (2010). The role of STD detection and treatment in HIV preventionCDC fact sheet. Retrieved from http://www.cdc.gov/std/hiv/STDFact-STDHIV.htm. 
U.S. Department of Health and Human Services, Centers for Disease Control and Prevention. (2010a). Sexually transmitted disease surveillance, 2009. Retrieved from http://www.cdc.gov/std/stats09/.

U.S. Department of Health and Human Services, Centers for Disease Control and Prevention. (2010b). HIV among African Americans. Retrieved from http://www.cdc.gov/hiv/topics/aa/index.htm.

U.S. Department of Health and Human Services, Centers for Disease Control and Prevention. (2010d). HIV transmission. Retrieved from http://www.cdc.gov/hiv/resources/qa/transmission.htm.

U.S. Department of Health and Human Services, Centers for Disease Control and Prevention. (2011b). HIV surveillance report, 2009. Retrieved from http://www.cdc.gov/hiv/library/reports/surveillance/index.html.

U.S. Department of Health and Human Services, Centers for Disease Control and Prevention. (2011c). Sexually transmitted disease surveillance, 2010. Retrieved from http://www.cdc.gov/std/stats10/.

U.S. Department of Health and Human Services, Centers for Disease Control and Prevention. (2011d). STDs in racial and ethnic minorities. Retrieved from http://www.cdc.gov/std/stats10/minorities.htm.

U.S. Department of Health and Human Services, Centers for Disease Control and Prevention. (2012a). New HIV infections in the United States. Retrieved from http://www.cdc.gov/nchhstp/newsroom/docs/2012/HIV-Infections-20072010.pdf. 
U.S. Department of Health and Human Services, Centers for Disease Control and Prevention. (2012b). Sexually transmitted disease surveillance, 2011. Retrieved from http://www.cdc.gov/std/stats11/.

U.S. Department of Health and Human Services, Centers for Disease Control and Prevention. (2012c). HIV in the United States: At a glance. Retrieved from http://www.cdc.gov/hiv/resources/factsheets/PDF/HIV_at_a_glance.pdf.

U.S. Department of Health and Human Services, Centers for Disease Control and Prevention. (2012d). HIV and AIDS in the United States by geographic location. Retrieved from http://www.cdc.gov/hiv/resources/factsheets/geographic.htm.

U.S. Department of Health and Human Services, Centers for Disease Control and Prevention. (2012e). HIV/AIDS and STDs. Retrieved from http://www.cdc.gov/std/hiv/default.htm

U.S. Department of Health and Human Services, Centers for Disease Control and Prevention. (2012g). Health insurance coverage: Early release of estimates from the National Health Interview Survey, January-March 2012. Retrieved from http://www.cdc.gov/nchs/data/nhis/earlyrelease/insur201209.pdf.

U.S. Department of Health and Human Services, Centers for Disease Control and Prevention. (2013). Diagnoses of HIV infection among adults aged 50 years and older in the United States and dependent areas, 2007-2010. Retrieved from http://www.cdc.gov/hiv/surveillance/resources/reports/2010supp_vol18no3/pdf/hs sr_vol_18_no_3.pdf. HIV Surveillance Supplemental Report 18(3). 
U.S. Department of Health and Human Services, Centers for Disease Control and Prevention. (2013a). HIV among women. Retrieved from http://www.cdc.gov/hiv/risk/gender/women/facts/index.html.

U.S. Department of Health and Human Services, Centers for Disease Control and Prevention. (2013c). HIV incidence. Retrieved from http://www.cdc.gov/hiv/statistics/surveillance/incidence/index.html.

U.S. Department of Health and Human Services, Centers for Disease Control and Prevention. (2013d). Basic statistics. Retrieved from http://www.cdc.gov/hiv/basics/statistics.html.

U.S. Department of Health and Human Services, Centers for Disease Control and Prevention. (2013e). Today's HIV/AIDS epidemic. Retrieved from http://www.cdc.gov/nchhstp/newsroom/docs/HIVFactSheets/TodaysEpidemic508.pdf.

U.S. Department of Health and Human Services, Centers for Disease Control and Prevention. (2013f). New study in low-income hetersexuals in America's inner cities reveals high HIV rates. Retrieved from http://www.cdc.gov/nchhstp/newsroom/povertyandhivpressrelease.html.

U.S. Department of Health and Human Services, Centers for Disease Control and Prevention. (2013g). HIV among gay and bisexual men. Retrieved from http://www.cdc.gov/hiv/risk/gender/msm/facts/index.html.

U.S. Department of Health and Human Services, Centers for Disease Control and Prevention. (2013h). HIV and substance use in the United States. Retrieved from http://www.cdc.gov/hiv/pdf/risk_HIV_Substance.pdf. 
U.S. Department of Health and Human Services, Centers for Disease Control and Prevention. (2013i). Black or African American populations. Retrieved from http://www.cdc.gov/minorityhealth/populations/REMP/black.html.

U.S. Department of Health and Human Services, Centers for Disease Control and Prevention, National Center for Health Statistics. (2010c). Health, United States, 2010 with special feature on death and dying. Retrieved from http://www.cdc.gov/nchs/data/hus/hus10.pdf. Hyattsville, MD.

U.S. Department of Health and Human Services, Health Resources and Services Administration. (2010). The HIV/AIDS programs: Who was Ryan White? Retrieved from http://hab.hrsa.gov/about/ryanwhite.htm.

U.S. Department of Health and Human Services, Health Resources and Services Administration (2010a). Population fact sheet: August 2010. Retrieved from http://hab.hrsa.gov/abouthab/populations/olderadultsfacts.pdf.

U.S. Department of Health and Human Services, C. f. D. C. a. P. (2006a). Morbidity and mortality weekly reports from 1993. Retrieved from http://www.cdc.gov/hiv/resources/reports/mmwr/1993.htm.

U.S. Department of Justice, Federal Bureau of Investigations. (2012). Caution against ranking. Retrieved from http://www.fbi.gov/about-us/cjis/ucr/crime-in-theu.s/2011/crime-in-the-u.s.-2011/cautionagainstranking_final.pdf.

U.S. Department of Justice, Federal Bureau of Investigations, Criminal Justice Information Services Division. (n.d.). Offense data by region. Retrieved from http://www.fbi.gov/about-us/cjis/ucr/crime-in-the-u.s/2011/crime-in-the-u.s.2011/offenses-known-to-law-enforcement/standard-links/region. 
U.S. Department of Labor, Bureau of Labor Statistics. (2010). Occupational outlook handbook, 2010-2011 edition. Retrieved April 15, 2011 from http://www.bls.gov/oco/ooh_item.htm.

Vingilis, E., Wade, T., \& Adlaf, E. (1998). What factors predict student self-rated physical health? Journal of Adolescence, 21(1), 83-97.

Wagstaff, D., Kelly, J., Perry, M., Sikkema, K., Solomon, L., Heckman, T., \& Anderson, E. (1995). Multiple Partners, Risky Partners and HIV Risk Among Low-Income Urban Women. Family Planning Perspectives, 27(6), 241-245.

Ward, E., Disch, W., Levy, J., \& Schensul, J. (2004). Perception of HIV/AIDS risk among urban, low-income senior-housing residents. AIDS Education and Prevention, 16(6), 571-588.

Ward, E., Disch, W., Schensul, J., \& Levy, J. (2011). Understanding Low-Income, Minority Older Adult Self-Perceptions of HIV Risk. Journal of the Association of Nurses in AIDS Care, 22(1), 26-37.

Wasserhiet, J. N. (1992). Epidemiologic synergy: Interrelationships between human immunodeficiency virus infection and other sexually transmitted diseases. Sexually Transmitted Diseases, 9, 61-77.

Waysdorf, S. (2002). The aging of the AIDS epidemic: Emerging legal and public health issues for elderly persons living with HIV/AIDS. The Elder Law Journal, 10(4189).

Wechsberg, W., Luseno, W., \& Lam, W. (2005). Violence against substance-abusing South African sex workers: Intersection with culture and HIV risk. AIDS Care, 17(Supplement), 55-64. 
Weigley, S., Hess, A., \& Sauter, M. (2012). States with the fewest (and most) doctors. Retrieved from http://247wallst.com/special-report/2012/10/19/states-with-thefewest-and-most-doctors/.

Westerhof, G. J., Maessen, M., de Bruijn, R., \& Smets, B. (2008). Intentions to seek (preventive) psychological help among older adults: An application of the theory of planned behaviour. Aging \& Mental Health, 12(3), 317-322. doi:

$10.1080 / 13607860802120797$

Whyte, J., Whyte, M. D., \& Cormier, E. (2008). Down Low Sex, Older African American Women, and HIV Infection. Journal of the Association of Nurses in AIDS Care, 19(6), 423-431.

Wigfall, L., Williams, E., Sebastiann, N., \& Glover, S. (2010). HIV testing among Deep South residents 50 to 64 years old with cardiovascular disease and/or diabetes. Journal of the National Medical Association, 102(12), 1150-1157.

Williams, E., \& Donnelly, J. (2002). Older Americans and AIDS: Some guidelines for prevention. Social Work, 47(105-111).

Wingood, G., \& DiClemente, R. (2000). Reconceptualizing women's HIV risk. Health Education \& Behavior, 27(5), 570-571.

Wingood, G., DiClemente, R., Mikhail, I., Lang, D., McCree, D., Davies, S., . . Saag, M. (2004). A randomized controlled trial to reduce HIV transmission risk behaviors and sexually transmitted diseases among women living with HIV: The WiLLOW Program. Journal of acquired immune deficiency syndromes (1999), 37, 58-67. 
Winningham, A., Corwin, S., Moore, C., Richter, D., Sargent, R., \& Gore-Felton, C. (2004). The changing age of HIV: sexual risk among older African American women living in rural communities. Preventive Medicine, 39(4), 809-814. doi: 10.1016/j.ypmed.2004.03.005

Wyatt, G. E. (2009). Enhancing cultural and contextual intervention strategies to reduce HIV/AIDS among African Americans. Am. J. Public Health American Journal of Public Health, 99(11), 1941-1945. doi: 10.2105/AJPH.2008.152181

Yegedis, B., Weinbach, R., \& Myers, L. (2012). Research methods for social workers (7th ed.). Saddle River, NJ: Allyn \& Bacon.

Zablotska, I., Gray, R., D., S., Nalugoda, F., Kigozi, G., Sewankambo, N., . . W Wawer, M. (2006). Alcohol use before sex and HIV acquisition: A longitudinal study in Rakai, Uganda. AIDS, 20, 1191-1196. 
Appendix A

Key for Table 5

\begin{tabular}{|l|l|}
\hline $1-$ & Do HIV risk behaviors apply \\
\hline $2--$ & percent of 65+ \\
\hline $3-$ & percent of females in each state \\
\hline $4-$ & percent of minorities in each state \\
\hline $5-$ & percent of White females in each state \\
\hline $6-$ & percent of African American females in each state \\
\hline $7-$ & percent of Hispanic females in each state \\
\hline $8-$ & percent of Asian females in each state \\
\hline $9-$ & percent of Native Hawaiian/Pacific Islander females in each state \\
\hline $10-$ & percent of American Indian and Alaskan Native females in each state \\
\hline $11-$ & percent in labor force \\
\hline $12-$ & percent of Women in labor force \\
\hline $13-$ & percent of White females in labor force \\
\hline $14-$ & percent of AA females in labor force \\
\hline $15-$ & percent of Hispanic females in labor force \\
\hline $16-$ & percent of Asian females in labor force \\
\hline $17-$ & percent of other females (NH and AmI) in labor force \\
\hline $18-$ & percent married \\
\hline $19-$ & percent of females married \\
\hline $20-$ & percent of White females who are married \\
\hline $21-$ & percent of African American females who are married \\
\hline $22-$ & percent of Hispanic females who are married \\
\hline $23-$ & percent of Asian females who are married \\
\hline $24-$ & percent of Other females married \\
\hline $25-$ & percent with college degree \\
\hline $26-$ & percent of females with college degree \\
\hline $27-$ & percent of White females with college degree \\
\hline $28-$ & percent of AA females with college degree \\
\hline $29-$ & percent of Hispanic females with college degree \\
\hline 30 & percent of Asian females with college degree \\
\hline $31-$ & percent of Other females with college degree \\
\hline $32-$ & percent of Lifetime prevalence of female victimization (including rape, \\
physical violence, and stalking) \\
\hline $33-$ & violent crime rate per 100,000 inhabitants \\
\hline $34-$ & peace index rank (1 most peaceful to 5 least peaceful) \\
\hline $35-$ & percent of states that are very religious \\
\hline & \\
\hline 1
\end{tabular}




\section{Appendix B}

Key for Table 6

\begin{tabular}{|l|l|}
\hline 1 & Do HIV behaviors apply \\
\hline 2 & Percent of $65+$ \\
\hline 3 & percent of White females \\
\hline 4 & percent of African American females \\
\hline 5 & percent of Women in labor force \\
\hline 7 & percent married \\
\hline 8 & percent of African American females who are married \\
\hline 9 & percent of Hispanic females who are married \\
\hline 10 & percent of Asian females who are married \\
\hline 11 & percent of Other females married \\
\hline 12 & percent of White females with college degree \\
\hline 13 & percent of AA females with college degree \\
\hline 14 & percent of Hispanic females with college degree \\
\hline 15 & percent of Asian females with college degree \\
\hline 16 & violent crime rate per 100,000 inhabitants \\
\hline 17 & peace index rank (1 most peaceful to 5 least peaceful \\
\hline 18 & percent of states that are very religious \\
\hline 19 & percent of people living below poverty \\
\hline 20 & percent of females in poverty \\
\hline 21 & percent of White females in poverty \\
\hline 22 & percent of African American females in poverty \\
\hline 23 & percent of Hispanic females in poverty \\
\hline 24 & percent of Asian females in poverty \\
\hline 25 & percent of other females in poverty \\
\hline
\end{tabular}




\begin{tabular}{|l|l|}
\hline 27 & percent of uninsured persons \\
\hline 28 & percent of females uninsured by state \\
\hline 29 & percent of uninsured White females \\
\hline 30 & percent of uninsured African American females \\
\hline 31 & percent of uninsured Asian females \\
\hline 32 & percent of uninsured Hispanic females \\
\hline 33 & percent of uninsured Other females \\
\hline 34 & per capita spending on Medicaid \\
\hline 35 & per capita spending on Medicare \\
\hline 36 & per capita spending on Medicaid enrollees with HIV \\
\hline 37 & Federal HIV/AIDS grant funding for per PLWA \\
\hline 38 & total ADAP budget \\
\hline 39 & physicians in patient care per 10,000 civilians \\
\hline 40 & population distribution by metropolitan status by state \\
\hline
\end{tabular}




\section{Appendix C}

Key for Table 7

\begin{tabular}{|l|l|}
\hline 1 & Do any HIV risk behaviors apply \\
\hline 2 & Percent of $65+$ \\
\hline 3 & percent of White females in each state \\
\hline 4 & percent of African American females in each state \\
\hline 5 & percent of Women in labor force \\
\hline 6 & percent of females married \\
\hline 7 & percent of African American females who are married \\
\hline 8 & percent of Hispanic females who are married \\
\hline 9 & percent of Asian females who are married \\
\hline 10 & percent of Other females married \\
\hline 11 & percent of White females with college degree \\
\hline 12 & percent of AA females with college degree \\
\hline 13 & percent of Hispanic females with college degree \\
\hline 14 & percent of Asian females with college degree \\
\hline 15 & violent crime rate 2009, per 100,000 inhabitants \\
\hline 16 & peace index rank (1 most peaceful to 5 least peaceful \\
\hline 17 & percent of states that are very religious \\
\hline 18 & percent of females in poverty \\
\hline 19 & percent of uninsured persons \\
\hline 20 & percent of uninsured Hispanic females 2010 \\
\hline 21 & per capita spending on Medicaid \\
\hline 22 & per capita spending on Medicare \\
\hline 23 & Federal HIV/AIDS grant funding for per PLWA \\
\hline & total ADAP budget \\
\hline & physicians in patient care per 10,000 civilians \\
\hline & \\
\hline
\end{tabular}




\begin{tabular}{|l|l|}
\hline 26 & population distribution by metropolitan status by state \\
\hline 27 & rates of chlamydia per 100,000 \\
\hline 28 & rates of chlamydia per 100,000 women \\
\hline 29 & rates of gonorrhea per 100,000 \\
\hline 30 & rates of per gonorrhea per 100,000 women \\
\hline 31 & rates of syphilis per 100,000 \\
\hline 33 & $\begin{array}{l}\text { rates of per syphilis per } 100,000 \text { women } \\
\text { adolescents by state }\end{array}$ \\
\hline 34 & percent of cumulative AIDS diagnoses by state \\
\hline 35 & percent of cumulative AIDS diagnoses by females \\
\hline 36 & percent of cumulative White PLWA by state \\
\hline 37 & percent of cumulative African American PLWA by state \\
\hline 38 & percent of cumulative Hispanic PLWA by state \\
\hline 39 & percent of cumulative Asian PLWA by state \\
\hline 40 & percent of cumulative Other PLWA by state \\
\hline 41 & $\begin{array}{l}\text { MSM Transmission of estimated cumulative AIDS } \\
\text { diagnoses }\end{array}$ \\
\hline 42 & IDU Transmission of estimated cumulative AIDS diagnoses \\
\hline 43 & $\begin{array}{l}\text { MSM and IDU Transmission of estimated cumulative AIDS } \\
\text { diagnoses }\end{array}$ \\
\hline 44 & $\begin{array}{l}\text { Heterosexual contact Transmission of estimated cumulative } \\
\text { AIDS diagnoses }\end{array}$ \\
\hline 45 & $\begin{array}{l}\text { Other Transmission of estimated cumulative AIDS } \\
\text { diagnoses }\end{array}$ \\
\hline
\end{tabular}




\section{CURRICULUM VITAE}

\section{Laneshia McCord}

1902 Greenleaf Drive, Lexington, KY 40505

859-421-7271 (cell)

Laneshia.McCord@1ouisville .edu

\section{EDUCATIONAL AND PROFESSIONAL HISTORY}

\section{Education}

2013

Ph.D. in Social Work, University of Louisville, Kent School of Social

Work

Louisville, KY.

Dissertation: Predictors of HIV Risk Behaviors Among Older Adults: A

Multilevel Analysis

2008 Master of Social Work, University of Georgia, School of Social Work Athens, GA.

2002 Bachelor of Arts in Social Work, University of Kentucky, College of

Social Work

Lexington, KY.

\section{Professional Positions}

2012- Current Part-Time Faculty Coordinator

University of Louisville, Kent School of Social Work, Louisville, KY Orient and mentor new part-time faculty and teaching assistants to teaching processes, offer technical assistance, and attend faculty and university-wide meetings related to curriculum development.

\section{Research Consultant}

Signature Healthcare

Served as a consultant on the development of a curriculum structure for a certificate program in gerontology. Analyzed Directory of Educational Programs in Gerontology and Geriatrics to determine accreditation and registration requirements; compiled report and presented to stakeholders. 
KY

University of KY, Center for Academic and Tutorial Services, Lexington,

Served as a mentor to student athletes, assisted with course load management, supporting the students' development regarding important academic and life skills, and assessed their exposure to new resources and how they understood how to make positive life choices.

2009

\section{Workforce Specialist}

Bluegrass Area Development District, Lexington, KY

Provided case management to those unemployed or underemployed through training programs. Advocated for career development opportunities for individuals, tracking their progress and outcomes with goals of increasing human capital and job access.

2008- 2009 Care Manager II

Visiting Nurse Health System, Atlanta, GA

Community-based case management for older adults in Metro Atlanta, enabling them to maintain independence and remain at home.

2006-2008 Care Manager I

Visiting Nurse Health System, Atlanta, GA

2005-2006 Case Manager

SOURCE Program, Emory Healthcare, Atlanta, GA

2003-2005 Social Service Case Manager, Advanced

Gwinnett County Department of Families and Children Services, Lawrenceville, GA

2002-2003 Therapeutic Child Support Worker

The Brinley Center for Children and Families, Lexington, KY

$2002 \quad$ Youth Counselor; Practicum Student

The Kentucky United Methodist Homes for Children and Youth, Versailles, KY

SCHOLARSHIP

\section{Refereed Publications}

Journal Articles

Published 
McCord, L. (2013). Attention HIV: Older African American women define sexual risk behavior. Culture, Health, and Sexuality. doi: 10.1080/13691058.2013.821714

Manuscripts under Review

Faul, A., Yankeelov, P., \& McCord, L. Inequitable access to health services for older adults with diabetes: Potential solutions on a state level. Journal of Aging and Social Policy.

Manuscripts in Progress

Faul, A., Ferreira, R., \& McCord, L. Social vulnerability and older adults: A model of care.

McCord, L. A review of sexual risk context among older women, 2001-2011. Journal of Women and Aging.

McCord, L. Making the connection: A student tool for evidence-based learning. Journal of Social Work Education.

\section{National/Regional Refereed Conference Presentations}

McCord, L. (2012). Attention HIV: Older African American Women Define Sexual Risk Behavior. Poster presented at the Gerontological Society of America Annual Meeting, San Diego, CA, November 2012.

McCord, L. (2009). How HIV/AIDS prevention education has missed a growing target: Older adults. Presented at the Annual conference of the Association for Gerontology in Higher Education, San Antonio, TX, February 2009.

McCord, L. (2008). Raising Awareness of HIV/AIDS in Older Adults: Be The Voice. Workshop presented at the Annual Conference of the National Association of Social Workers- Georgia Chapter, Atlanta, GA, October 2008.

\section{Grants, Honors, and Awards}

2013: Graduate Dean's Citation

2013: The Group for the Advancement of Doctoral Education (GADE) Student Award for Leadership and Service. To be presented during the 2013 Council on Social Work Education Annual Program Meeting in Dallas, TX on November 1, 2013.

2012: The Dr. M. Celeste Nichols Professional Development Award, University of Louisville Women's Center

2012: Michigan Center for Urban African American Aging Research Summer Workshop Fellow

2011: National Institute on Aging (NIA) Grants Technical Assistance Workshop Fellow 2011: i2a (Ideas To Action) Part-time Faculty Cohort Group 2010: Student Spotlight, December 2010. School of Interdisciplinary and Graduate Studies, University of Louisville, KY 
2010: Association for Gerontology Education in Social Work (AGE-SW) Gerontological Social Work Pre-Dissertation Initiative Awardee, Cohort I

\section{RESEARCH EXPERIENCE}

2009-2010

\section{Graduate Research Assistant}

University of Louisville

Researched consumer satisfaction and health outcomes among older adults based on their participation in the Kentuckiana Regional Planning and Development Agency (KIPDA) Emergency Care Services Program

\section{Graduate Research Assistant}

University of Georgia

Researched eating disorders among young, minority women, and the implications for appropriate interventions through direct social work practice

TEACHING EXPERIENCE 2009-Current

Teaching Assignments at the University of Louisville SW 426-BSW Intro to Social Work Research SW 626-MSW Intro to Social Work Research SW 397/697 HIV Disease Management (in-person and online)

SW 604/605 Generalist Social Work Practice I and II SW 668/669 Advanced Research Practice I and II SW 681 Social Gerontology (Guest lecturer)

2012-Current

\section{Teaching Assignments at Spalding University}

SW 633 Graduate Research II

\section{SERVICE}

\section{Professional}

Reviewer for Perspectives on Social Work journal (2013)

The Rose Dobrof Selection Committee (2013)

Student Representative for AGE-SW (2011-2013)

Member of AGE-SW Publications Task Force (2011-Present)

The Association for Gerontological Education in Social Work (AGE-SW) (2010-Present)

The Gerontological Society of America (GSA) (2010-Present)

National Association of Social Workers (2005- Present) 
Member of the Planning Committee, NASW-GA Chapter (2006-2010)

Guest reviewer of Perspectives on Social Work journal (2013-Present)

University (University of Louisville)

Faculty Senator for Part-Time Faculty Committee, University of Louisville (2012-2013)

Department (University of Louisville, Kent School of Social Work)

Kent School's Diversity Committee (2013) 